\title{
FEMINISMO/S 35
}

MONOGRAPHIC DOSSIER:

A critical practice of thinking otherwise: Bacchi, Gender and Public Policy Analysis

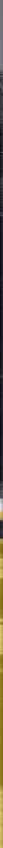

«Armonía», Plaza de la Igualdad, Universidad de Alicante

iᄂieg

D'INVESTIGACIÓ

D'ESTUDIS DE GËNERE

INSTITUTO UNIVERSITARIO

DE ESTUDIOS DE GÉNERO

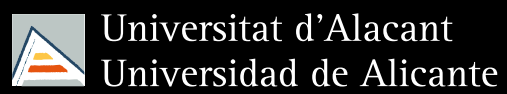





\title{
Feminismo/s, 35, June 2020
}

\author{
Monographic dossier: \\ A critical practice of thinking otherwise: \\ Bacchi, Gender and Public Policy Analysis
}





\title{
FEMINISMO/S \\ Revista del Instituto Universitario de Investigación de Estudios de Género de la Universidad de Alicante
}

\author{
Revista semestral \\ Editada por el Instituto Universitario de Investigación de Estudios de Género \\ de la Universidad de Alicante \\ con la colaboración del Vicerrectorado de Investigación y Transferencia de Conocimiento
}

Número 35, junio 2020

Directora: Helena Establier PÉREZ (Universidad de Alicante, Alicante)

Editoras adjuntas: Alejandra HERnÁNDEZ RuIz (Universidad de Alicante, Alicante)

Sara PRIETO GARCÍA-CAÑEDo (Universidad de Alicante, Alicante)

\section{CONSEJO DE REDACCIÓN}

Mar ESQuembre Cerdá (Universidad de Alicante, Alicante)

Purificación Heras GonZÁlez (Universidad Miguel Hernández, Elche)

Carmen MAÑas VIEJO (Universidad de Alicante, Alicante)

Nieves MONTESINOS SÁnCHEZ (Universidad de Alicante, Alicante)

Mónica Moreno SECo (Universidad de Alicante, Alicante)

Maribel PeÑAlVER VICEA (Universidad de Alicante, Alicante)

M. ${ }^{a}$ Dolores Ramos (Universidad de Málaga, Málaga)

María Pilar Rodríguez PÉREZ (Universidad de Deusto, San Sebastián)

M. ${ }^{a}$ Teresa Ruiz CANTERo (Universidad de Alicante, Alicante)

\section{CONSEJO ASESOR}

Nieves BARANDA LETURIO (UNED, Madrid)

Ester BARberÁ Heredia (Universidad de Valencia, Valencia)

Karine BergÈs (Université de Cergy-Pontoise, Cergy)

Mabel Burín (Universidad de Buenos Aires, Buenos Aires)

Silvia Caporale Bizzini (Universidad de Alicante, Alicante)

Àngels CARABí (Universidad de Barcelona, Barcelona)

Rosa CoBo BEDía (Universidad de La Coruña, La Coruña)

Pilar Cuder Domínguez (Universidad de Huelva, Huelva)

Bradley S. EPPS (University of Cambridge, Cambridge)

Joaquín DE JuAn Herrero (Universidad de Alicante, Alicante)

M. ${ }^{a}$ Victoria Gordillo (Universidad Complutense de Madrid, Madrid)

María Elia GutiÉRREZ Mozo (Universidad de Alicante, Alicante)

Annabel MARTín (Dartmouth College, Hanover)

Angela O'HaGAN (Glasgow Caledonian University, Glasgow)

Montserrat PALAU (Universitat Rovira i Virgili, Tarragona)

Eulalia PÉREZ SEDEÑo (Consejo Superior de Investigaciones Científicas, Madrid)

Alicia PUlEo (Universidad de Valladolid, Valladolid)

Carme RIERA GUILERA (Universidad Autónoma de Barcelona, Barcelona)

Begoña SAN Miguel DEl Hoyo (Universidad de Alicante, Alicante)

Marta SEgARRA (Universidad de Barcelona, Barcelona)

Cristina Segura Graíño (Universidad Complutense de Madrid, Madrid)

María del Carmen Simón PALmER (Consejo Superior de Investigaciones Científicas, Madrid)

Meri TORRAS (Universidad de Barcelona, Barcelona)

María Teresa Vera BALANZA (Universidad de Málaga, Málaga) 


\section{REDACCIÓN}

Instituto Universitario de Investigación de Estudios de Género de la Universidad de Alicante Campus de Sant Vicent del Raspeig

Apdo. 99 E-03080 Alicante

Tel. 965909415

e-mail: revistafeminismos@ua.es; iuieg@ua.es -web: https://ieg.ua.es

SUSCRIPCIÓN

Instituto Universitario de Investigación de Estudios de Género de la Universidad de Alicante Campus de Sant Vicent del Raspeig Apdo. 99 E-03080 Alicante

Tel. 965909415

e-mail: iuieg@ua.es -web: http://ieg.ua.es

Publicaciones de la Universidad de Alicante

Campus de San Vicente s/n

03690 San Vicente del Raspeig

publicaciones@ua.es

https://publicaciones.ua.es

Teléfono: 965903480

Edita:

Instituto Universitario de Investigación de Estudios de Género de la Universidad de Alicante con la colaboración del Vicerrectorado de Investigación y Transferencia de Conocimiento Cuenta con una Ayuda para la Publicación de Revistas Científicas del Vicerrectorado de Investigación y Transferencia de Conocimiento

ISSN: $1696-8166$

DOI: $10.14198 / \mathrm{fem} .2020 .35$

Depósito legal: A-910-2003

Diseño de cubierta: candela ink Maquetación: Marten Kwinkelenberg

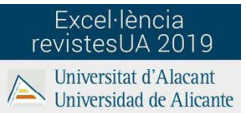

Sello de excelencia 2019 de la UA a las revistas científicas

Feminismo/s no se identifica necesariamente con los contenidos de los artículos firmados.

Prohibida la reproducción total o parcial de los artículos sin la autorización previa.

La revista está indizada en ESCI (WOS), DOAJ, REDIB, GenderWatch (ProQuest), InDICEs-CSIC, ERIH PLUS, MLA, CIRC, MlAR, Latindex, Dialnet, Ulrich's, Dulcinea, Google Scholar, SHERPA/RoMEO, RUA, DICE, REBIUN, RESH, OCLC WorldCat, Copac, SUDOC y ZDB/EZB. 


\section{INDEX / ÍNDICE}

\section{Monographic section / Sección monográfica:}

«A critical practice of thinking otherwise»:

Bacchi, Gender and Public Policy Analysis /

«Una práctica crítica de pensar de otra manera»:

Bacchi y el análisis de género en la política pública

(Coord. Angela O'Hagan, Glasgow Caledonian University)

Angela O’Hagan

Introduction. «A critical practice of thinking otherwise»:

Bacchi, Gender and Public Policy Analysis....

Introducción. «Una práctica crítica de pensar de otra manera»:

Bacchi y el análisis de género en la política pública.

\section{Margarita Ozonas Marcos}

How to integrate a gender perspective into well-being budgeting practices: Insights from a comparative case study between

Bhutan and New Zealand.

Cómo integrar la perspectiva de género en los presupuestos de bienestar:

ideas de un estudio comparativo entre Bután y Nueva Zelanda

Leanne Wilson and Jim Campbell

Gender Mainstreaming in action? The Scottish Structural

and Investment Funding Program 2014-2020....

¿Se incorpora la perspectiva de género en el Programa de Fondos

Estructurales y de Inversión europeos en Escocia 2014-2020?

Adele Wylie

Climate conscious professional kitchens?

Analysing the Scottish food sector through a feminist lens

¿Cocinas profesionales con conciencia climática?

Analizando el sector alimentario escocés a través de una lente feminista 


\section{Sue Cohen and Tove Samzelius}

Through the lens of single parenthood: A comparative snapshot of the impact of neoliberal welfare, housing and employment policies on single mothers in the UK and Sweden

A través de la lente de la maternidad soltera: una instantánea comparativa del impacto de las políticas neoliberales del Estado del Bienestar. Vivienda y empleo en las madres solteras de Reino Unido y de Suecia

\section{Nina Teasdale}

Flexible Working in the UK: interrogating policy through a gendered Bacchi lens

Trabajo flexible en el Reino Unido: interrogar políticas a través de un enfoque Bacchi con perspectiva de género

Finnborg Salome Steinpórsdóttir and Porgerður Einarsdóttir

Jumpstart, potentials and hindrances: Collaboration projects

in Gender Mainstreaming and Gender Budgeting

Estímulo, potenciales y obstáculos: proyectos de colaboración en transversalidad y presupuestos con enfoque de género

Angela O'Hagan

Bacchi as pedagogy: Surfacing equality and human rights in public policy teaching

Bacchi como pedagogía: la igualdad y los derechos humanos en la enseñanza de las políticas públicas

\section{Miscellaneous section / Sección miscelánea}

\section{Vicenta Garrido Carrasco}

Los arquetipos masculinos de los cuentos de Perrault: modelos de masculinidad que aprender o desaprender desde la infancia....

The male archetypes in Perrault's tales: Models of masculinity to learn or unlearn from childhood

\section{María Cecilia Johnson}

Las TRHA y los debates en la academia feminista sobre reproducción: relaciones de poder y tecnología

Arts and the debates in the feminist reproduction academy:

Power relations and technology 


\section{Marie-France Merlyn}

Dime lo que escuchas y te diré quién eres. Representaciones de la mujer en las 100 canciones de reggaetón más populares en 2018

Tell me what you listen to and I will tell you who you are.

Representing women in 100 of the more popular reggaeton songs in 2018

Silvia de Riba Mayoral

(Seguir) teorizando los afectos y las emociones en la investigación educativa desde enfoques feministas

(To keep) theorizing affects and emotions in educational research from feminist approaches

\section{Reviews / Reseñas}

Cambio generacional y mujeres universitarias. Genealogías, conocimiento y compromiso feminista, de Lorena C. Barco Cebrián, María José Ruiz Somavilla y María Teresa Vera Balanza (eds.).

Reseña de / Review by Marta Postigo Asenjo

El feminismo en 35 hashtags, de Sonia Reverter y María MedinaVicent.

Reseña de / Review by Laura Manzano-Zambruno

Mujeres con luz, de M. Gloria Ríos Guardiola y M. Belén Hernández González (eds.).

Reseña de / Review by Montserrat Planelles Iváñez

Preciados feminismos. Una lectura de Preciado para la antropología filosófica, de Mabel Alicia Campagnoli.

Reseña de / Review by Ariel Martínez. 



\section{Monographic section / Sección monográfica:}

"A critical practice of thinking otherwise»: Bacchi, Gender and Public Policy Analysis «Una práctica crítica de pensar de otra manera»: Bacchi y el análisis de género en la política pública 

To cite this article / Para citar este artículo:

O'Hagan, Angela. "Introduction. "A critical practice of thinking otherwise": Bacchi, gender and public policy analysis». En Feminismo/s, 35 (junio 2020): 13-28. Monographic dossier / Dossier monográfico: A critical practice of thinking otherwise: Bacchi, Gender and Public Policy Analysis, coord. Angela O'Hagan, DOI: 10.14198/fem.2020.35.01

\title{
INTRODUCTION. «A CRITICAL PRACTICE OF THINKING OTHERWISE»: BACCHI, GENDER AND PUBLIC POLICY ANALYSIS
}

\author{
INTRODUCCIÓN. «UNA PRÁCTICA CRÍTICA DE PENSAR \\ DE OTRA MANERA»: BACCHI Y EL ANÁLISIS DE GÉNERO \\ EN LA POLÍTICA PÚBLICA
}

\author{
Angela O'HAGAN \\ Glasgow Caledonian University \\ Angela.OHagan@gcu.ac.uk \\ https://orcid.org/0000-0002-6130-8186
}

Keywords: Gender analysis; Public policy; Inequality; Feminism; Human rights.

Palabras clave: análisis de género; política pública; desigualdad; feminismo; derechos humanos.

All too often the question «what's gender got to do with it?» still arises with government officials, policy actors, elected politicians and of course in everyday conversations. As long as these formal actors -policy makers and politicians- continue to contain thinking and consideration of gender equality in the policy making process to more superficial notions of equality of opportunity and equal treatment, the dimensions of gendered relations and the complex interactions across policy domains will remain invisible and policy making, and the silences of assumed norms that shape policy «representations» will remain. If gender equality is considered to be a matter of 
«women's policy» or a secondary component of labour market and employability, or childcare, or social security and health policy, for example, then the structural constraints of gendered norms and relations will not be addressed or the transformational potential of gender equality realised.

In Bacchi's 'What's the Problem Represented to be?' (WPR) approach, she offers an analytical strategy to reveal the politics inside policy making. Bacchi and Goodwin (13-26) propose using the WPR approach to «make politics visible», by exploring how governmental practices produce «problems» and particular kinds of problems. By seeking to reveal the assumptions and ascribed meanings and interpretations, Bacchi is encouraging critical engagement with what information, knowledge, and assumptions have led to the «representation» of a policy "problem» in a particular way.

In presenting Bacchi's «What's the Problem Represented to be?» (WPR) framework as the «critical practice of thinking otherwise», Bacchi and Goodwin capture the essence at the core of critical feminist policy analysis. This is the framing approach of this special issue of Feminismos. The aspiration of the authors -with an encouraging representation of Early Career Researchers among more established scholars- is to explore a series of public policy domains and topical «problems» using Bacchi's framework. Across the articles, the authors explore how gendered dimensions and gender equality objectives have informed or have been absent in the representation of the policies in focus, and in the teaching and learning of public and social policy students. The authors discuss how gendered knowledge continues to be treated as a secondary consideration, subjugated in the policy process. As a collective endeavour, this special issue engages in how gendered knowledge is deliberately developed and nurtured in policymaking institutions or is deliberately silenced or wilfully ignored.

Gender analysis continues to be a blind spot in public policy making. The absence of, or failure to access and utilise, gender data is problematic. Even more so is the ongoing lack of intersectional data that reveals the experience of individuals in relation to how their gender, race, class and potentially disability combine. That gender analysis is not an integrated or regularised part of policy making across policy domains means that the gendered dimensions of use of time and space in relation the access to and use of public services such as transport, health, education, public space, culture and sports facilities, 
and so on are silenced and rendered invisible. This means there is a lack of understanding of the «lived effects» (Bacchi 16-18; Bacchi and Goodwin 2) of gender norms that structure and constrain the social, economic and political opportunities and experiences of women and men, most usually to the detriment of women.

Bacchi's elaboration of the three types of effects of policy as discursive, subjugation, and lived effects are based on a Foucauldian analysis of «dividing practices» which function to separate groups of people from one another and which can also produce «governable subjects» (Bacchi and Goodwin 2). In this way, women can be separated out as a distinct problem to be dealt with separately from the «real» problem at hand -labour market participation rates, tax revenue, deficit reduction, or whatever the "problem» is that government is seeking to address. It was this problematizing of women, rather than the societal and institutional structures, resulting in the creation and sustained effects of gendered norms and relations that gender mainstreaming as a meta-analysis in the public policy process was intended to address. Furthermore, feminist institutionalism has sought to spotlight and challenge the analysis of institutional practice by exposing androcentric bias with the structures, staffing, and processes of policy institutions.

Over the years Bacchi and colleagues have urged some caution around the notion and implementation of gender mainstreaming with the repeated caveat of «What are we mainstreaming when we mainstream gender?» (Bacchi and Eveline, Mainstreamng-WPR). In Bacchi's construction of how policy «problems» are made, she argues that we should think about policies as «productive» or «constitutive». Drawing on her original framework, Bacchi explains this idea as

policies and policy proposals give shape and meaning to the 'problems' they purport to 'address'... policy 'problems' do not exist 'out there' in society, waiting to be 'solved' through timely and perspicacious policy interventions. Rather, specific policy proposals 'imagine' 'problems' in particular ways that have real and meaningful effects (111).

Bacchi and Eveline go on to build on previous proposition from Bacchi that «policies do not simply 'deal with' the 'problem' of 'gender inequality'. Rather, policies create different impressions of what the 'problem' of 'gender equality' entails.» (112) Therefore, how 'gender' is understood and what meanings are 
attached to the term 'gender equality' require to be unpacked, and the WPR approach helps us do that. In understanding policy decisions and propositions, if we can understand how they have been constituted - as what kind of problem (fiscal, social, structural) and about how 'who' the policy is 'for' or will effect was constructed, we can begin to work backwards, revealing the norms and assumptions that shaped the policy decision. Bacchi, and Bacchi and Eveline (Mainstreaming-WPR) have described that how policies are represented can reinforce categories of people, including «women» and «men», and can reproduce certain understandings discursively and therefore in terms of lived effects. This is their idea of gendering, that policies can reinforce social relations, producing and reinforcing «specific categories of social being and specific patterns of social organisation», and that these categories are, or should be, acknowledged and explored as political categories of identity (112).

In this special issue, the articles by Teasdale, and Cohen and Samzelius engage with the notion of gendering. They highlight how policies in relation to care, reconciliation of work and caring, and the specific categorising of lone parents who are predominantly women are constituted and framed in ways that reinforce expectations around established gendered norms and the role of women primarily as carers and secondarily as economically independent. Yet, as Cohen and Samzelius illustrate, in «problem representation» of social security support for lone parents, women's lack of economic independence and perceived reliance on the state, due to their parental and caring status, is to be castigated rather than the state having a role in the welfare and wellbeing of its population. The gendering of this «problem» takes its form from the persistent subjugation of women, socially and economically, rather than a progressive intent to liberate women from established roles, and recast gender relations to the benefit of women and men.

Wylie's interviews with women and men chefs in restaurant kitchens reinforces the prevalence of gendered thinking and the gendering of women's participation in a professional environment. In Wylie's interviews, her contributors break the «silences» that persist and continue to reinforce established categorisations and assumptions. Furthermore, the assumptions and knowledges on display a wilful ignorance from the male managers in relation to women's position and to the sustainability agenda also in focus. The entrenched, and 
even hostile resistances to addressing the structural constraints resonates with findings from studies of other occupational environments, such as the study of engineering workplaces in Australia by Franzway et al. Wylie points to the need for systemic change to gendered norms and attitudes to environmental sustainability practices and that the necessary macro-level policy and microlevel attitudinal changes are intertwined. This resonates with the calls from Franzway et al. for a focus on context and culture of policy and practice, rather than problematizing individual women (93).

In the contributions from Wilson and Campbell, Steinpórsdóttir and Einarsdóttir, we can see the silences in operation among bureaucrats who require direction from within the administration in order to action measures to unblock gendered barriers to services or regard the process of unpacking what's behind the problem as someone else's job, rather than integral to public policy design and implementation. Therefore, when gender mainstreaming is presented politically as a gender equality policy, Bacchi and Bacchi and Eveline are right to urge caution. As the contributors in this special issue highlight, unless there is a level of gendered knowledge, that reveals and recognises the discursive and lived effects of the categorisations of gendered roles and expectations, and a political engagement or will to intervene to transform these realities, then mainstreaming gender may just continue to mainstream gendering and the persistent inequalities that follow from that.

In Bacchi and colleagues' exploration of the types of effects of policy, they encourage analysis of the discursive effects that show how the «terms of reference established by a particular problem representation set limits on what can be thought and said» (Bacchi and Goodwin 2). Subjectification effects draw attention to how «subjects» are implicated in problem representations, how they are produced as specific kinds of subjects. Mukhopadhyay, also draws on Foucault's concept of «governamentality», that is «the way governments try to produce the citizen best suited to fulfil its policies and as well to the organised practices through which subjects are governed» (2). In her critique of gender mainstreaming in development policy and institutions, Mukhopadhyay focuses on «the dominant set of practices and technologies of power that have structured and shaped the process and framed our practice» (2). 
It is this dominance and the prevalence of established practices, which Bacchi and Goodwin claim produces «identified problem representations» (22). Feminist institutionalist and feminist economics analysis has exposed the androcentric bias of government institutions and the economic and political models they pursue. Insights from multiple feminist theories reveal both the «differential power relations» and the way in which different «knowledges» operate, resulting in some being «subjugated» (22). In practice, this means a disregard -intentional or otherwise- for ensuring gendered knowledge, based on an understanding of the lived effects of discrimination, subordination and inequality on the basis of gender and its intersections with race, class and disability, is the norm. The failure to generate, access and utilise gender disaggregated data as a matter of course is part of this persistent «problem»: the problem of «gender blind» policy making (Eveline and Bacchi) which in turn is not regarded as a problem in mainstream policy making because «what's gender got to do with it...?». So long as the gendered dimensions of economic relationships at the individual and household levels or with the state; or the gendered patterns of time use directed by the division of unpaid care work, which intersect with women and men's economic positions, use of public space and services, and access to political participation do not inform «problem representation» then gender equality will not be advanced through mainstream public policy at any transformative pace.

Bacchi's advocacy for understanding the «lived effects» of public policy decisions is a direction for policy makers -inside and outside governmentto make themselves aware of how the effects of policy decisions, based on identified problems representations, «translate into people's lives». It is a call for policy making that «encourage[s] a critical practice of thinking otherwise» (Bacchi and Goodwin 22). This means identifying and calling attention to the «silences» or «unproblematized» elements within what a problem is represented to be (Bacchi). For example, the «problem» of women's lower labour market participation rates or the occupational segregation and persistent gender pay gaps therein, are not a consequence of choice but rather the combined effects of gendered norms and expectations, and the undervaluing -conceptually and financially- of «women's work».

The absence of gender analysis is present across all policy domains -to greater and lesser degrees- and characterises all aspects of mainstream policy 
processes, from ideas generation through to implementation and evaluation. In calling for a re-gendering of public policy, María Bustelo (2) points to the worrying reality of the «evaporation» or fading away of gender from public policy, particularly by the evaluation stage of a policy, programme or project to assess what the outcomes or changes might have been. This further disregard and lack of policy interest in whether the status quo has changed and to whose benefit or detriment reinforces the lesser value attributed to gender equality, and other forms of inequality, in what is still regarded as «mainstream» policy. In this way, gender equality continues to be reserved as a marginal or «specialist» interest area of policy analysis and political science.

Since the mid 1990's proclamations by supranational institutions such as the United Nations, the Commission of the European Union, and the Council of Europe, heralded the arrival of «gender mainstreaming». This meta-analysis as an approach to policy making, rather than a gender equality policy in itself, intended to shift the onus from feminist advocates and the slow process of legal reform and extension of rights and protections, and to implicate institutions in the process of integrating an informed gender-awareness at all stages of policy making. This was an important shift, intending to make policy and institutions of government responsible for enacting transformational gender policy. Furthermore, among the original aspirations of gender mainstreaming was the ambition to open up the policy process to more democratic participation as well as transparency in the policy process. As the contributions in this special issue reflect, gender mainstreaming has not secured the desired results in terms of its transformative approach to equality and to policy making. The articles by Wilson and Campbell; Wylie; Steinpórsdóttir and Einarsdóttir particularly highlight this, along with the perspective from Teasdale, all of which expose the additive approach to gender and policy making. That is, where gender is seen as an additional rather than an integral component of policy analysis and formulation. How far have we come then from the what Bunch coined as the «add women and stir» approach that gender mainstreaming was to move us on from? The authors in this special issue present evidence of the absence of the «lived effects» of gender inequality as «analytical category» (Bacchi and Goodwin 2) and the evaporation of gender analysis and focus, even when expressed institutional 
commitments to gender mainstreaming or gender budgeting and legal imperatives to integrate gender in policy and practice are in place.

Gender budgeting has been gaining traction, particularly at regional or autonomous, and municipal level globally for over thirty years. As another example of an approach to decision-making in public policy and resource management, gender budgeting has the potential to «activate» gender mainstreaming by bringing in decisions on public finance -how it is raised and spent- into a whole systems approach to integrating gender analysis (O'Hagan 29). As Ozonas reveals in this issue, multiple theoretical perspectives, even those conceived from a human rights and Capabilities Approach perspective, can continue to marginalise a gender perspective, relegating gender equality as a secondary dimension of wellbeing, unless the project is explicitly framed as a gender equality exercise such as the emerging concept and practice of Wellbeing Gender Budgeting. This analysis of Gender Responsive Budgeting (GRB) and Wellbeing Budgeting (WB) is an original contribution in its use of the Bacchi WPR framework and empirically in its comparative case analysis of innovations in public budgets in Bhutan and New Zealand.

In relation to Wylie's research on gendered dimensions of professional kitchen practices, her evidence and analysis speak directly to Bacchi and Goodwin's assertions that «different power relations result in different discursive practices that can create forms of authority for certain knowledge» (22). Wylie offers an original insight into gender relations in a professional environment in the context of environmentally sustainable practices in restaurants. In an innovative combining of gender policy analysis using Bacchi's WPR framework, Wylie spotlights the limitations to integrating gender into «mainstream» policy of environment and sustainability, and business/employment practice. She highlights the missed intersections of both gender awareness and sustainability in organisational practice. In an ambitious analysis, Wylie distils the macro global policy agenda through policy commitments at sub-national government level, into the micro operational setting of professional kitchens where entrenched discriminatory behaviours persist unchecked. The progressive narrative of environmental policy, or business pledges for «Fair Work» in Scotland are insufficient stimuli to transform embedded practices and attitudes where gender equality is still considered not to be integral to everyday business practice. 
Cohen and Samzelius take on a completely different policy arena and point us to the even more damaging «lived effects» of a deliberately gender blind approach to policy in relation to lone parents, the majority of whom are women. In their comparative analysis of the treatment of women lone parents in Sweden and the UK. they reveal a disregard for everyday realities as experienced by women lone parents and the amplification of those everyday discriminations on the grounds of gender, race and ethnicity, and migration status. This article exposes the deficiencies in the Swedish approach, pulling back a curtain on the perceptions of the advanced and integrated nature of gender equality in this Nordic state. Cohen and Samzelius do not use the Bacchi WPR framework explicitly, but their evidence and analysis clearly expose particular ways of thinking that led to lone parents being problematized and converted into targets for government scrutiny and punitive action. They reveal the discursive effects of categorising lone parents as a "problem» for public spending and public policy. Working backwards critically from that problem representation, they expose the silences within policy decisions that disregard the everyday lived effects experienced by women lone parents particularly, and how such a punitive representation of the "problem» imperils the economic and social wellbeing of lone parents and their children, the consequences of which redouble the need for welfare support. To this end, a «problem representation» of lone parents as a public finance problem, rather than a consequence of structural inequalities which could be remedied or at least reduced through provision of services that recognise care provision as the starting point for intervention, in the end runs counter to the new public management and reduction of welfare dependency discourse that shaped the representation of the problem.

Teasdale takes a familiar area of «gender» policy in her analysis of worklife balance policy and practice. The «reconciliation»' agenda has been a go-to area of gender equality policy at national and supra-national level for many years. Recasting gender relations in pursuit of a transformation of unpaid care and women's access to economic independence have been core missions of the feminist project. The institutionalisation of these demands as policy goals, however, has increasingly subjugated one form of knowledge for another as Teasdale's analysis reveals. 
Wilson and Campbell take on another established institutional gender equality policy in their analysis of gender mainstreaming in the European Structural and Investment Funds. Previously held up as a successful area of horizontal gender analysis and gender mainstreaming. The analysis of documentation shaping the 2014-2020 programmes in Scotland reveals a fading away of attention to gender analysis in programme design, monitoring and outcomes in Scotland. Furthermore, this highlights the importance of maintaining institutional structures that support gender analysis as Scotland reconfigured its programme management structures which had previously driven more gender aware programmes to international acclaim. Not only has gender analysis faded away in the nature of the programmes, but the pioneer state has become one of laggard, despite political rhetoric that aims to suggest otherwise. Wilson and Campbell locate the exploration of gender mainstreaming in the persistent subjugation of gender as relevant to economic development and infrastructure investment, drawing on feminist economics analysis to drive home the continuing undervaluing of women's economic participation. Their analysis also echoes Franzaway et al.'s characterisation of wilful ignorance within policy, and the need for collective, organisational responses and endeavours that Eveline and Bacchi have highlighted as essential to progress.

Steinpórsdóttir and Einarsdóttir's contribution on gender mainstreaming and gender budgeting in public institutions combines a critique of the evaporation of formal gender equality policy that echoes much of Wilson and Campbell's critique of Scotland. Both countries have enjoyed certain similarities of public perceptions as pioneers and leaders, particularly Iceland, whereas behind the «window dressing» commitments to gender budgeting and gender mainstreaming are still limited. Steinpórsdóttir and Einarsdóttir highlight the institutional practice to seek out or pursue «quick wins» -similar to Wilson and Campbell's identification of small scale advances- in both cases adopted in preference to the longer-term and, crucially, more disruptive process of thinking backwards that Bacchi exhorts. There is an unspoken resistance to reconsidering how public services might be differently constructed and delivered, based on a different engagement with what is the «problem» in the first place, and an understanding that it might not be what the institutional policy makers considered it to be in the first instance. 
This satisficing with small scale advances that Wilson and Campbell cite, is symptomatic of enduring institutional resistances around gender mainstreaming. For street-level bureaucrats in both the Icelandic and Scottish examples, the absence of clear direction through organisational hierarchies and the failure to transfer authority and seal in accountability for integrating gender analysis and advancing gender equality outcomes were common weaknesses.

The experience of the University of Iceland also has parallels with O'Hagan's article on using Bacchi's WPR framework as a pedagogic tool, supporting learning and building knowledge among policy makers in the third and public sector. Students in Iceland were encouraged to look behind the governmental practices that produced «problems», and to think otherwise about what the effects of policy might be on different needs across the population, and for service provision and policy intervention to use that understanding as a starting point.

Bacchi's wok over the last decades, urging a more discursive approach to lived realities, provides a highly useful framework for inquiry both to reveal absences of gender equality analysis and then try to explain them. Over the same time period from Bacchi's presentation of the original framework in 1999, multiple governments, national and international legal frameworks and policy commitments have extoled the virtues and necessity for public policy to be «gender aware» and to advance gender equality. These arguments have been framed in multiple ways, variously emphasising the moral imperative of gender equality as a social justice goal; as an essential principle of non-discrimination, central to the realisation of human rights; and as a matter of both economic justice from a feminist economics perspective, and of economic efficiency from a business case perspective. Gender equality therefore has been articulated as a common policy goal and political ambition shared at all levels of governance. Yet as the articles in this special issue reveal -but to no-one's great surprise- gender equality continues to be a constant and persistent absence from political aspiration and the policy processes that underpin the achievement of public policy goals.

Bacchi's critique of government policy making tells us that the focus on solving «problems» without understanding the underlying and background contexts and conditions, or reflecting upon the assumptions of policy 
makers themselves is deeply flawed. The «problem» then is how public policy approaches or «frames» a problem. It is the process of reflection of being aware and situated in the discursive and lived effects of everyday realties that shape people's lives that Bacchi and her colleagues have sought to open up through the refinements to the WPR approach and its application.

O'Hagan's article in this issue offers an example, at a very small scale, of how the training of policy makers to solve «problems» can be differently approached through the opportunity -and arguably responsibility- of critical management education. In designing coursework from a reflexive practice perspective with a pedagogy rooted in a social justice perspective and critical thinking, a different approach to policy making at organisational and governmental level might be possible. Higher education business schools do have choices to make in the curricula they offer and the theoretical foundations they promulgate. The business as usual model, however, continues to prevail, despite the evidence from many sources that the economic models of growth and rentier benefit have not served well the majority of the world's population. Bacchi is exhorting us as educators not to encourage students to solve problems, but rather to "generate critical thinking, not through training students to solve 'problems', but through encouraging them to put 'problems' into question».

As we have been writing this special issue and preparing for publication, the coronavirus has been sweeping across the world, with many of the contributors themselves being variously affected. The global pandemic of C-19 has exposed the underlying inequalities and structural inadequacies that have contributed to staggering imbalances in how it has been experienced at individual, household, sectoral and country levels. Over a decade of political choices to pursue austerity policies in relation to public spending and public infrastructure has left public services, supplies and workforces weakened and ill-prepared for a response at scale to a crisis such as this. Pre-existing social and economic inequalities that result in hunger and deprivation for many, even in the midst of "plenty» should shame the countries and societies where political choices -by voters and politicians- have permitted these «lived effects» to be the daily realities of millions.

The gendered dimensions of the impacts and experiences of C-19 and responses to treating and containing the virus have been evident from the 
outset. As the crises of gender inequality in all its intersectional dimensions have collided with coronavirus, the gender and racialized structures and the current economic and social systems that create them have been exposed to public view. As mainly women health and social care workers from a disproportionately high level of Black and minority ethnic communities provide care and die in the process and as lower income men die from occupational exposure to the virus, the gendered structures cannot be ignored.

The implications for policy makers of these imbalances, as countries move to economic and social renewal in a new paradigm of living with the virus are multiple. How public policy represents the challenge of funding a humane, dignified, rights-based social care system, or ensures a basic income that protects not only the most vulnerable, but the essential human vulnerabilities we all share, will require ways of «thinking otherwise» about public services and public spending. Will public resourcing continue to undercut labour and work-related supplies, producing situations like those we have witnessed in relation to the shortages of Personal Protective Equipment (PPE)? Will the low paid and unpaid domestic labour of women (mainly) continue to be acceptable in the service of the market and profit?

Antonella Picchio already forewarned us of how public resources have been weaponised against the resident populations of countries where social security and welfare systems have been dismantled (352). In this issue, Cohen and Samzelius have focused on the deliberate marginalisation and impoverishment of lone women parents within a representation of the 'problem' of lone parents as economically draining for the state, rather than the state having a duty of care to ensure basic freedoms and capabilities for all.

By reflecting, acknowledging, and ultimately discarding the assumptions that have hitherto shaped our economic and social structures we can collectively revisit how we represent «problems». In that way, we might come to a collective realisation that gender equality is not a policy to serve business interests, or to be instrumentalised as a lever for labour market expansion and an increase in the workforce, as Teasdale discusses in this issue. We may perhaps secure the political commitment to gender equality as a core and shared political goal that is for all times, and not only the «good times» when economies are «doing well». The alternative representation of the problem of gender «inequality» that requires resolution is as a fundamental human 
right and a cornerstone of future wellbeing and an axis of equality of rights, representation, and access to and benefits from resources that works for all.

In this issue, Ozonas' analysis of innovative approaches to budgeting in government finance that encompasses an original review of gender responsive budgeting (GRB), wellbeing budgeting (WBB), and wellbeing gender budgeting (WBGB) gives clear guidance on how to incorporate gender equality into the aspirations for economic and social wellbeing that are increasingly expressed by governments round the world. It is interesting to note, as an aside to Ozonas' contribution, that the small nations engaged in wellbeing budgeting include (at the time of writing) Iceland, New Zealand, Scotland (within the United Kingdom), and Finland, all have women leaders as heads of government. Just as this issue goes to print, the government of Wales -not headed by a woman, but recently re-committed to feminist principles of government and a roadmap for gender equality -has signed up to be a Wellbeing Economy government.

Setting aside the centrality or causal relationship between women heads of government and wellbeing policy making, despite the clear links, as the focus of a future special issue perhaps, it is also worth pausing for a moment to consider the scale and size of government and the pursuit of gender equality policies. Contributors in this volume have all presented examples of gender and public policy from small countries -some independent states such as Sweden, Iceland, Bhutan and New Zealand, and other autonomous sub-national governments, mainly Scotland within the United Kingdom. The size and scale of government is important in relation to its agility, and flexibility to respond to innovation- or crisis. The case studies on gender budgeting and gender mainstreaming in Bhutan and New Zealand, Iceland, and Scotland, and the comparison between the UK all demonstrate the importance of international policy learning and transfer, which has been a feature of how gender mainstreaming and gender budgeting have travelled. Part of the importance of this shared learning is the exchange of common experiences of what works well, and understanging the institutional resistances that appear to be as prevalent in Scotland as they are in Iceland or New Zealand, whatever the superficial perception of a country's status as a gender equality champion. Perhaps there is a different humility with small nations towards learning from others. While still endowed with their own sense of self and natural arrogance of state, there 
is a willingness to learn and share. Such speculation is appropriate as we seek a shared response to the global coronavirus pandemic and the lessons that must be learned from it and the inequalities it so ruthlessly exposed.

That this small special issue has been able to include such a range of country perspectives is a source of great pride and pleasure. Feminismo/s is an international journal of increasing standing and reach. The importance of comparative analysis and shared learning has characterised this special issue. As the guest editor of this volume, I am immensely indebted to the authors and contributors, for some of whom this is their first publication and so they deserve special congratulations. The collaboration and enthusiasm with which the contributors have engaged have been immense and inspiring, and I am very grateful to all the authors for their commitment and hard work. The many reviewers who supported the process of producing this special issue have provided an academic and scholarly rigour to the process, and their contributions have significantly elevated and enhanced the authors' contributions. I appreciate the time the reviewers gave, especially when there are so many demands on academic researchers and teachers, and the diligence with this they conducted the evaluations. My biggest vote of thanks is, of course, reserved for the Editor and editorial team who have worked so very hard to support the special issue and to secure its timely publication to the best standards possible. My most sincere thanks and appreciation to you all. And to our readers, I hope we have offered knowledge, exposed silences, and further encouraged you in your «critical practice of thinking otherwise».

Angela O'Hagan, June 2020

\section{REFERENCES}

Bacchi, Carol. Analysing Policy: What's the Problem Represented to be? Frenchs Forest, NSW: Pearson Education. 2009.

Bacchi, Carol, and Joan Eveline. «Approaches to gender mainstreaming: What's the problem represented to be?». In Mainstreaming politics: Gendering practices and feminist theory. Eds. Carol Bacchi and Joan Eveline. Adelaide: University of Adelaide Press, 2010. 111-138.

Bacchi, Carol, and Joan Eveline. "What are we mainstreaming when we mainstream gender?». In Mainstreaming politics: Gendering practices and feminist 
theory. Eds. Carol Bacchi and Joan Eveline. Adelaide: University of Adelaide Press, 2010. 87-110.

Bacchi, Carol, and Susan Goodwin. Poststructural policy analysis: A guide to practice. New York: Springer, 2016.

Bunch, Charlotte. «Women's rights as human rights: Toward a re-vision of human rights», Human Rights Quarterly 12. 4 (1990): 486-498.

Bustelo, María. «Evaluation from a gender+ perspective as a key element for (re) gendering the policymaking process.» Journal of Women, Politics \& Policy 38. 1 (2017): 84-101.

Eveline Joan, and Carol Bacchi. «Obeying organizational 'rules of relevance': gender analysis of policy». In Mainstreaming politics: Gendering practices and feminist theory. Eds. Carol Bacchi and Joan Eveline. Adelaide: University of Adelaide Press, 2010. 283-310

Franzway, Suzanne, Rhonda Sharp, Julie E. Mills, and Judith Gill. «Engineering ignorance: The problem of gender equity in engineering». Frontiers: A Journal of Women Studies 30. 1 (2009): 89-106.

Goodwin, Susan, and Archana Preeti Voola. «Framing microfinance in Australia-gender neutral or gender blind?». Australian Journal of Social Issues 48. 2 (2013): 223-239.

Mukhopadhyay, Maitrayee. «Mainstreaming gender or reconstituting the mainstream? Gender knowledge in development». Journal of International Development 26.3 (2014): 356-367.

O'Hagan, Angela. «Conceptual and Institutional Origins of Gender Budgeting». In Gender Budgeting in Europe: Developments and Progress. Eds. Angela O'Hagan and Elisabeth Klatzer. New York, London: Palgrave Macmillan, 2018. 19-42.

Picchio, Antonella. «Reflections on the Politics and Context of Gender Budgets: A Feminist Perspective». In Gender Budgeting in Europe: Developments and Progress. Eds. Angela O'Hagan and Elisabeth Klatzer. New York, London: Palgrave Macmillan, 2018. 345-360. 
To link to this article / Para enlazar con este artículo:

https://doi.org/10.14198/fem.2020.35.02

To cite this article / Para citar este artículo:

Ozonas Marcos, Margarita. «How to integrate a gender perspective into well-being budgeting practices: Insights from a comparative case study between Bhutan and New Zealand». En Feminismo/s, 35 (junio 2020): 29-61. Monographic dossier / Dossier monográfico: A critical practice of thinking otherwise: Bacchi, Gender and Public Policy Analysis, coord. Angela O'Hagan, DOI: 10.14198/fem.2020.35.02

\title{
HOW TO INTEGRATE A GENDER PERSPECTIVE INTO WELL-BEING BUDGETING PRACTICES: INSIGHTS FROM A COMPARATIVE CASE STUDY BETWEEN BHUTAN AND NEW ZEALAND
}

\section{CÓMO INTEGRAR LA PERSPECTIVA DE GÉNERO EN LOS PRESUPUESTOS DE BIENESTAR: IDEAS DE UN ESTUDIO COMPARATIVO ENTRE BUTÁN Y NUEVA ZELANDA}

\author{
Margarita OzONAS MARCOS \\ Independent freelance \\ http://www.consultant-gender-equality.com/ \\ marga.ozonas@gmail.com \\ orcid.org/0000-0001-8942-2709
}

\begin{abstract}
Well-being gender budgeting (WBGB) experiences use a multidimensional approach for planning and budgeting combining the Capability Approach along with gender responsive budgeting, which entails a feminist approach. However, what happens to the other well-being budgeting initiatives that do not explicitly include this «gender focus» in their conceptualization?

Based on the central question expressed by Carol Bacchi - «What is the problem represented to be?»-, this article explores the gender bias that can be found in well-being budgeting that does not fit into the category of WBGB and the difficulties of integrating a gender perspective in these practices. It is based on the review of the documentation of the main well-being domains, political priorities and tools used from 2019-2020 in Bhutan and New Zealand. The article concludes with some insights and recommendations to merge GRB practices into well-being budgeting approaches.
\end{abstract}


How to integrate a gender perspective into well-being budgeting practices:

Insights from a comparative case study between Bhutan and New Zealand

Keywords: Well-being Budgeting; Well-being Gender Budgeting; Gender Responsive Budgeting; Capability Approach; Gender Mainstreaming.

\section{Resumen}

Las experiencias de presupuestos de bienestar y género (PBG) utilizan un enfoque multidimensional en el que combinan dos enfoques, uno basado en las capacidades y otro basado en presupuestos con enfoque de género. Sin embargo, ¿qué sucede con las otras iniciativas presupuestarias de bienestar que no incluyen explícitamente este «enfoque de género» en su conceptualización?

En base a la pregunta central expuesta por Carol Bacchi: «iCuál es el problema representado en cuestión?», este artículo explora los sesgos de género que pueden encontrarse en presupuestos de bienestar que no se ajustan a la categoría explícita de los PBG y las dificultades que puede entrañar integrar la perspectiva de género en estas prácticas. Se basa en la revisión bibliográfica de los principales dominios de bienestar, prioridades políticas y herramientas utilizadas en Bután y Nueva Zelanda en 2019 y 2020. El artículo concluye con algunas ideas y recomendaciones para fusionar las prácticas de presupuestos con enfoque de género con los presupuestos de bienestar.

Palabras clave: presupuestos de bienestar; presupuestos de bienestar y género; presupuestos con enfoque de género; enfoque de capacidades: transversalización del enfoque de género.

\section{INTRODUCTION}

\subsection{Background}

The 2030 Sustainable Development Goals (SDGs) pledge to «leave no one behind» recognizes that «extreme inequality persists within countries and cities as well as among countries» (United Nations, Leaving no one behind 3 ). Despite progress made in many countries around the world, gender inequality is still a global problem (United Nations, Leaving no one behind 34) and in addition, we are experiencing a tremendous climate crisis. How can policymakers address all of these issues? Just as problems are interrelated, so are the solutions to poverty, inequality, climate change and other global challenges (United Nations, The Sustainable Development Goals 3). These multiple and interconnected crises, including that of gender inequality, undermine 
How to integrate a gender perspective into well-being budgeting practices:

Insights from a comparative case study between Bhutan and New Zealand

attainment of collective well-being (Trebeck $1^{1}$ ). Policymakers have to find a solution through innovative, multidimensional and strategic planning and budgeting. Well-being budgeting (WBB) presents a potentially promising solution. Furthermore, introducing Gender Responsive Budgeting (GRB) into well-being budgeting practices supports the SDGs of «leaving no one behind», promoting gender equality and empowering specific segments of the population. GRB is embedded in international agreements and commitments such as CEDAW and SDG indicator 5C1 «Proportion of countries with systems to track and make public allocations for gender equality and women's empowerment». (UN Women, Financing for Gender Equality 18 February 2020)

This article presents a comparative study of two cases of well-being budgeting from Bhutan and New Zealand: two countries of different sizes and contexts that decided to adopt a wellbeing approach to public policy at national government level, but with almost a 50-year gap in implementation, different conceptual well-being frameworks and different policy tools. A critical point of reflection in this article is to identify to what extent WBB approaches in Bhutan and New Zealand conceptualize well-being from a gender perspective, examining how the problem of gender inequality is represented in their respective well-being approaches, and if the policy tools used integrate a gender perspective.

This article aims to provide some insights that can enrich present and future WBB experiences by adapting some existing GRB approaches to gender-neutral WBB practices ${ }^{2}$, and considering the possible difficulties this might imply. To do this, the article engages with Carol Bacchi's «What is the problem represented to be?» (WPR) approach (2009) as an analytical framework through which to critically explore this inquiry, probing implicit gender biases in the problem representation of well-being and proposing possible solutions to how WBB can be conceptually conceived in a gender-neutral or gender-blind way.

1. This paper was commissioned by the Women's Budget Group to inform the Commission on a Gender-Equal Economy. At the time of writing this article, this paper was not yet been published.

2. In this article, references to "gender-sensitive» means that the gender perspective is taken into account. «Gender blind» and «gender-neutral» are terms used interchangeably and means that this perspective is not taken into account.

Feminismo/s 35, junio 2020, pp. 29-61 
There are two related policy and budgetary practices that consider the gender perspective in exploring WBB in the comparative case study and which are used in the WPR analysis: 1) Gender responsive budgeting (GRB) for which the literature dates back to the 1990s with gender mainstreaming in policymaking as the underlying approach, and 2) well-being gender budgeting (WBGB), which appeared in the literature in the 2000s and reconciles the well-being approach with the GRB approach.

\subsection{Structure}

Section one sets out the principal method used and the findings from a literature review and a documentary analysis of information collected from public governmental websites of Bhutan and New Zealand, comprising the main well-being domains, policy priorities and tools used in 2019-2020. These inform a set of comparative tables and illustrative figures elaborated by the author. The first section of this paper introduces the concepts of GRB, the Capability Approach as an inspiring framework for WBB and WBGB and describes the interrelations of these three concepts. The second section presents Carol Bacchi's analytical framework «What is the problem represented to be?» (2009) applied to WBB. The third section compares the well-being budgeting practices of Bhutan and New Zealand focusing on the conceptualization of well-being and the main tools used to assess whether well-being is considered from a gender perspective in the policy and budget cycle. The fourth section discusses conceptual frameworks and tools in relation to stated well-being aspirations and Bacchi's recommendations for improving gendered policymaking. The last section concludes with insights and recommendations on integrating the gender perspective in well-being budgets.

\section{GENDER RESPONSIVE BUDGETING, WELL-BEING BUDGET AND WELL-BEING GENDER BUDGETING: CONVERGENCES AND DIVERGENCES}

\subsection{Gender responsive Budgeting (GRB)}

GRB emerged as a key strategy to integrate a gender perspective into fiscal policies following feminist economic thinking in the 1980s. The main goal of GRB is to promote gender equality and redress inequality (Budlender and 
How to integrate a gender perspective into well-being budgeting practices:

Insights from a comparative case study between Bhutan and New Zealand

Hewitt 7; Council of Europe 10; Stotsky 4; Downes, Von Trapp, and Nicol 6) through gender responsive planning and budget allocations by governments. It is a concept aligned with gender mainstreaming, defined by The Council of Europe as follows:

The (re)organization, improvement, development and evaluation of policy processes, so that a gender equality perspective is incorporated in all policies at all levels and at all stages, by the actors normally involved in policymaking. (Council of Europe 8).

GRB aims to allocate resources to meet the different needs and priorities of men and women -needs and priorities that differ in nature- to allow men and women to achieve equality of outcomes from economic policies (Galizzi, Bassani, and Cattaneo 3). For GRB to be truly transformative, «it must be embedded in its feminist roots» (Khan 7): that means transforming gender blind budgets by adding a gender lens. GRB implementation can take different forms, depending on several factors that determine the scope, methods used and actors involved as Table 1 shows.

Table 1. Possibilities in GRB implementation

\begin{tabular}{|c|c|}
\hline Approaches & $\begin{array}{l}\text { - Gender responsive budgeting, } \\
\text { - Well-being gender budgeting, } \\
\text { - Socially inclusive and gender responsive budgeting, } \\
\text { - Integrating gender perspectives into participatory budgeting, } \\
\text { - Child friendly and gender responsive budgeting }\end{array}$ \\
\hline $\begin{array}{l}\text { Stages of the } \\
\text { budget cycle }\end{array}$ & $\begin{array}{l}\text { - Budget preparation, } \\
\text { - Budget approval, } \\
\text { - Budget execution, } \\
\text { - Budget audit and evaluation } \\
\end{array}$ \\
\hline $\begin{array}{l}\text { Scope of the } \\
\text { budget }\end{array}$ & $\begin{array}{l}\text { - Public spending } \\
\text { - Public revenues }\end{array}$ \\
\hline $\begin{array}{l}\text { Level of } \\
\text { government }\end{array}$ & $\begin{array}{l}\text { - National level } \\
\text { - Sub-national level (e.g. regional/autonomous; municipal level) }\end{array}$ \\
\hline $\begin{array}{l}\text { Governmental } \\
\text { planning }\end{array}$ & $\begin{array}{l}\text { - Policy priorities } \\
\text { - Specific sectors, programmes or projects }\end{array}$ \\
\hline
\end{tabular}

Feminismo/s 35, junio 2020, pp. 29-61 
How to integrate a gender perspective into well-being budgeting practices:

Insights from a comparative case study between Bhutan and New Zealand

\begin{tabular}{|c|c|}
\hline $\begin{array}{l}\text { Actors } \\
\text { involved and } \\
\text { coordinating } \\
\text { bodies }\end{array}$ & $\begin{array}{l}\text { - Actors inside the government } \\
\text { - Actors outside the government } \\
\text { - Coordinating mechanisms (e.g. GRB committee, gender focal } \\
\text { points in institutions, etc.) }\end{array}$ \\
\hline $\begin{array}{l}\text { Basic requisites } \\
\text { and other } \\
\text { conditions }\end{array}$ & $\begin{array}{l}\text { - Ability or capacity to conduct a gender analysis at all stages of } \\
\text { budget development and throughout the budget process } \\
\text { - Access to sex-disaggregated data and gender statistics } \\
\text { - Capacity building } \\
\text { - Other favourable conditions }\end{array}$ \\
\hline Methods & $\begin{array}{l}\text { - Integrating gender perspectives into performance-based and } \\
\text { programme-based budgeting } \\
\text { - Categorizing budget programmes and gender analysis } \\
\text { requirements } \\
\text { - Tracking financial allocations to promote women's rights and } \\
\text { gender equality } \\
\text { - Costing approaches }\end{array}$ \\
\hline Tools & - Ex ante, concurrent and ex-post tools \\
\hline
\end{tabular}

Source: Author's own elaboration

GRB implies the integration of a gender perspective into all stages of the budget cycle including multiannual and annual budget processes (Anwar, Downes, and Davidson 6; Downes, Von Trapp, and Nicol 6; Stotsky 14; Villagómez et al. 14; Khan 3). This requires gender analyses at all stages of budget development (Klatzer and Stiegler 2; Khan 3) and throughout the budget process to assess whether its composition responds to the pursued gender equality objectives.

Knowing how to conduct a gender analysis is a basic pre-requisite for GRB implementation, as it requires an understanding of how gender inequalities arise, the underlying structural causes, and how to tackle the ways in which they are manifested through gender responsive policies and budgets. In addition, GRB requires conducting assessments at different stages of the policy-budget cycle, especially to assess the impact of government revenue and expenditure on women and men, girls and boys (Budlender and Hewitt 7; Council of Europe 10). However, government institutions do not always have the capacity to integrate gender into budgetary policies (Budlender, Sharp, and Allen 8) and there is often a lack of knowledge about gender mainstreaming in theory and in practice (Villalba, Jubeto, and Guridi 6). For 
this reason, capacity building on gender analysis and gender mainstreaming is another requisite in GRB implementation. Strengthening the capacity of budget actors, through skills and knowledge transfer is critical (Khan 4). Access to sex-disaggregated data and gender statistics are also another basic pre-requisite for gender assessments and to mainstream a gender approach into the budget cycle. Another indispensable step is to collect quantitative and qualitative data and produce gender-related indicators on a regular basis. Likewise, collecting other categories of data, such as age, ethnicity, urban/ rural areas, etc., will provide data for «socially inclusive budgeting», a process by which the rights of all, in particular those suffering from poverty and exclusion, are better reflected in public policymaking, notably in the government budget (United Nations, Leaving no one behind 6). In many countries GRB initiatives have improved the availability of sex-disaggregated data essential for assessing budgetary impacts and for improving statistics and indicators when they have successfully engaged with performance budgeting systems (Sharp and Elson 2). In addition to these pre-requisites, there are other favourable conditions that can contribute to establishing GRB including a series of contextual, normative, institutional, and relational conditions (O'Hagan 237).

There is a wide range of methodologies and tools for GRB implementation, as Table 1 shows, and which vary according to the context and objectives (Anwar, Downs, and Davidson 6). Ronnie Downes, Lisa von Trapp and Scherie Nicol (7) in their study «Gender Budgeting in OECD Countries» classify gender budgeting interventions into three relevant stages in the budget process: ex-ante, concurrent, and ex-post.

\subsection{The Capability Approach: Inspiring framework for Well-being Budgeting (WBB)}

Amartya Sen, Martha Nussbaum and Ingrid Robeyns have been among the major contributors to the Capability Approach. This alternative framework for social justice is based on the notion of capabilities, that is, individuals' functioning and freedom of choice. Capabilities are potential functioning, for example, people's access to sufficient food, taking part in the community, having shelter, relating to other people, working in the labour market, caring for others, and being healthy (Robeyns, «Sens Capability» 63). These 
How to integrate a gender perspective into well-being budgeting practices:

Insights from a comparative case study between Bhutan and New Zealand

functionings can also incorporate subjective values such as «being happy» (Sen, Inequality 39).

The conceptual framework of the Capability Approach, has inspired WBB practices and used, «to measure well-being recognizing its complexity and the interaction of different dimensions of well-being» (Addabbo et al. «Senegal» 15). A wellbeing economy pursues the social foundations of gender equality, social equity, peace and justice, health, food, water and education that must be secured within environmental boundaries (Coscieme et al. 5). In 2018, Scotland, Iceland and New Zealand established the Wellbeing Economy Governments (Wellbeing Economy Website, 27 February 2020). The wellbeing economy proposes that

Economics and business practices need to be reoriented to what an economy should actually deliver: an equitable distribution of wealth, health and wellbeing, while protecting the planet's resources for future generations and other species» (Hough-Steward et al. 6).

Previous well-being practices have been developed in various countries and have been quite diverse to date. The oldest one comes from the nation of Bhutan and is «the most widely known example of wellbeing policy», where well-being is linked to the concept of «happiness» with the «rationale for making happiness an integral part of its public policy» (Biswas-Diener, Diener, and Lyubchik 2). In 1972, Bhutan's fourth king Jigme Singye Wangchuck declared: «Gross National Happiness is more important than Gross National Product» (Government of Bhutan GNH Centre Website, 27 February 2020). By July 2008, Bhutan had officially enshrined Gross National Happiness (GNH) in its constitution. Bhutan was the first country to focus its planning and budgeting system to respond to the GNH Index.

In sum, there have been a variety of WBB practices, as the concept of well-being is open to multiple interpretations, and the methods and tools used will differ based on those interpretations. Trebeck categorizes well-being as «a multifaceted concept» and highlights that, besides all different meanings and interpretations, it is possible to broadly cluster them in two main categories: definitions that emphasize self-reported well-being, and collective and multidimensional well-being (3). As the findings in this article show, how these categories are applied in WBB policymaking has implications for the achievement of gender equality outcomes.

Feminismo/s 35, junio 2020, pp. 29-61 
How to integrate a gender perspective into well-being budgeting practices:

Insights from a comparative case study between Bhutan and New Zealand

If the variables and indicators included in a WBB approach are limited, the advancement of gender equality is reduced, as evidenced here in the examples from Bhutan and New Zealand which spotlight the weaknesses of the WBB approaches followed there. The first consideration refers to the subjective dimension of well-being. For Nussbaum and Sen, the Capability Approach includes subjective concepts of well-being, such as «pleasures, happiness, or desire fulfilment» regarded as parameters of «personal utility» (Sen, «Capability and Well-being» 2). Citing Sen (The idea of justice), Alkire clarifies that «happiness is often recognized as a dimension of well-being in the Capability Approach» (8), and according to Stewart, the subjective measures of happiness in the Capability Approach form the focus of the Happiness Approach today (3). The well-being conceptualization in Bhutan focuses on happiness, which fits the subjective dimension in the Capability Approach.

As a policy framework, the Happiness Approach has a series of limitations. The first is the difficulty of setting objectives, as there is no consensus of what is meant by «happiness» (Stewart 5). Secondly, «the approach must nevertheless be practical in the sense of being usable for actual assessments of the living standard» which «imposes restrictions on the kinds of information that can be required and the techniques of evaluation that may be used» (Sen, «Standard» 20). Then, there are difficulties in the use of subjective measures for policy purposes (Binder 8; Alkire 10) due to measurement imprecision and bias (Binder 4). For example, in self-reporting well-being processes, some individuals may report high levels of happiness in a context of structural inequalities (Trebeck 4). Middlemiss, citing Ahmed, highlights gender bias in self-reported well-being in a context of socially accepted discriminatory gender roles whereby:

Happiness has been used to promote a range of unsavory agendas in the past, including the subjugation of women ( Women are happy being in caring roles»)... [Ahmed] points out that if happiness becomes an aim, it also becomes a duty, and then to be unhappy is to be «causing trouble». In the context of feminism, this means the unhappy woman, the feminist, is a «killjoy,» when another framing might cast her as the freedom fighter (Middlemiss 1).

Another limitation of the Capability Approach in the pursuit of gender equality outcomes is when it takes the form of «collective well-being». There is 
How to integrate a gender perspective into well-being budgeting practices:

Insights from a comparative case study between Bhutan and New Zealand

no judgement about distribution beyond some distributional implications giving priority to universal access or to some critical capabilities (Stewart 8). Second, there is a risk of simplifying and clustering all the needs and interests of women and men, girls and boys (different population groups) as a unified and homogeneous group.

Historically, feminists have shown that when policy focuses on the collective level, instead of the individual, the needs and experiences of women can be subsumed by those of the collective; their voices silenced or talked over when the collective is represented; and that analysis at the collective, or household level can mask poverty, financial control and other forms of violence and abuse (Trebeck 4).

Both cases, New Zealand and Bhutan, follow an approach of collective and multidimensional well-being with the further complication of the case of Bhutan being built on the Happiness Approach.

\subsection{Well-being Gender Budgeting (WBGB)}

Before examining the concept of well-being gender budgeting it is important to understand the academic contributions, especially those of Robeyns and Nussbaum, to incorporate gender equality in the Capacity Approach. Robeyns highlighted weaknesses in how the Capability Approach responds to gender inequality

One of the crucial questions that Sen has not answered is which capabilities are relevant for assessing inequality. In other words, Sen has not proposed a well-defined list of capabilities (Robeyns, «Capability» 62).

Robeyns and Nussbaum subsequently proposed a list of capabilities that are relevant for gender equality, contributing to this analytical gap (See: Nussbaum, «Human» 83-5; Nussbaum, Women 78-86; Robeyns, «Capability» 74). For Robeyns, gender inequality includes gender division and time use of paid and unpaid work (household work and care work) (Robeyns, «Justice» 14). Nussbaum (Women) has emphasized the importance of reproductive health and reproductive rights, the negative effects of domestic violence, women's education and socio-economic status, participation in the labour market and time autonomy (Addis et al. 8). 
Aligned with these contributions, there have been feminist examinations of the broad concept of well-being, which entails knowledge of the different roles played by men and women in the definition of well-being (Addabbo, «Gender budgeting» WISE 3) and requires micro and macro analysis (Addabbo et al, «Social-reproduction» 106). Well-being is defined at the individual level and this, according to feminist economics, requires investigating what happens inside the family and recognizing the possibility of conflicts among its members regarding the construction of well-being (Addabbo, «Gender budgeting» WISE 3). This means an assessment of distribution of resources, work (both paid and unpaid), responsibilities and power relationships between institutions and residents (Addabbo et al., "Social-reproduction» 106).

Well-being gender budgeting practices have emerged as an approach to revealing and addressing gendered inequalities in terms of well-being (Klatzer et al. 116), inspired by a revised Capability Approach with a gender approach as well as by the feminist examination of the broad concept of well-being. (Gunluk-Senesen et al. «Gender budgeting in Turkey» 179). To date there is limited literature on this approach. According to Addabbo et al., "the Capability Approach to gender budgeting is a relatively underexplored area of research» («Senegal»1), confirmed by Klatzer et al. (134), who consider a group of Italian academics, notably Addabbo and Picchio, to have led the application of the theoretical framework of WBGB.

WBGB literature makes reference to how the Capability Approach has been used in auditing gender budgeting practices in public service provision (Addabbo, Lanzi, and Picchio, «Gender auditing» 1; Yucel and GunlukŞenesen 2) and auditing the gender impact of policies on well-being (Addabbo, «Gender budgeting» WISE 3). This approach has been applied mostly at local level in municipalities and universities in Italy, Turkey and Spain (Klatzer et al. 123) and Senegal. In the example of municipal budgeting in Turkey, WBGB was introduced as part of a GRB initiative supported by United Nations. In this case, a list of capabilities relevant for gender equality were used along with a set of indicators, presented in a matrix (Gunluk-Senesen et al., "Gender budgeting in Turkey» 184). 


\subsection{Well-being Gender Budgeting (WBGB): Between Gender Responsive Budgeting (GRB) and Well-being Budgeting (WBB)}

In this section, the relationship among of three described budgetary practices is explored. As figure 1 shows, WBGB is the point of convergence in the conceptualization of WBB and GRB.

The concept of GRB differs from WBB as GRB does not necessarily encompass the multidimensional notion of well-being and Capability Approach, except when conceptualized as WBGB (Addabbo et al., «Social-reproduction» 105). Alternatively, «WBGB goes beyond GRB, since it includes the auditing of institutional budgets from the well-being perspective» (Addabbo, RodríguezModroño, and Gálvez-Muñoz 1).

On the other hand, both GRB and WBGB share a feminist way of thinking in their conceptualization while WBB does not include this in its conceptualization. Figure 1 below illustrates the overlap where both WBGB and GRB approaches take into account feminist demands in the original concept of GRB, such as the visibility and recognition of women's unpaid work and social reproduction including care and household work, informal work and time use.

Figure 1. Similarities and differences among the conceptualization of WBB, WBGB and GRB
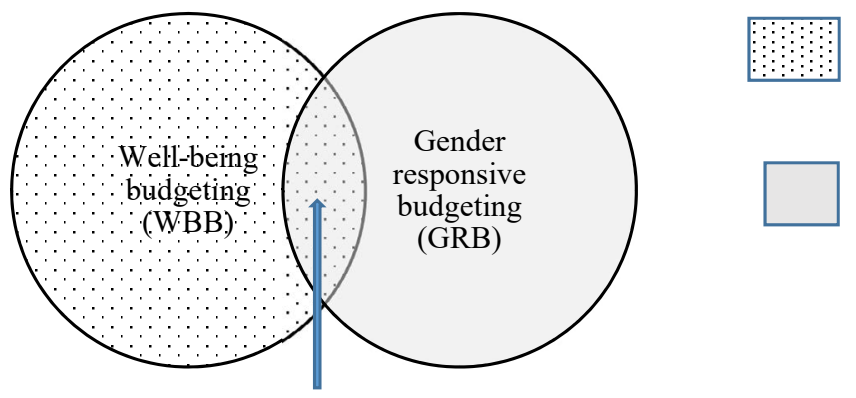

Well-being conceptualization: Capability approach

Feminist conceptualization: Care economy, social reproduction work, addressing roots of gender discrimination

Well-being gender budgeting (WBGB)

Source: Author's own elaboration

Feminismo/s 35, junio 2020, pp. 29-61 
How to integrate a gender perspective into well-being budgeting practices:

Insights from a comparative case study between Bhutan and New Zealand

A distinction between WBGB and GRB, is that WBGB is used as a framework to carry out gender analysis and guide public policy and budgeting, converting public resources into individual and social well-being, thereby supporting the expansion of capabilities and the effective functioning of both women and men (Addabbo et al., «Senegal» 1). Based on a list of essential capabilities and functions, the WBGB approach combines the individual's functions with policy domains and areas of responsibility of the government for service provision (Klatzer et al. 122).

As with GRB, WBGB implies assessing the impact that policies have on women and men's well-being, in all its multiple dimensions, as demonstrated in the previous example of well-being gender analysis in Turkey (Yucel and Gunluk-Senesen 272). It is necessary to assess the potential gender differentiated impacts that policies may have on individuals and inside households that can give rise to an unequal development of capabilities (Addabbo, «Gender budgeting» WISE 4). Picchio (1) described that as women are the main caregivers of children and the elderly, in a context where child care and elder care public services are rationed (e.g. Italy), this can have negative effects on the development of their other capabilities who as principal carers face time constraints and discrimination in their access to the labour market.

\section{CAROL BACCHI'S CONCEPTUAL FRAMEWORK: WHAT IS THE PROBLEM REPRESENTED TO BE? APPLIED TO WELL-BEING BUDGETING}

Bacchi's «What is the problem represented to be?» (WPR) approach is an analytical framework intended to facilitate critical interrogation of public policies. It starts from the premise that what one proposes to do about something reveals what one thinks is problematic (needs to change). Following this thinking, policies and policy proposals contain implicit representations of what is considered to be the «problem» («problem representations») (Bacchi, «Introducing» 21). The task in a 'WPR' analysis is to read policies with an eye to discerning how the 'problem' is represented and to subject this problem representation to critical scrutiny. That means, to put «problems» into question in order to identify where the implicit bias in the problem conceptualization is and what could be a solution to avoid this implicit bias. This

Feminismo/s 35, junio 2020, pp. 29-61 
How to integrate a gender perspective into well-being budgeting practices:

Insights from a comparative case study between Bhutan and New Zealand

article focuses on the implicit bias inherent in the problem representation that well-being is gender-neutral, that means, in general terms well-being is conceptualized in a gender blind way.

Bacchi proposed a set of six questions to analyse problem representation in order to scrutinize policy proposals, their potential impact, and for thinking how else the problem representation could be addressed. Table 2 below applies these questions to well-being budgeting.

Table 2. Using WPR for WBB

\begin{tabular}{|c|c|}
\hline Questions & Answers \\
\hline $\begin{array}{l}\text { 1. What's the «problem» represented } \\
\text { to be in a specific policy or policy } \\
\text { proposal? }\end{array}$ & $\begin{array}{l}\text { Gender analysis is not reflected in well- } \\
\text { being conceptualization, and the main } \\
\text { policy tools used are designed without a } \\
\text { gender approach. Gender mainstreaming } \\
\text { is lacking. }\end{array}$ \\
\hline $\begin{array}{l}\text { 2. What presuppositions or assumptions } \\
\text { underpin this representation of the } \\
\text { «problem»? }\end{array}$ & Well-being is gender-neutral \\
\hline $\begin{array}{l}\text { 3. How has this representation of the } \\
\text { "problem» come about? }\end{array}$ & - \\
\hline $\begin{array}{l}\text { 4. What is left unproblematic in this } \\
\text { problem representation? }\end{array}$ & - \\
\hline $\begin{array}{l}\text { 5. Where are the silences? Can the } \\
\text { "problem» be thought about } \\
\text { differently? What effects are produced } \\
\text { by this representation of the } \\
\text { "problem»? }\end{array}$ & $\begin{array}{l}\text { The silences are that the roots of gender } \\
\text { inequality and gender discrimination } \\
\text { are not addressed in well-being } \\
\text { conceptualization. The "problem» can be } \\
\text { thought about differently when gender } \\
\text { analysis is included in gender-blind WBB } \\
\text { and gender mainstreaming is promoted. }\end{array}$ \\
\hline $\begin{array}{l}\text { 6. How/where has this representation } \\
\text { of the «problem» been produced, } \\
\text { disseminated and defended? How has } \\
\text { it been (or could it be) questioned, } \\
\text { disrupted and replaced? }\end{array}$ & Well-being gender budgeting \\
\hline
\end{tabular}

A central argument in this article is that overall, well-being budgeting approaches do not include gender analysis components such as addressing the root causes of gender-based discrimination, transforming imbalances in

Feminismo/s 35, junio 2020, pp. 29-61 
How to integrate a gender perspective into well-being budgeting practices:

Insights from a comparative case study between Bhutan and New Zealand

power relationships between men and women, recognizing and giving value to the care economy and the impacts of the different participation of men and women on unpaid work. The main reason why these components are not naturally included is because well-being is commonly conceptualized in a gender-neutral way as discussed in the following section on the cases of Bhutan and New Zealand.

Using WPR to analyse WBB, we observe that «the problem» is that the conceptualization of well-being and the way in which interventions are prioritized for planning and budgeting (e.g. policy priorities, well-being dimensions) are gender-blind as well as the tools used. Self-reporting well-being tools such as surveys are gender neutral (unless the gender perspective is included intentionally in the tool design) and collective and multidimensional well-being approaches tend to homogenize population needs and interest, which entails a «problem representation» (with the exception of WBGB). Some problem representations benefit the members of some groups at the expense of others (Bacchi, Analysing policy 44), with the effect that strategic needs and interest of some groups, especially women and girls, are hampered if this «problem» is not solved. The silences are that the roots of gender inequality and gender discrimination are not addressed in well-being conceptualization, and the concept of well-being is thought to be the same for men, women, girls and boys. The «problem» can be thought about differently when gender mainstreaming is fully integrated in WBB practices, starting with gender analysis of both revenue and expenditure decisions. For example, analyzing policy impacts on gender-based discrimination, imbalances in power relationships between men and women, the care economy and the impacts of the different participation of men and women on unpaid work. An illustrative example of this is the New Zealand GRB analysis of the 2016 Tax Expenditure Statement which indicated that the Tax Expenditure Statement in New Zealand lacked any gender specific analysis and that a number of the tax concessions have a potentially negative impact on gender equality (Morrissey, Gender Budgeting ii). Women earn less than men, have lower levels of savings and derive more of their income from wages than from wealth. This means that progressivity is particularly important for women (Morrissey, «Women and the Tax» 50). This representation of the problem is disrupted with the concept of «Well-being gender budgeting (WBGB)» which

Feminismo/s 35, junio 2020, pp. 29-61 
is a particular well-being budget approach that considers gender issues in its conceptualization and implementation.

Overall, the «problem» can be thought about differently by intentionally introducing a feminist conceptualization in WBB practices, along with all gender sensitive tools and competences for gender mainstreaming. In this way, both approaches - WBGB and gendered WBB - would be a specific type of GRB (See Figure 2).

Figure 2. Proposal for merging WBB with GRB
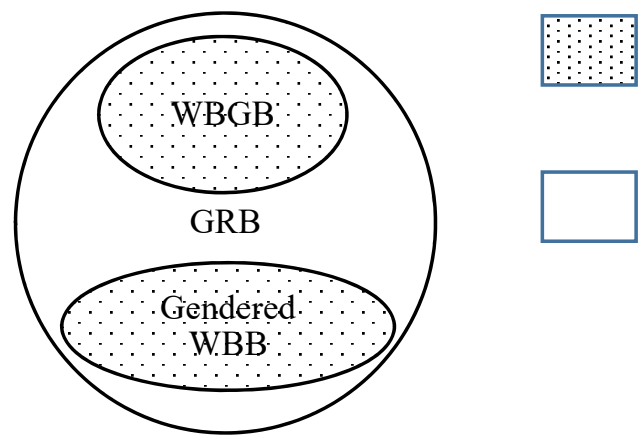

Well-being conceptualization: Capability Approach

Feminist conceptualization: Care economy, social reproduction work, addressing roots of gender discrimination

Source: Author's own elaboration

\section{BHUTAN AND NEW ZEALAND: A COMPARATIVE STUDY OF WELL-BEING BUDGETING}

\subsection{Comparing Well-being approaches, policy priorities and domains}

Currently in Bhutan, well-being is conceived under the Happiness Approach described in section 3, with four pillars that comprise Gross National Happiness (GNH) and nine domains that articulate the different elements of GNH. In New Zealand, the national budget is organized according to a set of well-being principles with five priority areas and twelve well-being domains. Both the policy pillars and the well-being domains are presented in Table 3. As this table shows, gender equality is currently neither a policy domain nor a policy priority in both countries. 
How to integrate a gender perspective into well-being budgeting practices:

Insights from a comparative case study between Bhutan and New Zealand

Table 3. Policy priorities and well-being domains and gender in Bhutan and New Zealand

\begin{tabular}{|c|c|c|c|c|c|}
\hline Country & & $\begin{array}{l}\text { licy pillars or } \\
\text { priorities }\end{array}$ & & Well-being domains & $\begin{array}{l}\text { Is gender } \\
\text { equality one } \\
\text { of the main } \\
\text { pillars? }\end{array}$ \\
\hline Bhutan & & $\begin{array}{l}\text { Good } \\
\text { governance, } \\
\text { Sustainable } \\
\text { socio- } \\
\text { economic } \\
\text { development, } \\
\text { Preservation } \\
\text { and promotion } \\
\text { of culture, and } \\
\text { Environmental } \\
\text { conservation. }\end{array}$ & $\begin{array}{l}\text { i) } \\
\text { ii) } \\
\text { iii) } \\
\text { iv) } \\
\text { v) } \\
\text { vi) } \\
\text { vii) } \\
\text { viii) } \\
\text { ix) }\end{array}$ & $\begin{array}{l}\text { Psychological well-being } \\
\text { Health } \\
\text { Time use } \\
\text { Education } \\
\text { Cultural diversity and } \\
\text { resilience } \\
\text { Community vitality } \\
\text { Good governance } \\
\text { Ecological diversity and } \\
\text { resilience } \\
\text { Living standards }\end{array}$ & No \\
\hline $\begin{array}{l}\text { New } \\
\text { Zealand }\end{array}$ & & $\begin{array}{l}\text { Taking } \\
\text { Mental Health } \\
\text { Seriously, } \\
\text { Improving } \\
\text { Child } \\
\text { Well-being, } \\
\text { Supporting } \\
\text { Māori and } \\
\text { Pasifika } \\
\text { Aspirations, } \\
\text { Building a } \\
\text { Productive } \\
\text { Nation, and } \\
\text { Transforming } \\
\text { the Economy. }\end{array}$ & $\begin{array}{l}\text { i) } \\
\text { ii) } \\
\text { iii) } \\
\text { iv) } \\
\text { v) } \\
\text { vi) } \\
\text { vii) } \\
\text { viii } \\
\text { ix) } \\
\text { x) } \\
\text { xi) } \\
\text { xii) }\end{array}$ & $\begin{array}{l}\text { Civic Engagement and } \\
\text { governance, } \\
\text { Cultural identity, } \\
\text { Environment, } \\
\text { Health, } \\
\text { Housing, } \\
\text { Income and consumption, } \\
\text { Jobs and earnings, } \\
\text { Knowledge and skills, } \\
\text { Time use, } \\
\text { Safety and security, } \\
\text { Social connection, and } \\
\text { Subjective well-being. }\end{array}$ & No \\
\hline
\end{tabular}

Source: Government of Bhutan, GNH Centre (Website, 18 February 2020) and Treasury in New Zealand (Website, 18 February 2020) 
The New Zealand Budget Policy Statement (BPS) is the first document in the budget cycle and sets out the five priorities for the Well-being Budget, which are the same for 2019 and 2020. In 2019, academics based in New Zealand conducted an initial gender impact analysis of the 2019 Well-being Budget which provided concrete examples on how gender analysis was missing in the policy priorities and well-being domains. For example, the policy priority «building a productive economy» did not consider the cost of inequality, such as violence against women and girls as something that negatively impacts on the country's economy. According to the assessment:

family violence costs New Zealand between $\$ 4.1$ to $\$ 7$ billion per year, with nearly $\$ 1$ billion a year in lost productivity in the workplace. Without intervention, the figure was predicted to result in a 10-year cumulative cost approaching $\$ 80$ billion (Curtin and Morrissey 1 ).

This led the researchers to conclude that «We cannot assume that a focus on well-being will automatically address gender inequalities» (Curtin and Morrissey 1).

\subsection{Comparing main tools used for well-being budgeting}

The main tools used in both countries for the Government to guide policymaking are presented in Table 4. None of these tools, except the New Zealand's tool «Bringing Gender In» integrate a gender analysis component in their design. However, most of them facilitate data for gender analysis as the table shows. 
How to integrate a gender perspective into well-being budgeting practices:

Insights from a comparative case study between Bhutan and New Zealand

Table 4. Main tools used in Bhutan and New Zealand for policymaking

\begin{tabular}{|c|c|c|c|}
\hline Country & Tools & $\begin{array}{l}\text { Are these tools } \\
\text { designed with a } \\
\text { gender approach? }\end{array}$ & $\begin{array}{c}\text { Do these tools } \\
\text { facilitate production } \\
\text { of data for gender } \\
\text { analysis? }\end{array}$ \\
\hline \multirow[b]{2}{*}{ Bhutan } & $\begin{array}{l}\text { 1) The GNH Screening } \\
\text { Tool }\end{array}$ & No & No \\
\hline & 2) GNH Happiness Index & No & $\begin{array}{l}\text { Yes. It provides sex- } \\
\text { disaggregated data } \\
\text { useful for gender } \\
\text { analysis of the } \\
\text { results }\end{array}$ \\
\hline \multirow{3}{*}{$\begin{array}{l}\text { New } \\
\text { Zealand }\end{array}$} & $\begin{array}{l}\text { 1) The Treasury's Living } \\
\text { Standards Framework }\end{array}$ & No & $\begin{array}{l}\text { Yes. It provides sex- } \\
\text { disaggregated data } \\
\text { useful for gender } \\
\text { analysis of the } \\
\text { results }\end{array}$ \\
\hline & 2) The LSF Dashboard & No & $\begin{array}{l}\text { Yes. It provides sex- } \\
\text { disaggregated data } \\
\text { useful for gender } \\
\text { analysis of the } \\
\text { results }\end{array}$ \\
\hline & 3) Bringing Gender In & Yes & Yes \\
\hline
\end{tabular}

Source: Author's own elaboration

In Bhutan, the main governmental tools are the GNH Screening Tool and the GNH Happiness Index. The objective of the GNH Screening tool is to systematically assess the impacts of any policy and project on GNH, thereby simultaneously selecting GNH enhancing policies and projects and rejecting projects and policies that adversely affect key determinants of GNH. The tool is applied to all policies and projects at the formulation stage of the policy process. However, this tool does not assess the gender impacts of the policies, either before (ex-ante) or after (ex-post) policy implementation. Therefore, it is missing an assessment of the potential consequences that each policy can have on gender equality. The methodology includes a set of «screening questions» that cover the nine domains of GNH in order to test their applicability in enhancing the values of GNH. To assess the result of the 
How to integrate a gender perspective into well-being budgeting practices:

Insights from a comparative case study between Bhutan and New Zealand

screening questions, there is a scoring system which, according to the GHN Centre website, is done by a heterogeneous group with diverse occupational backgrounds to work towards a consensus on project impacts. However, at the time of writing this article there was no reference to the ratio of women to men in this group, nor a reference to groups that could represent vulnerable segments of the population.

The GNH Happiness Index is based on a GNH Happiness Survey. It includes the nine domains, which are further supported by 33 indicators. The Index provides the framework for analyzing the happiness and well-being of the people. It also guides how policies may be designed to further create enabling conditions for the weaker scoring results of the survey. To conduct the analysis, it collects information disaggregated by sex and other categories such as region (rural, urban) and marital status. This allows an analysis of demographic groups. For instance, results of the 2010 Gross National Happiness showed that men were happier than women. Forty-nine per cent of men were happy, while only one-third of women were happy, a result considered statistically significant (Ura et al. 50). The data obtained in the survey allows sex differentiated results in each one of the nine domains, including relevant data for gender analysis such as time use. However, the questions in the survey to address the nine domains does not make reference to certain issues that affect women in particular. To illustrate this point, the domain «community vitality» used a set of questions to measure «family well-being», however:

1. In the questionnaire the definition of «family» is not clear. It seems to be the concept of «traditional family»; a heterosexual couple with descendants (children) and ascendants (third age) in the household. This excludes non-traditional families, for example, LGBTQ+. At the beginning of the questionnaire, there are no questions on sexual orientation or gender identity;

2. There are some references to time-use in relation to family (i.e. Do you get enough time to spend with your family?) but there is no mention of time spent on care or housework;

3. There is no variable to capture any possible violence within the family. There is, however, the variable «victim of crime» in the domain 
«safety in the community», which is where respondents are asked whether they have been a victim of a crime in the past 12 months. The crime indicator has a simple two-point scale of «yes» and «no» and does not allow for the identification of the type of crime, including inter-personal violence (IPV). There is, however, specific ethical guidance, such as the WHO and other specific questionnaires to collect data on gender based violence in a sensitive way, as there is often underreporting on IPV cases.

In New Zealand, the main tools used for the Government to guide policymaking are «The Treasury's Living Standards Framework» (LSF), a set of well-being indicators. These are related to the twelve domains to guide policy advice and the LSF Dashboard, a tool that supports the Treasury to use the LSF providing information on cross-government policy priorities. At the time of writing, the Policy Budget Statement 2020 and the LSF Dashboard, last updated in December 2019, highlighted that both tools are works in progress and that the Treasury will update the them in mid-2021 to better reflect priority areas. Data provided by both tools focuses on three sections: «Our country», «Our future», and «Our people». The Dashboard is linked to the LSF providing a set of indicators for each of these sections. It provides data disaggregated by sex and other information relevant for gender analysis. For example, in the section of «Our future», the indicator «Experience of discrimination» shows the percentage of people aged 15 years and older who reported having been subject to some form of discrimination in the previous 12 months. Examples of discriminatory treatment include racism, sexism and ageism. (Stats NZ Website, 18 February 2020). However, the information collected does not specify gender identity and sexual orientation and it only covers four types of ethnicities: Asian, European, Māori and Pacific, and four type of families: couple with or without children, not in a family nucleus and sole parent (McLeod 5). In addition, the LSF is missing time use data to conduct an analysis of its relation to unpaid work. Estimates of the impact of unpaid work on material standard of living are affected by a lack of regular time use data (Smith 47).

Ironically, the new Living Standards Framework does allow policymakers to value unpaid labour and address relevant inequities. [...]. In effect, then, the 
How to integrate a gender perspective into well-being budgeting practices:

Insights from a comparative case study between Bhutan and New Zealand

ability to measure whether unpaid and paid labour is equitably distributed, and the impact such distribution has on its sustainability for different genders, ethnicities and levels of abilities, is technically built in. Yet this potential is not being realised, given the inadequacy of the framework's measures related to unpaid work (Berentson-Shaw 49).

One of the challenges that has been discussed in New Zealand is related to «representation», which is aligned with the SDG concept of «leaving no one behind» and to one of the original aspirations of GRB to enhance democratic participation, civil society participation and accountability (Budlender and Hewitt 10). In the Third International Conference on Well-being and Public Policy held in Wellington in 2018, the concepts of diversity and inequality were highlighted, pointing out that it is not appropriate to assume sub-populations are homogeneous in their views on what contributes to well-being. This is regarded as a challenge in representation that aims that all voices are heard and that people feel that their well-being, what matters to them and their community is recognised (Weijers and Morrison 8).

As with the case in Bhutan, New Zealand tools are not designed from a gender approach. Women are slightly more likely than men to have low well-being across a number of domains, particularly Health, Housing and Social connections (McLeod 25). Larger differences are evident with respect to Safety and Income and consumption (McLeod 25). On the other hand, women reported higher levels of violence. According to the Ministry of Justice crime and victims survey, $4.8 \%$ of females over 15 years old reported that they were victims of family violence in 2018. This information is presented in the results of the well-being data, within the indicator of domestic violence. Despite all this evidence, there is not a specific focus on gender equality or women's empowerment indicators, however, several well-being indicators focus on children's well-being (e.g. «harm against children», «child poverty: material hardship», and «child poverty: low income») but without making the gender dimensions explicit. There is a general comment about these data gaps in the Dashboard update of 12 December 2019, which shows two weaknesses of the method; the first one is the failure in obtaining substantive information for evidence-based policy making, and the second one, the externalization of essential governmental tasks of policy making, to local governments and interest groups: 
How to integrate a gender perspective into well-being budgeting practices:

Insights from a comparative case study between Bhutan and New Zealand

The Dashboard does not provide the depth of quantitative and qualitative well-being evidence needed for agency policy analysis, such as the detailed distributional information needed for policy targeting. The Treasury expects agencies, local governments and relevant interest groups to develop their own well-being datasets, with a much deeper range of well-being data and evidence to analyse the performance of their sectors and policies (Treasury New Zealand, «The well-being budget 2019»6).

In addition, in New Zealand, there is another tool called «Bringing Gender In» available in the Ministry of Women in NZ's Website, for conducting gender assessments on the impact of policies. This gender-specific tool guides policymakers in the development a compulsory statement, which is required in papers for the Cabinet Social Well-being Committee on whether proposals have gender implications. It provides key questions, examples and links to useful data and other relevant material in order to develop a gender statement for the policy. The statement should say what has been done to consider the gender implications of a proposal. This tool draws on theoretical models and similar analysis tools, such as the Canadian tool «Gender-based Analysis Plus (GBA+)» introduced in New Zealand in 2019 and adapted to New Zealand's context. It is a policy-based tool which can be catalogued as an ex-ante GRB tool. This type of policy tools are basic in GRB implementation as

GRB must necessarily begin with purposive gender planning for each scheme/ sector, first by identifying the gender gaps in the sector and then delineating prioritized action points to address the gender gaps (Mishra and Sinha 56).

\subsection{Efforts made to introduce gender responsive budgeting}

In Bhutan, GRB has been attempted with some notable milestones in a gradual process that started with a «Gender Responsive Budgeting High Level Sensitization Workshop» in 2012. Since then, many GRB actions have been developed with the support of international cooperation, particularly by the United Nations. Examples include gender responsive policy and planning development, modification of budget documents to include a gender perspective, development of specific GRB tools and manuals as well as development of technical capacities, organization of working groups, gender focal points in all agencies and gender mainstreaming coordination bodies, improvements in the production and collection of gender-sensitive data and reports 
How to integrate a gender perspective into well-being budgeting practices:

Insights from a comparative case study between Bhutan and New Zealand

of gender analysis in specific sectors. The Ministry of Finance regards GRB as an important part of their Annual Report and presents the performance on gender equality measures and GRB to the Parliament. The most relevant milestones are found in two reports: a GRB report produced by UN Women in cooperation with the Royal Government of Bhutan in 2016 (Ganju and Jhamb), and the National Review Report on the Implementation of the Beijing Declaration and Platform for Action, June 2019.

In New Zealand, in 2016, there were limited signs of progress in introducing GRB. The OECD's 2016 gender budgeting survey showed that at that time the Government had not indicated any intention to adopt gender budgeting tools (Downes, Von Trapp, and Nicol 8). In 2018, a report produced by the Treasury pointed out that, «New Zealand could benefit from applying explicit gender budgeting as part of the pre-budget decision process or the post-budget reporting process» (Morrissey, «Gender Budgeting» ii). Since the well-being budget was approved in 2019 there have been some actions in favour of gender budget analysis, such as the introduction of the tool «Bringing Gender In» presented previously in section 4.2. As the tool has been introduced recently, it is too early to assess to what extent it could be successful to reach the aim of engendering WBB in New Zealand.

In sum, Bhutan has already begun to progressively introduce GRB complementary interventions. New Zealand, has introduced a GRB tool, «Bringing the gender in» that serves for the planning stage of public programmes. Both countries, are approaching GRB in different ways, with potential differences in future applications and outcomes.

\section{CONCLUSIONS AND RECOMMENDATIONS}

\subsection{Conclusions}

Gender blindness in well-being conceptualization: As this comparative case example showed, there is no unique formula or methodology for achieving well-being. Each country has a particular way of understanding and defining well-being and adapting their budget process to it, such as defining well-being dimensions, pillars, analytical categories and indicators to be considered in the planning and budgeting stages. Well-being budgeting, per se, does not entail an integrated approach to address gender inequality, nor to push for 
How to integrate a gender perspective into well-being budgeting practices:

Insights from a comparative case study between Bhutan and New Zealand

«gender transformative» measures that go beyond closing gender gaps. In reviewing the priority areas of Bhutan and New Zealand (Table 3), it becomes clear that gender inequality or any specific problems or demands related to it, such as addressing inter-personal violence or promoting the care economy, are not articulated as governmental priorities in both case studies. We can therefore say that the high-level policy priorities in both case studies are gender blind. This can be explained using the policy tool WPR proposed by Bacchi, which shows that the «representation of the problem» in both case studies were conceived with a «gender bias»: well-being is described and addressed in a gender-neutral way. Although in both case studies, it is possible to analyse data disaggregated by sex, such as the results in well-being by sex in each one of the well-being dimensions it doesn't mean that the focus of the planning and budgeting efforts are designed to solve inequality problems or to enhance gender equality outcomes.

GRB can improve well-being budgetary practices: Implementing commitments towards gender equality requires intentional measures to incorporate a gender perspective in planning and budgeting frameworks and concrete investment in addressing gender gaps (UN Women Website, 18 February 2020). GRB is a powerful approach to address gender inequality and to leave «no one behind» as the SDGs state. It favours data-driven policy decisions and the production of quantitative and qualitative data and information on the gender-differentiated impacts of policies and budget implementation.

Open window for engendering gender-neutral well-being budgetary practices:

With supportive political will, it is possible to introduce a gender perspective in well-being budgeting. Applying GRB in a comprehensive way should comprise the complete budget, both public revenues and expenditures as well as all stages of the budget cycle. There is a wide range of GRB tools and documented practices that can be adapted to specific contexts and budgetary practices, including well-being budgetary practices. The case study of Bhutan shows a continued effort to go in that direction. New Zealand has a specific gender analysis tool «Bringing Gender In», which can be a starting point to looking at policies and budgets with a gender lens. GRB entails not only the usage of analytical tools, it requires sustained interventions to transform planning and budgetary processes, likewise, it requires enhancement of individual and institutional capacities to achieve this purpose and maintain it over time.

Feminismo/s 35, junio 2020, pp. 29-61 
It is also important to recognise that the political will is essential at different levels of government. The Bhutan and New Zealand wellbeing budgeting and gender budgeting efforts are at national level, whereas the Wellbeing Gender Budgeting (WBGB) activities in Italy, Turkey and elsewhere have been a municipal government level. This important differential raises important question in relation to flexibility of government institutions at different levels of governance, proximity and permeability, openness to change and to engage with local initiatives. All of which indicate interesting pathways for future research building on this analysis of the distinctive methods and their combined potential, as set out in the following recommendations.

\subsection{RECOMMENDATIONS}

Responding to Bacchi's WPR question 5: Can the «problem» be thought about differently?, these are some initial measures that can serve to start building the basis for GRB work within gender-blind well-being budgeting experiences:

1. Political will to introduce GRB, despite the complexities that it can entail.

2. Collect and produce gender-sensitive data in a systematic way: e.g. sex-disaggregated data, time use surveys, violence against women surveys, among others.

3. Revise self-reporting well-being tools, and collective and multidimensional well-being approaches to ensure that the gender perspective is integrated.

4. Advocate for the introduction of gender equality objectives in the main well-being policy priorities.

5. Introduce and/or adapt GRB ex-ante tools to conduct gender assessments and gender responsive planning as well as ex-post tools for gender impact assessments and budget audits.

6. Ensure feminist perspectives are contained in any lists of capabilities, including on care work, unpaid work, removing roots of gender discrimination such as preventing gender-based violence.

7. Ensure capacity building efforts to strengthen the individual capacities of governmental staff with a role in planning and budgeting. 
How to integrate a gender perspective into well-being budgeting practices:

Insights from a comparative case study between Bhutan and New Zealand

8. Modify call circulars in order to make new procedures of gender responsive planning and budgeting compulsory and provide guidance on how to do it.

9. Establish a coordination body of key governmental and non-governmental actors working on GRB.

10. Explore possibilities to allow the participation of civil society organizations in GRB, such as production of non-governmental gender impact assessments, participation in GRB inter-multidisciplinary committees or participatory gender responsive budgeting practices (especially at local level), among others.

11. Document and share good practices and challenges.

\section{REFERENCES}

Addabbo, Tindara. «Gender budgeting in the capability approach. From theory to evidence». WiSE: Women in Scotland's Economy Series Conference 'Counting on Women-Gender, Care and Economics', Glasgow Caledonian University (2011). https://www.gcu.ac.uk/media/gcalwebv2/theuniversity/centresprojects/wise/ addabbo.pdf

Addabbo, Tindara, Diego Lanzi, and Antonella Picchio. «Gender auditing in a capability approach». CAPPaper 40. Centro di Analisi delle Politiche Pubbliche. Università di Modena e Reggio Emilia (2008): 1-44 https://core.ac.uk/download/pdf/6644003.pdf

Addabbo, Tindara, et al. «A social-reproduction and well-being approach to gender budgets: experiments at local government level in Italy». Gender and Well-Being. The Role of Institutions (2011): 105-124.

Addabbo, Tindara, et al. «Gender Budgeting From a Capability Approach Perspective: Evidences From Senegal». International Conference on Gender Research. Academic Conferences International Limited (2019): 15-23 https://search.proquest.com/openview/7188f110578b6ff23c02a011eb1c5a58/1?pq-origsite $=$ gscholar\&cbl=4451209

Addabbo, Tindara, Paula Rodríguez-Modroño, and Lina Gálvez-Muñoz. «Gender budgeting in education from a well-being approach: An application to Italy and Spain». Política económica 31.2 (2015): 195-212. 
How to integrate a gender perspective into well-being budgeting practices:

Insights from a comparative case study between Bhutan and New Zealand

Addis, Elisabetta, et al. "Gender and well-being: the role of institutions». In Gender and Well-Being: the role of institutions. Abingdon, Oxon: Routledge, 2016. 21-46.

Alkire, Sabina. «The capability approach and well-being measurement for public policy». OPHI Working Paper 94 (2015): 1-34.

Anwar, Samina, Anna Downs, and Euan Davidson. How Can PFM Reforms Contribute to Gender Equality Outcomes? New York: UN Women \& DFID, 2016. https://gender-financing.unwomen.org/es/resources/h/o/w/ how-can-pfm-reforms-contribute-to-gender-equality-outcomes

Bacchi, Carol Lee. Analysing policy: What's the problem represented to be?. Frenchs Forest, N.S.W: Pearson Australia, 2009.

Bacchi, Carol Lee. «Introducing the 'What's the problem represented to be?'approach». Engaging with Carol Bacchi: Strategic Interventions and Exchanges. Ed. Angelique Bletsas and Chris Beasley. South Australia: University of Adelaide Press, 2012. 21-24.

Berentson-Shaw, Jess. «Where There is a Will: Encouraging policymakers to value unpaid labour». Policy Quarterly Volume 15, Issue 1 (2019): 46-53. Doi: https://doi.org/10.26686/pq.v15i1.5296

Binder, Martin. «Subjective Well-being Capabilities: Bridging the Gap Between the Capability Approach and Subjective Well-being Research». Journal of Happiness Studies 15.5 (2014): 1197-1217. Doi https://doi.org/10.1007/ s10902-013-9471-6

Biswas-Diener, Robert, Ed Diener, and Nadezhda Lyubchik. «Well-being in Bhutan». International Journal of Well-being 5.2 (2015): 1-13. Doi:10.5502/ ijw.v5i2.1

Budlender, Debbie, and Guy Hewitt. Gender Budgets Make More Cents: Country Studies and Good Practice. London, UK: Commonwealth Secretariat, 2002. https://www.femtech.at/sites/default/files/How_to_do_a_gender-sensitive_ budget_analysis.pdf

Budlender, Debbie, Rhonda Sharp, and Kerri Allen. How to do a gender-sensitive budget analysis: Contemporary research and practice. London, UK: Commonwealth Secretariat, 1998. https://www.femtech.at/sites/default/files/ How_to_do_a_gender-sensitive_budget_analysis.pdf

Cavaghan, Rosalind. «Gender knowledge: A review of theory and practice». Gender Knowledge and Knowledge Networks in International Political Economy. 
How to integrate a gender perspective into well-being budgeting practices:

Insights from a comparative case study between Bhutan and New Zealand

Volume 3. Ed. by Brigitte Young and Christoph Scherrer. Munich: Nomos Verlagsgesellschaft (2010):18-36. Doi: 10.5771/9783845223858-18

Coscieme, Luca, et al. «Overcoming the Myths of Mainstream Economics to Enable a New Well-being Economy». Sustainability 11.16 (2019): 2-17. Doi: 10.3390/sul1164374

Council of Europe. Steering Committee for Equality between Women, and Men. Group of Specialists on Mainstreaming. Gender mainstreaming: Conceptual framework, methodology and presentation of good practices. Strasbourg: Council of Europe, 2004.

Curtin, Jennifer, and Morrisey, Suzy. »Where does gender equality fit into the Budget?». Ideasroom. 31 May 2019: 1 https://www.newsroom. co.nz/ideasroom/2019/05/31/614191/where-does-gender-equality-fitinto-the-budget

Downes, Ronnie, Lisa Von Trapp, and Scherie Nicol. «Gender budgeting in OECD countries». OECD Journal on Budgeting 16.3 (2017): 71-107.

Galizzi, Giovanna, Gaia Viviana Bassani, and Cristiana Cattaneo. «Adoption of Gender-Responsive Budgeting (GRB) by an Italian Municipality». Administrative Sciences 8.4 (2018): 68.

Ganju Thakur, Sarojini, and Bhumika Jhamb. Gender Responsive Planning and Budgeting in Bhutan: From Analysis to Action. UN Women in collaboration with the Royal Government of Bhutan and suppot of Asian Devekopment Bank, 2016. https://asiapacific.unwomen.org/en/digital-library/ publications/2016/05/gender-responsive-planning-and-budgeting-in-bhutan Government of Bhutan, GNH Centre. Website. http://www.gnhcentrebhutan.org/ Gunluk-Senesen, Gulay, et al. «Gender Budgeting in Turkey: An Assessment of Local Practices from the Well-Being Perspective». Politica Economica/ Journal of Economic Policy 31.2 (2015): 175-194.

Hough-Stewart, Lisa, et al. What is a wellbeing economy? Different ways to understand the vision of an economy that serves people and planet. WEALL. Wellbeing Economy Alliance, December 2019. https://wellbeingeconomy.org/wp-content/uploads/2019/12/A-WE-Is-WEAll-Ideas-Little-Summaries-of-Big-Issues4-Dec-2019.pdf

Khan, Zohra. «Gender-Responsive Budgeting». Encyclopedia of Business and Professional Ethics. Ed. Deborah C Poff, Alex C. Michalos. Springer Nature Switzerland AG. 2019. https://doi.org/10.1007/978-3-319-23514-1_141-1 
How to integrate a gender perspective into well-being budgeting practices:

Insights from a comparative case study between Bhutan and New Zealand

Klatzer, Elisabeth, and Barbara Stiegler. «Gender budgeting-an equality policy strategy». Friedrich-Ebert-Stiftung and Shanghai Coordination Office for International Cooperation. Briefing Paper Shanghai. N. ${ }^{\circ} 12$. (2011): 1-8. https://ibrary.fes.de/pdf-files/bueros/china/11416.pdf

Klatzer, Elisabeth, et al. «Developments in Practice: Methodologies and Approaches to Gender Budgeting». Gender Budgeting in Europe. Ed. Angela O'Hagan and Elisabeth Klatzer. Palgrave Macmillan, Cham, 2018. 109-133. Doi: 10.1007/978-3-319-64891-0_6

McLeod, Keith. Our People-Multidimensional wellbeing in New Zealand (Analytical Paper 18/04). 4 December 2018. The Treasury of New Zealand. https://treasury.govt.nz/publications/ap/ap-18-04

Middlemiss, Lucie. «Commentary on 'Sustainability and Well-Being: A Happy Synergy'». Great Transition Initiative, April 2017.

Ministry for Women in New Zealand. Website. https://women.govt.nz/gender-tool Mishra, Yamini, and Navanita Sinha. "Gender Responsive Budgeting in India: What Has Gone Wrong?». Economic and Political Weekly Vol. 47, No. 17 (2012): 50-57. https://www.jstor.org/stable/23214838

Morrissey, Suzy. Gender Budgeting: A Useful Approach for Aotearoa New Zealand. (WP 18/02) 18 April 2018. The Treasury of New Zealand. https://treasury. govt.nz/publications/wp/wp-18-02

Morrissey, Suzy. «Women and the Tax Working Group». Journal of Australian Taxation Vol 21 (2). New Zealand Specials Edition. (2019): 50-64 https://www. jausttax.com.au/Articles_Free/JAT\%20Volume\%2021\%20Issue\%202\%20 -\%20NZ\%20Special\%20Edition.pdf

Nussbaum, Martha C. «Human capabilities, female human beings». Women, Culture and Development: A Study of Human Capabilities. Ed. Martha C. Nussbaum and Jonathan Glover. A study prepared for World Institute Economics Research (WIDER) of the United Nations University. Oxford: Clarendon Press, 1995.

Nussbaum, Martha C. Women and Human Development: The Capabilities Approach. Vol. 3. Cambridge: United Kingdom. The Press Syndicate of the University of Cambridge, 2000.

O'Hagan, Angela. «Favourable conditions for the adoption and implementation of gender budgeting: Insights from comparative analysis». Politica economica, Journal of Economic Policy. 31.2 (2015): 233-252. Doi: 10.1429/80935 
How to integrate a gender perspective into well-being budgeting practices:

Insights from a comparative case study between Bhutan and New Zealand

Picchio, Antonella, ed. Unpaid work and the economy: a gender analysis of the standards of living. London and New York: Routledge, 2003.

Robeyns, Ingrid. «Sen's capability approach and gender inequality: selecting relevant capabilities». Feminist Economics. 9:2-3 (2003): 61-92. https://doi. org/10.1080/1354570022000078024

Robeyns, Ingrid. «The Capability Approach: a theoretical survey». Journal of Human Development 6:1 (2005): 93-117. Doi: 10.1080/146498805200034266

Robeyns, Ingrid. Wellbeing, Freedom and Social Justice: The Capability Approach Re-Examined. Cambridge, England: Open Book Publishers. 2017. Doi:10.11647/OBP.0130

Royal Government of Bhutan. The National Commission for Women and Children. National Review Report on the Implementation of Beijing Declaration and Platform for Action. June 2019. http://www.asiapacificgender.org/sites/default/ files/documents/Bhutan\%20(English).pdf

Sen, Amartya Kumar. «The standard of living: lecture II, lives and capabilities». The standard of living. Ed. Geoffrey Hawthorn. Cambridge: Cambridge University Press, 1987. 20-38. https://doi.org/10.1017/CBO9780511570742.003

Sen, Amartya Kumar. Inequality Reexamined. New York Russell Sage Foundation Cambridge, MA, Harvard University Press, 1992.

Sen, Amaryta Kumar. «Capability and Well-being». The quality of life. Eds. Martha Nussbaum and Amaryta Sen. Oxford Scholarship Online, November 1993. https://doi.org/10.1093/0198287976.003.0003

Sen, Amartya Kumar. The idea of justice. Cambridge: The Belknap Press of Harvard University Press, 2009.

Sharp, Rhonda, and Diane Elson. Improving budgets: A framework for assessing gender responsive budget initiatives, accessed on 15 May 2020. https://www. unisa.edu.au/siteassets/episerver-6-files/documents/eass/hri/gender-budgets/ sharp-elson-improving-budgets.pdf

Smith, Conal. «Treasury Living Standards Dashboard: Monitoring Intergenerational Well-being». Commissioned report. 7 Juny 2018. The Treasury of New Zealand. https://treasury.govt.nz/publications/commissioned-report/ treasury-living-standards-dashboard-monitoring-intergenerational-wellbeing Stats NZ. Well-being statistics. Website. https://www.stats.govt.nz/topics/well-being Stewart, Frances. "Against happiness: A critical appraisal of the use of measures of happiness for evaluating progress in development». Journal of Human Development and Capabilities 15.4 (2014): 293-307. 
How to integrate a gender perspective into well-being budgeting practices:

Insights from a comparative case study between Bhutan and New Zealand

Stotsky, Janet Gale. Gender budgeting: Fiscal context and current outcomes. WP/16/149. Washington, District of Columbia: International Monetary Fund, 2016. http://dx.doi.org/10.5089/9781475575460.001

Treasury, New Zealand. The well-being budget 2019. Website: https://treasury.govt. nz/publications/wellbeing-budget/wellbeing-budget-2019-html

Treasury, New Zealand. The Living Standards Framework: Dashboard Update. Treasury Paper. December 2019. https://treasury.govt.nz/publications/tp/ living-standards-framework-dashboard-update

Treasury, New Zealand. The well-being budget 2020. Website: https://budget.govt. nz/budget/2020/wellbeing/approach/index.htm

Treasury, New Zealand. Website. https://treasury.govt.nz/

Trebeck, Katherine. Supporting but not synonymous: the wellbeing economy and a gender-equal economy. Paper commissioned by The Women's Budget Group. 6 April 2020.

United Nations. The Sustainable Development Goals Report 2019. New York: United Nations, 2019. https://unstats.un.org/sdgs/report/2019/

United Nations Committee for Development Policy (UNCDP). Leaving no one behind. New York: United Nations, 2018. https://www.un.org/development/ desa/dpad/wp-content/uploads/sites/45/CDP-excerpt-2018-1.pdf

UN Women. Financing For Gender Equality. Website. 18 February 2020. https:// gender-financing.unwomen.org/es

Ura, Karma, et al. An Extensive Analysis of Gross National Happiness Index. Thimphu, Bhutan: The Centre for Bhutan Studies, 2012.

Villagómez, Elisabeth, et al. Gender budgeting. Mainstreaming gender into the EU budget and macroeconomic policy framework. European Institute for Gender Equality (EIGE). Luxembourg: Publications Office of the European Union, 2018.

Villalba, Unai, Yolanda Jubeto, and Luis Guridi. «Participation and gender in Latin America: perspectives from decentralized cooperation and Local Human Development approaches». Community Development Journal 49.2 (2014): 228-244.

Weijers, Dan, and Phillip S. Morrison. «Well-being and Public Policy: Can New Zealand de a leading light for the 'wellbeing approach'?». Reflections on the Third International Conference on Wellbeing and Public Policy, Beehive and Victoria University of Wellington, 5-7 September 2018». Policy Quarterly 
How to integrate a gender perspective into well-being budgeting practices:

Insights from a comparative case study between Bhutan and New Zealand

Volume 14 Issue 4. November 2018. https://www.victoria.ac.nz/_data/assets/ pdf_file/0008/1713626/Weijers_Morrison.pdf

Wellbeing Economy Alliance. Website. https://well-beingeconomy.org/

Yucel, Yelda, and Gulay Gunluk -Senesen. «Sustainability of Gender Budgeting in Local Administrations in Turkey: An Assessment from the WellBeing Perspective». Gender Budgeting in Europe. Ed. Angela O'Hagan and Elisabeth Klatzer. Palgrave Macmillan, Cham, 2018. 271-293. Doi: 10.1007/978-3-319-64891-0_6 

To link to this article / Para enlazar con este artículo:

https://doi.org/10.14198/fem.2020.35.03

To cite this article / Para citar este artículo:

Wilson, Leanne y Campbell, Jim. «Gender mainstreaming in action? The Scottish Structural and Investment Funding Program 2014-2020». En Feminismo/s, 35 (junio 2020): 63-93. Monographic dossier / Dossier monográfico: A critical practice of thinking otherwise: Bacchi, Gender and Public Policy Analysis, coord. Angela O'Hagan, DOI: 10.14198/fem.2020.35.03

\title{
GENDER MAINSTREAMING IN ACTION? THE SCOTTISH STRUCTURAL AND INVESTMENT FUNDING PROGRAM 2014-2020
}

\author{
¿SE INCORPORA LA PERSPECTIVA DE GÉNERO EN \\ EL PROGRAMA DE FONDOS ESTRUCTURALES Y DE \\ INVERSIÓN EUROPEOS EN ESCOCIA 2014-2020?
}

\author{
Leanne WILSON \\ Glasgow Caledonian University, Glasgow \\ Leanne.wilson@gcu.ac.uk \\ orcid.org/0000-0002-9521-177X \\ Jim CAMPBELL \\ Glasgow Caledonian University, Glasgow \\ J.Campbell@gcu.ac.uk \\ orcid.org/0000-0002-2702-1122
}

\begin{abstract}
Since its inception, the European Union (EU) has been at the forefront of the promotion of gender equality. A key feature of the EUs approach to gender equality was the development and promotion of Gender Mainstreaming (GM) as an innovative approach to achieving gender equality. GM has been used as an approach to integrate gender into programme formulation, design, implementation, monitoring and evaluation across the EU policy programmes, including the European Structural and Investment Funds (ESIF), which plays a key role for both the inclusion and promotion of the contributions of women in economic development.
\end{abstract} (CC BY 4.0)

Feminismo/s 35, junio 2020, pp. 63-93 
GM is a well-researched gender equality strategy, however there is little consensus on its effectiveness and its ability to transform the policy paradigm and attempts to operationalise GM have been limited. Despite a large body of academic literature, there is limited recent research which links GM and the ESIF, specifically at a local level. Therefore, this article aims to do that by considering whether GM as part of regional development policy can be utilised as a tool for delivering transformative changes. Scotland's approach to GM within the ESIF is analysed utilising process tracing and semi-structured interviews with ESIF stakeholders in Scotland. Key findings are outlined for the 2014-2020 funding period at the national and project level.

Keywords: Gender Mainstreaming; Gender; Regional Policy; Scotland; European Union.

\section{Resumen}

Desde su inicio, la Unión Europea (UE) ha estado a la vanguardia de la promoción de la igualdad de género. Una característica clave del enfoque de la UE sobre la igualdad de género fue el desarrollo y la promoción de la integración de la Perspectiva de Género (PG) como un enfoque innovador para lograr la igualdad de género. La PG se ha utilizado como un enfoque para integrar el género en la formulación, diseño, implementación, monitoreo y evaluación de programas de la agenda política de la UE, incluidos los Fondos Estructurales y de Inversión Europeos (FEIE) que desempeñan un papel clave tanto para la inclusión como para promover las contribuciones de mujeres en el desarrollo económico.

La PG es una estrategia de igualdad de género ampliamente investigada, sin embargo, hay poco consenso sobre su efectividad y su capacidad para transformar el paradigma de decisiones políticas. Además, los intentos de operacionalizar la PG han sido limitados. A pesar de una gran cantidad de literatura académica, existe una limitación de investigaciones recientes que vinculan la PG y FEIE, específicamente a nivel local. Por lo tanto, este artículo tiene como objetivo analizar si la PG integrada en la política de desarrollo regional se puede utilizar como una herramienta para generar cambios transformadores. La experiencia en Escocia sobre los GM dentro del FEIE se analiza utilizando el seguimiento del proceso y entrevistas semiestructuradas con las partes interesadas del FEIE en Escocia. Los resultados clave se describen para el período de financiación 2014-2020 a nivel nacional y de proyecto.

Palabras clave: prespectiva de género; género; política regional; Escocia; Unión Europea. 


\section{INTRODUCTION}

The concept of gender mainstreaming (GM) was formally adopted by the European Union (EU) as part of the Treaty of Amsterdam in 1997 (Guerrina 42). At the time, it offered the potential to achieve greater gender equality in the labour market (Walby 329).

GM has been defined as;

the promotion of gender equality through its systematic integration into all systems and structures, into all policies, processes and procedures, into organisations and its culture, into ways of seeing and doing (Rees, «Reflections» 560).

The idea behind GM was to ensure that those responsible for designing polices are aware of any potential gendered impacts by incorporating gender equality consideration into both policy development, implementation and evaluation. The adoption of GM implied that it was no longer acceptable to assume that additional resources targeted at stimulating economic development and growth benefited men and women equally, in other words, that the intervention was gender neutral (Campbell, Fitzgerald, and McSorley 141). Unintended consequences and/or effects that could undermine or prevent the achievement of policy aims for either women or men can be identified, avoided or monitored from the earliest stages (McKay and Gillespie 191-212). Therefore, in order to maximise the economic impact of policies designed to stimulate regional development they needed to become more «gender aware». GM is attempting to bring gender equality considerations to the mainstream policy development and delivery process. This approach is now central to the EU's policy for promoting gender equality and has been a key feature of its regional policy since 2000 .

A wealth of research has been undertaken on GM, however there is little consensus on its effectiveness. While there is recognition that there is widespread commitment to gender equality policies within the EU, there are questions as to how successful GM has been in delivering transformative changes in the policy process (Cavaghan and O'Dwyer 98). Bacchi («The Mageeq Project» 222) argues that the disappointment of GM implementation is due to the converging ways that inequality has been «discursively constructed» into policy frames. The concept of gender equality and the gendered dimensions 
across public policy are not well, or consistently, understood and therefore the policy responses to gender inequality have not resulted in the transformational policy objectives of gender mainstreaming being realised. Rather, the framing of the solution aims to fit women into the «status quo» effectively the «add women and stir» approach (Harding 15).

This article analyses the effectiveness of GM within the Scottish ESIF Programme 2014-2020. It draws on both discursive policy analysis (Bacchi and Goodwin 36) and feminist economics. Bacchi and Goodwin bring a useful perspective on policy analysis as they consider «what the problem is represented to be», therefore considering what are the underlying assumption and socially constructed knowledge upon which policies are made and understood. This method of policy analysis fits well with feminist economic underpinnings that consider inequality a consequence of the action of social actors. Feminist economists have long argued against that the notion of «rational economic man» (REM) upon which mainstream economics is based (Beneria, Berik, and Floro 53). Instead recognising the social construction of people and their preferences which may shape / limit their «choices», particularly for women. These tend to be ignored in mainstream economic policy making which considers efficiency in the market a measure of success rather than equity.

This research comprised discursive analysis of ESIF Programme documentation, regulations, application forms and guidance at the EU level, Scottish Government and project levels. The analysis identifies «what the problem is represented to be» as well as levels of commitment to GM. This was combined with semi-structured interviews of twenty-five «street level» civil servants and project managers to further understand the level of commitment and knowledge of GM. The interviews were analysed using thematic analysis and organised by predetermined themes and then allowing emergent themes to come to the fore.

Implementation of GM, which is a «fuzzy» concept, at the project level is an important process to understand and evaluate, as this is where the written intentions of a policy can come to fruition or fall away. The combination of both policy analysis and qualitative data allows for a deeper understanding of all the levels of the GM process. It highlights any slippages between the written policy, at supranational, national and local levels, and implementation 
and therefore any resulting consequences for the ability of GM to be transformational. It is important to understand the way that gender is conceptualised and interpreted through the layers of governance within ESIF and for the way in which GM has been operationalised at a local level. This paper analyses the process in Scotland from written policy to local implementation and therefore provides the platform for creating a more effective and transformational way to operationalise GM at a local level.

However, before discussing the research findings, the following section considers some of the conceptual problems with defining and implementing GM and the processes which the EU has developed for its gender equality strategy over time.

\section{CONCEPTUALISATION OF GM IN THE EU}

The EU faces many challenges in advancing gender equality, among them, the variances in understanding of what constitutes gender equality (Kantola 56) and the relevance of gender relations in public policy, including economic development. The lack of consensus on the meaning of gender equality creates conflict over what is entailed in GM policies and their implementation (Bustelo and Verloo 4). Lombardo and Meier (152) describe the EU definition of GM as an «empty signifier»:

the (re)organization, improvement, development and evaluation of policy processes so that a gender equality perspective is incorporated in all policies at all levels and at all stages, by the actors normally involved in policy-making.

According to Verloo (118), this has led to downplaying the goals of gender equality with the assumption that everyone knows and agrees on what the goals are. Furthermore, this confusion of the meaning of GM resulted in the inconsistent and uneven implementation and political will across the member states. Previous research has indicated that this inconsistency has led to the goals of gender equality being interpreted as equal opportunities or alternatively diversity. Policies are inherently political therefore the way in which gender equality is defined as a policy problem, relates to the political environment of member states and therefore has an impact on the way solutions are framed (Bacchi, Women, Policy and Politics 199). 
GM goes beyond simply changing the disadvantaged position of women and attempts to change the whole policy system and institutions which create and implement them. GM is a strategy for achieving transformative change in behaviour, of both men and women as well as institutions, which ultimately is expected to deliver gender equality. However, GM is a contestable strategy and its ability to transform structural inequalities has been debated since its introduction. According to Walby (466), GM involves two different structures, «gender equality» and the «mainstream». The new gender norms and policy objectives that are sought by GM have to fight with the already well established and routed gender norms within institutions. This has resulted in gender norms persisting in the policy process and therefore in the implementation of economic policies including regional policy.

Rees (Mainstreaming Equality 46) argued that for true gender equality there must be transformational change which challenges the structures of existing gender relations. The transformational goal for gender equality would change the behaviours and standards of everyone by taking into consideration the associations of masculinity and femininity within institutions (Walby 323). However, Pollack and Hafner-Burton (452) concluded that the EU had adopted a more integrationist approach to GM by framing and selling the policy as a means to an end rather than challenging the dominant «mainstream» ends of the market. Beyond the goals of implementation of GM there is also the problem with the conceptualisation of gender.

Within the EU the grounds for legal action due to discrimination have become more diverse including ethnicity, disability, faith and sexual orientation. This has implications for the practice of GM (Walby 322; Woodward 297) as this change of context within the EU has led to a shift from gender equality to a more diverse equality framework. There are concerns that this shift of focus from "gender» to diversity can dilute efforts to GM (Walby 322 ) or can potentially create a level of competition between the different inequalities (Woodward 294). There is an assumption that all inequalities are homogenous and can be approached by the same policy mechanisms. As Kantola (134) argues, the use of only sex disaggregated data to measure the success of GM within the EU suggests that gender has been interpreted as a noun which assumes «fixity» rather than a fluid social construct (Eveline and Bacchi 501). The inclusion of «gender» in GM was supposed to be a 
move away from only counting women and men however, the bureaucratic requirements for data strips the political nature of GM and instead reduces it to measuring gaps as opposed to addressing the deep rooted structures reproducing inequality. As Kantola (134) argues the use of statistics to measure the success of GM within the EU leads to the failure to recognise the interplay of gender, race and other forms of discrimination.

In the early period of GM, Beveridge, Nott and Stephen (392) and Wittman (53) described two approaches to implementing GM. The first is the expert-bureaucratic model where GM is carried out by specialists who could be gender experts with high levels of understanding of gender relations. This approach is highly dependent on technocratic tools such as gender budgeting and audits which fit well with normal processes within organisations therefore making GM an easier process to implement (Wittman 55). However, that is detrimental to the overall goal of GM as it can lead to a focus on doing GM without dealing with the underlying structural issues of gender inequality. The danger is that it becomes a tick box exercise which will not lead to positive deep routed change within an organisation. The second approach is the participatory-democratic model where there are a range of individuals and organisations that are involved in GM implementation. This approach promotes access to the policy-making process as well as giving more people a voice (Wittman 56). This model is more conducive to the social justice aims of GM by placing importance on the many tools used for mainstreaming but also in recognising the importance of a democratic and deliberative continuing throughout the implementation.

The EU has adopted the expert-bureaucratic approach (Kantola 133; Walby 332), where GM addresses gender equality through already existing frameworks and fails to consider the voices of disadvantaged groups through consultation with civil society organisations. This is evident in the multiple handbooks, checklists and assessment guidance for the implementation of GM, which fail to challenge the dominant policy paradigm.

Furthermore, since the financial crisis of 2008, which hit the EU member states hard and the subsequent austerity measures, the status of gender equality as a policy objective has been downgraded (Kantola and Lombardo 74). This has had consequences for the effectiveness of GM. Bettio et al. (205) found that «gender mainstreaming has been sidestepped both at the policy 
design and the implementation stage» in the response to the aftermath of the financial crisis of 2008. For example, the Europe 2020 strategy moved towards a gender-neutral approach with no specific targets for female employment or specific focus on GM (Jacquot 33). In a further weakening of policy capacity, the institutional arrangements for advancing gender knowledge and gender analysis were diminished, as the Gender Equality Unit was transferred from DG Employment to DG Justice which narrowed their focus to anti-discrimination (Hubert and Stratigaki 28).

Further evidence of the retreat from gender quality can be found in the way the EU framed the regulation for the operation of Structural \& Investment Funds in the period 2014-20 which the following section explores in more detail.

\section{GENDER EQUALITY IN THE EUROPEAN STRUCTURAL \& INVESTMENT FUNDS 2014-2020 PROGRAMME PERIOD}

Gender equality is a horizontal theme across all the European Structural and Investment Funds (ESIF) including the European Regional Development Fund (ERDF) and the European Social Fund (ESF). Therefore, GM is a key principal and is specifically addressed within the ESF. Despite this, the EU failed to designate gender equality as a thematic objective in the 2014-20 period, which has reduced the level of importance of integrating gender into Operational Programmes, planning, evaluation or implementation (Samek Lodovici, Pesce and Loi 11).

Gender equality as a horizontal theme should be considered across all funds, Article 7 of the Common Regulation (EU) No 1303/2013 states:

The Member States and the Commission shall ensure that equality between men and women and the integration of gender perspective are taken into account and promoted throughout the preparation and implementation of programmes, including in relation to monitoring, reporting and evaluation.

Within ESF regulations there is a mandatory requirement to promote gender equality and to address equal opportunities and anti-discrimination (Samek Lodvici, Pesce and Loi 27). This makes ESF the largest source of targeted funding for gender equality measures within the ESIF. However, in the 20072013 programme period, only $3.7 \%$ of the total ESF funding on average per 
Member State was allocated to gender equality actions (Samek Lodvici, Pesce and Loi 30).

ERDF regulations have no specific reference to gender equality, this exclusion suggests that projects not directly related to women and equality, such as infrastructure, are gender neutral. This is a sign of «strategic silencing» (Cavaghan and O'Dwyer 96) within the ERDF where economic activities predominantly performed by women, as producers and carers in the home, are excluded from economic development. Instead, there is a focus on investing in physical infrastructure, in order to generate economic and employment growth (De Henau et al 3127). The exclusion of the requirement for gender data in ERDF has allowed for the prioritisation of «men's jobs» in construction and physical infrastructure rather than in social infrastructure. Social infrastructure refers to education, care and health services (De Henau et al 31).

Women dominate the care sector, therefore investment in social infrastructure such as child and long-term care services, would create more employment for women as well as physical services for care. This reflects the neoclassical economic bias that what is viewed as traditionally male employment is more important, as men are viewed as the breadwinner, despite the increasingly changing structures of family units. This highlights what is valued in the economy where neoclassical economics considers "work» as something that is motivated by money and not care therefore only valuing non-caring roles (Folbre et al. 12). Furthermore, according to UN System of National Accounting, expenditure on social infrastructure is categorised as consumption as opposed to physical infrastructure which is counted as investment. Therefore, social infrastructure is believed to be a burden on the public finances rather than considering the economic benefits, in terms of creating employment, and increasing social welfare (Elson and Seth 55; De Henau et al 10).

During the current funding period, the ESIF have been utilised to deliver the Europe 2020 strategy, which as has already been mentioned, no longer consists of a specific target for women's employment rate. According to Samek Lodvici, Pesce and Loi (15) in their study of selected member states Operational Programmes, including the UK, the lack of inclusion of gender equality and evaluation means that GM is likely to fail at the EU 
level, especially when there are difficult economic conditions. Furthermore, the inclusion of the dual approach to gender equality in Member States Operational Programmes is voluntary, therefore allowing the Member States to selectively dismiss the gender perspective as a priority. ERDF funds specifically are «thematically concentrated» on the objectives shown in Table 1 , all of which have a gendered impact.

Table 1. Thematic Objective Concentration

\begin{tabular}{|c|l|}
\hline $\begin{array}{c}\text { Thematic Objective } \\
\text { Number }\end{array}$ & \multicolumn{1}{c|}{ Thematic Objective Title } \\
\hline 1 & $\begin{array}{l}\text { Strengthening research, technological development and } \\
\text { innovation }\end{array}$ \\
\hline 2 & $\begin{array}{l}\text { Enhancing access to, and use and quality of information and } \\
\text { communication technologies }\end{array}$ \\
\hline 4 & $\begin{array}{l}\text { Supporting the shift towards a low-carbon economy in all } \\
\text { sectors })\end{array}$ \\
\hline
\end{tabular}

As discussed in the previous section, since the 2008 economic crisis there has been a notable downgrading of gender equality polices and interventions. Rubery (580) argues that this has revealed that the «EU are an unreliable source of support for gender equality» and that the EU have not been a solution to gender equality rather they have contributed to greater gender inequality through the promotion of austerity measures and the unrelenting reliance on neoliberal economic policies. Furthermore, the EU has increasingly downplayed measures to influence member states commitment to gender equality as a priority. This extends into the Multiannual Financial Framework for the upcoming programme period (2021-2027), which no longer contains GM as a horizontal principal and gender budgeting is not applied (Klatzer and Schlager 54). The EUs «integration» approach has failed to challenge the neoliberal norms and therefore the transformational goals of GM have failed. This failing strategy therefore is likely to have filtered down to the national and local levels and potentially become even further diluted. 


\section{SCOTTISH STRUCTURAL FUNDING PROGRAM}

During the 2014-2020 funding period, the Structural Funds were worth $€ 941$ million to Scotland which is split between ERDF (approx. €476 million) and ESF (€465 million) (Scottish Government, Structural funds 2014-20). In this period, Scotland has two programme areas - the Highlands and Islands (H\&I) and the rest of the country the Lowlands and Uplands (LUPS). The H\&I was designated a Transition Region as it had a GDP between $75 \%$ and $90 \%$ of the EU average (Thom 14).

In Scotland, the 2014-2020 period saw the complete centralisation of the management of the funding as the European Structural Funds Division (ESFD), dissolving the Programme Management Executives (PMEs) and bringing the process in-house (Keith 1) which allowed the Scottish Government to have full control of the distribution of the funds. Moving away from the previous system which was considered a «model» by the European Commission toward a more «top down» approach (Davies et al 18). This may have been due to the reduction in funding allocated to Scotland and the requirement to reduce administration costs of PMES which were estimated to be $£ 30.89$ million in the 2000-2006 period (Davies et al. 38). The approach adopted by the Scottish Government was intended to bring together national objectives which would help meet the Europe 2020 strategy in a move towards a more «subsumed» system which was thought to be more cost efficient and align EU funds with domestic priorities (Davies et al. 16).

The Scottish Government distribute ESIF through Lead Partners who provide the match funding for projects which they either deliver themselves or through Delivering Partners. Lead Partners are government policy directorates, agencies and local authorities who are judged to have the capacity and capabilities to deliver the Strategic Interventions (SI) on behalf of the Scottish Government (Thom and Kenyon 24). SIs are «large scale funding allocations (minimum of $€ 15$ million), structured around 13 specific themes defined as 'programmes of work of significant scale and defined scope» (Dozhdeva, Mendez, and Bachtler 17) including employability and business competitiveness. However, this approach potentially excludes small third sector organisations from accessing the funds, which therefore results in larger organisations and local authorities consuming most of the funds as demonstrated in Figure 
1 showing the distribution of the funds across Scotland. Furthermore, despite trying to reduce the administrative costs from previous funding periods the Scottish Government retain 34\% of the funds internally, which amounts to approximately $£ 320$ million separated between administrative costs and internally managed projects.

\section{Distribution of the Structural Funds in Scotland (2014-2020)}

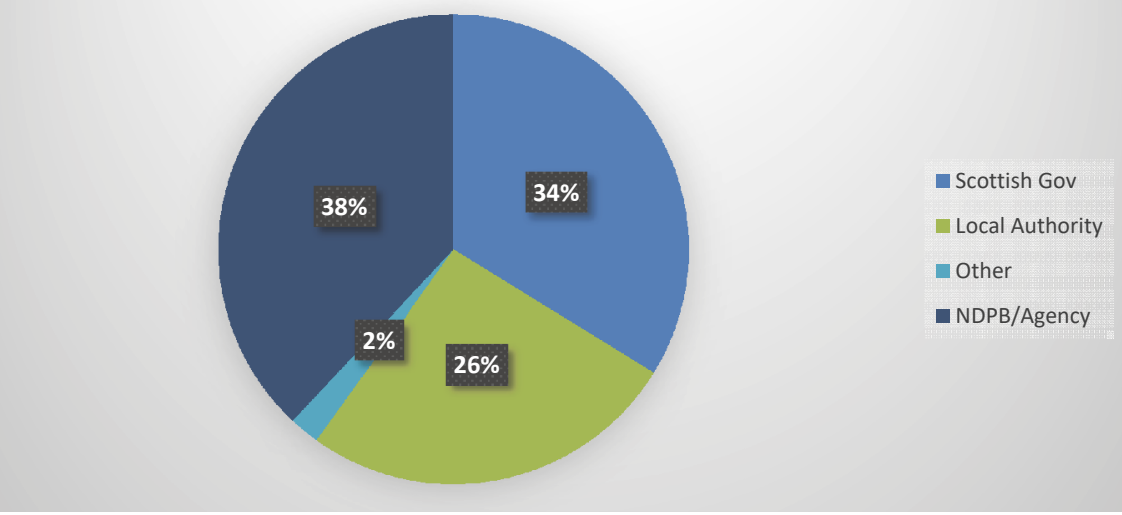

Figure 1. Distribution of Structural Funds across Scotland (2014-2020) (Source: Thom and Kenyon, 2018).

The Scottish Government has made a commitment to ensure that equality is considered in all their policies, both as an aspiration and a legal requirement (Scottish Government, European Structural). Indeed, the Scottish Government's Economic Strategy (launched in 2007 and updated 2015) is based around the twin goals of increasing competitiveness and tackling inequality in order to deliver sustainable economic growth (Scottish Government, Scotland's Economic Strategy 7). GM was stated as part of the strategy within the Scottish Operational Programmes for ERDF and ESF: 
«Gender mainstreaming will be incorporated not only throughout the lifetime of the project but also the planning, preparation, implementation, monitoring and evaluation stage» (Scottish Government, Operational Programme 200).

Furthermore, ESF and ERDF project applications are required to state their commitment and plans to tackle the horizontal themes of; sustainable development, equal opportunities and non-discrimination and equality between men and women. Although Scotland has continued to have a commitment to gender mainstreaming, there is evident resistance in committing fully to the strategy as compared with the Welsh Government who have a specific gender mainstreaming horizontal theme. Furthermore, they have a «Crosscutting theme team» who are there to offer guidance through the life cycle of funded projects (Welsh Government 14). The Scottish Government do not have any horizontal theme experts; projects are allocated a generalist contact person for advice on all matters of the project. This highlights the difference in interpretation of the EU regulations as well as the difference in political will. The Scottish Government has interpreted GM as equalities mainstreaming which has resulted in equal opportunities policies. These policies rely on the assumptions of an individualistic nature and assumes that individuals can influence their own opportunities rather than challenge cultural norms and stereotypes (Bacchi and Eveline 41).

\section{GENDER AND THE ESIF IN SCOTLAND}

\subsection{Analysis of gender in programme documentation}

Written policies are open to interpretation and dilution particularly as they travel through layers of governance. Therefore, to understand the way in which gender equality has been interpreted and framed through these layers is an important step to understanding the extent to which gender equality strategies such as GM can be successfully implemented at a local level. Therefore, this research analysed the documents in Figure 2 to identify the application of GM through the ESIF policy. 


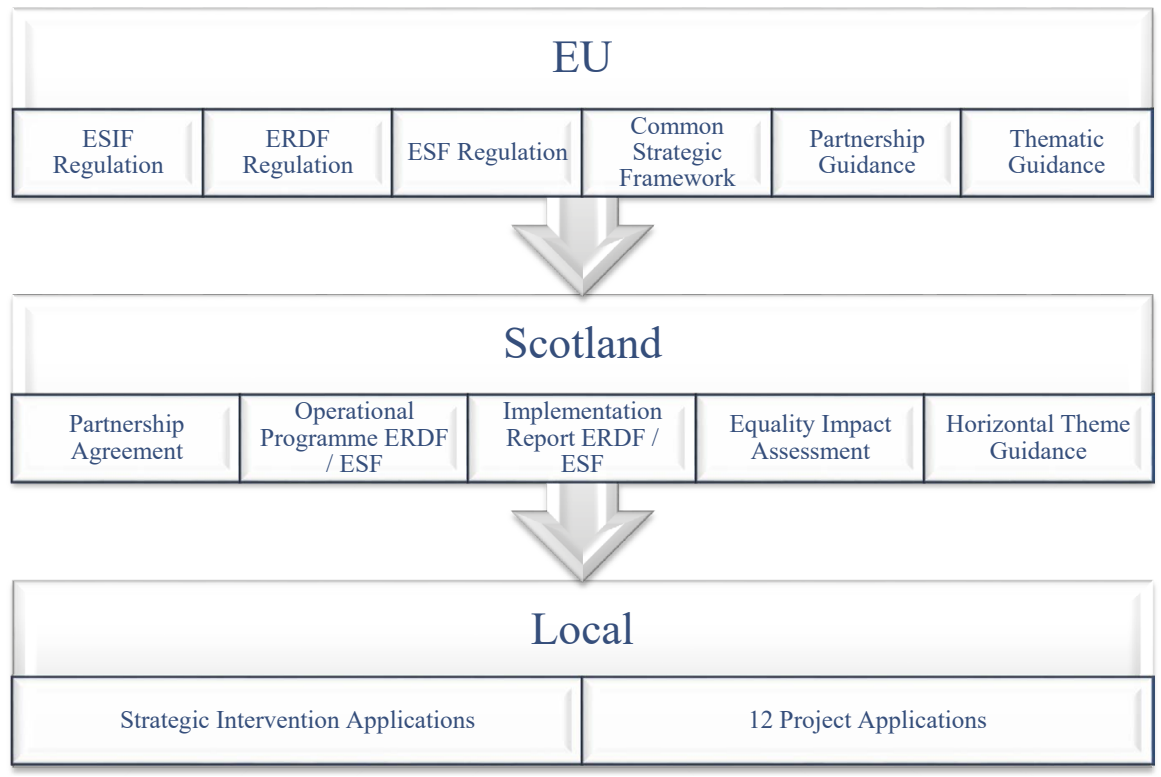

Figure 2. Programme Documentary Analysis.

It is clear from analysis of the 2014-2020 Scottish programme documentation that there has been some confusion regarding the horizontal themes. The Scottish Government set out the three themes of: sustainable development, equal opportunities and non-discrimination, and equality between men and women, highlighting their additional commitment to gender equality. However, the original project application forms to Lead Partners and equality impact assessment by the Scottish Government (Equality Impact) stated the themes as: Equality, Social Inclusion and Environmental Sustainability, thereby omitting the specific commitment to equality between men and women. Consequently, projects were not asked about their commitment to equality between men and women and furthermore their application was not assessed on the correct horizontal themes. This is despite the ex-ante evaluation concluding that the gender perspective had been evident within both the ERDF and ESF Operational Programmes and the Equality Impact

Feminismo/s 35, junio 2020, pp. 63-93 
Assessment (Hall Aitken 23). The ERDF Operational Programme suggests that the application forms have been updated to include questions regarding gender stereotyping and other questions directly linked to the horizontal themes. However, when analysing the project application forms, there is no indication that this is the case. This discrepancy suggests only a limited effort to commit seriously to the themes beyond superficial policy statements.

The recognition of the importance of significant gender analysis is evident throughout the Scottish Government Operational Programmes however this is not carried through to project applications and therefore has consequences for the implementation of GM at a local level. This may be due to the framing of the problem with the focus on equality mainstreaming rather than specifically gender. There is also little evidence of positive outcomes from the inclusion of GM within projects. The 2017 ESF Annual Implementation Report shows a significantly higher number of men benefiting from the projects than women in most of the categories as shown in Figure 3.

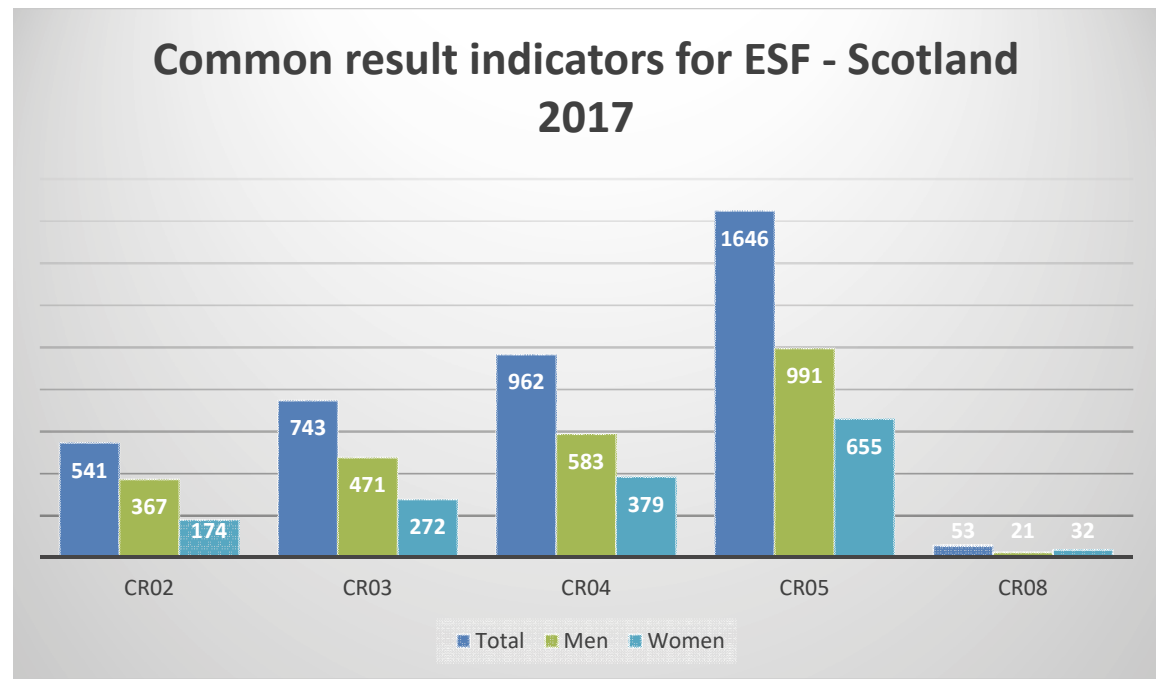

Figure 3. Common Indicators for ESF Scotland 2017. 
Table 1. Common Indicator ID Key

\begin{tabular}{|c|c|c|}
\hline ID & Indicator & Category of Region \\
\hline CR02 & participants in education/training upon leaving & More Developed \\
\hline CR03 & participants gaining a qualification upon leaving & More Developed \\
\hline CR04 & $\begin{array}{l}\text { participants in employment, including self- } \\
\text { employment, upon leaving }\end{array}$ & More Developed \\
\hline CR05 & $\begin{array}{l}\text { disadvantaged participants engaged in job searching, } \\
\text { education/ training, gaining a qualification, or in } \\
\text { employment, including self-employment, upon } \\
\text { leaving }\end{array}$ & More Developed \\
\hline CR08 & $\begin{array}{l}\text { participants above } 54 \text { years of age in employment, } \\
\text { including self-employment, six months after leaving }\end{array}$ & More Developed \\
\hline
\end{tabular}

Source: Scottish Government Annual and Final Implementation Report.

This imbalance is also evident within the evaluation of the Youth Employment Initiative (YEI), where 4,669 men engaged compared with 3,255 women between 2015 and 2018 (Economic and Social Development 47). The YEI states that the aim of the programme is to put young people into «quality» employment however the only evaluation is on quantitative outcomes and there appears to be no way of measuring quality and therefore ensuring there is no entrenchment of occupational segregation by sex.

Furthermore, there is no specific commentary on the progress in promoting gender equality within the ESF or ERDF Annual Implementation Reports. Individual evaluations for mainstreaming environmental sustainability and the Youth Employment Initiative are available, however there is no such evaluation for equality between men and women or GM. This indicates the strong commitment from the Scottish Government may be mere rhetoric and that there is a gap between the written intent of the ESIF and the actual implementation at a national and local level.

\subsection{Interview Findings}

Twenty-five key stakeholders from the 2014-2020 Scottish Structural Funding Program, including the Scottish Government, local authorities, other Lead Partners and delivering agents, were interviewed (Table 3). The interviews 
were structured around questions designed to establish their understanding of GM and the inclusion of GM within the project application, monitoring and evaluation stages.

Table 3. Interview Participants

\begin{tabular}{|c|c|c|c|}
\hline Organisation & Region & Organisation & Funding \\
\hline Barnardos & National & Delivering agent & ESF \\
\hline Clackmannanshire Council & LUPS & Local Authority & ESF \\
\hline Comhairle nan Eilean Siar & H\&I & Local Authority & ERDF \\
\hline East Lothian Council & LUPS & Local Authority & ESF \\
\hline Engender & National & Feminist Advocacy Organisation & N/A \\
\hline Fife Council & LUPS & Local Authority & ESF \\
\hline Highland and Island PME & $H \& I$ & $\begin{array}{l}\text { Programme Management Executive } \\
\text { (previous funding periods) }\end{array}$ & Both \\
\hline Highland Council & H\&I & Local Authority & Both \\
\hline $\begin{array}{l}\text { Highland and Island } \\
\text { Enterprise }\end{array}$ & $H \& I$ & Lead Partner & Both \\
\hline National Lottery & National & Lead Partner & ESF \\
\hline North Ayrshire Council & LUPS & Local Authority & ERDF \\
\hline North Lanarkshire Council & LUPS & Local Authority & ESF \\
\hline Scottish Enterprise & National & Lead Partner & ERDF \\
\hline Scottish Funding Council & National & Lead Partner & ESF \\
\hline $\begin{array}{l}\text { Scottish Government (Lead } \\
\text { Partner) }\end{array}$ & National & Lead Partner & ESF \\
\hline $\begin{array}{l}\text { Scottish Government } \\
\text { (Managing Authority) }\end{array}$ & National & Managing Authority & Both \\
\hline Scottish Natural Heritage & National & Lead Partner & ERDF \\
\hline SCVO & National & Delivering agent & ESF \\
\hline Shetland Council & H\&I & Local Authority & ESF \\
\hline Skills Development Scotland & National & Lead Partner & ESF \\
\hline South Ayrshire Council & LUPS & Local Authority & ESF \\
\hline Stirling Council & LUPS & Local Authority & ESF \\
\hline Strathclyde Eu Partnership & LUPS & $\begin{array}{l}\text { Programme Management Executive } \\
\text { (previous funding periods) }\end{array}$ & Both \\
\hline $\begin{array}{l}\text { University of the Highlands } \\
\text { and Islands }\end{array}$ & $\mathrm{H} \& \mathrm{I}$ & Delivering agent & ESF \\
\hline Zero Waste Scotland & National & Lead Partner & Both \\
\hline
\end{tabular}

Feminismo/s 35, junio 2020, pp. 63-93 


\subsubsection{Understanding of GM}

The interviews revealed that there was little understanding of GM at either the national or local level with most of the participants admitting that they had never heard of the term. Their understanding is framed as equal opportunities and non-discrimination, demonstrated in the quote below, which is consistent with the message conveyed by both the Scottish Government and the EU documentation.

My take on that would be that it is just about there is no gender bias in any employment sectors, no gender bias in recruitment, no gender bias in job roles or anything like that. It's just like... it's just not an issue. Here's the job, here's the job role, it doesn't matter who you are, if you have the competency and the ability to do that job then you should get that job (Barnardos).

From a feminist economics perspective, the underlying assumptions of neoliberal economic policies and equal opportunities are that individuals can make free rational choices and equal opportunities in a market economy creates competition for those opportunities (Nelson 31). Furthermore, Bacchi's framework, with its reminder of the silences and assumptions inherent in policy making, further explains how dominant economic models fail to consider the constraints on women and their ability to access the opportunities. the equal opportunities approach implicitly assumes that women need to be integrated into existing gender and power structures rather than challenge the gender norms that create and reinforce those structures (Eveline and Bacchi 113).

Furthermore, when asked about gender specifically, there was the tendency to refer to all the protected characteristics which is consistent with the concerns about the dilution of gender equality. Only one stakeholder was aware that GM involved considering all project stages from a gender perspective and that policies are not gender neutral. While this points to the level of discretion that «street level» bureaucrats have in the implementation of policy which Lipsky describes (13-26), it illustrates a particular concern that implementers can potentially bend and stretch the policy to fit existing structures (Lombardo, Meier and Verloo). In the context of the fluidity of gender mainstreaming and its reduced status as an «empty signifier», this 
reveals low levels of gender knowledge in the implementation as well as in the design of ESIF programmes and funded projects.

\subsubsection{Application Process}

In the project application stages, there was acknowledgement of the requirement for an equality statement, however it was not specific to gender and in fact it considered all protected characteristics, race, age sex, disability, etc. When gender was addressed, it was only regarding quantitative data in ESF projects. ERDF projects were difficult to evaluate as there was a misconception that gender is not relevant as ERDF does not cover social issues. This was the response from a representative of Scottish Enterprise who control a large proportion of ERDF funding in Scotland.

The monitoring of things like 'gender mainstreaming' would be associated with the European Social Fund as opposed to the ERDF route. The funding was granted as part of a Business Competitiveness objective only.

Furthermore, some participants reported that it was a «tick box» exercise when completing the application section on equality: "sometimes you were just... it felt; like you were really just having to state the obvious. At times slightly a tick box exercise» (East Lothian Council)

Stakeholders reported that they felt they were duplicating work already done by their local authority or their gender equality «person» or team, thus indicating that gender equality policies were already institutionalised and therefore no specific action was required. According to Ferguson (386), when gender is marginalised in this way, there is no incentive for other departments to take the issue seriously, the interview data supports this argument. When there is an attempt to integrate gender or do any gender analysis, the ESIF operational teams overly rely on the «experts» out with their department. There was no attempt to ensure gender knowledge and capacity building was present within the team. This approach will not ensure transformative changes in the existing programme structures and limits the ability of GM as strategy. Capacity building in gender knowledge and awareness are essential for GM to be successful as suggested by Eveline and Bacchi. Very few of the projects had considered gender impacts at the design stage; most were content with the idea that their services were open to all. When asked about the 
possibility of barriers faced by men and women accessing their services, there was some recognition that providing childcare was a potential enabler for women. However, there was no analysis of the current economic differences between men and women or the identification of potential issues women may face in accessing services. This is in direct contrast to the expectations of Lead Partners outlined in both the ERDF and ESF Operational Programmes. Despite this, the interviewees reported that there was no scrutiny of this at a national level.

All the participants, including the Scottish Government, acknowledged that there was no guidance available for Phase lof the application or implementation stage, in 2016 for delivery until 2018, and that there was no point of contact for gender specific advice. This is in direct conflict with the Common Regulation (EU) No 1303/2013 (347) ex-ante conditionality requirement which states the requirement for «provision of advice on gender equality in ESI Fund-related activities» and with the requirements outlined in the Operational Programme. Participants expressed concern on the lack of guidance for the whole programme and that the rules changed throughout the Phase 1 period. This is especially evident with the National Rules being published after the start of some of the projects, as well as the confusion with the horizontal themes, as evidenced in this interview excerpt,

So, the horizontal themes at the moment are...they have changed the terminology halfway through the programme which hasn't been particularly helpful (Scottish Natural Heritage).

Many of the participants report that they were informed of the new theme of equality between men and women during an audit in 2018. This was their first knowledge of the theme and they were being asked to report on it when they had not been informed of the change. Participants expressed the need for more guidance regarding the horizontal themes:

I don't feel actually we have a lot of guidance and it is something I have asked for and would welcome. I have also suggested that it would be good to get some knowledge and experience sharing between various Lead Partners and how their projects are actually getting on delivering and how they are finding it at a programme level to collate information and show what impact is being made (Scottish Natural Heritage). 


\subsubsection{Implementation and Evaluation of GM}

Regarding the implementation of GM, very few participants were able to identify the way in which they had mainstreamed gender into their projects. They considered the inclusion of gender equality policies within the overall organisation as sufficient.

At the evaluation stage, only projects funded by ESF gathered data on the number of female and male participants and reported this back to the Scottish Government on an annual basis. No participants could recall any occasions when their data was scrutinised by either the Scottish Government or the European Commission. Furthermore, they acknowledged that they did not do anything meaningful with the data, mainly due to a lack of resources and other bureaucratic issues regarding the management of ESIF projects. Onerous evidence is required from participants which consumes resources within the services and resources are further stretched by the pressured environment to provide quantitative data to the Scottish Government and European Commission. This results in the loss of a gender mainstreaming approach as neither the knowledge, the data, the personnel, or the process to integrate gender analysis is sustained. As evidenced in earlier sections, gender is downgraded in times of restricted resources as reflected in work by Bettio et al. (205). Gender equality analysis is seen as a luxury which the organisations do not have enough resources to deliver. Bustelo (85) argues that the evaluation stages are vital for identifying this «evaporation» of gender therefore without this stage in the project life-cycle GM will fail to make transformative changes in patriarchal structures.

Many participants reported their frustration with the lack of understanding of their service users who are furthest away from the labour market. They often regard limited engagement with small outcomes to be a success with their clients however as this cannot be measured in terms of employment gained, they are not considered which shows the service as underperforming.

obviously the programme targets are very much about jobs, qualification and you know some of these folks are...by the time they leave the National Third Sector Fund Intervention are still nowhere near a qualification or a job (Skills Development Scotland). 
As there are no quantitative measurable outcomes which would fit what Shanks (590) describes as the the mainstream economic «balance sheet» (590), the services are devalued, adding pressure on organisations running projects which could cause the exclusion of some people from the service. The requirement for auditing evidence is burdensome and leaves delivering agents and Lead Partners at risk of not receiving funds if they cannot demonstrate compliance. This focus on quantitative outcomes ignores the «lived effects» (Bacchi and Goodwin 23) of discrimination. This is an example of what has been left «unproblematized» (Bacchi and Goodwin 21) in the design of ESIF programme requirements, adding pressure on organisations running projects which could potentially result in the exclusion of the very people that ESF projects are designed to support. For example, the National Lottery reported that the pressure to hit target numbers meant that the management within their projects: «were not the least bit interested in what the gender approach is... it is just strictly a numbers game».

Lead partners attend yearly events organised by the Scottish Government to discuss the implementation of ESIF in Scotland. However, none of the stakeholders recalled having discussed the horizontal themes at these events. There is the opportunity to share good practice with the Scottish Government however these are individual cases, and as there is no scrutiny, there is no way of confirming if this is normal practice. Some participants indicated that they would appreciate the opportunity to discuss how they have integrated the horizontal themes in their projects; however, this is not available.

I have also asked several times... you know they have lead partner event which are maybe once or twice a year and I suggested several times that it would be really useful to have a session on the horizontal themes there which would give us a chance to...just to do exactly what we have been talking about. You know for the Managing Authority to give their perspective and then the maybe for some lead partners to ask question or share experience or whatever... you know I have asked for it a lot, it just not happening (Scottish Natural Heritage).

Contrary to Common Regulation (EU) No 1303/2013), there seems to be less involvement of Scottish feminist groups and civil society organisations in the planning of the Scottish Programme in 2014-2020 period than in previous programming periods. Engender, a leading feminist advocacy group stated: 
We have much fewer discussions now with the Scottish Government than when, for example, the East of Scotland Partnership existed. Where there would be discussions on Structural Funds. We weren't recipients of funding, but we were brought in as gender experts to have conversations about the horizontal themes and how they worked. So, it seems that those conversations are no longer happening.

\section{CONCLUSION}

The EU institutions were early adopters of GM and claim to be pioneers in the promotion of gender equality. The inclusion of GM within ESIF was an important step in recognising women's contribution to the economy. However, it is evident from analysis of the EU and Scotland's approach to the implementation of GM that the transformational goals of the strategy have not materialised. This may well be because GM is fundamentally flawed (Hankivsky 647) and cannot perform the transformational role championed by its advocates. On the other hand, it could be that it has not been implemented properly, that is that it is not the concept, which is flawed, but rather the processes adopted in its implementation. The results of the Scottish case study presented here would tend to support that contention.

Policy makers in Scotland have continued to represent the problem of gender equality as women's inactivity in the labour market. However, they have done that without meaningful analysis of the structural issues which have prevented women's participation in the labour market. EU funding has not been used to address structural inequalities including the uneven allocation of caring responsibilities. This representation of the problem and the underlying mainstream economic assumptions have resulted in the solution being continually stuck within the neoliberal frame of equal opportunities and non-discrimination. This results in economic development policy, and specifically the management of the ESIF not moving beyond the «social arrangements and practices which support the status quo and maintain the position of the powerful groups» (Bacchi The Mageeq Project 228). Furthermore, this portrayal of the problem continues to problematize women's disadvantaged position in the economy, excluding a gendered analysis and a focus on transformation of men's experience and of gender relations, instead suggesting women remain the source of the issue and are responsible for fixing it. In 
addition, this has taken place at a time when gender equality policies have been downgraded at an EU and national level.

The findings from the interviews supports the argument made by Walby (322) and Campbell, Fitzgerald and McSorley (21) that when the solutions to gender inequality are framed as equal opportunities there is dilution of the structural changes that are required to achieve gender equality and successfully implement GM. ESIF stakeholders in Scotland believe that their services are available to all with no discrimination. This understanding of the solutions to gender inequality are insufficient in dealing with the reason women are not able to access these opportunities or the societal influences which shape their choices. Therefore, a more transformational intersectional approach, that recognises that gender cuts across all other inequalities, is required. Furthermore, there must be more emphasis, at both national and local level, on monitoring and evaluation from a gender perspective.

If GM is to be transformational, evaluation of projects is essential as this is where the leakages of gender knowledge and commitment can be found. This article has argued that «street level» implementers in all sectors, private, public and third, have the ability to implement GM, however the infrastructure to deliver this has not been made available through the EU or Scottish Government. The lack of resources and the breakdown of gender equality infrastructure since the financial crisis has had a severe impact on the success of GM. The Scottish Government should build capacity within Lead Partners and project managers to implement GM effectively across all stages of the process, by engaging with external organisations who have adequate gender knowledge to effectively evaluate the gender impact of the projects and the programmes.

ESIF continue to be guided by burdensome quantitative outcomes resulting in projects being solely concerned with numbers and this potentially leads to a loss of project quality through a diminished focus on qualitative activity and outcomes. This bureaucratic approach (Beveridge, Notts and Stephen 392; Wittman 53) has increased pressure to hit target numbers which means that any jobs are acceptable and therefore there is a risk of exacerbating gender inequality through generating low paid unskilled and casualised labour. The approach of counting women as a unitary category has led to doing GM rather than challenging the structural problems that would result 
in transformational gender equality (Wittman 54). Consequently, during an economic crisis, gender equality becomes a luxury rather than an essential element of sustainable economic development and this is evident in the subsequent policies of austerity and cuts in public spending. The findings from the interviews support the view that during economic crisis gender equality policy gets downgraded (Rubery 576-581).

The EU and Scottish approach to GM as a solution to gender inequality implies that there is no requirement for gender experts, despite the referral to civil society in the EU documentation. Furthermore, this has led to a lack of responsibility amongst the stakeholders. They believe that they have the right policies in place, therefore there is no requirement for further action to ensure there is no unintended gender consequences resulting from their projects or policies. However, there is no scrutiny of this, and it is simply an assumption which is not tested. Furthermore, the centralisation of ESIF by the Scottish Government has meant that there was a loss of regional expertise, leading to institutional memory loss in both gender and the administration of the ESIF. Therefore, the requirement for gender expertise both inside and outside the Scottish Government is needed more than ever. The requirement for gender expertise throughout the programme life cycle and the building of gender knowledge in 'street level' implementors should be written into the program. Targeted funding is therefore essential to ensure gender knowledge does not leak through the various levels and the needs of women are incorporated at every stage of regional development.

The Scottish approach to ESIF programme provides useful lessons on the implementation of GM. At a local level, the interviews suggest that GM remains a vague term of which there is very little understanding. If it is to perform its potentially transformative role, GM requires the structure and knowledge to be in place at a local level, but this requires political will at the national level. The evidence suggests that in Scotland this political will has been absent in recent years and GM has become an «empty signifier» present in name only in existing structures rather than transforming those structures. 


\section{REFERENCES}

Bacchi, Carol. Women, policy, and politics: The construction of policy problems. London: Sage Publications, 1999.

Bacchi, Carol. «Discourse, Discourse Everywhere: Subject 'Agency' in Feminist Discourse Methodology». NORA - Nordic Journal of Feminist and Gender Research 13. 3 (2005): 198-209.

Bacchi, Carol. «The Mageeq Project: Identifying Contesting Meanings of 'Gender

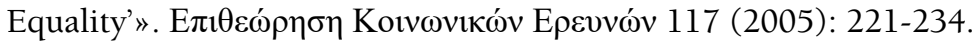

Bacchi, Carol, and Joan Eveline. Mainstreaming Politics: Gendering practices and feminist theory. Adelaide: University of Adelaide Press, 2010.

Bacchi, Carol, and Susan Goodwin. Postructural Policy Analysis. New York, Palgrave MacMillan, 2016.

Beneria, Lourdes, Günseli Berik; and Maria Floro. Gender, Development, and Globalization. Oxon: Routledge, 2016.

Bettio, Francesca, Marcella Corsi, Carlo D'Ippoliti, Antigone Lyberaki, Manuela Samek Lodovici, and Alina Verashchagina. The Impact of the Economic Crisis on the Situation of Women and Men and on Gender Equality Policies, European Commission 2012. 19 May 2020. https://op.europa.eu/en/publication-detail/-/ publication/4a10e8f6-d6d6-417e-aef5-4b873dla4d66/language-en

Beveridge, Fiona, Sue Notts, and Kylie Stephen. «Mainstreaming and the engendering of policymaking: a means to an end?». Journal of European Public Policy 7. 3 (2000): 385-405.

Bustelo, Maria. «Evaluation from a Gender+ Perspective as a Key Element for (Re)gendering the Policymaking Process». Journal of Women, Politics and Policy 38:1 (2017): 84-101.

Bustelo, Maria, and Mieke Verloo. «Exploring the possibilities of Critical Frame Analysis for evaluating policies», IPSA World Congress, Fukuoka (2006). 1 February 2020. http://paperroom.ipsa.org/papers/paper_5377.pdf

Campbell, Jim, Rona Fitzgerald, and Leaza McSorley. «Structural Funds and Gender Equality: The Impact of Gender Mainstreaming in Western Scotland». Local Economy 24.2 (2009): 140-150.

Campbell, Jim, Ailsa McKay, Leaza McSorley, and Susanne Ross. The Legacy of Gender Mainstreaming within the Scottish Structural Funds Programme 20072013. Final Report. Scottish Government, 2014. https://www2.gov.scot/ resource/0043/00434671.pdf 
Cavaghan, Rosalyn, and Muireann O'Dwyer. «European Economic Governance in 2017: A Recovery for Whom?». Journal of Common Market Studies 56 (2017): 96-108.

Common Regulation (EU) No 1303/2013 of the European Parliament and of the Council of 17 December 2013, laying down common provisions on the European Regional Development Fund, the European Social Fund, the Cohesion Fund, the European Agricultural Fund for Rural Development and the European Maritime and Fisheries Fund and laying down general provisions on the European Regional Development Fund, the European Social Fund, the Cohesion Fund and the European Maritime and Fisheries Fund and repealing Council Regulation (EC) No 1083/2006. 9 September 2019. https://eur-lex.europa.eu/legal-content/en/TXT/?uri=celex\%3A32013R1303

De Henau, Jerome, Susan Himmelweit, Zofia Lapniewska, and Diane Perrons. Investing in the Care Economy. A gender analysis of employment stimulus in seven OECD countries. International Trade Union Confederation, 2016. 5 June 2019. http://oro.open.ac.uk/50547/1/care_economy_en.pdf

Davies, Sara, John Bachtler, Frederike Gross, Rona Michie, Heide Vironen, and Douglas Yuill. The impact of structural funds programmes in Scotland 1994-2006. Glasgow: European Policy Research Centre, 2007. https://www.eprc-strath. eu/public/dam/jcr:cef38f10-7033-4788-a8fb-148e57dde59f/EPRP\%2060.pdf Dozhdeva, Viktoriya, Carlos Mendez, and John Bachtler. Cohesion policy implementation, performance and communication. Scotland Case Study. Cohesify, 2018. 27 August 2019. http://www.cohesify.eu/wp-content/uploads/2018/06/ UK_Scotland-1.pdf

Economic and Social Development. Evaluation of Youth Employment Initiative in South West Scotland: Final Report for the Scottish Government. 2018. 18 November 2019. https://www.gov.scot/binaries/content/documents/ govscot/publications/corporate-report/2016/01/yei-evaluation-report-2014-2020/documents/youth-employment-initiative-second-evaluation-report-for-the-2014-2020-scottish-operational-programmes-december-2018/youth-employment-initiative-second-evaluation-report-for-the-2014-2020-scottish-operational-programmes-december-2018/ govscot\%3Adocument/Final\%2BReport\%2B-\%2BYouth\%2BEmployment $\% 2$ BInitiaitve\%2BEvaluation\%2B-\%2B28th\%2BDec\%2B2018.pdf 
Elson, Diane, and Anuradha Seth, eds. Gender equality and Inclusive Growth: Economic Policies to Achieve Sustainable Development. New York: UN Women, 2019.

Eveline, Joan, and Carol Bacchi. "What are we mainstreaming when we mainstream gender?», International Feminist Journal of Politics 7. 4 (2005): 496-512.

Ferguson, Lucy. «This Is Our Gender Person». International Feminist Journal of Politics 17. 3 (2015): 380-397.

Folbre, Nancy, Laura Lee Downs, and Helena Perivier. «Nancy Folbre: a Feminist Economist». Travail Genre et Societes 28 (2012). 5 May 2020. https://www. cairn-int.info/article-E_TGS_028_0005-nancy-folbre-a-feminist-economist. htm

Guerrina, Roberta. Mothering the Union: Gender Politics in the EU. Manchester: Manchester University Press, 2005.

Hall Aitken. Ex-ante Evaluation of ERDF and ESF 2014-20 Scottish Operational Programmes, 2016. 25 May 2020. https://www.gov.scot/binaries/content/ documents/govscot/publications/advice-and-guidance/2017/09/esif-formal-evaluations/documents/ex-ante-assessment-pdf/ex-ante-assessment-pdf/ govscot\%3Adocument/Ex-ante\%2Bassessment.pdf

Hankivsky, Olena. «Gender Mainstreaming: A Five-Country Examination». Politics \& Policy 41. 5 (2013): 629-655.

Harding, Sandra. «Can feminist thought make economics more objective?». Feminist Economics 1. 1 (1995): 7-32.

Hubert, Agnes, and Maria Stratigaki. «Twenty Years of EU Gender Mainstreaming: Rebirth out of the Ashes?». Femina Politica 2 (2016): 21-36.

Jacquot, Sophie. «A Policy in Crisis the Dismantling of the EU Gender Equality Policy». In Gender and the Economic Crisis in Europe: Politics, Institutions and Intersectionality. Eds. Johanna Kantola and Emanuela Lombardo. Basingstoke: Palgrave Macmillan, 2017. 27-28.

Kantola Johanna. Gender and the European Union. Hampshire: Palgrave MacMillan, 2010.

Kantola, Johanna, and Emanuela Lombardo. Gender and the Economic Crisis in Europe: Political Institutions and Intersectionality. Basingstoke: Palgrave MacMillan, 2017. 
Keith, Morag. European Structural and Investment Funds, Scottish Parliament, 2018. 10 December 2019. http://www.parliament.scot/S5_EconomyJobsFairWork/ Inquiries/ESIF-012-Morag_Keith.pdf

Klatzer, Elisabeth, and Christa Schlager. «Losing Ground: Masculine-Authoritarian Reconfiguration of Power Structures in the European Union». In The State of the European Union: Fault Lines in European Integration. Eds. Wohl, Stepfanie, Elisabeth Springler, Martin Pachel, and Bernhard Zeilinger. Wiesbaden: Springer, 2019. 45-75.

Lipsky, Michael. Street Level Bureaucracy: Dilemmas of the Individual in Public Services. New York: Russell Sage Foundation, 1980.

Lombardo, Emanuela, and Petra Meier. «Gender Mainstreaming in the EU: Incorporating a Feminist Reading?». European Journal of Women's Studies 13. 2 (2016): 151-166.

Lombardo, Emanuela, Petra Meier, and Mieke Verloo. "Stretching and bending equality: a discursive politics approach». In The Discursive Politics of Gender. Eds. Emanuela Lombardo, Petra Meier, and Mieke Verloo. New York: Routledge, 2009. 1-18.

McKay, Ailsa, and Morag Gillespie. «Gender mainstreaming or 'mainstreaming gender'? A question of delivering on gender equality in the new Scotland». In Scottish Social Democracy Progressive Ideas for Public Policy. Ed. Michael Keating. Brussels: Presses Interuniversitaires Europeennes, 2007. 191-212.

Nelson, Julie. Feminism, Objectivity and Economics. Chicago: University of Chicago Press, 2002.

Pollack, Mark, and Emilie Hafner-Burton. «Mainstreaming gender in the EU». Journal of European Public Policy 7. 3 (2002): 432-456.

Rees, Teresa. Mainstreaming Equality in the European Union, Education, Training and Labour Market Policies. London: Routledge, 1998.

Rees, Teresa. «Reflections on the uneven development of gender mainstreaming in Europe». International Feminist Journal of Politics 7.4 (2005): 555-574.

Rubery, Jill. «The triumph of instrumental over equality policy in European employment policy». Canadian Journal of Development Studies 38. 4 (2017): 576-581.

Samek Lodovici, Manuela, Flavia Pesce, and Daniela Loi. The use of funds for gender equality in selected Member States. Directorate-General for Internal Policies, 2016. 2 February 2018. http://www.europarl.europa.eu/RegData/ etudes/STUD/2016/571393/IPOL_STU(2016)571393_EN.pdf 
Scottish Government. Scotland's Economic Strategy, 2015. https://www.gov.scot/ publications/scotlands-economic-strategy/

Scottish Government. Operational Programme Under the Investment for Growth and Jobs' Goal, 2016. 10 December 2019. https://www.gov.scot/binaries/ content/documents/govscot/publications/advice-and-guidance/2016/11/ esif-operational-programmes-2014-2020/documents/european-regional-development-fund-operational-programmes-2014-2020/european-regional-development-fund-operational-programmes-2014-2020/govscot\%3Adocument/ ERDF\%2BScotland\%2Boperational\%2Bprogrammes\%2B2014-2020\%2B\%2BOctober\%2B2019.pdf

Scottish Government. Equality Impact Assessment Record: European Structural Funds Programmes 2014-2020, 2017. 27 August 2019. https://www.gov. scot/binaries/content/documents/govscot/publications/advice-and-guidance/2017/09/esif-formal-evaluations/documents/equalities-impact-assessment-pdf/equalities-impact-assessment-pdf/govscot:document/Equalities\%20 impact\%20assessment.pdf

Scottish Government. Structural funds 2014-20, 2017. 10 December 2019. http://www.gov.scot/Topics/Business-Industry/support/17404/ EuropeanStructuralFunds.

Scottish Government. Annual and Final Implementation Reports for the Investment for Growth and Jobs Goal: Part A, 2018. 10 December 2019. https://www. gov.scot/binaries/content/documents/govscot/publications/corporate-report/2018/07/european-social-fund-annual-implementation-report-2017/ documents/implementation-report-2017-european-social-fund-pdf/implementation-report-2017-european-social-fund-pdf/govscot\%3Adocument/Imp lementation\%2BReport\%2B2017\%2B-\%2BEuropean\%2BSocial\%2BFund.pdf.

Scottish Government. European Structural and Investment Funds, 2019. 9 December 2019. https://www.gov.scot/policies/european-structural-funds/

Shanks, Neil. «Against 'economic man': A feminist challenge to prevailing neoclassical norms in K-12 economics education». Theory \& Research in Social Education 47. 4 (2019): 77-603.

Thom, Ian. EU Structural Funds in Scotland, SPICe, 2019. 10 December 2019. https://sp-bpr-en-prod-cdnep.azureedge.net/published/2019/4/10/ EU-Structural-Funds-in-Scotland/SB\%2019-19.pdf

Thom, Ian and Wendy Kenyon. European Union Funding in Scotland. The Scottish Parliament, 2018. 4 June 2019. https://digitalpublications.parliament. 
scot/ResearchBriefings/Report/2018/9/28/European-Union-fundingin-Scotland\#Structural-funds-in-Scotland-today

Verloo, Mieke. Multiple Meanings of Gender Equality: A Critical Frame Analysis of Gender Policies in Europe. New York: Central European University Press, 2007.

Walby, Sylvia. «Introduction: Comparative gender mainstreaming in a global era». International Feminist Journal of Politics 7. 4 (2005): 453-470.

Welsh Government. Cross Cutting Themes Key Document, 2018. 12 May 2020. https://gov.wales/sites/default/files/publications/2019-09/european-socialfund-cross-cutting-themes.pdf

Wittman, Amanda. «Looking local, finding global: paradoxes of gender mainstreaming in the Scottish Executive». Review of International Studies 36 (2010): 51-76.

Woodward, Alison. «Too late for gender mainstreaming? Taking stock in Brussels». Journal of European Social Policy 18. 3 (2008): 289-302. 

To link to this article / Para enlazar con este artículo:

https://doi.org/10.14198/fem.2020.35.04

To cite this article / Para citar este artículo:

Wylie, Adele. "Climate conscious professional kitchens? Analysing the Scottish food sector through a feminist lens». En Feminismo/s, 35 (junio 2020): 95-125. Monographic dossier / Dossier monográfico: A critical practice of thinking otherwise: Bacchi, Gender and Public Policy Analysis, coord. Angela O'Hagan, DOI: $10.14198 / \mathrm{fem} .2020 .35 .04$

\title{
CLIMATE CONSCIOUS PROFESSIONAL KITCHENS? ANALYSING THE SCOTTISH FOOD SECTOR THROUGH A FEMINIST LENS
}

\author{
¿COCINAS PROFESIONALES CON CONCIENCIA \\ CLIMÁTICA? ANALIZANDO EL SECTOR ALIMENTARIO \\ ESCOCÉS A TRAVÉS DE UNA LENTE FEMINISTA
}

\author{
Adele WYLIE \\ Glasgow Caledonian University, Glasgow \\ adelewylie3@gmail.com \\ orcid.org/0000-0002-4200-526X
}

\begin{abstract}
As we enter what has been defined as a climate emergency, governments are formulating policy responses that address sustainability through low carbon transitions. This article examines the relationship between policy representation in climate mitigation, business and food policies, and the implementation of sustainable practices in professional kitchens. The restaurant industry is a major consumer of natural resources as many practices throughout the supply chain are carbon intensive. Following Carol Bacchi's "What is the problem represented to be?» framework, this article examines the extent to which policy representation of sustainability and food governance influences everyday practices in professional kitchens in Glasgow, Scotland, based on research undertaken in 2019. This study revealed that climate change, business and food policies promote the idea that sustainability will be achieved alongside economic growth, without considering the complexities of social inequalities. The policies significantly overlook the private sector responsibility to transform away from unsustainable practices, whilst the potential approaches to improve social and environmental sustainability are obscured. The article concludes by calling for policies
\end{abstract}

Los contenidos de la revista se publican bajo una licencia de Creative Commons Reconocimiento 4.0 Internacional (CC BY 4.0)

Feminismo/s 35, junio 2020, pp. 95-125 
to integrate issues of social justice in the representation of the problem to produce more transformative and socially equitable outcomes.

Keywords: Climate change; Sustainability; Professional kitchens; Policy; Gender.

\section{Resumen}

Este artículo examina la relación entre la representación de políticas públicas en mitigación climática, políticas comerciales y alimentarias, y la implementación de prácticas sostenibles en cocinas profesionales. La industria de hostelería es una gran consumidora de recursos naturales, ya que muchas prácticas en toda la cadena de suministro son intensivas en carbono. Siguiendo el marco analítico de Carol Bacchi «What is the problem represented to be?», este artículo examina hasta qué punto la representación política de la sostenibilidad y la gobernanza alimentaria influyen en las prácticas cotidianas en las cocinas profesionales de Escocia, a partir de un estudio realizado en 2019. Este trabajo revela que el cambio climático y las políticas comerciales y alimentarias promueven la idea de que la sostenibilidad se logrará junto con el crecimiento económico, sin considerar las complejidades de las desigualdades sociales. Las políticas pasan por alto significativamente la responsabilidad del sector privado de transformarse alejándose de prácticas insostenibles, mientras que los enfoques potenciales para mejorar la sostenibilidad social y ambiental quedan oscurecidos. El artículo concluye reclamando políticas para integrar las cuestiones de justicia social en la representación del problema para producir resultados más transformadores y socialmente equitativos.

Palabras clave: Cambio climático; sostenibilidad; cocinas profesionales; política; género.

\section{INTRODUCTION}

Climate change has been described as the «defining moral issue of the 21st century» (Levy and Patz 311) with consensus growing that we are living in a climate emergency (Cretney and Nissen 15; Lenton et al. 592; Ripple et al. 8-12). This emergency has been described as a manifestation of unsustainable human activities (Hulme 899). These unsustainable practices, sparked by energy intensive technological advances since the industrial revolution, have resulted in global biodiversity loss and degradation, vulnerable global economies, increasing inequalities, and public disconnect from political agendas (Giddens 1-16). In response, many countries around the world are attempting

Feminismo/s 35, junio 2020, pp. 95-125 
to mitigate these effects through the implementation of policies at both international and country level. However, scholars from different disciplinary backgrounds problematize emerging policy approaches because they may reproduce or exacerbate inequalities that mostly affect the poorest and most marginalised people in society. Underlying these critiques is the concern that policymaking in general tends to be gender, race and class blind, neglecting how such intersecting factors enable or constrain the agency of individuals to respond (Eveline and Bacchi 87).

The first substantive international policy response to climate change was the United Nations Framework Convention on Climate Change (UNFCCC). The framework highlighted the need for the concentration of greenhouse gases in the earths' atmosphere to be significantly reduced to prevent triggering an irreversible anthropogenic climate catastrophe. The UNFCCC called for an international response to address greenhouse gas emissions through international treaties to produce protocols or agreements (UNFCCC). The most recent treaty flowing from the framework is the Paris Climate Agreement (2016), in which world leaders committed to reduce greenhouse gas emissions with the hope of preventing the global average temperature from rising more than two degrees. Emission reduction targets have been set, at country level, for both 2030 and 2050 (Du Pont et al. 5). Scotland is taking an ambitious approach towards reaching its 2050 climate targets, aiming to be a carbon neutral country by 2045 . The Scottish Government are progressive in their climate ambitions and Scotland's first minister Nicola Sturgeon maintains that the environmental and social gains called for within environmental, climate and business policies will be met without compromising the country's economic growth. Despite this positive intent, the Scottish Government's policies are still framed within an economic growth discourse. Without addressing the social oppression and environmental degradation, two significant consequences of capitalism (Rose and Cachelin 518-525), Scotland could be overlooking potential social and environmental trade-offs that may occur alongside a low carbon transition. If economic gains are prioritised, this could result in an unjust transition.

In considering the restaurant industry, it is clear that this industrial sector has consistently benefited from access to natural resources and food produce from all over the world. This commodification of nature has contributed 
towards negative environmental, social, cultural and political consequences for many people around the world (Moore 97). Restaurants should therefore be considered as potential major actors in assisting countries move towards a sustainable transition. Such engagement would entail embracing social, environmental and economic obligations in a whole systems approach, rather than the prioritizing of one. Arguably, if all dimensions of sustainability are in equilibrium, socio-economic inequalities and environmental degradation should progressively reduce. The question arises then in relation to policy objectives such as those expressed by the Scottish Government and, more widely, as to whether such necessary principles are reflected within government policies. Is there a visible and meaningful policy focus on combining concern to eliminate the harmful commodification of natural resources and workers, central to climate change mitigation policy? Or is there a fine selection on the policy menu but the real cooking is on the back burner?

This article examines the extent to which the Scottish Government's climate change, business, and food policies are influencing the environmental conscience and everyday practices of head chefs in Glasgow. Examining current practices in professional kitchens helps to gauge if and how governmental policies are supporting the drive for more sustainable business practices. This article progresses from a succinct literature review that explores the relationship between gender, nature, sustainability and business. It is informed by feminist and ecofeminist scholarship that calls for a transformation of traditional organizational structures, built upon masculine ethics. As patriarchal societies are associated with dominance over women and exploitation of nature, the evaluation of gendered norms and roles within society and within sustainable transitions are now as relevant as ever. It is therefore essential to examine the relation between sustainability, gender, and business. As Allwood (10) suggests, focusing on gender in the context of climate change and sustainability highlights the lived experiences of women, and the ways in which gendered dynamics play out in practice and how these might be changed, and change them. Secondly, this article critically evaluates the way in which climate, business and food policies in Scotland frame and represent the issue of sustainability as a direct response to climate change. To do so, this article will draw from Bacchi's framework «What is the problem represented to be?» (Bacchi, Policy problems 5). It investigates whether such representation of

Feminismo/s 35, junio 2020, pp. 95-125 
sustainability conceals underlying institutional discrimination, in turn minimizing the potential for authentic sustainable practices to be implemented. The policy analysis is combined with qualitative empirical data gathered from semi-structured interviews with head chefs, in order to determine to what extent the 'problems' represented in these policies are consistent with experiences in professional kitchens. This article concludes by calling for governmental climate, business and food policies to integrate issues of social justice more transparently and substantively in the framing and definition of the problem of sustainability.

\section{LITERATURE REVIEW}

\subsection{Policy Representation}

Over the last twenty years, feminist theorist Carol Lee Bacchi has made a significant contribution to policy analysis, disputing the idea that public policies are developed as means to solve arising, identifiable societal challenges (Practice; Policy problems; WTP). In 1999 Women, policy and politics: The construction of policy problems (1999) Bacchi argued that societal issues can be shaped, moulded or created through the way in which governments frame and represent the issue they are responding to, extending this approach into an analytical tool to examine the ways in which policy problems are constructed. By asking «what is the problem represented to be?» (WPR), this analytical framework explores the ways in which assumptions and presuppositions result in misrepresentation of a problem, leaving underlying issues at the root of the problem masked, silenced or ignored. Although Bacchi acknowledges that problem representation can be instrumentalised at times for political gains, she calls for the WPR approach to be used at a level which will «probe the deep conceptual underpinnings of problem representations» (Bacchi, WTP 1). According to Carol Bacchi and Susan Goodwin (7) this method of analysing policy can be transferred to many policy areas. As such, the framework is applied here to dissect Scottish Government's climate and food policies as discourse, whilst semi-structured interviews complement this analysis by gauging how policy is being interpreted and translated (or not) into practice. 


\subsection{Connecting gender and the commodification of nature}

Feminist and ecofeminist perspectives have importantly reconceptualised the relationship between nature and society, and within society in relation to gender. Ecofeminism suggests that before technological and economic progress became the main indicator of a successful society, societies were more egalitarian and the relationship between nature and society was more equitable and sustainable. Ecofeminist scholars invoke a rebalancing of power between nature and society and a return to pre-scientific and pre-industrialisation (Leach 67-85), when nature's value was more than just instrumental (Kneel). Concurrently, domination over nature is to be examined in relation to domination within society. Ecofeminist theorists such as Ruether and Merchant argue that we live in a patriarchal, capitalist society produced by historical domination and oppression of both women and nature. Such hierarchal power over nature has created a nature-human «dualism», which both the feminist scholar Plumwood (43-60) and environmental ethics scholar Attfield argue is the root cause of our contemporary climate and ecological crises. Altogether these arguments are key in rethinking the core values of sustainability in relation to gender.

Ecofeminism, with its association to feminist activism (Leach 67-85), has been perceived at times as too radical and critiqued by scholars such as Brohman and Leach (67-85) for its one-dimensional analysis of the relationship between women and nature. Brohman argues that ecofeminism fails to acknowledge intersecting factors such as race, class and privilege, which shape every woman's identity differently. Intersectionality has become a theoretical-methodological model in its own right and an increasingly important analytical tool within climate research to understand behaviours and vulnerabilities (Aavik 509-527). Therefore, there is a need to evaluate gendered differences which enable or constrain one's ability to adapt and change behaviour. That is not to say that one gender is more instinctively concerned with nature preservation than the other. Yet, to create change, we need to dig beneath the surface and reveal the motivations and gendered power structures at institutional, societal, organisational level, which dictate how much control people have over their own options. The next section examines how 
gendered barriers within organisations constrain or enable transformation of organisational and economical structures.

\subsection{Sustainability in a masculine business world}

Through her studies of gendered organisations, Acker highlights that traditional hierarchy within an organisation always favours men, as the roles of power and authority are given to those who can commit to full-time paid work («Hierarchies»139-158). Unlike women, men have been able to have a full-time job and life long career as their wives or mothers would generally care for their children on their behalf. On the other hand, choices for women in relation to paid employment have been more limited. Due to the gendered structural constraints, women must divide their commitments between family-work time, as societal norms and gendered expectations dictated that raising children was the role of the mother, and work was the role of the father (Gerson 8-24). Consequently, women have been more likely to be positioned in lower-ranking roles within organisations. Over thirty years ago, Morrison et al. (1987) described the phenomenon of few women securing roles within the most powerful positions as the «glass ceiling», a metaphor of the invisible barrier preventing women from progressing upwards, still in daily use. Acker suggests that the glass ceiling may never be broken through by women, unless there is an overall transformation within the organisational and economical structures which foster inequalities in the first place («Glass ceiling» 199-21).

Steinberg describes male dominated work environments as organisations built upon «masculine values», suggesting that since men were historically in positions of power, they have had the greatest influence over the way in which a business -its structure, ethos, and identity- was organised (576581). In such businesses women are under-represented and subject to the dominant masculine bias and hierarchy, detrimental to their status in terms of position and power. Steinberg further argues that men, who have an interest in maintaining their superior status, do so by reproducing gendered stereotypes such as dominant behaviour in the work place (Steinberg 576-581). This «masculine ethic» produces a male dominated work environment (Moss 245-266), and is adopted by the organisational leader, whether they are a man or woman (Steinberg 576-581). 
These gendered dynamics are the norm in professional kitchens which are known for their male dominated workforce, especially in decision making roles, and associated with anti-social working hours and high pressured work environments. Deborah Harris and Patti Giuffre (27-52) highlight that men still outnumber women in leadership roles within professional kitchens. These environments are known for being adrenaline fuelled, aggressive, sexualized misogynistic (Cooper 681-704). Stereotypes of cooking as a «feminine» activity and a «male ethic» combine in efforts of male head chefs to disassociate their job role from feminine stereotypes. Male chefs may «compensate» by overt displays of stereotypical masculine traits in their kitchen such as stamina, resilience, no emotion under pressure, and the ability to work for long hours in extreme conditions (Koch 75-79; Nilsson 647-663). All levels of staff in professional kitchens are known to endure long working hours and unregulated working conditions. Women mostly must «prove» themselves to be as capable as male chefs to withstand the masculine working environment of a professional kitchen (Harris and Giuffre 27-52). Therefore, as signalled by Acker, if the gendered stereotypes, ideologies and fundamental structure of a work place continue to favour male employees, then that organization will continue to be male dominated («Hierarchies» 139-158).

The leadership style of kitchens has also been associated with bullying, demeaning verbal abuse and a hierarchical structure that resembles that of the military (Koch 75-79; Nilsson 647-663). Testing these propositions, a study of women in the Swedish Armed Forces (Kronsell, «Methods» 108128; «Practices» 280-298) explored the experiences of women and gendered relations within a traditionally hegemonic masculine environment. The author found that women are made to feel an excluded minority within this masculine institution and underscores the importance of documenting the largely overlooked gendered experiences of women in the forces. Listening to the experiences of some of the women provides the insight needed to help understand and transform masculine institutions, especially ones which are not exposed to outside influences such as activism and social movements.

Altogether these studies invite us to reconsider sustainability in the context of a masculine business world and raise important questions as to how the structures of a work place enable or constrain change. In line with these considerations, this study problematizes sustainability in the context of the

Feminismo/s 35, junio 2020, pp. 95-125 
gendered professional kitchen and the article explores the discursive ambitions of climate and food policy and the reality of food catering as a business activity.

\section{METHODOLOGY}

The design of this research was influenced by personal experience as a professional chef of 18 years and my perspective as a feminist researcher. As a female professional within a male dominated industry, I was exposed to the challenges of working in a masculine environment. Further, working in kitchens raised my awareness towards sustainability concerns such as resource consumption and the carbon footprint of restaurants. These experiences have kindled my research focus on sustainability in the food industry.

The analysis of sustainability as a policy discourse and of the practices in restaurants was carried out in three stages. Firstly, this article identified the relevant policy documents from the Scottish Government which were developed as a climate mitigation strategy and in the attempt to ensure food sustainability in the country. Annex 1 contains the analysis of these documents using Carol Bacchi's feminist framework «What is the problem represented to be?» (Policy problems), applying each of the following questions to the policy documents:

- What is the problem represented to be within the policy? Are there references to restaurants, gender, gender equality, social inequalities, environmental protection, responsibilities for the private sector in climate mitigation?

- What assumptions underlie this representation?

- In what ways does this representation mask, obscure or silence underlying issues, such as institutional discrimination and absence of accountability to act?

- What are the potential effects of this representation?

- How can this representation be reconceptualised or replaced?

Thirdly, this analysis was combined with data collected from ten semi-structured face to face interviews, carried out with six male and four female head chefs in Glasgow. Glasgow is Scotland's largest city with a reputation for leisure and nightlife with a strong hospitality sector base and a progressive 
outlook. These factors influenced the selection of Glasgow as a mini-case study to explore the issues in focus. During the interviews participants where asked open ended questions. This allowed participants to freely express their opinions and perspectives. Interviews were carried out at the restaurant in which the head chefs were employed and lasted between 20 and 90 minutes, depending on participants' knowledge and interest in the topic of the interview. I explained to all participants that I am also a chef. This, I believe, resulted in an open and authentic discussion as participants knew they were engaging with a person that understood the context.

During the interviews, all chefs were asked questions on sustainability, including internal and external drivers influencing their everyday practices in kitchens, training of junior staff, personal values regarding sustainability and gendered dynamics in kitchens. Interviews were recorded and transcribed in full and data was analysed for evidence of the effects (or lack of) on everyday practices of head chefs. All of the participants were anonymized and given a pseudonym: M-number for male chefs and F-number for female chefs.

Through the coding process, the following key themes were identified: perceived frictions between environmental and social responsibilities in the restaurant industry; limited «kitchen conscience», with sustainability ranking low in perceived responsibility of chefs; normalisation of gendered discrimination and «glass ceiling» in kitchens; social injustice in kitchens. I then examined if and how these concerns were represented in Scottish climate and food policies.

\section{THE POLICY REPRESENTATION OF CLIMATE CHANGE MITIGATION AND FOOD SUSTAINABILITY}

Drawing on Bacchi's framework «What is the problem represented to be?» (Policy problems), this section analyses the way in which the Scottish Government is framing Scotland's response to the global climate emergency and to what extent this discourse values social and environmental inclusiveness. 


\subsection{Climate policies}

Scotland's climate policies centre around the problem of climate change as a global threat, which the government is tasked to address in order to reach the emission targets set out in the 2016 Paris Agreement. The government plans, policies and acts for climate mitigation focus and Scotland's commitments to the Paris Climate Agreement, emphasise economic growth alongside the necessary low carbon transitions. Analysis of the Scottish Government climate policies revealed that restaurants remain outside the governing sphere of nation-wide climate mitigation policies (Scottish Government, Good food; Climate Change (Scotland) Act, 2009). Although the climate policies stress the need for Scotland to meet the emissions reduction targets by 2050, no explicit accountability is placed on the private sector. Food systems are only discussed in the context of sustainable agriculture (i.e. food production). No focus is placed upon food consumption and production practices further down the food system, including the restaurant industry. In the eyes of the government there seems to be no significant correlation between restaurants as food consumers and greenhouse gas emissions. Consequently, these policies are potentially encouraging a «business as usual» rather than a transformative approach, within smaller industries such as hospitality.

Documentary analysis reveals that the term sustainability is often used, without being unpacked and critically defined. As a result, they reflect a very superficial interpretation of this concept whereby the possible trade-offs between current economic growth and socio-environmental pillars of sustainability are not addressed and, even less so, resolved. The impacts of reducing carbon emissions on different societal groups are not outlined. On the contrary, individual behaviour is discussed and addressed assuming homogeneity, without considering how dimensions such as gender, economic status and race intersect in enabling or constraining agency of individuals (as well as organisations) attempting to reduce emissions.

Waste management, rather than food consumption, is the sector that is addressed in more detail. Scotland has ambitious waste reduction targets set for 2025, reflected within Scottish Government climate policies. Waste management and recycling are seen as priority from business to household level. The Scottish Environmental Agency (SEPA) and the Climate Change 
Act (2009) both focus on waste prevention, recycling, and reduction of packaging as a means to ensure sustainability. This is a key part of climate policy measures, and both public and private sectors are legally obliged to recycle their plastic, metal, glass and paper, with lack of compliance leading to a monetary fine.

Overall, these policies are cherry picking ways in which changes can be instrumental in assisting the government to reach their 2025 and 2050 targets. At the same time, these policies encourage economic growth and overlook the fact that social and environmental dimensions may be compromised by maintaining a core focus on growth rather than sustainability. By sending the message that economic growth will prosper with a low carbon transition, and that a low carbon future is an essential investment that can bring future financial opportunities to Scotland, climate change mitigation is portrayed as a business opportunity rather than an international response to a climate emergency. This «profit from Paris» narrative is not the basis of a just transition.

\subsection{Government Food Related Policies}

The main message of food related policies is that the Scottish food system is unsustainable because the country is not self-sufficient. Restaurants and food businesses are only discussed in relation to food and health policies (Scottish Government, Good Food Consultation; Good Food Measures; Recipe for Success). In June 2016, Fergus Ewing MSP and Cabinet Secretary for the Environment announced a new food policy aimed at ensuring that «people from every walk of life take pride, pleasure and benefit from the food that they buy, serve and eat day by day» (Scottish Food Commission 1). Following this announcement, a consultation process was initiated by the government. In this context, the Scottish Food Commission recommended that:

All food businesses, including restaurants, cafes and other outlets, should be licensed in the same way as applies to alcohol and betting. A condition of the license [...] should be that, food preparation, purchasing and serving staff are trained in the impacts of food and health and sustainability matters commensurate with their work activity (1). 
The government, however, does not want to extend the policy to «private food related businesses» as this would significantly increase their costs and «unfairly disadvantage them compared to competitors» (Scottish Government, Climate Change Plan 1). By adopting such measures in the public sector the government is acknowledging the need for change and for tightening regulation. At the same time, by not extending this regulation to the private sector, it has openly prioritised economic gains over sustainability concerns within this sector. Ironically, in the same year (2018) the Scottish Government published the Food Tourism Action Plan, aimed at stimulating $£ 10$ billion growth in the food industry over 10 years. This initiative is promoted as a way to «capitalise on the best of our natural resources» (Scottish Government, Good Food Measures 15). This is arguably a missed opportunity for food policy to include measures which influence or promote sustainability in restaurants as integral to stimulating business, opting instead for an economic growth agenda, blind to sustainability practices, to dominate. In the process, the trade-offs between economic growth and sustainable food businesses are overlooked. As for the climate policies above, the notion of sustainability used does not challenge sectors to make difficult choices and does not provide clear guidance on how to achieve sustainability. Furthermore, these policies do not address feminist concerns and values such as inclusiveness, and agency to make decisions and are silent on the relationship between gender and socio-economic inequalities despite activity elsewhere by the Scottish Government to promote its «Fair Work» agenda, as discussed below.

\subsection{The Government Business Pledges}

Gender discrimination in the work place still exists and could impact the productivity of businesses: this is the message sent by the Scottish Government in partnership with businesses through the Scottish Business Pledge (2015), and the Fair Work Convention (2015). Occupational segregation in the labour market has been acknowledged by the Scottish Government as a policy priority, as evidenced in various policy statements by the Scottish Government and its continued funding of gender equality organisations such as Equate Scotland and Close the Gap. These initiatives seek to resolve gendered occupational segregation (horizontal and vertical) within paid employment where

Feminismo/s 35, junio 2020, pp. 95-125 
women are less present in higher paid senior positions. Furthermore, they analyse data on gender equality in the workplace and the right to equal pay and campaign for change. Emily Thomson and Naveed Hakeem (6-7) highlighted that occupational segregation and the gender pay gap in Scotland's labour markets may be intensified through vulnerable economic activities, as a result of the 2007 global financial recession. The restructuring of the labour market after the subsequent recession led the Scottish Government to attempt to more closely reflect the relationship between economic growth and inequalities, with the message to businesses that gender equality and maximizing the potential of women in the all areas of the labour market, can enhance productivity.

The Scottish Government's gender pay-gap action plan «A fairer Scotland for women» (2019) introduced by the First minister of Scotland Nicola Sturgeon, proclaimed her commitment to reducing the gender pay gap in the next four years, and sent a message to women in Scotland that «no glass ceiling should prevent you from reaching your dreams» (1). In the «Scottish Business Pledge, 2015» the Scottish Government calls for businesses to be more racially and gender balanced as a way to make businesses more «productive». The pledge highlights that many women are working below their skill set and that employing more women and utilizing their capabilities can only be a positive contribution to businesses (Weaver et al. 6).

Framing gender equality as a support to increased productivity represents the problem of gender equality as a business growth problem to be addressed and aims to reveal underlying discriminations that Scottish businesses have not yet challenged head on. However, without addressing the root causes and everyday practices of such discriminations, this framing can silence the ways in which the fundamental structure of businesses, specifically professional kitchens and the restaurant sector, can prevent women, particularly those with families from progressing upwards. If many women are working below their skill-set, then the organisational structure in which they are being squeezed into must be flawed, yet women continue to be presented as having untapped economic value, rather than people who have the same right to employment and professional progression as men. Of course this representation of women is a way of speaking the language which appeals to businesses and potential employers. By portraying women as having economic value,

Feminismo/s 35, junio 2020, pp. 95-125 
the business pledge aims to assist women in securing employment. However, this «promotion of a business case for equality» (Thompson 128) is risky as it leaves gender equality in the hands of the private sector that can decide to adhere to this idea on a voluntary basis and only if this is beneficial to them. A further risk is that businesses will make room for women in a structure that remains flawed, rather than transforming their business structure to eliminate institutional discrimination. Flexibility as a key aspect of transformation within a business structure has been proposed by Emily Thomson and Naveed Hakeem (17-18), based on the premise that gender balance within the work place can enhance business performance. The implementation of more flexible working conditions which are shown to increase the well-being of employees, have the potential to attract many women who would otherwise face under-employment or are struggling to balance work-family responsibilities (Thomson and Hakeem 2).

\section{POLICY 'PROBLEMS' IN PRACTICE: SUTAINABILITY AND GENDER IN PROFESSIONAL KITCHEN}

In this section I examine the extent to which the policy «problems», as represented in the policy analysis above, are understood and addressed in practice by head chefs in professional kitchens. Determining the «conscience» of a kitchen is instrumental to understand whether chefs are aware of the social, environmental and economic consequences of their actions.

The analysis in this section is based on current practices in professional kitchens. The case study findings reveal that many underlying issues constrain the necessary inclusion of sustainable values and practises within professional kitchens. Furthermore, as chefs operate in a highly masculine environment, the gendered culture of kitchens was evident. Gendered assumptions regarding the need to choose between a career or a family were common. Such gendered experiences and perceptions are in line with Acker's («Hierarchies») and Steinberg's analysis of the way in which organisational structures favour men and with recent accounts of hierarchies in professional kitchens (Harris and Giuffre 27-52). 


\subsection{Organisational norms and behaviours}

Professional kitchens are a prime example of a working environment that is structured in a way in which women (and men) face constraints in securing more senior positions whilst raising a family. The Scottish Government calls for businesses to be more racially and gender balanced as a way to make businesses more productive. The problem is framed simply as needing to address women being in positions that are way below their skillset. This representation fails to capture the discrimination female chefs in this study have experienced in the workplace on a daily basis because of the way businesses are structured. To illustrate, there are only a few female head chefs in Glasgow. While male chefs explain this as women's inflexibility to fit in the industry, they do not consider the possibility that the industry should be changing to accommodate women. For M2, women cannot have both a senior role and a family, asserting that «it just doesn't work for them». Mothers looking for a family/work life balance could only progress to a senior position if they «commit further [than 45 hours a week]». In Ml's kitchen, the only female chef is a mother who needs to complete her 36 hours each week over three days, in order to balance family life. To M1 this lack of flexibility is a «hindrance»:

If there is someone who not necessarily does not want to pull their weight, but can't pull their weight because they have a child and can't do extra work, it means the people around them have to pick up the slack, which is not really fair in this industry. In other industries it would be fair, but not in hospitality.

Female chefs who cannot take on extra working hours when needed, he continues, create an unfair work balance for other staff members that do. Yet, neither M1 nor M2 question the fact that working mothers are asked to choose between family life and a successful career in the industry, but fathers are not. These male chefs seem to also imply that whilst men are in the position to progress and have a family, women (likely to have bigger responsibilities in the household) need to choose. As M2 puts it, «women that don't have kids and want to focus on their career, can go to the top!». As a result, women maintain a low-status and a lower paid role if they want to have a family and stay in the industry. 
Family life is only one reason as to why there are few female head chefs. Many women (F4, F1 and F2) emphasized that they had to work twice as hard as men to have the same position or gain a promotion. F4 felt awkward saying this as she thought the idea could sound a «bit out there». Yet, 3 out of 4 female participants felt the same way. Gender seems to be a topic that is never discussed within the industry, especially by female chefs, perhaps this is because it could be portrayed as a weakness.

Another challenge women face is being taken seriously by junior staff. F2 mentioned that she is always aware of her gender in the kitchen. In her first experience as sous chef (second in command), she found that her assertiveness was a problem for the men in the kitchen. On multiple occasions she was called a «bitch» and she felt she was taken less seriously than her male counterparts. Both F4 and F2 feel the industry is «hard for a woman» and that they «need to have a thick skin» if they want to progress. F4 mentioned that to be taken seriously and deter unwanted sexist and patronising comments from colleagues and the restaurant suppliers, she must communicate sternly to the point of coming across as «almost rude». Some female chefs believe they are also not taken seriously by suppliers and delivery drivers. F1 and F4 recall suppliers entering the kitchen and failing to acknowledge them as the head chef, insisting on talking to the male junior chefs instead. Both had to persuade the supplier that they were in fact the head chef. On many occasions, F4 was made uncomfortable by a delivery driver asking her to «smile» and «cheer up». She further elaborated: «my job is stressful, I am not there to smile and welcome people. These comments would never be said to the (male) owner». Gendered relations in the kitchen, therefore, could limit professional progression and the interactions with male colleagues could become female chefs' «glass ceiling».

Male chefs do not seem to consider gender as an important aspect of their job: «I never really think about gender» (M6). When men consider gender, they interpret it as a synonym for women, as if men do not have a gender. M4's response to a question on gender dynamics in kitchens, for instance, focuses on women: «I think the girls knew what the environment was like before they started». M1 aptly summarises these dynamics by explaining that racism, misogyny and sexism are present throughout the industry «as it exists 
throughout all of society». He believes such negative traits are exacerbated within kitchens as the anti-social working hours and harsh working environments can lead many chefs to live «isolated lives». He adds that «kitchens are not exactly hives of progressive thought, they are places of people with very isolated lives and ideas».

Furthermore, evidence from interviews underscores the need for policy -at governmental and organisational levels - to acknowledge and address some of the underlying dynamics of established behaviours that both produce further incidences of gendered behaviours and barriers to their resolution. Working practices that undermine collective and individual wellbeing contribute to poor working conditions and the ability of managers to engage in and promote change (Murray-Gibbons and Chris Gibbons 32-40). Such issues can affect a chef's ability and mind-set, preventing them from prioritising sustainability in their work routine. For example, F1, M2, F2, and F4 emphasised that the physical and mental stress can take its toll on chefs. A 33-year-old head chef (M2), mentioned that he is tired every day of his life: his average workday starts at 9 a.m. and ends at lam. During this time, he is constantly on the move and under pressure. F1 emphasised the mental stress she has experienced as a head chef, to the point that she recognised that it was «changing her personality» in a negative way. She also witnessed «talented» and «creative» chefs «self-medicate» with drugs and alcohol to calm down from the «natural adrenaline» and «stress» experienced on a daily basis at work.

Another factor that may affect the wellbeing of the chefs is their income and working hours. Only a few chefs (M2, F2 and F3) confirmed their staff were being paid more than minimum wage, whilst in all other cases staff were on minimum wage. The average working week is 45 hours before overtime. F4 said she can work up to 60 hours per week and her job leaves her no opportunity for a family-work life balance. These working conditions are unsustainable and financially unrewarding for chefs. This reality is overlooked in policies, which fail to unpack the complexities of an unsustainable food system in relation to an unequal society. For the chefs to be a part of the change towards sustainable restaurants, their well-being must be as valued as the profit they generate. 


\subsection{The effects of policy representation in practice}

The Scottish Government's minimising of the leadership role and responsibilities of the private sector in climate change mitigation is also clearly reflected in the perceptions and actions of head chefs. For example, the interview data shows that head chefs fail to see a direct link between their actions and climate change, and in turn, they feel no responsibility to be actively sustainable on a professional level. When asked what sustainability meant to them, most chefs used buzzwords such as «recycling», «zero waste» and «local produce». Given the extent to which chefs are interconnected with and reliant on the natural environment, it was surprising that, for example M3 found «nothing came to mind» when he thought about sustainability. As the head chef of one of the most prestigious restaurants in the city, M3 is in the luxurious position of charging his customers a far higher price than the average restaurant. With these higher costs to the customer, M3 prioritizes quality of products over animal welfare, environmental degradation and the local economy. For example, he pointed out that «local» is a grey area for him and classified England and continental Europe as buying locally. He wants the best quality product and it does not matter where he gets it from «if I can get a better chicken from France than up the road, then I am getting it from France». Evidently, sustainability does not formulate his standard of a «good quality» product. The way M3 classifies «local» reflects a key oversight of the Scottish Government policies, which promote a local sustainable food system without providing guidance on what sustainable and local are. Under these circumstances, «local» will continue to be a «grey area» and chefs' attempts to be sustainable may be counterproductive.

All participants, however, agree that the most important part of their job is to make a profit. Therefore, a chef with the best social and environmental intentions will always be limited by the budget. Even F1, by far the most environmentally aware chef, mentioned that her kitchen is as sustainable «as the budget can afford». M6, M5 and M2 emphasised many times that their hands were tied as they cannot pass certain costs on to the customers.

A second effect is that restaurants are not yet exploring their potential contribution towards a sustainable transition and it does not appear that they 
will anytime soon. Knowledge and awareness are key factors in driving change (Meinzen-Dick et al. 29-25), yet all the chefs interviewed mentioned that they do not engage in discussions about environmental issues with junior staff members. Even when head chefs make more sustainable choices, these are not discussed with junior staff. For example, when M6 replaced cod with hake on his menu, he did so because he had read it was unsustainable, however, he never discussed the reason with the junior staff. He admitted he could do a lot better in communicating and teaching, but the structure and nature of the business means that there is always something more «pressing» and that «you are just trying to make it through each day without a disaster happening». With junior staff not being trained to be environmentally and socially conscious of their actions, it raises the question, where are the junior chefs learning about their environmental responsibilities and the consequences of their everyday practices if not in the work place?

Consequently, the next generation of kitchen leaders are not being equipped with ecological literacy and awareness. With little guidance from government, chefs are vulnerable to being misinformed regarding climate issues. Policy representation plays a role in informing the private sector in what problem exists and how they should respond. If this representation obscures reality, the response will be ineffective.

Solid waste management represents an exception. Government regulation on recycling and waste management have had an impact on chefs. All chefs confirmed they recycle and comply with regulations, even though they perceive them as a burden. All participants mentioned the recycling protocols in place as the only influence at government and council level, they are aware of, in terms of enforcing the implementation of sustainable practices. This shows that regulation can influence the industry and promote positive behaviour changes. Recycling is, however, a tiny contribution towards a global problem and has the potential to create the illusion that we can generate as much waste as we desire because we have recycling facilities in place. 


\section{DISCUSSION AND CONCLUSIONS}

In this article, I have analysed the gap between discursive ambitions of Scottish food and climate policies and the reality of the restaurant industry. The combination of professional practice, personal experience and policy analysis make an original contribution to the literature, with the additional perspective of a feminist analysis. This article has revealed through a feminist lens that policies put in place to steer Scotland on a path of sustainability and a low carbon transition have promoted the idea that these goals will be achieved alongside economic growth. This representation silences the multiple ways in which social and environmental dimensions may be compromised in the process. Similarly, government policies do not directly call upon the private sector to contribute significantly towards a sustainable low carbon transition. Climate policies do not focus on food consumption, thus also silencing the correlation between restaurants and greenhouse gas emissions. Furthermore, food policies that are mostly concerned with promoting the Scottish food industry, often overlook sustainability practices in restaurants and the wider hospitality industry. Overall, the way in which the Scottish Government is framing Scotland's response to the global climate emergency and food governance does not mainstream how gender, economic status and race intersect in enabling or constraining agency of individuals and businesses attempting to reduce emissions. By silencing gendered discriminations, potential approaches to improve social and environmental sustainability are also obscured.

The case of head chefs in professional kitchens illustrates how policies promote economic growth over social and environmental sustainability. Professional kitchens are still male dominated and characterized by an adrenaline fuelled, aggressive and sexualized environment, as identified by MurrayGibbons and Chris Gibbons (32-40). The gendered dynamics in professional kitchens resemble in many ways those described by Kronsell («Methods» 108-128) in her study on the Swedish Armed Forces. In both sectors women face a predominantly masculine environment, in which they feel they are treated differently. A further contribution of the research in this article is that it reveals that women chefs must work harder to gain their position or to be respected by their male colleagues. Furthermore, in both cases gender is not 
perceived as an issue by men, whose masculinity is implicitly seen as «the norm». Women, on the contrary, live the consequences and struggles of their associated femininity and the gendered structures of their professional and private lives. From an ecofeminist perspective, which places gender in relation to environmental sustainability, the fact that kitchens are dominated by patriarchal norms and capitalistic logics has important implications. The silencing of gendered discriminations and lack of convincing attempts towards transforming unsustainable nature-society relations mirror the commodification of nature described by Ruether in 1975 and Merchant in 1980. It also raises a question for future research as to how much progress there has been over forty years on from their observations.

The Scottish Government Business Pledge is an important significant attempt to address the issues women face in professional environments. However, it fails to identify and address the structural barriers within businesses that cause women to work below their skill-set. As argued by Kendrigan, "while treating women the same as men would provide a significant improvement in the lives of many women, treating men and women the same will not solve the problems of institutional discrimination» (221). In practice, this means that ensuring that female chefs have the same employment opportunity as male chefs might entail treating them differently (McPhail 39-61; Kendrigan 221) to avoid institutional discrimination from impacting their right to work. Different needs may require different treatment in order to give someone an equal opportunity, which is far more complicated than treating everyone the same (Bagilhole 144-147). It is the need for transformations within unequal systems that policies should be addressing, rather than a passive approach which leaves room for business as usual. This resonates with Acker's argument that breaking the glass ceiling will require a profound transformation of organisational and economical structures that foster inequalities in the first place ( Glass ceiling» 199-217).

In conclusion, in order to produce more transformative and socially equitable outcomes, as Bacchi has consistently argued (Practice; Policy problems; WTP) policy analysis requires to be informed by evidence and understanding of the gendered differences that shape experiences of public policy decisions. That means when examining what a problem is represented to be, the analysis 
needs to consider gendered social, economic, and political dimensions, rather than assume a gender neutral reality. Furthermore, integrating an intersectional perspective into policy making processes will contribute to achieve this goal. An intersectional lens, in the context of sustainability and gender, can highlight the limitations and advantages individuals and groups have towards being sustainable, in direct relation to the socio-economic, power and gendered structures within which they are situated.

In the future, a sustainable restaurant industry would be one which refrains from solely prioritising economic gains over their corporate responsibility to ensure environmental stewardship and gender equality. If sustainability entails contributing towards environmental targets within a just society, it cannot be manipulated into an economic strategy that perpetuates current growth patterns. In considering the restaurant industry, this means that a real sustainability agenda would need to place value on the wellbeing of chefs as well as to address the business pressures, for chefs to buy fully into sustainability as a set of working and productive practices.

To conclude, this article has spotlighted several issues of relevance for future research to explore further. This includes examinations of engagement with sustainability through continuous professional learning and knowledge sharing, trade-offs between economic drivers, environmental values and social inequalities in professional kitchens, and barriers and opportunities to establish socially and environmentally just professional kitchen. 


\section{ANNEX 1. POLICY ANALYSIS}

\begin{tabular}{|c|c|}
\hline Climate Policies & Analysis \\
\hline \multirow{5}{*}{$\begin{array}{l}\text { 1. Scottish Government } \\
\text { Climate Change Plan. The } \\
\text { Third Report on Proposals } \\
\text { and Policies 2018-2032. } \\
\text { 2. Climate change } \\
\text { (Scotland) Act, } 2009 . \\
\text { 3. SEPA, Waste (Scotland) } \\
\text { Regulations } 2012- \\
\text { Guidance for Restaurants E } \\
\text { Bars, 2012. }\end{array}$} & $\begin{array}{l}\text { What the problem is represented to be: } \\
\text { - Climate change is a global threat and Scotland must play its } \\
\text { part in reaching the emission reduction } 2050 \text { targets set out in } \\
\text { the Paris Agreement. }\end{array}$ \\
\hline & $\begin{array}{l}\text { Assumptions: } \\
\text { - A low carbon future is an essential investment which can } \\
\text { bring future financial and social opportunities to Scotland. } \\
\text { - Economic growth must coexist and prosper with low carbon } \\
\text { transitions. } \\
\text { - No trade-offs required between the different dimensions of } \\
\text { sustainability (social, environmental and economic). }\end{array}$ \\
\hline & $\begin{array}{l}\text { Effects: } \\
\text { - Economic gains, encourages business as usual attitude. } \\
\text { - Society and economy are seen as a homogenous whole. } \\
\text { Behaviour is discussed and addressed assuming homogeneity, } \\
\text { with no reference to how gender, economic status, race } \\
\text { intersect in enabling or constraining agency of individuals and } \\
\text { organisations attempting to reduce emissions. } \\
\text { - Emphasis on waste management and recycling. } \\
\text { - Can deflect sustainability responsibilities as businesses are not } \\
\text { held accountable for actions. }\end{array}$ \\
\hline & $\begin{array}{l}\text { Silences: } \\
\text { - Gender blind/race/class blind. } \\
\text { - Trade-offs of low-carbon transitions and vulnerability of } \\
\text { marginalised groups. } \\
\text { - Inequalities. } \\
\text { - Failure to acknowledge the explicit roles and responsibilities } \\
\text { of individuals and the private sector. } \\
\text { - Accountability for emissions and what behaviours need to } \\
\text { change. }\end{array}$ \\
\hline & $\begin{array}{l}\text { Disrupted/contested/contradictions/reconceptualization } \\
\text { - The international response to a climate emergency as } \\
\text { something to profit from. Without profit would there be no } \\
\text { action? } \\
\text { - Who is really benefitting from this 'just' transition? } \\
\text { - Concretely, what does the behaviour change entail and for } \\
\text { whom? } \\
\text { - Why is the private sector remaining neutral in this? To remain } \\
\text { a stabile contributor to the economy? } \\
\text { - «Profit from Paris» }\end{array}$ \\
\hline
\end{tabular}

Feminismo/s 35, junio 2020, pp. 95-125 
Climate conscious professional kitchens? Analysing the Scottish food sector through a feminist lens

\begin{tabular}{|c|c|}
\hline Food Policies & Analysis \\
\hline $\begin{array}{l}\text { 1. Scottish Government. } \\
\text { Recipe for Success: } \\
\text { Scotland's National Food E }\end{array}$ & $\begin{array}{l}\text { What the problem is represented to be: } \\
\text { - The Scottish food system is unsustainable and the country is } \\
\text { not self-sufficient. }\end{array}$ \\
\hline $\begin{array}{l}\text { Good Food Nation. } \\
\text { 2. Scottish Food } \\
\text { Commission. } \\
\text { Recommendations from the } \\
\text { Scottish Food Commission } \\
\text { for the implementation of, }\end{array}$ & $\begin{array}{l}\text { Assumptions: } \\
\text { - We should adopt a more local approach to fix this. } \\
\text { - Inequalities would not exist within a more localised food } \\
\text { system. } \\
\text { - Micro food producers could cope with the increasing demand } \\
\text { in a sustainable way. } \\
\text { - Access to food, affordability and eating habits will change } \\
\text { through the adoption of a «buy local approach». }\end{array}$ \\
\hline $\begin{array}{l}\text { Good Food Nation Bill. } \\
\text { 3. Scottish Government. } \\
\text { Good Food Nation } \\
\text { proposals for legislation: } \\
\text { analysis of consultation }\end{array}$ & $\begin{array}{l}\text { Effects: } \\
\text { - Does not unpack the complexities of an unsustainable food } \\
\text { system and unequal society. } \\
\text { - The responsibility of change is put on the public sector which } \\
\text { deflects it away from individuals and the private sector. Non- } \\
\text { sustainable method. }\end{array}$ \\
\hline $\begin{array}{l}\text { 4. Scottish Government. } \\
\text { Good Food Nation } \\
\text { Programme of Measures, } \\
\text { September 2018: }\end{array}$ & $\begin{array}{l}\text { Silences: } \\
\text { - Gender blind regarding social and institutional gender } \\
\text { discrimination. } \\
\text { - Uncritical approach to sustainability with no mention of } \\
\text { potential trade-offs between dimensions of sustainability. }\end{array}$ \\
\hline $\begin{array}{l}\text { 5. Scottish Tourism } \\
\text { Alliance. Food Tourism } \\
\text { Action Plan, } 2019 . \\
\text { 6: Scottish Government. } \\
\text { Recipe for Success } \\
\text {-Scotland's National Food } \\
\text { and Drink Policy. }\end{array}$ & $\begin{array}{l}\text { Disrupted/contested/contradictions/reconceptualization } \\
\text { - Buying local could be more expensive than purchasing lower } \\
\text { quality produce in the supermarkets. } \\
\text { - A transition to local buyers/growers considers environmental } \\
\text { benefits but what about increased emissions through } \\
\text { transportation and agriculture? } \\
\text { - Who determines what is local and what is good? } \\
\text { - Promotes the living wage as a method to aid access to good } \\
\text { food. }\end{array}$ \\
\hline
\end{tabular}

Feminismo/s 35, junio 2020, pp. 95-125 
Climate conscious professional kitchens? Analysing the Scottish food sector through a feminist lens

\begin{tabular}{|c|c|}
\hline Business report/pledge & Analysis \\
\hline \multirow{5}{*}{$\begin{array}{l}\text { 1. Scottish Business } \\
\text { Pledge, 2019. The Scottish } \\
\text { Government in partnership } \\
\text { with businesses. } \\
\text { 2. Tackling Occupational } \\
\text { Segregation in Scotland: A } \\
\text { report of activities from the } \\
\text { Scottish Government Cross- } \\
\text { Directorate Occupational } \\
\text { Segregation Working Group }\end{array}$} & $\begin{array}{l}\text { What the problem is represented to be: } \\
\text { - Institutional discrimination in the work place still exist today } \\
\text { and it could be impacting the productivity of businesses. }\end{array}$ \\
\hline & $\begin{array}{l}\text { Assumptions: } \\
\text { - Businesses which are equal, fair and socially sustainable can be } \\
\text { far more productive. } \\
\text { - «Woman are working below their skill level». Therefore, } \\
\text { businesses are encouraged to employ more women and utilise } \\
\text { their capabilities. } \\
\text { - That productivity of a business is more important than } \\
\text { eradicating underlying discrimination. }\end{array}$ \\
\hline & $\begin{array}{l}\text { Effects: } \\
\text { - Promotes the living wage and highlights the importance of } \\
\text { reducing gender pay-gap and job flexibility. } \\
\text { - Highlights the gendered segregation in employment positions } \\
\text { referring to feminist concepts such as the «glass ceiling» and } \\
\text { «sticky floor» effects which prevent women from reaching } \\
\text { higher status and higher paid positions } \\
\text { - Gender pay gap } \\
\text { - The business pledge provides examples of how a business can } \\
\text { be socially, economically and environmentally sustainable. }\end{array}$ \\
\hline & $\begin{array}{l}\text { Silences: } \\
\text { - The underlying discrimination which allows for women to } \\
\text { work below their skillset. } \\
\text { - Organisations and institutions are structured in a way which } \\
\text { allows for inequalities to reproduce. } \\
\text { - Women are made to feel different as a minority in a } \\
\text { predominantly male environment. }\end{array}$ \\
\hline & $\begin{array}{l}\text { Disrupted/contested/contradictions/reconceptualization } \\
\text { - Many women today are working below their skillset as } \\
\text { business structures are free to discriminate. } \\
\text { - Women are portrayed as having untapped economic value } \\
\text { rather than human beings who have the right to work and } \\
\text { provide for their families. }\end{array}$ \\
\hline
\end{tabular}

Feminismo/s 35, junio 2020, pp. 95-125 


\section{REFERENCES}

Aavik, Kadri. «The animal advocacy movement in the Baltic states: Links to other social justice issues and possibilities for intersectional activism». Journal of Baltic Studies 49.4 (2018): 509-527.

Acker, Joan. «Hierarchies, jobs, bodies: A theory of gendered organizations». Gender E society 4 (1990): 139-158.

Acker, Joan. «From glass ceiling to inequality regimes.» Sociologie du travail 51 (2009): 199-217.

Allwood, Gill. «Gender mainstreaming and EU climate change policy». In The persistent invisibility of gender in EU policy. Elaine Weiner and Heather MacRae, eds. European Integration online Papers (EIoP), Special issue 1. 18 (2014): 1-26.

Attfield, Robin. Environmental ethics: An overview for the twenty-first century. New Jersey: John Wiley \& Sons, 2014.

Bacchi, Carol Lee. Women, policy and politics: The construction of policy problems. London: Sage, 1999.

Bacchi, Carol Lee. What's the Problem Represented to be: An introduction. Flinders University Adelaide. 10 February 2020. <https://scholar.googleusercontent.com/scholar?q=cache:VPCr4ijJw2MJ:scholar.google. $\mathrm{com} /+$ What $\% 27 \mathrm{~s}+$ the+Problem+represented+to+be\%3F+an+Introduction $+\&$ thl $=$ en\&as_sdt $=0,5>$.

Bacchi, Carol, and Joan Eveline. Mainstreaming politics: Gendering practices and feminist theory. Adelaide: University of Adelaide Press, 2010.

Bacchi, Carol, and Susan Goodwin. Poststructural policy analysis: A guide to practice. Basingstoke: Palgrave Macmillan, 2016.

Bagilhole, Barbara. Understanding equal opportunities and diversity: The social differentiations and intersections of inequality. Bristol: Policy Press, 2009.

Brohman, John. Popular development: Rethinking the theory and practice of development. Oxford: Wiley-Blackwell, 1996.

Cooper, Ann. A woman's place is in the kitchen»: The evolution of women chefs. International Thomson Publishing Services, 1998.

Cretney, Raven, and Sylvia Nissen. «Climate politics ten years from Copenhagen: Activism, emergencies, and possibilities.» Women Talking Politics (2019): 15.

Du Pont, Yann Robiou, M. Louise Jeffery, Johannes Gütschow, Joeri Rogelj, Peter Christoff, and Malte Meinshausen. «Equitable mitigation to achieve the Paris Agreement goals». Nature Climate Change 7. 1 (2017): 38-43. 
Food Tourism Scotland. Food Tourism Action Plan, 2019. 29 January 2020. <https://scottishtourismalliance.co.uk/wpcontent/uploads/2019/04/ FoodTourismStrategy.pdf>.

Gerson, Kathleen. «Moral dilemmas, moral strategies, and the transformation of gender: Lessons from Two Generations of Work and Family Change». Gender E Society 16. 1 (2002): 8-28.

Giddens, Anthony. «The politics of climate change.» Policy \& Politics 43.2 (2015): 155-162.

Harris, Deborah, and Patti Giuffre. ««The price you pay»: How female professional chefs negotiate work and family.» Gender Issues 27.1-2 (2010): 27-52.

Hulme, Mike. Why we disagree about climate change: Understanding controversy, inaction and opportunity. Cambridge: Cambridge University Press. UK, 2009.

Kendrigan, Mary Lou. Gender differences: Their impact on public policy. New York: Greenwood Publishing Group, 1991.

Kheel, Marti. Nature ethics: An ecofeminist perspective. Lanham, Maryland: Rowman \& Littlefield, 2007.

Koch, Shelley. Gender and Food: A Critical Look at the Food System. Lanham, Maryland: Rowman \& Littlefield, 2019.

Kronsell, Anna. «Gendered practices in institutions of hegemonic masculinity: Reflections from feminist standpoint theory». International Feminist Journal of Politics 7 (2005): 280-298.

Kronsell, Anna. «Methods for studying silences: gender analysis in institutions of hegemonic masculinity». In Feminist methodologies for international relations. New York: Cambridge University Press, 2006. 108-128.

Leach, Melissa. «Earth mother myths and other ecofeminist fables: How a strategic notion rose and fell». Development and change 38.1 (2007): 67-85.

Lenton, Timothy M., Johan Rockström, Owen Gaffney, Stefan Rahmstorf, Katherine Richardson, Will Steffen, and Hans Joachim Schellnhuber. «Climate tipping points-too risky to bet against.» Nature.Com (2019): 592-595. 10 February 2020. <https://www.oceanplan-project.com/ uploads/1/0/5/5/105562895/2019_lenton_et_al_-_cc_tiping_points.pdf>.

Levy, Barry S., and Jonathan A. Patz. "Climate change, human rights, and social justice.» Annals of global health 81. 3 (2015): 310-322.

McPhail, Beverly A. «A feminist policy analysis framework: Through a gendered lens.» The Social Policy Journal 2. 2-3 (2003): 39-61. 
Meinzen-Dick, Ruth, Chiara Kovarik, and Agnes R. Quisumbing. «Gender and sustainability.» Annual Review of Environment and Resources 39 (2014): 29-55.

Merchant, Carolyn. «The Death of Nature: Women, Ecology, and the Scientific Revolution». San Francisco: Harper \& Row (1980): 348.

Moore, Jason. «The Rise of Cheap Nature». Sociology Faculty Scholarship. Binghamton University, 2016. 10 February 2020. <https://orb.binghamton. edu/cgi/viewcontent.cgi? article=1001\&context=sociology_fac $>$

Morrison, Ann M., Randall P. White, and Ellen Van Velsor. Breaking the Glass Ceiling: Can Women Reach The Top Of America's Largest corporations? New Jersey: Pearson Education, 1987.

Moss, Kanter Rosabeth. «Men and Women of the Corporation, New Edition.» Cambridge (2008): 245-266.

Murray-Gibbons, Robert, and Chris Gibbons. «Occupational stress in the chef profession». International Journal of Contemporary Hospitality Management 19. 1. (2007): 32-42.

Nilsson, Gabriella. «Balls Enough: Manliness and Legitimated Violence in Hell's Kitchen». Gender, Work E Organization 20.6 (2013): 647-663.

Plumwood, Val. «Gender, eco-feminism and the environment.» In Controversies in environmental sociology. New York: Cambridge University Press, 2004. 43-60.

Ripple, William J., Christopher Wolf, Thomas M. Newsome, Phoebe Barnard, and William R. Moomaw. "World scientists' warning of a climate emergency.» BioScience, 2019. 10 February 2020.

Available from <https://academic.oup.com/bioscience/article/70/1/8/5610806>.

Rose, Jeff, and Adrienne Cachelin. «Critical sustainability: incorporating critical theories into contested sustainabilities». Journal of Environmental Studies and Sciences 8.4 (2018): 518-525.

Ruether, Rosemary Radford. New woman, new earth: Sexist ideologies and human liberation. New York: Seabury Press, 1975.

Scottish Business Pledge. The Scottish Government in partnership with businesses, 2019. Accessed on February 12 2020. Available from <https://scottishbusinesspledge.scot/>

Scottish Food Commission Recommendations from the Scottish Food Commission for the implementation of, and content for, the Scottish Good Food Nation Bill. Compiled on behalf of the Scottish Food Commission. Scotland, 2017. 10 February 2020. <https://www.gov.scot/binaries/content/documents/govscot/publications/corporate-report/2019/01/scottish-food-commission-final-report/

Feminismo/s 35, junio 2020, pp. 95-125 
documents/food-commission-final-report-december-2017/food-commission-final-report-december-2017/govscot\%3 Adocument/ Food\%2BCommission\%2Bfinal\%2Breport\%2B\%2BDecember\%2B2017.pdf> Scottish Government. Tackling Occupational Segregation in Scotland: a report of activities from the Scottish Government Cross-Directorate Occupational Segregation Working Group, 2008. 12 February 2020. <https://www2.gov. scot/resource/doc/236539/0064855.pdf>

Scottish Government. Climate Change (Scotland) Act, 2009. 2 February 2 2020. <http://www.scotland.gov.uk/Topics/Environment/climatechange/ scotlandsaction/climatechangeact>

Scottish Government. Recipe for Success -Scotland's National Food and Drink Policy. The Scottish Government, 2009. 10 February 2020. <https://www. gov.scot/publications/recipe-success-scotlands-national-food-drinkpolicy/>

Scottish Government. Recipe for Success: Scotland's National Food \& Drink Policy Becoming a Good Food Nation. Discussion Document, Edinburgh, 2014. 10 February 2020. <https://www.gov.scot/publications/ recipe-success-scotlands-national-food-drink-policy-becoming-good-food/>

Scottish Government. Fair Work Convention, 2016. 10 February 2020. <https:// www.fairworkconvention.scot/the-fair-work-framework/>

Scottish Government. Climate Change Plan. The Third Report on Proposals and Policies 2018-2032, 2018. 10 February 2020. <https://www.gov. scot/publications/scottish-governments-climate-change-plan-third report-proposals-policies-2018-9781788516488/>

Scottish Government. GoodFood Nation-Programme of Measures, 2018. 13 February 2020. <https://www.gov.scot/publications/good-food-nation-programmeof-measures/pages/4/>

Scottish Government. Good Food Nation proposals for legislation: analysis of consultation responses, 2018. 2 February 2020. <https://www.gov.scot/publications/ good-food-nation-proposals-legislation-consultation-analysis-report/>

Scottish Government. A fairer Scotland for women: gender pay gap action plan - gov.scot, 2019. 21 January 2020. <https://www.gov.scot/publications/ fairer-scotland-women-gender-pay-gap-action-plan/>

Scottish Government. Working on women and work. Close the Gap. 29 January 2020. <https://www.closethegap.org.uk/>. 
Scottish Tourism Alliance. Food Tourism Action Plan, 2019. 13 February 2020. <https://scottishtourismalliance.co.uk/wpcontent/uploads/2019/04/ FoodTourismStrategy.pdf>

SEPA. Waste (Scotland) Regulations 2012 - Guidance for Restaurants E Bars. 29 January 2020. <https://www.sepa.org.uk/media/40256/zerowaste_guidance_ restaurants-bars.pdf>

Steinberg, Ronnie J. «Gender on the agenda: male advantage in organizations». Contemporary Sociology. (1992): 576-581.

Thomson, Emily. «Do ends justify means? Feminist economics perspectives on the business case for gender equality in the UK labour market». e-cadernos ces 5 (2009). 29 January 2020. <https://journals.openedition.org/eces/298>

Thomson, Emily, and Naveed Hakeem. «Gender equality pays: the economic case for addressing women's labour market inequality». Glasgow Caledonian University Online, 2016. 21 January 2020. <https://researchonline.gcu.ac.uk/en/publications/gender-equality-pays-the-economic-casefor-addressing-womens-l>

UN General Assembly. United Nations Framework Convention on Climate Change, 1994. 5 February 2020. <https://legal.un.org/avl/ha/ccc/ccc.html>

Weaver, Miles, Steven Paxton, Hock Tan, and Kenny Crossan. «Cultivating responsible business in Scotland through the lens of the Scottish business pledge». Edinburgh Napier University, 2016. 5 February 2020. <https:// www.researchgate.net/profile/Miles_Weaver/publication/298354369_ Cultivating_Responsible_Business_in_Scotland_through_the_lens_of_the_ Scottish_Business_Pledge/links/56e8a4a508ae166360e526c8/CultivatingResponsible-Business-in-Scotland-through-the-lens-of-the-Scottish-BusinessPledge.pdf>.

Feminismo/s 35, junio 2020, pp. 95-125 

To link to this article / Para enlazar con este artículo:

https://doi.org/10.14198/fem.2020.35.05

To cite this article / Para citar este artículo:

Cohen, Sue y Samzelius, Tove. "Through the lens of single parenthood: a comparative snapshot of the impact of neoliberal welfare, housing and employment policies on single mothers in the UK and Sweden». En Feminismo/s, 35 (junio 2020): 127-153. Monographic dossier / Dossier monográfico: A critical practice of thinking otherwise: Bacchi, Gender and Public Policy Analysis, coord. Angela O'Hagan, DOI: 10.14198/ fem.2020.35.05

\title{
THROUGH THE LENS OF SINGLE PARENTHOOD: A COMPARATIVE SNAPSHOT OF THE IMPACT OF NEOLIBERAL WELFARE, HOUSING AND EMPLOYMENT POLICIES ON SINGLE MOTHERS IN THE UK AND SWEDEN
}

\author{
A TRAVÉS DE LA LENTE DE LA MATERNIDAD SOLTERA: \\ UNA INSTANTÁNEA COMPARATIVA DEL IMPACTO \\ DE LAS POLÍTICAS NEOLIBERALES DEL ESTADO \\ DEL BIENESTAR. VIVIENDA Y EMPLEO EN LAS MADRES \\ SOLTERAS DE REINO UNIDO Y DE SUECIA
}

\author{
SUE COHEN \\ University of Bristol, Bristol \\ sue.cohen@bristol.ac.uk \\ orcid.org/0000-0002-8831-7963 \\ TOVE SAMZELIUS \\ Malmö University, Malmö \\ tove.samzelius@mau.se \\ orcid.org/0000-0003-3641-5542
}

\begin{abstract}
The paper considers why feminists working on gender mainstreaming in the UK looked to Sweden for models to effect structural change and why in recent years the models in Sweden are deficient, embodying an ever-increasing blind spot to the socio/economic constraints experienced by single parents, migrant mothers the most marginalised. Referencing academic feminist research in Sweden and the UK, as well
\end{abstract}


Through the lens of single parenthood: a comparative snapshot of the impact of neoliberal welfare, housing and employment policies on single mothers in the UK and Sweden

as participatory research over many years involving single mothers, the paper examines why poverty is more entrenched in the UK: how in both countries neo-liberal trajectories of welfare, employment and housing policies are increasingly similar with exclusionary outcomes; how the position of single mothers acts is a touchstone for persistent intersectional inequalities in both countries. We conclude that by examining welfare, housing and employment policies through the lens of single parenthood, feminists can better re-frame strategies informed by the reproductive economy furthering the socio/economic independence of female headed households.

Keywords: Single mothers; UK; Sweden; Gender analysis; Social Security.

\section{Resumen}

Este artículo estudia por qué las feministas que trabajan en una perspectiva integrada de género en el Reino Unido se han acostumbrado a mirar a Suecia para buscar cambios estructurales efectivos, y por qué en los últimos años los modelos suecos son deficientes, a la vez que ejemplifican un punto muerto cada vez mayor respecto a las limitaciones socioeconómicas que viven las familias monoparentales, siendo las madres migrantes las más marginalizadas. Si tomamos en cuenta tanto la investigación académica feminista como la investigación participativa llevada a cabo en Suecia y el Reino Unido durante muchos años en lo que concierne a las madres solteras, el estudio examina por qué la pobreza está más arraigada en el Reino Unido; cómo ambos países, de trayectorias neo liberales, en cuanto a las políticas de bienestar social, empleo y vivienda, son cada vez más similares y muestran resultados de exclusión; y cómo la situación de las madres solteras es una piedra angular en las persistentes variables de desigualdad y discriminación en ambos países. Consideramos que, si examinamos el bienestar social, la vivienda y las políticas de empleo desde la perspectiva de las familias monoparentales, el feminismo debe reformular estrategias basadas en la economía reproductiva no remunerada que favorezcan la independencia socioeconómica de los hogares encabezados por mujeres.

Palabras clave: madres solteras; Reino Unido; Suecia; análisis de género; Seguridad Social.

\section{BACKGROUND}

Many feminist activists, practitioners and academics working on gender mainstreaming in the UK had previously looked to Sweden for inspiration to effect structural change (Kiernan, Land and Lewis 144). The reasons for this were historical. While many of the fundamental principles underpinning the early

Feminismo/s 35, junio 2020, pp. 127-153 
Through the lens of single parenthood: a comparative snapshot of the impact of neoliberal welfare, housing and employment policies on single mothers in the UK and Sweden

British and Swedish welfare states were based on patriarchal ideologies, the gender regimes began to diverge in the 1960s. The booming Swedish post-war economy opened up new opportunities for women, who were encouraged to enter the labour market. To support the increasing number of mothers moving into paid employment at the time, a host of «family friendly» policies were introduced and publicly funded childcare was expanded, benefiting single mothers and their children.

The guiding principle of social policy towards single mothers in Sweden has, since, the 1970s, been one of integration and inclusion within policies for gender equality and labour market participation. To a large extent it was the combination of labour-market participation, redistribution and support services that enabled a majority of single mothers to escape the poverty trap (Hobson and Takahashi 121-139). In contrast, single mothers in the UK endured high rates of unemployment and poverty, effectively abandoned by the state under Conservative rule 1979-1997. Many also faced discrimination on the housing and labour markets due to their status as «single». The Swedish model was seen to come closest to solving the economic problems of one parent families, compared to the UK where gendered inequality was proving especially harmful to one parent families. The more unequal the society, the greater the difference between men and women and the greater the difference between rich and poor, the worse single parents seemed to be doing (Kiernan, Land and Lewis 138-145), a virulent contagion where patriarchy and poverty enmesh.

In the UK, a male worker model continued to underpin employment policies up to the end of the $20^{\text {th }}$ century. Women had always been present in the workplace, but to succeed many had to become like men, working long hours, with little flexibility, or if they were mothers, settle for part-time low paid employment that could be organised around childcare needs. For two parent families, this was eased somewhat with a male earner in the family. However, single mothers were particularly disadvantaged given that the infrastructure of the work place had historically failed to integrate the needs of parents or indeed motherhood into the equation (Kiernan, Land and Lewis 242-275). There was some progress under New Labour including tax credits and greater investment in childcare provision. Progressive improvements in employment protections were also fought for and achieved by women

Feminismo/s 35, junio 2020, pp. 127-153 
Through the lens of single parenthood: a comparative snapshot of the impact of neoliberal welfare, housing and employment policies on single mothers in the UK and Sweden

NGOs and Trade Union movements at a national and EU level. Single Parent Action Network was part of that movement (Select Committee on Work and Pensions, Memorandum submitted by Single Parent Action Network; Wright and Giullari). The UK was on the cusp of developing an adult worker welfare state that was beginning to include women and care into the equation (Annesley 9-12). However, although New Labour's program represented an improvement for many single mothers, it should also be understood in the broader context of international welfare reform programmes designed to dis-incentivise «welfare dependency». Furthermore, the neoliberal Coalition and Conservative governments' austerity project that followed the Labour government after 2010, and continued the thrust to get more people into work whilst slashing public services by up to $50 \%$, undermined any advances. Single parents and black and minority ethnic women have been the hardest hit (Hall et al.). The adult worker model now prevails, with care no longer on the political agenda (Pearson; Van Lancker).

On the surface, active welfare policies targeting workless single mothers in the UK might appear far removed from the policy context of Sweden where single mothers were already expected to work and where universal affordable childcare continues to cater for the needs of a majority of working parents. However, as we will argue in this paper, there are also worrying similarities, in particular when examining the situation of single mothers disadvantaged by discriminations inherent in class, ethnicity and citizenship status. The ideological underpinnings and the punitive nature of workfare policies targeting marginalized single mothers in both countries are more and more alike. Furthermore, in both countries the most vulnerable single mothers and their children are facing the brunt of a housing crisis that is pushing many into destitution.

\section{FEMINIST CRITIQUES OF THE NEOLIBERAL WELFARE STATE}

In the late 1980s, Nancy Fraser («Women, Welfare» 103) had argued that «social-welfare struggles should become more central for feminists» yet again. She predicted that battles over social spending would soon come to dominate national politics in every late-capitalist welfare state in Western Europe and North America. Women, Fraser said, comprised the overwhelming majority 
Through the lens of single parenthood: a comparative snapshot of the impact of neoliberal welfare, housing and employment policies on single mothers in the UK and Sweden

of social-welfare programme recipients and employees, and therefore would become the main victims of what some analysts had dubbed 'the coming welfare wars'. Fraser concluded that this would lead to what Diane Pearce (28-36) has referred to as the «feminization of poverty». Single mothers, in particular those with weak material and social capital would be hit the hardest.

Over the past 30 years, these «welfare wars» have led to the restructuring and retrenchment of welfare states across Western Europe and North America instigated through neoliberal reforms. During the same period changes in the labour market have led to both the erosion and intensification of gender differences (Fudge and Cossman 24-30). On the one hand, shifts in the labour market have led to a convergence of female and male labour market experiences that are to some extent more polarized in relation to class and ethnicity rather than gender. On the other hand, the intensification of gender differences is more evident in the care and service sectors, where high numbers of women are in low-paid, precarious and often part-time employment (Bezanson 27-40). The gender pay gap remains a constant, over and above these shifts and changes.

Coupled with these changes in the labour market (where increased female participation is often cloaked in a language of gender equality), feminists have critiqued the state's reduction in welfare redistribution that has led to a deficit in «time to care», particularly difficult for low-income single mothers (Fraser, «Capitalism's»). While middle-class women are able to deal with the «care-gap» by buying time through domestic services, this is not an option available to those with less resources and means. Furthermore, although the transformation of social policy is described in terms of shifts of power from the state to the market, and in responsibility from public to private domains, the neoliberal state also develops new regulatory interventions that privilege the market to the detriment of care-giving. Indeed, as argued by Feldman:

While it (neo-liberalism) embraces laissez-faire and promotes the market as an ideal to be championed in all spheres of life, in practice it offers harsh treatment for those at the bottom of the socio-economic order, who do not meet the threshold requirements for being able to be successful market actors (344).

The increased pressure on «the regulation of time» is an issue encountered in our past and present research projects involving low-income single mothers 
Through the lens of single parenthood: a comparative snapshot of the impact of neoliberal welfare, housing and employment policies on single mothers in the UK and Sweden

(Samzelius, Family homelessness 76; Cohen et al. 71-72). This is not only a problem when balancing employment with care. The process of negotiating state regulatory controls can in itself become a stressful, time-consuming exercise. As pointed out by our colleagues in the Productive Margins programme:

In experiential co-produced research participants with experience of poverty are having to negotiate a myriad of regulations in a state controlled environment in which «multiple regulatory domains criss-cross, fragment and overlap.» (McDermont et al. 189)

Policies in the areas of housing, social security, employment and child welfare traverse in complex ways the lives of disadvantaged single mothers (Murphy 250). Yet failure to move forward tends to be cast in terms of a parent's «individual responsibility» (Samzelius, Family homelessness 231). This is the real-life outcome of a persistent discourse and ever-increasing process of individualisation that has spread from one advanced welfare state to another since the 1980s (Giddens; Dwyer; Beck and Beck-Gernsheim). Welfare recipients are nowadays expected to free themselves from need through «a form of self-actualization that revolves around personal responsibility, choice and autonomy» (Mik-Meyer and Villardsen 4). If, as argued by Nancy Fraser, the present strains on care are not accidental, but rather «a more or less acute expression of the social-reproductive contradictions of financialised capitalism» («Crisis of Care?» 22), the impact of individualisation on power-inferior groups might be more detrimental than recognised in political discourses.

Social reproductive conditions for capitalist production have historically assumed different institutional forms and embodied different normative regulatory controls. However, the status of single mothers unable to sustain their families remains unresolved. When inherent inequalities in market economies with regard to gender, ethnicity, class and disability intersect in the lives of one parent families, they struggle to maintain financially secure households. Over time «the problem» of single motherhood has been dealt with by the state through different normative modes. Historically, in both Britain and Sweden, until redistributive welfare policies enabled single women with children to form separate households, the «solution» to «the problem» was often fostering or adoption, while the mother was shamed in to silence. Today, despite an increased societal acceptance of single motherhood, the status of poor single mothers as an anomaly within the capitalist system has

Feminismo/s 35, junio 2020, pp. 127-153 
Through the lens of single parenthood: a comparative snapshot of the impact of neoliberal welfare, housing and employment policies on single mothers in the UK and Sweden

never been resolved (Samzelius, Family homelessness). The «new solution» is workfare in an increasingly regulated and controlling environment. However, as we will discuss in this paper, the intersection of welfare to work policies and housing regulations can work in perverse ways. Regulations can make it difficult for some single parents to find a job or indeed hold down a job that keeps them out of poverty, whilst at the same time having access to secure housing. This disjuncture threatens some families with displacement/homelessness. In their case, the stated policy intent of welfare-to-work policies backfires, with single parent working mothers especially affected; and when ethnicity and citizenship status also intersect, an ever-increasing number of them are black and minority ethnic (BAME) migrant mothers (Reis, A home of her own 10; Reis, Migrant Women.)

\section{THE RESTRUCTURING OF THE WELFARE STATE AND THE IMPACT ON ONE PARENT FAMILIES IN SWEDEN}

When British feminist activists, practitioners and academics working on gender mainstreaming looked to Sweden for models to effect structural change, it was the parent-worker model that was of key interest: In particular, how it seemed to «resource» single mothers through universal affordable wrap-around childcare, a generous parental leave scheme, and, paid leave to care for sick children. The history of the reconciliation of work and family life can be found in debates during the 1960s. The unequal life circumstances of women from different class backgrounds and in particular the situation of single mothers, were central to these debates, at the same time as the booming Swedish post-war economy opened up new opportunities for women who were encouraged to enter the labour market. This created an opening for Swedish feminists to push for further emancipation. Since the early 1970s, female labour-market participation has been a key component of Swedish gender equality policies (Hobson and Takahashi 121-139).

However, if analysed through a broader political/economic lens, the Swedish parent-worker model was not necessarily created on the basis of emancipatory ideals alone, but also in response to the increased need for labour. As single mothers were absorbed in to a model of general «resourcing», enabling mothers to enter the labour market like other members of 
Through the lens of single parenthood: a comparative snapshot of the impact of neoliberal welfare, housing and employment policies on single mothers in the UK and Sweden

society, they benefited from improved living conditions. The Swedish labour market remained highly structured in terms of gender, with women more likely to work part-time and as well as in the expanding public sector. The fragility of this model would come to the fore as the state-managed Swedish welfare state was shaken to its core when the country was hit by a deep fiscal crisis in the early 1990s. In the following years, resources that had previously facilitated the inclusion of low-income single mothers began to be pulled back by both left- and centre-right governments. Among the lasting effects of the welfare retrenchment that took place was the downsizing of social insurance benefit schemes, pension reforms, and the end of full employment as a defining feature of the Swedish welfare state. Gradually, many key functions within the welfare state -for example the care, education and housing sectors- have been de-regularized, de-centralized and privatized to varying degrees. Sweden also saw a shift in labour market policies from a more uniform approach, to a two-tier system where uninsured adults with means tested benefits are referred to secondary activation measures, very similar to those developed in austerity Britain. This latter approach is encapsulated in the discourse on «individual responsibility» and «active citizenship» (Sainsbury and Morrisen).

In the early $21^{\text {st }}$ century, it is clear that those who lost out as a result of these reforms were single mothers and Sweden's refugee population (Gähler; Fritzell, Gähler and Nermo). The proportion of single parents (the vast majority mothers) with a migrant background and low income standard increased from 20\% in 1998 to 56\% in 2017. Single parents born in Sweden (Swedish born) have also been affected, with an increase in those on low income from 9\% in 1998 to $27 \%$ in 2017. During the same period, low income among Swedish-born two-parent households remained consistent around 5\% (Försäkringskassan 9). Between 2003 and 2008, the share of single mothers in temporary employment increased from $12.6 \%$ to $17.5 \%$, whilst decreasing for mothers with a partner from 11.8 to 9.6\% (Jaehrling, Kalina and Mesaros 95).

This means that single mothers are at greater risk of redundancy and have more unstable employment patterns. In a study comparing the prospects for single mothers in France, Germany, Sweden and the UK, Karen Jaehrling, Thorsten Kalina and Leila Mesaros (98) have argued that the overall poverty rate among single mothers in Sweden is lower than elsewhere due to high

Feminismo/s 35, junio 2020, pp. 127-153 
Through the lens of single parenthood: a comparative snapshot of the impact of neoliberal welfare, housing and employment policies on single mothers in the UK and Sweden

levels of full-time employment. However, the relatively low level of income benefits and income protection (through social assistance) makes them vulnerable and increases the risk of poverty in the event of under-employment/ unemployment. Although labour-market participation rates are consistently high, the risk of poverty in this group has risen sharply over the past 20 years, an indication of the policy's limitations.

A recent study conducted by Susan Alm, Kenneth Nelson and Rense Nieuwenhuis, shows the link between welfare state retrenchment and the rising poverty of single-adult households in Sweden between 1988 and 2011. The decline in income replacement in the event of unemployment, stringent qualifying requirements, together with the rise in precarious employment, have contributed to a sharp increase in relative income poverty among unemployed single-earner households (with and without children) in comparison with dual-earner households. The downsizing of old forms of income replacement policies stand in sharp contrast to the development of Swedish work and family reconciliation policies that are mainly benefitting middle-class families, and which have been further expanded.

Those who fail to qualify for first-line benefits are forced to turn to the social assistance scheme for subsistence. There is clear evidence that the cuts to the welfare state initiated in the 1990s have resulted in a 'shift in burden' from social security to means-tested social assistance (Salonen, Övervältringar). Single mothers are over-represented among recipients of social assistance in Sweden and are also more likely to rely on benefits for longer periods of time, making their families particularly vulnerable to persistent poverty and deprivation (Stranz and Wiklund 270). This is problematic for those affected as Sweden makes virtually no exceptions in the means-tested system. You cannot own anything, including a car or a flat, to be eligible for assistance, nor have savings. Assessments are based on a claimant's financial situation rather than needs. Secondly, there is often a stigma attached to means-tested and selective benefits targeting the poor (Sunesson et al. 19). The right to social assistance in Sweden is still built on poor-relief foundations, the idea that relief can never be a right. Fundamental characteristics of the Swedish social assistance scheme are «the duty to accept any job; a willingness to relocate to find work; means testing; discretionary implementation by local officials; 
Through the lens of single parenthood: a comparative snapshot of the impact of neoliberal welfare, housing and employment policies on single mothers in the UK and Sweden

and sanctions if the claimant refuses any of the recommended measures» (Panican and Ulmestig 485).

Despite Sweden's image as «child-friendly», several Swedish studies have shown that decision-making can vary significantly from case to case and that the well-being of children becomes secondary to the activation of their parents (Samzelius, «Ensamstående mammor»; Näsman). The discretionary and localized implementation of welfare conditionality targeting social assistance recipients in Sweden means that activation measures and sanctions are not recorded systematically. Instead, the focus is often placed on caseload reduction and budget savings which means that we know very little about the actual impact on parents and children (Hjort). Interviews with single mothers in the region of Stockholm conducted between 2017 and 2019 however, have uncovered some deeply problematic decisions. For example, homeless mothers have been sanctioned and financial assistance for emergency accommodation has been withdrawn even in situations out of their control, they are still deemed to have broken their claimant commitments (Samzelius, «Ensamstående mammor»).

Neoliberal welfare policies in Sweden target claimants who fail to qualify for the more generous contribution-based income replacement schemes administered through trade unions and the National Insurance Agency. Unlike the UK, that has never developed a parent-worker model, Sweden has continued to resource family friendly policies through generous parental leave, universal access to affordable wrap-around childcare and social security measures that enable working parents to stay at home to look after sick children. Yet, as pointed out by numerous Swedish welfare scholars, such policies primarily benefit parents who are already established in the labour market and exclude those employed in the expanding part-time service and care sectors where zero-hour contracts are rife (Roman; Salonen, Välfärd; Wennberg). In Sweden, unlike its Anglo-Saxon counter parts, the middle-classes (including more established single mothers) are for the time being more protected from crises as described by Fraser ( Crisis of Care?»). This, we argue, has laid the ground for a peculiar form of «poverty blindness» that serves to protect the privilege and status of those who are already «established» in the labour and housing markets, whilst silently excluding the most marginalized one parent families (Samzelius, Family homelessness). 
Through the lens of single parenthood: a comparative snapshot of the impact of neoliberal welfare, housing and employment policies on single mothers in the UK and Sweden

\section{THE RESTRUCTURING OF THE WELFARE STATE AND THE IMPACT ON ONE PARENT FAMILIES IN THE UK}

During the Thatcher and post Thatcher periods under Conservative rule 1979-1997, high numbers of single parents were overly dependent on social security, existing in deeply embedded poverty, stigmatized by political and media discourses. Many single parents wanted to move into paid work but with structured unemployment, and without investment in the childcare infrastructure, this proved deeply challenging (Millar and Ridge; Kiernan, Land and Lewis). When the Labour Government came to power in 1997, $55 \%$ of single parents were not in paid employment (Coleman and Lanceley).

Since that time there has been rapid change. Successive Labour, Coalition and Conservative governments proselytized work as the route out of poverty. By 2019, 69.9\% of single parents were in paid employment (Office for National Statistics, Families). Nevertheless, under Conservative rule single parents have experienced the fastest rise in in-work poverty in the UK, with three in ten employed single parents in poverty by 2018 compared to two in ten in 2010/11 (Joseph Rowntree Foundation UK Poverty 2019/20 31). Whereas Conservative governments in the 1980s and 1990s consigned single parent mothers to welfare dependency, under austerity, neo-liberal driven social welfare policies were re-regulated, with single parent families a specific target. Welfare-to-work policies may mean that single parents are now more likely to be employed, yet at the same time more likely to be trapped within a pernicious intersection of new benefits, housing and employment regulations which together with austerity cuts to public services leave their families increasingly vulnerable to poverty and deprivation (Cohen, The Punitive Impact; Hall et al.).

Although neo-liberalism purports to further the relaxation of regulatory controls, an inherent contradiction in what Feldman describes as the duplicity of the ideology, is that this is belied by the regulation of those in poverty (Feldman 341). Deregulation is designated for the market. Rather than a reduction in the role of the state, the UK neoliberal state now polices single parents, forcing them into employment whilst at the same time reducing state investment in those social infrastructures that would better support caring 
Through the lens of single parenthood: a comparative snapshot of the impact of neoliberal welfare, housing and employment policies on single mothers in the UK and Sweden

responsibilities, time management and family life (Hall et al.). Childcare has largely been handed over to the market.

The Welfare Reform Act 2012 and the roll out of Universal Credit since that time have placed employment over the welfare of the child. Those single parents with young children are the hardest hit, with their mental health particularly affected. (Webb 1). Up until 2008 single parents with children under 16 were not required to work. However, after 2008 the limit was gradually lowered, to 12 and then 7 under the Labour government. The drive to get single parents into work accelerated under the austerity measures of the Coalition government with the limit lowered to 5 years in 2012 and under Conservative rule lowered even further in 2017 for single parents with children over 3. Those single parents not in employment can be sanctioned if judged to be non-compliant with stringent welfare regulations. Yet at the same time they receive the highest proportion of unfair sanctions. From 2012 when the new rules were introduced to $2016,62 \%$ of formal challenges to single parent benefit sanctions were successful. In spite of this success, many of these same families were left in long-term debt (Rabindrakumar 20).

The expectation for parents with young children to be in paid work may have been paralleled in Sweden for many more years, but what is not paralleled is Sweden's significant investment in childcare. The closing of up to 1000 Children's Centres in the era of austerity has meant that quality, accessible childcare in disadvantaged areas is presently at crisis point in the UK (Smith et al.). Under the Labour Government, the welfare of children was better protected, not least because there was state investment in Children's Centres and children were of school age before a single parent was required to work. Cuts to public services and welfare reform under the successive Coalition and Conservative governments have removed those protections.

By 2018, nearly half (49\%) of children in single parent families lived in poverty, compared with one in four in two parent families (25\%) (Joseph Rowntree Foundation, UK Poverty 2018 33). Mothers head 9 out of 10 single parent families in the UK. With tax and benefit changes and cuts to public services, it is estimated that between 2010-2020 they will have experienced an average drop in living standards of $18 \%$ per annum $(£ 8,790)$. Black and Asian households in the lowest fifth of incomes are expected to experience the biggest average drop in living standards of $19.2 \%$ and $20.1 \%$, respectively.

Feminismo/s 35, junio 2020, pp. 127-153 
Through the lens of single parenthood: a comparative snapshot of the impact of neoliberal welfare, housing and employment policies on single mothers in the UK and Sweden

The intersection of structural inequalities further impedes their life chances. Discriminations borne as a result of gender, class, race, citizenship and disability are much more likely to intersect than in two parent families. Single parents are more likely to be disabled (27\%), and more likely to have disabled children (16\%). 19\% of single parents have a BAME background, compared with $14 \%$ of people in the UK (Hall et al.).

Job Centre rulings too often drive single parents into inflexible low paid employment, bringing more problems than solutions, especially when trying to balance childcare (Treanor 65). Over two thirds of single parents enter the three lowest paid occupations (Gingerbread Employment). When compulsory welfare into work measures were first introduced for single parents with children over 7, SPAN and the University of West of England tracked their journey. Of those single parents who found work, all entered the lowest paid jobs - whatever their qualifications - some had degrees but all ended up in cleaning, childcare, and supermarkets (Haux et al. 55-63). Limited social mobility follows from these roles.

Five in every six people in low-paid work fail to escape low pay over 10 years. Barriers to increasing pay can be even greater for those with family responsibilities. Caring for children can limit the number of hours you can work and the distance you can travel for work. (Joseph Rowntree Foundation, UK Poverty 2018 2).

Time poverty as well as material poverty has also become a significant issue for many working single parents.

A single parent on a zero-hours contract will be denied autonomy over parenting time at the same time as earning low and precarious wages. Here, there is no compensating upside. It is the worst of both worlds (Calder 421).

Conversely, under previous Conservative governments single parent members of SPAN for example, had more time for childcare and more space to develop supportive social networks, acting as a form of resistance to stigma and discrimination (SPAN). Now there is little space for self-help groups or collective action. The regulation of time imposed by legislation and prevailing power structures has a knock-on effect on single parents' ability to decide how to use their own time as well as their ability to dissent. If they dissent they may 
Through the lens of single parenthood: a comparative snapshot of the impact of neoliberal welfare, housing and employment policies on single mothers in the UK and Sweden

be punished through sanctions. If they are sanctioned, they have no money to feed their children (Cohen et al. 72).

The introduction of Universal Credit has meant that single parents with children over three are less likely to be prepared for moving into employment than they were a few years ago. They have less time to study, less time to volunteer and develop vocational and non-vocational networks, less time to develop informal childcare support. The Social Security Advisory Committee to the Department of Work and Pensions understood that informal networks helped single parents take control of their lives but that they were largely invisible to Job Centre service providers (Gray and Timmins).

Embedding children's welfare and care in to welfare policies and the delivery of those policies, would help Job Centre advisors to better understand and support the informal networks that sustain and nurture one parent families (Haux et al. 113) and go some way to stemming the deterioration in the lifechances of one parent families with young children. Exemplifying Pearson's assertion that caring responsibilities are not the responsibility of the neoliberal state, Job Centre service providers are required by the neoliberal welfare state to regulate their clients' conduct so that it aligns more closely with the requirements of the market, in particular that they accept individual responsibility for their own poverty (Feldman).

\section{THE FINANCIALISATION OF HOUSING: IMPACT ON ONE PARENT FAMILIES IN SWEDEN AND THE UK}

It is in the everyday struggle involved in working to maintain an independent household, that the unequal positioning of single mothers in poverty is most evident and most difficult. Keeping a roof over one's head is part of that struggle. Although there have been many studies on the impact of welfare and employment policies on single parent families, housing policies have not received the same focus. And yet neo-liberal economic policies that have led to the financialization of housing now intersect in malign ways with the restructuring of welfare in both Sweden and the UK.

In our view, contemporary accounts of poverty in Sweden and the UK can underestimate the complexity of outcomes when housing regulations intersect with social security, employment, and child welfare regulations, increasing 
Through the lens of single parenthood: a comparative snapshot of the impact of neoliberal welfare, housing and employment policies on single mothers in the UK and Sweden

the number of female-headed households that suffer from homelessness and housing exclusion in both countries. (Murphy; Baptista; Bretherton; Mayock, Bretherton and Baptista). There is a growing body of evidence that the experience of homelessness is differentiated by gender, citizenship status and ethnicity (Baptista et al.; Bretherton; Warburton, Whittaker and Papic; Reis, A home of her own). Family homelessness is often hidden or concealed due to a combination of factors including inadequate institutional responses, and the informal strategies used by many mothers in their attempts to find shelter (Baptista; Pleace; Mayock et al.). Migrant women with no recourse to public funds are especially affected in the UK (Reis, A home of her own 36). Likewise evaluation reports in Sweden have shown that where family homelessness is on the increase, families headed by a single migrant mother are disproportionally overrepresented (Samzelius, En plats att kalla hemma). In the latest mapping exercise conducted by the municipality of Stockholm in April 2019, 50\% of the homeless families recorded were headed by a migrant single mother (Samzelius, Family homelessness).

\subsection{Sweden}

From the 1930s to the 1990s, public housing in Sweden was a key element in the country's ambition to construct a housing system that would secure high-quality, affordable housing for all. However, the past 30 years have seen politically initiated changes that have altered the function of the public housing market, in particular in greater Stockholm. The national housing policy has more or less disappeared and left municipalities to decide locally what the public housing sector will look like. Inspired by the British right-to-buy scheme introduced in the 1980s, the Swedish Liberal-Conservative government through a formal decision in 1992, allowed municipalities to convert public rental housing into different market forms. In some municipalities in and around metropolitan Stockholm this meant that all, or at least substantial parts of, the public housing stock was sold off to private housing companies or converted to market-based tenancy owned cooperatives.

During the 21st century, low-income families have found it increasingly difficult to establish themselves in the housing market, especially in the larger cities. Single parent households renting homes in urban areas are struggling 
Through the lens of single parenthood: a comparative snapshot of the impact of neoliberal welfare, housing and employment policies on single mothers in the UK and Sweden

the most (Boverket, Boende till rimlig kostnad). Brett Christophers (885886) refers to the contemporary Swedish housing system as a 'monstrous hybridity'. He argues that it is the housing market's mixed political-economic character that helps to explain why the current Swedish housing system has become so detrimental to the country's most disadvantaged groups. The absence of institutional coordination at a regional level has meant that each municipality has pursued their own housing agendas, which in most cases has been about attracting the middle class, resulting in an underinvestment in affordable rental-housing (Andersson and Magnusson Turner). Although tenancy rights for sitting tenants are strong, direct discrimination based on income and number of household members is legal and creates particular problems for single-earner households with children.

As a result, a growing number of families are unable to access housing through the regular housing market. Instead, they have to look for housing on the unregulated, expensive and insecure sublet market. Between 2009 and 2017, the rents for secondary sublet properties increased by $59 \%$ and for cooperative flats by $84 \%$. This was 3-4 times more than the increase in household incomes. As a result, more and more single parent families are forced to double up with friends or family or can only afford to rent a single room in a shared flat (Boverket, Uppdrag att följa utvecklingen). Lacking secure tenancies or contracts they are not eligible for housing benefits. Families that live under such circumstances are not officially counted as homeless and overall, knowledge about numbers of families affected and their living circumstances is limited (Samzelius, Family homelessness; Listerborn).

An increasing number of families, the vast majority headed by a single mother, are turning to social services for help. Those categorized as in 'acute homelessness' during a week of national mapping in 2017 had increased by $60 \%$ since the previous count six years earlier (Socialstyrelsen). However, unlike the UK, in Sweden there is no statutory duty to assist families that are at risk of homelessness. Instead, we are seeing a worrying trend where families with children are categorised as only eligible for short-term emergency assistance, expected to solve their own housing situation on the sublet market. This includes survivors of domestic violence, who are only entitled to short-term support in acute situations. When leaving a women's shelter, they are expected to find housing by themselves (Ekström). Those who fail to find

Feminismo/s 35, junio 2020, pp. 127-153 
Through the lens of single parenthood: a comparative snapshot of the impact of neoliberal welfare, housing and employment policies on single mothers in the UK and Sweden

housing through this route are, in greater Stockholm for example, pushed to take up housing offered by «slum landlords» in the Swedish countryside far away from social networks and with few employment opportunities. Wealthy urban local authorities tend to use the «housing shortage» as an excuse for pushing poor residents into other municipalities. The intersection between inadequate income protection, poor employment conditions, inadequate housing options and the lack of response from public authorities are thereby contributing to the destitution of vulnerable single mothers and children (Samzelius, Family homelessness).

\section{$5.2 \mathrm{UK}$}

In the UK the financialization of housing, together with the longer term trend that began in the Thatcher period of selling off social housing in less prosperous neighbourhoods, is leading to increasing gentrification in areas where many one parent families have settled. Single parent households based in high rent areas in major cities in the South of England for example, have become victims of growing gentrification, leading to their displacement, often to other parts of the country, dislocated from schools, family and friends. This is because more recent welfare reforms have seen the introduction of both a «bedroom tax» limiting the number of bedrooms a family is entitled to, and a housing benefit cap limiting the amount that can be claimed in high rent areas. Some tens of thousands of low-income families are forced out of their long-term homes, so that the properties can either be sold, or rented at market prices, seen by some as a form of «social cleansing» (Taylor 1). Given that one-parent families are more likely than ever to live in rented accommodation single parents are more likely to be subject to the benefit cap in high rent areas.

The intersection of housing and social security regulations is proving overtly discriminatory to single parents with children under 5. In a perverse ruling, single parents can escape the housing benefit cap if they work over 16 hours a week. But this applies to all single parents whatever the age of the children. Thus, the reality for single parents with children under school age is that they either have to work over 16 hours a week, or if they do not have access to childcare, they are forced to either move outside of their area 
Through the lens of single parenthood: a comparative snapshot of the impact of neoliberal welfare, housing and employment policies on single mothers in the UK and Sweden

and/or be made homeless. 38,390 single parent families were made homeless after the introduction of the cap, accounting for $63 \%$ of all homeless families, a rise of 54\% over the five-year period from when the benefit cap was first introduced. (Cohen, The Punitive Impact; Rich 2018).

According to data from Gingerbread, under legacy benefits, three-quarters (76\%) of these capped single parents' youngest children were of pre-school age (under five years) and therefore not subject to full job-seeking conditions under work-related benefit rules, despite the government's intentions with the benefit cap. A third (31\%) of capped single parents had a youngest child aged two or under. (Benefit-cap 1-2)

Single mothers with experience of abuse are particularly at risk, increasingly isolated by welfare and housing policies from the supportive social networks that have often proved critical to leaving abusive relationships. The association between single parenthood and abuse is too rarely made. Many members of SPAN became single parents in order to escape violence and abuse. In 2018, 52\% of respondents answering a questionnaire on singleparents.org.uk, a website set up by SPAN, cited domestic violence and abuse as the cause of their single parenthood.

The Office of National Statistics reported that a fifth (20.5\%) of single women with children said they had experienced abuse from a partner in the previous 12 months, compared with 4.9 per cent of women living with other adults and children (ONS, Domestic abuse). The period when a woman is planning or making her exit is often the most dangerous time for her and her children (Femicide Census 9). Many mothers are not alive today because they were not able to leave their partners.

The inability of low-income mothers experiencing abuse to forge and sustain independent female-headed households is resulting in either homelessness or continuing entrapment in abusive relationships. Women are more likely to go back to an abusive partner if they are living in poverty. Under austerity major cuts in publically funded support services are taking their toll. $64 \%$ of refuge referrals were declined in 2019 (Women's Aid 33). If women do leave, many end up homeless.

This is particularly the case for migrant mothers, many of whom came into the UK on family visas, dependent on a male partner that can increase the likelihood of coercion and violence. Those mothers declined places in a 
Through the lens of single parenthood: a comparative snapshot of the impact of neoliberal welfare, housing and employment policies on single mothers in the UK and Sweden

refuge are very often migrant women with «No Recourse to Public Funds» (NRPF) status: The options left to them - return to the abuser, dependency on friends and acquaintances, or other risky means of survival (Reis, Migrant Women 7).

\section{WAYS FORWARD FOR A MORE GENDER EQUAL SOCIETY? FOCUSING THE LENS ON SINGLE PARENT MOTHERS}

The level to which single parents are able to establish and maintain independent households is a good indication of the level of equality within society with regard to gender, ethnicity, class, disability, and citizenship status. The fact that the UK is doing so poorly in these arenas, explains why one parent families are faring so badly given the impact of intersectionality on their life chances (Hall et al.). Although not on the same scale, one parent families in Sweden are beginning to face comparable exclusions. The detail and history of welfare reform may differ between the two countries: Single parents in the UK are now more highly regulated and controlled by social security systems than at any other time in the history of welfare delivery. In Sweden, the retrenchment of the welfare state is leading to the most marginalised one parent families falling through the safety net. More generally however, the broader trajectories of welfare reform, liberalization of the housing market and the increase in single parent poverty are not that dissimilar, in spite of Sweden's more gender-equal back-story.

Equality protections for new migrants have been downgraded in both countries. We are seeing the largest migration of peoples across the world since the Second World War, yet very little research has been undertaken on the intersectional impact of housing, social welfare and employment policies on refugee and migrant single parent families in the UK and Sweden, or indeed in other EU countries. Research critical to progressing women's economic and social independence in any given country will need to take these changing demographics into account. Otherwise, furthering gender equality even in more gender equal settings will inevitably be partial, and of benefit to women who are established citizens already well protected by employment and economic and social infrastructures, whilst excluding those outside of those protections. 
Through the lens of single parenthood: a comparative snapshot of the impact of neoliberal welfare, housing and employment policies on single mothers in the UK and Sweden

We can see that in Sweden, with the protections of state feminism complacency may have set in. Here the Nordic model is not immune to the neo-liberal policies of the housing market, the racialization of the labour market and the feminization of poverty. If we look at welfare to work and housing policies through the lens of single parenthood, we see in this snapshot a very different picture to the more gender equal society that Sweden has been famed for.

Many feminists are developing socio/economic strategies over and above what it takes to succeed in the labour market. The Women's Budget Group (WBG) in the UK prioritises the Reproductive Economy as the way forward whereby giving and receiving care is central to life, central to being human, and central to the economy. In a neoliberal economic construct, GDP fails to take account of women's reproductive and caring roles. If we deconstruct the economy, we see that it is underpinned by the production and reproduction of people; that the unpaid work of women is central not only to the economy, but to the well-being of children and future generations. (Women's Budget Group, What is Feminist Economics?; Pearson).

Countering the intersectional discriminations of gender, class, ethnicity, citizenship and disability will be central to the restructuring of socio/economic infrastructures in a reproductive/care economy. Single mothers can be seen as ciphers in this respect. Focusing the lens on single mothers and the strategies needed to develop autonomous households, becomes a feminist way forward, given that multiple discriminations are much more likely to intersect in one parent families than in two parent families.

Our vision for the future, and the contribution of this article to wider debate therefore is for female headed households and mothers more generally, no matter their class, ethnicity or status, to have greater control in furthering their own and their families' well being and life chances.

\section{REFERENCES}

Alm, Susan, Kenneth Nelson, and Rense Nieuwenhuis. «The Diminishing Power of One? Welfare State Retrenchment and Rising Poverty of Single-Adult Households in Sweden 1988-2011». European Sociological Review (2019): 1-20. DOI: $10.1093 /$ esr/jcz053 
Through the lens of single parenthood: a comparative snapshot of the impact of neoliberal welfare, housing and employment policies on single mothers in the UK and Sweden

Andersson, Roger and Lena Magnusson Turner. «Segregation, gentrification, and residualisation: from public housing to market-driven housing allocation in inner city Stockholm». International Journal of Housing Policy 14. 1 (2014): 3-29. DOI: 10.1080/14616718.2013.872949

Annesley, Claire. State Feminism in New «Adult Worker Model» Welfare States? Paper presented to the ECPR Joint Sessions of Workshops. April 14-19, 2005. Web. 7 May 2020. https://ecpr.eu/Filestore/PaperProposal/aaf80081-2d7b4780-a8d4-e192c61ee8df.pdf

Baptista, Isabel. «Women and Homelessness». In Homelessness Research in Europe. Eds. Eoin O'Sullivan, Volker Busch Geertsema, Deborah Quilgars and Nicholas Pleace. Brussels: FEANTSA, 2016. 163-186

Baptista, Isabel, Lars Benjaminsen, Volker Busch-Geertsema, and Nicholas Pleace. Family homelessness in Europe. EHO Comparative Studies on Homelessness. Brussels: European Observatory on Homelessness, 2017. https://www.feantsaresearch.org/download/feantsa-studies_07_web3386127540064828685.pdf Boverket. Boende till rimlig kostnad Hushållens boendeutgiftsprocent och konsumtionsutrymme. Rapport 2016: 11.

https://www.boverket.se/globalassets/publikationer/dokument/2016/ boende-till-rimlig-kostnad.pdf

Boverket. Uppdrag att följa utvecklingen på andrahandsmarknaden. Rapport 2018: 29. https://www.boverket.se/globalassets/publikationer/dokument/2018/ utvecklingen-pa-andrahandsmarknaden.pdf

Beck, Ulrich, and Elisabeth Beck-Gernsheim. Individualization: Institutionalized Individualism and Its Social and Political Consequences. London: SAGE Publications, 2002.

Bezanson, Kate. Gender, the State, and Social Reproduction: Household Insecurity in Neo-liberal Times. Toronto: University of Toronto Press, 2006.

Bretherton, Joanne. «Reconsidering Gender in Homelessness». European Journal of Homelessness 11. 1 (2017): 1-21.

Cain, Ruth. «Responsibilising recovery: Lone and low-paid parents, Universal Credit and the gendered contradictions of UK welfare reform». British Politics. 11. 4 (2016): 488-507.

Calder, Gideon. «Social justice, single parents and their children». In The triple bind of single-parent families. Resources, employment and policies to improve wellbeing. Eds. Rense Nieuwenhuis and Laurie C. Maldonado. Bristol: Policy Press, 2018. 
Through the lens of single parenthood: a comparative snapshot of the impact of neoliberal welfare, housing and employment policies on single mothers in the UK and Sweden

Christophers, Brett. «A Monstrous Hybrid: The Political Economy of Housing in Early Twenty-first Century Sweden». New Political Economy 18. 6 (2013): 885-911.

Cohen, Sue. The Punitive Impact of Universal Credit on the Life Chances of Single Parents with Children Under 5. Women's Budget Group 13th May 2019. Web 7 May 2020.

Cohen, Sue, Allan Herbert, Nathan Evans, and Tove Samzelius. «From poverty to life chances: framing co-produced research in the Productive Margins programme». In The impact of co-production: From community engagement to social justice. Ed. Aksel Ersol. Bristol: Policy Press, 2017. 61-84.

Coleman, Nick, and Lorraine Lanceley. Lone parent obligations: supporting the journey into work. Department of Work and Pensions (DWP), 2011. https:// dera.ioe.ac.uk/3010/1/rrep736.pdf

Dwyer, Peter. Welfare rights and responsibilities: Contesting social citizenship. Bristol: Policy Press, 2000.

Ekström, Veronica. «Behovet av stöd till våldsutsatta kvinnor». In Manifest för ett social arbete i tiden. Eds. Magnus Dahlstedt and Philp Lalander. Lund: Studentlitteratur, 2018. 113-124.

Elliott, Larry. «Gordon Brown: I didn't think I'd see child poverty again in my lifetime.» Guardian 14 December 2018. Web. March 172020.

Feldman, Guy. «Neo liberalism and poverty: An unbreakable relationship». In Routletdge International Handbook of poverty. Ed. Bent Greve. London: Routledge, 2019. 340-350.

Femicide Census, 2018. Web. May 7 2020. https://femicidescensus.org/wp-content/uploads/2020/02/Femicide-Census-Report-on-2018-Femicides-.pdf

Försäkringskassan. Barnhushållens ekonomi - resultatindikatorer för den ekonomiska familjepolitiken, 2018. https:/www.forsakringskassan.se/wps/wcm/connect/ bbfe2133-a360-4a7f-b1d5-27e8db8d0ec4/barnhushallens-ekonomi-2018. pdf?MOD=AJPERES

Fraser, Nancy. «Women, Welfare and the Politics of Need Interpretation». Hypatia 2. 1 (1987): 103-121.

Fraser, Nancy. «Capitalism's Crisis of Care». Dissent 63.4 (2016): 30-37.

Fraser, Nancy. «Crisis of Care? On the Social-Reproductive Contradictions of Contemporary Capitalism». In Social Reproduction Theory : Remapping Class, Recentering Oppression. Eds. Tithi Bhattacharya and Lise Vogel. London: Pluto Press, 2017. 
Through the lens of single parenthood: a comparative snapshot of the impact of neoliberal welfare, housing and employment policies on single mothers in the UK and Sweden

Fritzell, Johan, Michael Gähler and Magnus Nermo. »Vad hände med 1990-talets stora förlorargrupper? Välfärd och ofärd under 2000-talet.» Socialvetenskaplig tidskrift 14. 2-3 (2007): 110-33.

Fudge, Judy, and Brenda Cossman, eds. Privatization, Law and the Challenges to Feminism. Toronto: Toronto University Press, 2002.

Gähler, Michael. »Bara en mor: ensamstående mödrars ekonomiska levnadsvillkor i 1990-talets Sverige». In Ofärd i Välfärden. Ed. Ake Bergmark. Stockholm: Fritzes (SOU 2001: 54). 15-97-

Giddens, Anthony. Modernity and self-identity: Self and society in the late modern age. Stanford: Stanford University Press, 1991.

Gingerbread. Employment and skills policy work. Sept 2019. Web. 5 May 2020. https://www.gingerbread.org.uk/policy-campaigns/employment-and-skills/ Gingerbread. Benefit-cap enquiry submission. 10 Sept 2018. Web. 8 March 2020. https://www.gingerbread.org.uk/policy-campaigns/publications-index/benefit-cap-inquiry-gingerbread-written-submission-work-pensions-select-committee/

Gray, Paul, and Nicholas Timmins. Reforming working-age social security: lessons for policy makers. IfG INSIGHT. June 2018. https://www.instituteforgovernment.org.uk/sites/default/files/publications/working-age-social-security-final. pdf

Gregg, Paul, Susan Harkness, and Sarah Smith. «Welfare Reform and Lone Parents in the UK». The Economic Journal 119. 535 (2009): 38-65.

Hall, Sarah-Marie, Kimberly McIntosh, Eva Neitzert, Laura Pottinger, Kalwinder Sandhu, Mary-Ann Stephenson, Howard Reed, and Leonie Taylor. Intersecting Inequalities: The impact of austerity on Black and Minority Ethnic women in the UK. WBG \& The Runnymede Trust, 2017. http://wbg.org.uk/wp-content/ uploads/2018/08/Intersecting-Inequalities-October-2017-Full-Report.pdf

Harkness, Susan. "The Effect of Employment on the Mental Health of Lone Mothers in the UK Before and After New Labour's Welfare Reforms». Social Indicators Research 128. 2 (2016): 763-791.

Haux, Tina, Debra Salmon, Lucy Taylor, Toity Deave, Sue Cohen, Laura Dewar, and Tove Samzelius. A longitudinal qualitative study of the journey of single parents on Jobseeker's Allowance. Project report. University of the West of England and Single Parent Action Network, 2012. Journal of Poverty and Social Justice 20. 3: 337-342. DOI: 10.1332/175982712X657172

Hjort, Torbjörn, ed. Det yttersta skyddsnätet. Lund: Studentlitteratur, 2019. 
Through the lens of single parenthood: a comparative snapshot of the impact of neoliberal welfare, housing and employment policies on single mothers in the UK and Sweden

Hobson, Barbara, and Masahide Takahashi. «The Parent-worker Model: Lone Mothers in Sweden». Lone Mothers in European Welfare Regimes: Shifting Policy Logics. Ed. Jane Lewis. London: Jessica Kingsley, 1997. 121-139.

Jaehrling, Karen, Thorsten Kalina, and Leila Mesaros. «A Paradox of Activation Strategies: Why Increasing Labour Market Participation among Single Mothers Failed to Bring Down Poverty Rates». Social Politics: International Studies in Gender, State \& Society 22. 1 (2015): 86-110.

Joseph Rowntree Foundation. UK Poverty 2018: a comprehensive analysis of poverty trends and figures. Web. April 172020.

Joseph Rowntree Foundation. Budget 2018: Tacking the rising tide of in-work poverty. jrf.org.uk, 12 ${ }^{\text {th }}$ Oct 2018. Web. April 172020.

Joseph Rowntree Foundation. UK Poverty 2019/20: Work. 2020. Web. April 17 2020.

Kiernan, Kathleen, Hilary Land, and Jane Lewis. Lone Motherhood in TwentiethCentury Britain. Oxford: Clarendon Press, 1998.

Lewis, Jane, ed. Lone Mothers in European Welfare Regimes: Shifting Policy Logics. London: Jessica Kingsley, 1997.

Lister, Ruth. «She Has Other Duties- Women, Citizenship and Social Security.» In Social Security and Social Change: New Challenges to the Beveridge Model. Eds. Sally Baldwin and Jane Falkingham. New York; London: Harvester Wheatsheaf, 1994. 31-44.

Listerborn, Carina. Bostadsojämlikhet. Röster om bostadsnöden. Falun: Premissförlag, 2017.

MacLeavy, Julie. "A 'new politics' of austerity, workfare and gender? The UK coalition government's welfare reform proposals». Cambridge Journal of Regions, Economy and Society, 4. 3 (November 2011): 355-367. https://doi. org/10.1093/cjres/rsr023

Mayock, Paula, Joanne Bretherton, and Isabel Baptista. «Women's Homelessness and Domestic Violence: (In) visible Interactions». Eds. Paula Mayock and Joanne Bretherton. Women's Homelessness in Europe. London: Palgrave MacMillan, 2016. 125-152.

McDermont Morag, Tim Cole, Janet Newman, Angela Piccini (eds.) Imagining regulation differently, Co-creating for engagement. Bristol: Policy Press, 2020. Mik-Meyer, Nanna, and Kaspar Villardsen. Power and Welfare: Understanding Citizens' Encounters with State Welfare. Hoboken: Taylor and Francis, 2012. 
Through the lens of single parenthood: a comparative snapshot of the impact of neoliberal welfare, housing and employment policies on single mothers in the UK and Sweden

Millar, Jane, and Tessa Ridge. Families, poverty, work and care: A review of the literature on lone parents and low-income couple families with children. Research Report No. 153. Department for Works and Pensions. 2001. https://dera.ioe. ac.uk/10096/. Web. April 172020.

Millar, Jane, and Fran Bennett. «Universal Credit: Assumptions, contradicitons and virtual reality». Social Policy and Society 1 (2017): 169-182.

Murphy, Mary. «Dual conditionality in welfare and housing for lone parents in Ireland: Change and continuity?» Social Policy and Administration 54. 2 (2019): 250-264.

Näsman, Elisabeth. «Barnperspektiv på ekonomiskt bistånd». In Det yttersta skyddsnätet. Ed. Torbjörn Hjort. Lund: Studentlitteratur, 2019. 247-266.

Office for National Statistics. Families and the Labour Market UK. ONS, 2019. Web. 17 April 2020.

Office for National Statistics. Domestic Abuse: findings from the crime survey for England and Wales. ONS, 2018. Web. 17 April 2020.

Panican, Andreu, and Richard Ulmestig. «Social rights in the shadow of poor relief - social assistance in the universal Swedish welfare state». Citizenship Studies 20. 3-4 (2016): 475-489.

Pearce, Diane. «The Feminization of Poverty: Women, Work, and Welfare». Urban and Social Change Review 11. 1-2 (1979): 28-36.

Pearson, Ruth. «A feminist analysis of neoliberalism and austerity policies in the UK». Soundings 71. Neoliberalism, feminism and transnationalism. Spring 2019. DOI: 10.3898/SOUN.71.02.2019.

Pleace, Nicholas. «Family Homelessness in Europe». Homeless in Europe, The Magazine of FEANTSA (Autumn 2019): 22-23.

Rabindrakumar, Sumi. On the Rise - Single Parent Sanctions in Numbers. Gingerbread, April 2017. Web. April 172020.

Reis, Sara. A home of her own: Housing and women. WBG, July 2019. https://wbg. org.uk/wp-content/uploads/2019/07/WBG19-Housing-Report-full-digital.pdf

Reis, Sara. Migrant Women and the Economy. WBG, May 2020. https://wbg.org.uk/ wp-content/uploads/2020/05/WBG-28-Migrant-Women-Report-v3-Digital. pdf

Rich, Hannah. The Full Extent of the Homelessness Crisis. Shelter blog, July 2018. Web. April 172020. 
Through the lens of single parenthood: a comparative snapshot of the impact of neoliberal welfare, housing and employment policies on single mothers in the UK and Sweden

Roman, Christine. "Gendered and classed experiences of work-family conflict among lone mothers in Sweden». Community, Work \& Family, 22.3 (2019). DOI: $10.1080 / 13668803.2018 .1456404$

Rowlingson, Karen, and Stephen Mckay. Lone Parent Families: Gender, Class and State. London: Routledge, 2014: 30.

Sainsbury, Diane, and Anne Morissens. «Sweden: The Feminization of Poverty?». Poor Women in Rich Countries: The Feminization of Poverty Over the Life Course. Ed Gertrude Schaffner Goldberg. Oxford Scholarship Online, February 2010. Salonen, Tapio. Övervältringar från Socialförsäkringar till Socialbidrag. Lund: Meddelanden från Socialhögskolan, 1997.

Salonen, Tapio. Välfärd inte för alla. Stockholm: Rädda Barnen, 2019.

Samzelius, Tove. En plats att kalla hemma: Barnfamiljer i bostadskrisens skugga. Stockholm: Rädda Barnen, 2017.

Samzelius, Tove. «Ensamstående mammor och rätten till bostad.» Manifest för ett social arbete i tiden. Eds. Magnus Dahlstedt and Philp Lalander. Lund: Studentlitteratur, 2018. 113-124.

Samzelius, Tove. Family homelessness and poverty in Sweden: A single mother perspective. PhD Dissertation, Malmö University. Forthcoming 2020.

Select Committee on Work and Pensions Memorandum. Memorandum submitted by Single Parent Action Network, Sept 2006. Web. 7 May 2020. https://publications.parliament.uk/pa/cm200506/cmselect/cmworpen/1649/1649m12.htm Smith George, Kathy Sylva, Teresa Smith, Pam Sammons and Aghogho Omonigho Stop/Start. University of Oxford and the Sutton Trust, 2018. Web. 17 April 2020.

Socialstyrelsen. Öppna jämförelser av hemlöshet och utestängning från bostadsmarknaden. Enkätundersökning 2016. Stockholm: Socialstyrelsen, 2017.

SPAN. A hands on history project. 2019. Web. 7 May 2020. www.thespanproject. org.uk

Stranz, Hugo, and Stefan Wiklund. «Ekonomiskt bistånd i särskilda grupper exemplet ensamstående kvinnor med barn». Det yttersta skyddsnätet. Ed. Torbjörn Hjort. Lund: Studentlitteratur, 2019. 269-288.

Sunesson, Sune, Stefan Blomberg, Per Gunnar Edebalk, Lars Harrysson, Jan Magnusson, Anna Meeuwisse, Jan Petersson, and Tapio Salonen. «The flight from universalism». European Journal of Social Work 1. 1 (1998): 19-29.

Taylor, Matthew. «Vast 'social cleansing' pushes tens of thousands of families out of London». Guardian. 28 August 2015. 
Through the lens of single parenthood: a comparative snapshot of the impact of neoliberal welfare, housing and employment policies on single mothers in the UK and Sweden

Treanor, Morag. Child Poverty: Aspiring to Survive. Bristol: Policy Press, 2020. Van Lanker, Wim. «Does the use of reconciliation policies enable single mothers to work? A comparative examination of European countries». In The triple bind of single-parent families: Resources, employment and policies to improve wellbeing. Eds. Rense Nieuwenhuis and Laurie C. Maldonado. Bristol: Policy Press, 2018.

Warburton, Wayne, Elisabeth Whittaker, and Marina Papic. «Homelessness Pathways for Australian Single Mothers and Their Children: An Exploratory Study». Societies 8.16 (2017): 1-22.

Watt, Paul. «Gendering the right to housing in the city: Homeless female lone parents in post-Olympics, austerity East London». Cities 76 (2018): 43-51.

Webb, Roger. «Neoliberal welfare reform and single parents mental health». The Lancet. Public Health 3. 7 (1 July 2018). Web. 7 May 2020. https://doi. org/10.1016/S2468-2667(18)30116-6

Wennberg, Lena. Social Security for Swedish Solo-Mothers in Swedish and EU Law: On the Constructions of Normality and the Boundaries of Citizenship. Umea: Iustus förlag, 2008.

Withworth, Adam and Julia Griggs. «Lone Parents and Welfare-to-work Conditionality: Necessary, Just, Effective?» Ethics and Social Welfare 7. 2 (2013): 124-140.

Women's Aid. The Domestic Abuse Report 2020: The Annual Audit. Bristol: Women's Aid, 2020.

Women's Budget Group. What is Feminist Economics? 10 January 2018. Web. 17 April 2020. http://wbg.org.uk/wp-content/uploads/2018/08/WBG-What-isFem-Ec-PDF-v3-1.pdf

Women's Budget Group. Migrant women and social security. 20 March 2020. Web. 17 April 2020. https://wbg.org.uk/wp-content/uploads/2020/03/finalmigrant-women-2020.pdf

Wright, Polly, and Susanna Giullari. Proofed for Parents by Parents Participatory One Parent Proofing: Toolkit. Millpond, Bristol: SPAN, 2007. https://opfs. org.uk/wp-content/uploads/2020/02/Participatory_One_Parent_Proofing_ Toolkit.pdf 

To link to this article / Para enlazar con este artículo:

https://doi.org/10.14198/fem.2020.35.06

To cite this article / Para citar este artículo:

Teasdale, Nina. «Flexible Working in the UK: interrogating policy through a gendered Bacchi lens». En Feminismo/s, 35 (junio 2020): 155-177. Monographic dossier / Dossier monográfico: A critical practice of thinking otherwise: Bacchi, Gender and Public Policy Analysis, coord. Angela O'Hagan, DOI: 10.14198/ fem.2020.35.06

\title{
FLEXIBLE WORKING IN THE UK: INTERROGATING POLICY THROUGH A GENDERED BACCHI LENS
}

\author{
TRABAJO FLEXIBLE EN EL REINO UNIDO: \\ INTERROGAR POLÍTICAS A TRAVÉS UN ENFOQUE \\ BACCHI CON PERSPECTIVA DE GÉNERO
}

\author{
Nina TEASDALE \\ Glasgow Caledonian University, Glasgow \\ Nina.Teasdale@gcu.ac.uk \\ orcid.org/0000-0001-9862-5858
}

\begin{abstract}
This article focuses on organisations' flexible working policies and the UK's Right to Request Flexible Working legislation first introduced in 2002 and progressively extended in 2009 and 2014. It critically explores the existing literature around flexible working to examine the UK's policy approach through a gendered lens and by adopting Bacchi's framework «What's the problem represented to be». Three themes from the literature are identified and explored to problematise the deep-seated assumptions and silences underpinning policy: namely, the dominance of the business case rationale; the gendered substructure of organisations; and the disjuncture between policy «on paper» and policy «in practice». Through the lens of Bacchi, the article highlights that the "problems» underpinning the UK's Right to Request legislation and organisation's flexible working policies are neither fixed nor static, discursively shifting across «time», and that flexible working policies must be analytically situated within their social and economic contexts.
\end{abstract}

Keywords: Bacchi; Flexible working; Gender; Policy; Organisations

Los contenidos de la revista se publican bajo una licencia de Creative Commons Reconocimiento 4.0 Internacional (CC BY 4.0)

Feminismo/s 35, junio 2020, pp. 155-177 


\section{Resumen}

Este artículo se centra en las políticas de trabajo flexible de las organizaciones y en la legislación del Reino Unido sobre el derecho a solicitar trabajo flexible, introducida en 2002 y ampliada progresivamente en 2009 y 2014. Explora críticamente la literatura existente sobre el trabajo flexible para examinar el enfoque de políticas del Reino Unido a través de una lente de género y adoptando el marco de Bacchi «¿Cómo se representa el problema?». A partir del marco teórico, se identifican y exploran tres temas para problematizar los supuestos y silencios que están profundamente arraigados y sostienen la política: a saber, el predominio de la lógica de los negocios; la subestructura de género de las organizaciones; y la brecha entre la política «en papel» y la política «en la práctica». A través de la lente de Bacchi, el artículo destaca que los «problemas» que yacen debajo de la legislación sobre el derecho a solicitar trabajo flexible del Reino Unido y las políticas de trabajo flexible de las organizaciones no son fijos ni estáticos, cambian discursivamente a través del «tiempo», y que las políticas de trabajo flexibles deben estar situadas analíticamente dentro de sus contextos sociales y económicos.

Palabras clave: Bacchi; trabajo flexible; género; política; organizaciones

\section{INTRODUCTION}

With women's increased participation in the labour market in the latter part of the $20^{\text {th }}$ century and organisations' growing reliance on female labour (Haas, Hwang and Russell 1), traditional assumptions about the separation of work and personal life and the gendering of these spheres have long been argued to be outdated (Kanter 4). A suite of work-life policies has been introduced and developed by governments and organisations across different countries to try to help reconcile work and family responsibilities (Gambles, Lewis and Rapoport 3). Such policies have been labelled as family-friendly, work-life «balance» and/or flexible working policies, and have tended to embrace differing types of working arrangements to give a degree of flexibility on how long, where, when and at what times employees work (CIPD 2). Often included as part of such working arrangements, among others, are part-time working; term-time working; job-sharing; flexitime; compressed hours; annual hours; and remote working. Government and organisational policies have also been developed and extended around pre-school childcare provision and parental arrangements such as maternity, paternity and shared

Feminismo/s 35, junio 2020, pp. 155-177 
parental leave or «daddy quotas» (as is the case in Norway). In particular, there has been a strong commitment to gender equality in Norway and other Scandinavian countries, with state policies encouraging men's engagement in childcare and family life. Nevertheless, despite well-paid paternity and individualised parental leave, men in Scandinavian countries continue to be less likely to pursue shorter working hours with commitment still equated with presence in the workplace (Gambles, Lewis and Rapoport 30; Haas and Hwang 10).

Focusing on the UK context, this article explores policy around flexible working, with a specific emphasis on the Right to Request Flexible Working legislation introduced in the UK by the New Labour Government in 2002. Driven in part by the policy agenda of the European Union to promote women as an untapped labour market resource, the legislation in the UK was initially targeted to help working parents (especially mothers) with young children, to enable them to participate more fully in the workforce (Fagan and Rubery 298; Kelliher and de Menezes 10). The Right to Request Flexible Working legislation was extended in 2009 and then 2014 to incorporate all workers regardless of care responsibilities. Yet, while the policy language has been couched in gender-neutrality and universalism, there has remained an implicit association of flexible working with working parents, particularly mothers.

Over the last thirty years, the UK's Right to Request legislation and organisations' response to managing and negotiating the work-home nexus through flexible working-related policies and initiatives has attracted much research attention (Lewis and Lewis 2; Gambles, Lewis and Rapoport 3). Consideration has been devoted to definitions and the language of policies, as well as the gap between policy and practice. Since the late 1990s survey data has examined the provision and uptake of the Right to Request and different Flexible Working Arrangements (for example, Kersley et al. 5), with qualitative studies drawing attention to some of the social, cultural, economic and organisational barriers impacting the implementation of policy in practice in differing national and organisational contexts (Gambles, Lewis and Rapoport 5; Lewis, «Family» 15). The aim of this article is to contribute to this literature by critically problematising and interrogating the UK's Right to Request Flexible Working legislation and organisations' flexible working policies 
more generally from a gendered perspective and through the lens of Bacchi's framework «What's the problem represented to be?» (WPR hereafter) (10).

The article begins by setting out Bacchi's WPR approach to policy analysis and why a gendered lens is adopted. The next section outlines the UK's Right to Request Flexible Working legislation and the progressive extension of the policy. The article then focuses on three key themes that emerge from applying a Bacchi and gender-influenced lens to the extant literature on flexible working in the UK between the 1990s and 2019. The three themes explored are: firstly, the dominance of the business case rationale underpinning UK flexible working policy; secondly, the gendered substructure of work organisations that policy is implemented and played out in; and thirdly, the disjuncture between policy and practice, and the negotiation and enactment of flexible working policy in daily workplace life. Drawing upon a Foucault-influenced, post-structural perspective and framing policy as discourse, social policy is conceptualised by the Bacchi framework as a highly normative discipline which constructs ideal models of society based on notions of social justice which disguise underlying relations and dynamics of power (20). This article follows the Bacchi approach in arguing that the UK Right to Request and flexible working-related policy at an organisational level are neither fixed nor static -policies and the problems they ostensibly represent, discursively shifting across «time». As part of this argument it is stressed that policies as discourse must be analytically situated within their social and economic contexts and in work organisations that are deeply embedded along gendered lines, both enabling and constraining the ways policy «plays out» in practice and thus exposing through the lens of Bacchi the «silences» behind policy (5).

\section{WHAT'S THE PROBLEM REPRESENTED TO BE?}

The WPR approach to policy analysis brings a sequence of questions that allows policies to be opened up to interrogation (Bacchi 9; Bacchi and Goodwin 20). Bacchi's approach captures six interrelated questions (box one) and works backwards from policy as discourse to question their underlying premises, their historic context and their complex and contradictory effects and implications. 
Box One: What's the problem represented to be?

1 . What's the problem represented to be in a specific policy?

2. What deep-seated presumptions underlie the representation of the problem?

3. How has this representation of the problem come about?

4. What is left unproblematic in this problem representation? Where are the silences?

5. What effects are produced by this representation of the problem?

6. How and where has this representation of the problem been produced?

Informed by Foucault and post-structuralism, a strength of Bacchi's WPR approach is the use of text as «levers» to open up and reflect on the production of «truths» instituted through a particular way of constituting a problem (14). Bacchi's approach starts from the premise that policy as discourse is not «axiomatic or self-evident» (22). In so doing, the conventional view that policies address problems are explicitly challenged, enabling the probing of deep-rooted assumptions and a light to be shone on the implications of policy for how lives are imagined and lived in practice, and thus was is left unproblematic or silenced by policy (Bacchi and Goodwin 101).

Following Crompton («Decline»), while gender in this article is understood as performative and as continually being created and re-created, structures nevertheless still count, with gender deeply entrenched in wider social and economic contexts and institutions, recognising that neither the individual nor the social «can exist without the other» (Crompton, «Decline» 8). Through the lens of Bacchi's overarching framework of interrelated questions, the article specifically draws out themes from the literature in relation to gender linked to the following Bacchi's question areas: (i) the representation of the policy problem, (ii) the deep-seated presumptions underling policy and where they come from and (iii) the effects and silences that it produces (see box one) (20). This allows not only for the probing of the social, cultural and economic contexts in which flexible working policy as discourse «plays out» but, combined with a «gendered» lens, provides an insight into the gendered power relations embedded in such contexts and how such dynamics shape 
and influence policy in practice (Acker, «Hierarchies» 140). Thus, in line with a Foucauldian perspective, policy «cannot be seen as the expression of a neutral rationality, but it is the expression of knowledge as power» (Bacchi and Goodwin 10).

\section{UK CONTEXT}

Increasingly the workforce in the UK and other countries is made up of women and men with responsibilities for both the care and economic support of families (Lewis, «Rethinking» 2). To facilitate the reconciling of family and employment responsibilities, governments and organisations have introduced policies captured broadly under the rubric of work-life «balance» (WLB). Although historically the UK has typically been a liberal welfare regime (Crompton, Employment 120), with the care of dependents not only gendered but deemed a private, family issue (Lewis and Campbell 5), a suite of policies and initiatives to try to support the work-family nexus have been introduced and developed by the UK government since the late 1990s. This began in March 2000 with the launch of a work-life «balance» campaign by the New Labour government (see Fagan 240; Woodland et al. 3). While both social and economic objectives informed the policy agenda, the UK work-family «balance» discussion was simultaneously conceptualised and driven in the context of broader European debate, particularly around opportunities to increase women's participation in the labour market (Lewis and Campbell 7). Looking at policy through the lens of Bacchi, it is women's labour market activation that first formed «the representation of the problem» (4).

As part of the New Labour government work-life «balance» campaign, at the level of the state and the firm, in 2002 legislation was introduced to provide employees the right to request reduced or flexible working if they had a dependent child under six years of age or a disabled child under 18 years of age. This legislation was extended in 2009 to include parents with children aged 16 years and under (ACAS) and in 2014 (under the Coalition government) was made available to all workers regardless of caring responsibilities. While there remains no formal or clear definition of flexible working (CIPD 2), policies tend to consist of arrangements such as job sharing, compressed hours (e.g. a nine-day fortnight or four and a half day week) career break 
schemes, flexi-time homeworking, term-time working, part-time or reduced hours of work (Kersley et al. 305; Pyper 5).

A vast literature has been established in relation to flexible working and work-life «balance» more generally (see Gambles, Lewis and Rapoport 5). Discussion has focused on the language that is used to talk about the issues shaping and informing such policies, with the concept of work-life «balance», as opposed to «work-family» or «family-friendly» argued to reflect a broader and more inclusive way of framing the debate, including the right to request flexible working -one that attempts to engage men and women, with and without young children or other caring commitments. Nevertheless, work-life «balance» is a concept that has been heavily criticised for implying that work is not a part of life, and thus that there is a «trade off» between paid work and family commitments. While discussion continues over the language that should be used to frame flexible working and work-life «balance» debates more generally (Gambles, Lewis and Rapoport 4), for the purposes of this article, three themes are identified by adopting Bacchi's WPR approach as a way to explore and interrogate the extant literature (between the period 1990 and 2019) on UK flexible working policy -namely, the dominance of the business case rationale, the gendered substructure of work organisations, and the gap between policy and practice. Each theme emerged by examining the literature through the lens of the Baachi's framework of inter-related questions to capture the representation of the policy-problem; the deep-seated underlying assumptions of the problem and how they came about; and their silences and effects (Bacchi and Goodwin 20). Each theme is now discussed in turn.

\section{THE DOMINANCE OF THE BUSINESS CASE RATIONALE}

Central to much of the government and academic literature relating to the UK's work-life «balance» campaign and Right to Request Flexible Working legislation introduced in 2002 has been social as well as economic objectives (Lewis and Campbell 9; Dex, 4; Dex and Scheibl 412). While the government's social objectives focused on challenges related to an aging society, falling fertility rates, tackling child poverty and children's social and educational development through high quality childcare, the goal of gender equality was not explicitly articulated (Lewis and Campbell 21). Further, economic objectives 
and the so-called «business case argument» have become increasingly prominent. By «business case argument» it is meant, as Dex and Scheibl point out «establishing that there are measurable business net benefits over costs which would clearly give organisations an incentive to adopt such arrangements» (414). In the UK, as part of the Department of Trade and Industry's (DTI) initial promotion of flexible working practices was a pamphlet of case studies to highlight successful stories and an alliance of 22 leading work-life «balance» employees was set up (Fagan 239; Tomlinson 413). In line with the EU economic agenda to promote women's increased labour market participation (Lewis and Campbell 6), the economic and business benefits of the right to request flexible working legislation and organisations' policy initiatives have focused on the recruitment and retention of women, with an emphasis on the cost of every lost employee, increased productivity levels, reduced absenteeism and minimising stress (Brannen and Lewis 99). Ultimately, the problem represented to be by the New Labour government's 2002 Right to Request Flexible Working policy was to increase women's labour market participation in the context of the growing service sector economy.

First introduced under the New Labour Government (1997-2010), the Right to Request Legislation (2002; 2009; 2014) enabled an employee who has been employed continuously for 26 weeks or more to apply in writing to their employer requesting a change in hours, times or location of work as between his home and employer's place of business. However, the legislation stipulates that only one application may be made by an employee in any 12-month period and employers could reject an application on any of the following business grounds:

- the burden of additional costs;

- detrimental effect on ability to meet customer demand;

- inability to re-organise work among existing staff;

- inability to recruit additional staff;

- detrimental impact on quality;

- detrimental impact on performance;

- insufficiency of work during the periods the employee proposes to work; or planned structural changes (Pyper 6) 
It is important to emphasise, therefore, that the UK government's approach has been to introduce policy into existing organisational systems, and consistent with its traditional, supportive relationship with business has sought «to encourage employers into voluntary action, as the market permits, rather than to regulate for change». (Gambles, Lewis and Rapoport 26).

The UK Equalities and Human Rights Commission, along with the charity, Working Families has recently advocated that all jobs should be advertised and made available on a flexible working basis, and as a day one right (rather than after 26 weeks continuous employment), in order to increase opportunities for both men and women and to give individuals greater choice about the roles they play at work and at home (Equality and Human Rights Commission 1; Kelliher and de Menezes 8). Further, a Flexible Working Task Force was established by the Conservative government in March 2018 to widen the availability and uptake of flexible working across the workforce, with the government committing to increase communications around flexible working, following recommendations from the Taylor Review (2016) and the Women and Equalities Commission (WEC) in their Gender Pay Gap report (2016) (Pyper 15). Dialogue at organisational and government level around flexible working policy and the Right to Request Flexible Working legislation has therefore continued.

Linked to discussions in the research literature around flexible working and the business case has been the employee-employer dichotomy, with flexibility and flexible working arrangements understood, in the words of Kelliher and de Menezes as either:

employer-driven -that is, primarily concerned with efficiency, productivity, speed of response and competitiveness; or employee-driven -that is, intending to accommodate employees non-work lives and help them achieve a satisfactory work-life balance. (10)

While flexible working was initially presented by the New Labour Government as «mutually beneficial» for the employee and employer (Gregory and Milner 2 ), this has been challenged by scholars adopting a critical perspective, especially across changing economic contexts, with many arguing that policies are overly employer driven (Fleet 397; Kossek, Lewis and Hammer 5). Indeed, as Lewis et al. (507) argue, the discursive shifting of flexible working policy through what Lombardo et al. refers to as processes of «fixing, shrinking 
stretching and bending» has become particularly visible in times of economic change (cited in Lewis et al. 590). Many companies during the 1990s for example, as Brannen and Lewis assert, adopted a plethora of strategies, including downsizing their labour forces, «delayering» and outsourcing business functions to other companies, to provide them with the flexibility to deal with poor economic conditions (100). Flexibility from an employer perspective also became significant and prioritised following the 2008 global recession and the introduction of associated austerity policies. According to Lewis et al. in their research on flexible working policies in UK public sector organisations, this led to cost-cutting and efficiency measures drawing on neo-liberal discourse around the principles of new public sector management and the rolling back of the state, while presenting them in the language of flexibility and work-life «balance» as a way to try to soften the blow for employees and to obscure the instrumental economic decision-making driving them (593). Thus, through the lens of Bacchi, the representation of the problem not only shifts, moving away from their original goal of principally getting more women into the labour market, but the ways in which flexible working policy is implemented by organisations can often reduce the opportunities to manage personal needs and lead to increased working hours (Putnam, Myer and Gailliard 416).

Figures from the CIPD indicate the uptake of most types of flexible working over the last decade has largely plateaued in the UK (6). This is despite the fact that the legal right to request flexible working has been extended and made available to all workers regardless of caring responsibilities. However, this could also be linked to organisations offering fewer flexible working arrangements following the 2008 financial crisis (Bessa and Tomlinson 154). Data from the 2019 UK Working Lives survey (CIPD 12) shows that just over half of UK workers work flexibly in some way, with those in higher-level occupations most able to use flexible working to support their work-life «balance». While there is evidence in the CIPD report of an increase in more informal flexible working, such as people working from home on an ad hoc basis, there remain unmet demands and a lack of equality of access to both formal and informal flexible working. Silences from a Bacchi perspective therefore emerge in relation to who is able to take up flexible working arrangements 
and who is benefiting from government and organisational policy (Bacchi and Goodwin 20).

Among employees who have no access to flexible working, the 2019 UK Working Lives Survey also indicates that $78 \%$ would like it and more than half the workforce would like to work flexibly in at least one form that is not currently available to them (CIPD 14). Survey data indicates that larger firms (especially in the public sector) have been more likely to offer worklife policies than smaller ones. Larger firms are also more likely than smaller organisations to devise such arrangements as a package of measures (Kersley et al. 251). Similarly, workplaces where more than half the workforce were female, were more likely to have access to flexible working arrangements (with the exception of home working and flexitime which tend to be used by men). A further key theme, therefore, identified by applying a Bacchi approach to the flexible working literature is that policy take up has been gendered. Indeed, despite attempts to present and position flexible working policy as gender-neutral, overlooked is the implementation of policy within existing organisational structures and cultures that reinforce work and family spheres as not only gendered, but as separate (Fletcher and Rapoport 142).

\section{THE «GENDERED» NATURE OF WORK-LIFE POLICIES}

Threading through the literature on work-life «balance» and flexible working is the argument that «the mere existence of work-life policies alone does not necessarily result in organisation integration» (Kossek, Lewis and Anderson 9), especially when both present social arrangements for care, and cultures and practices in work organisations, tend to benefit «men» (Wajcman 160). Thus, while the UK government has attempted to encourage the promotion of flexible working for both men and women (Smithson et al. 116), the implementation of flexible working policy occurs at an organisational level and in what some feminist theorists have referred to as gendered organisations (Acker, «Hierarchies» 139). Indeed, it is clear by looking at the literature through a Bacchi lens that a privileging of the business case and women as an economic growth resource by government and business, overlooks the social context in which work-family linkages are situated and neglects that they are deeply embedded in gendered social institutions. As a consequence, 
flexible working policy in the UK has been presented as gender-neutral while implicitly reinforcing caring matters as «women's issues».

Pivotal to theorising on the «gendered» work organisation (Acker, «Hierarchies» 139) has been the concept of the «ideal worker» which positions the ideal worker as someone, usually a man, who can work as though they have no caring or social responsibilities beyond paid employment. It is suggested that it is especially difficult for men to take-up flexible working arrangements when notions of the «ideal worker» remain deeply entrenched in conventional career and work structures. It also engenders challenges for women who have adopted strategies to gain acceptance and advance in organisations that are grounded in a «male» model of work (Teasdale 399). As Raabe asserts, even in a supportive work-family environment such as Sweden, organisational cultures remain highly gendered and many men are reluctant to take up their entitlement to policies (128; see also Haas and Hwang 58). Indeed, research indicates that it has not only been predominantly women who take up flexible working, but women working at senior grades who have had real access to flexible working policies, and gain access to what Tilly has called «retention part-time work» which is often informally negotiated (see Tomlinson 415). The few men that opt for flexibility, as Smithson et al. point out, tend to be older, already partners or directors in their organisations, financially stable and with older children who are beyond the stage of continuous care (130).

In terms of gendered take-up, a report for the TUC by Fagan et al. indicates that although significant numbers of men have requested flexible work, they experience greater barriers to their requests than women (12). For example, Fagan et al. note that $19 \%$ of women employees in the UK have made requests for flexibility compared to $10 \%$ of men, and that mothers (36\%) are three times more likely to request flexibility than fathers (12\%) (12). Yet, it is stressed that when men do make a request in the UK, it is more likely to be rejected outright compared to their female counterparts, and that their cases are more likely to be lost, ruled out on procedural grounds or dismissed at tribunals. Women and men also use different types of flexible working and use it in different ways that leads to different outcomes in terms of work-life «balance», well-being and work-intensification (Chung and van der Lippe 5). So while the ideal «male» worker model is outdated, it nevertheless remains 
deeply embedded and «silenced» in work organisations (Haas, Hwang, and Russell 11), along with discourses of motherhood and the ideal carer (Lewis and Humbert 242). Consequently, despite shifts and the broadening of polices for parents to policies for all workers, this has not necessarily been aligned with shifts in gender attitudes and expectations and the need for men to be more actively involved in care work. Women's employment, therefore, still tends to remain more strongly affected by parenthood (Haas, Hwang and Russell 246).

Two further reasons are put forward in the research literature that from a Bacchi approach «problematise» the gendered contexts in which flexible working policy are implemented and «played out». Firstly, it is suggested that in the UK employees tend to have a low sense of entitlement to such policies (Lewis and Smithson 1455). This has especially been the case when policies have implicitly and historically been targeted at a particular group of workers -namely parents with young children (usually mothers), with policies often interpreted as perks rather than rights (Lewis, «Family» 15). Secondly, it is suggested that organisational «discourses of time» and «presenteeism» which equate long working hours with «commitment» to the job and being in the office, do not encourage employees to feel they have a right to flexibility (Lewis, «Family»). Indeed, in terms of the «gendered» take up of flexible working policies, a primary concern for individual workers is the career implications (perceived or actual) (Lewis and Lewis 16; Kossek, Lewis and Anderson 5). As McDonald, Brown, and Bradley point out:

In a climate that accepts and encourages long hours of working ...the legacy of being committed to the job for as long as it takes remains the prevailing ethos. (274)

Thus, rather than being seen as equivalent to full-time forms of employment, left unproblematic and silenced, is the fact that flexible working arrangements have been associated with work penalties including lower pay, lack of opportunities for promotion and poorer working conditions and mainly utilised by women workers (Fagan et al. 10; Raabe 128; Kelliher and de Menezes 8).

Clear then from applying a Bacchi lens to the research literature is that while a growing list of policies and programmes appear to indicate government and organisations' commitment to flexible working, overlooked is the 
appropriateness of the existing systems and structures that policy is being brought into. Consequently, as Lewis argues, policies have tended to be implemented as «quick fixes», introduced at the margins of organisations, but seldom challenging or making visible traditional gendered patterns of paid employment and unpaid caring work and the traditional gendered division of labour («Family»14). This also has ramifications for the playing out and negotiation and enactment of policy at the level of managerial and co-worker social relations. This is especially interesting in the context of high workloads and staff shortages. It is to this that the discussion now turns.

\section{DISJUNCTURE BETWEEN POLICY AND PRACTICE: SUPPORT, TENSIONS AND RESENTMENT}

One of the ramifications sometimes touched on by scholars in their evaluations of the implementation of flexible working policies is that they can create hostilities or tensions among managers and their staff, and between different groups of workers (Teasdale 404). In some organisations it may be argued that work-life and flexible working policies have enhanced organisational attachment «even amongst workers with no current dependent care responsibilities, because the employer is perceived as caring for its workers» (Lewis, «Family» 17). Yet, in other organisations it creates resentment, and poor co-worker support. In such cases employees are often reluctant to pursue work-family and flexible working policies (McDonald, Brown, and Bradley 38). For example, Lewis notes that poor support is often linked to the belief that policies are inequitable -that is they benefit one group of workers- generally parents, at the expense of their childless colleagues who feel resentful for having to work longer hours and cover the workloads of their colleagues who have children («Family» 18). Consequently, there is a tendency for workers who make use of flexibility to be perceived as getting «special treatment» and employees who have used such policies are very aware of the need to balance «use» versus «abuse» so as not to be seen and treated as a less committed worker (McDonald, Brown, and Bradley 49). Kelliher and Anderson draw upon social exchange theory to argue that flexible working policies can actually lead to work-intensification (83) or what Putnam et al., (2013) refers to as the «autonomy-paradox» -that is, the more autonomy an employee has, 
the greater the number of hours they tend to work, often feeling they have to work harder in exchange for their flexibility (427).

Emphasised in the flexible working research literature is that policies in practice are not only implemented and played out in organisations that are inherently gendered (Teasdale), with individual career and pay implications but have depended on individual managerial discretion as well as co-worker cooperation (Crompton, Employment 110; McDonald, Brown, and Bradley 37; Teasdale 399). It is argued that few managers received training on flexible working policies despite their responsibility for implementing such policies (Wise and Bond 20). Thus, while flexible working policies have been introduced by organisations at a formal level, policy implementation tends to occur on an informal and flexible basis, and often reflects reciprocity between managers and employers (Yeandle et al. 5). A similar point is made by Perrons who argues that not only does the implementation of work-life policies tend to be based on give and take between managers and their staff but also varies among employees themselves, with long standing staff more likely to have their requests met (391).

Looking through the lens of Bacchi's framework of questions, it is clear that an important factor in the decision-making process of managers is their own individual and gendered attitudes to the management of work and family responsibilities. Around two thirds of the managers (particularly in private sector organisations) that contributed to the 2004 Work Employment Relations Survey (WERS) believed that it was up to individual employees to balance their family and work responsibilities. Although it is important to stress that such attitudes are changing (Working Families 3) and have also been less prevalent in numerically female dominated organisations and among female managers (Kersley et al. 250). However, research indicates that in a climate of work intensification employees' utilisation of work-life policies has been made even more difficult, particularly when workers are employed in small teams or units and there is perceived to be a knock on effect for their colleagues (McDonald, Brown, and Bradley 37; Smithson et al. 115).

Underpinning much of the resentment in workplaces is discourse around the ideal worker and around motherhood and the assumption that mother's primary responsibility should be to her children (Lewis and Humbert 242). Discourses of motherhood contrast with notions of the ideal worker, creating 
not only identity dilemmas for women but results in flexible working policy taking place around the margins of organisations for those who do not fit the idealised «male model» (Lewis «Family» 15; Lewis and Humbert 242). Understanding the uptake of flexible working policy and the potential for resentment and tensions must be considered within this context, as well as the individualistic context of contemporary society, in which the family still tends to be seen as an individual's responsibility (Lewis, «Family» 19). This is especially interesting in the context of «greedy organisations» and organisations predicated upon a performance-based culture and in which employees are being expected to work harder than ever in organisations that operate globally (Crompton, Employment 8; Kossek, Lewis, and Hammer 5). Teasdale's research on flexible working and social relations among professional women, in the context of the «gendered» workplace, revealed both support and resentment, highlighting that co-workers are a pivotal part of the lived experience or «playing out» of flexible working policy in practice (399). In particular, her research points to the «complex ways in which policies are negotiated at the level of daily workplace relations» (Teasdale 398). But as Hegtvedt, Caly-Warner, and Ferrigno point out, co-worker support is a factor that is often overlooked and left «silent» by policy analysts (386).

\section{DISCUSSION AND CONCLUSIONS}

The focus of this article has been on the UK's Right to Request Flexible Working legislation and organisations' flexible working policies. Adopting a gendered lens and drawing upon Bacchi's WPR approach, policy is understood as discourse with its meaning neither fixed nor static, but shifting across «time» (5). Three key themes were identified through applying the Bacchi framework of inter-related questions to the existing literature around UK flexible working policy. This included the dominance of the business case rationale; the gendered substructure of organisations; and the gap between policy on paper and policy in practice. The three emerging themes identified and discussed have helped expose: (i) the problem representation of flexible working policy -initially, getting more women into paid employment; (ii) the underlying premises and deep-seated presumptions of flexible working policy - that is normative assumptions around gender roles and how these are deeply 
embedded and taken for granted in work and other social institutions; and (iii) their effects or outcomes in practice for social relations in the workplace, and who does and does not take up flexible working arrangements and the career implications of doing so. By applying a gender influenced Bacchi lens to the literature around UK flexible working the gendered underpinnings of policy, the discourses shaping them and the gendered contexts they are implemented in, and that are silenced and taken for granted, are revealed. Indeed, a very real consequence of this is that gender inequalities have tended to be perpetuated by the UK's Right to Request legislation rather than challenged and transformed.

The first theme emerging from the literature was the dominance of the business case in the promotion of policy. While arguments linked to social justice were part of the New Labour discourse around flexible working and work-life «balance» more generally when legislation was first introduced in 2002, central to the approach and the representation of the flexible working problem have been economic objectives, including the recruitment and retention of women workers. This has gradually shifted from a particular focus on increasing women's labour market participation to businesses using flexibility as a way to adapt quickly to changing markets (Lewis and Campbell 21; Lewis et al. 598). The UK policy approach has also been incremental to cause the least burden to companies, with the scope for requests to be turned down for businesses reasons.

The second theme identified through applying the Bacchi (5) framework of questions to the flexible working literature was that despite the language of gender neutrality, policies have been introduced and implemented into existing social systems and structures that are inherently gendered and must be understood and interrogated through a gendered lens. Thus, not only are work organisations' structures, cultures and practices gendered in terms of who does what jobs, but women and men enter the workplace as different types of workers, with traditional responsibilities for care as women's work taken for granted and silenced by flexible working policy discourse (Acker, «Hierarchies» 140; Wacjman 36). Thus, flexible working policy is more likely to be taken up by women and when men do use it, they tend to opt for different types of flexible working than women workers and for different reasons. In particular, men are more likely to utilise flexitime and remote working,

Feminismo/s 35, junio 2020, pp. 155-177 
with very few men opting for such arrangements for the specific purpose of meeting childcare and family needs (CIPD 16; Ewald, Gilbert, and Huppatz 28).

The third theme identified from the flexible working literature through the lens of Bacchi was the significance of policy in practice -that is the effects it produces, particularly the way policy is negotiated and enacted in the daily «gendered» workplace and the implications for workplace relations. Indeed, it tends to be assumed that policies are being introduced and played out not only into gender-neutral organisations but supportive organisations. Studies show that policy in practice not only differs in different economic and social contexts but is shaped and informed by managerial discretion and co-worker relations, engendering tensions as well as relations of support and cooperation, which reinforce and silence normative assumptions around gender at the workplace level (Teasdale 409).

In this article, the focus has explicitly been on gender and has contributed to the extant literature by utilising the Bacchi approach to explore and problematise flexible working policy. In particular, it is shown that through a gendered lens and by adopting Bacchi's Foucauldian and post-structuralist informed approach that scholars and policy-makers should continue to question and shine a light on how policy is «problematised» and represented, negotiated, enacted and lived in daily workplace life. The article also highlights how policy as discourse, and the discourses shaping and informing flexible working policy, must be considered analytically in their social and organisational contexts to expose their gendered underpinnings and thus what is being «silenced». So although the UK's flexible working policy, first introduced through legislation in 2002 to workers with children under six, has been extended to all worker regardless of caring responsibilities and is now presented as universal and gender-neutral, the specific context in which policy is implemented continues to be overlooked. Thus, the extension of flexible working to all workers does not mean in practice that all workers are equal and that all workers benefit. Instead, flexible working policy in the UK has been introduced as a «quick fix» (Lewis, «Family» 14) into existing organisational structures and cultures, taking for granted normative gendered assumptions around paid and unpaid roles «rather than leading to long-term 
structural and cultural changes not only in gendered work organisations but in society more widely» (Teasdale 410).

Despite the merits of adopting the Bacchi framework to analyse the UK policy around flexible working, there are some limitations to the article. While the focus of the article has been on the UK, the trajectories of flexible working and work-life policies have developed in different countries in different ways and these are thus worthy of exploring to interrogate how policies are «problematised» and how they are being «playout» in practice in different national contexts. Likewise, gender is not the only relevant factor -class, race, sexuality and age, for example, are also influential and intersect with the ways in which policy is implemented, interpreted and experienced in practice. Future research could consider using the Bacchi framework to explore flexible working policy in organisations not only as «gendered» but as «inequality regimes» (Acker, «Inequality» 441).

In conclusion, the UK Flexible working legislation and policy was due for review by the government in 2019, but has been delayed as a result of the predominance of the Brexit-agenda, and is likely to be delayed further due to the current COVID-19 pandemic and ensuing economic crisis. Re-visiting flexible working and work-life related policies, then, and utilising a Bacchi approach to do so by interrogating the representation of policy problems and the deep underlying assumptions shaping and informing them remains as relevant as ever.

\section{REFERENCES}

ACAS. Making a Flexible Working Request. https://www.acas.org.uk/making-aflexible-working-request

Acker, Joan. «Hierarchies, jobs, bodies: a theory of gendered organizations». Gender and Society 4 (1990): 139-158.

Acker, Joan. «Inequality Regimes: Gender, Class, and Race in Organizations». Gender and Society 20.4 (2006): 441-464.

Bacchi, Carol. Analysing Policy: What's the Problem Represented to be? Frenchs Forest, NSW: Pearson Education, 2009.

Bacchi, Carol, and Susan Goodwin. Poststructural policy analysis: A guide to practice. New York: Springer, 2016. 
Bessa, Ioulia, and Jennifer Tomlinson. «Established, accelerated and emergent themes in Flexible Work Research». Journal of Industrial Relations 59. 2 (2017): 153-169.

Brannen, Julia, and Suzan Lewis. «In Workplace Programmes and Policies in the United Kingdom». In Organizational Change and Gender Equity. Eds. Linda L Haas, Philip Hwang and Graeme Russell. London: Sage, 2000. 99-116.

Chung, Heejung, and Tanja van der Lippe. «Flexible Working, Work-Life Balance, and Gender Equality: Introduction». Social Indicators Research (2018): 1-18. CIPD. Megatrends Report: Flexible Working, 2019. https://www.cipd.co.uk/Images/ megatrends-report-flexible-working-1_tcm18-52769.pdf

Crompton, Rosemary. «The Decline of the Male Breadwinner: Explanations and Interpretations». In Restructuring Gender Relations and Employment: The Decline of the Male Breadwinner. Ed. Rosemary Crompton. Oxford: Oxford University Press, 1999. 1-25.

Crompton, Rosemary. Employment and the Family. Cambridge: Cambridge University Press, 2006.

Dex, Shirley. Families and Work in the Twenty-First Century. York: Joseph Rowntree Foundation, 2003.

Dex, Shirley, and Fiona Scheibl. «Flexible and Family-Friendly Working Arrangements in SMEs: Business Cases». British Journal of Industrial Relations 39.3 (2001): 411-431.

EHRC. «Shake up of working culture and practices recommended to reduce pay gaps». 15 August 2017. https://www.equalityhumanrights.com/en/our-work/ news/shake-working-culture-and-practices-recommended-reduce-pay-gaps

Ewald, Alina, Emilee Gilbert, and Kate Huppatz. «Fathering and Flexible Working Arrangements: A Systematic Interdisciplinary Review». Journal of Family Theory \& Review 12 (2020): 27-40.

Fagan, Colette. «Time, Money and the Gender Order: Work Orientations and Working-time Preferences in Britain». Gender, Work and Organization 8.3 (2001): 239-266.

Fagan, Colette, Araine Hegewisch, and Jane Pillinger. Out of Time: Why Britain Needs a New Approach to Working-time Flexibility. London: Trade Union Congress, 2006.

Fagan, Colette, and Jill Rubery. «Advancing Gender Equality through European Employment Policy: The Impact of the UK's EU Membership and the Risks of Brexit». Social Policy and Society 17.2 (2017): 297-317. 
Fleet, Stephen. «Why Work-Life Balance Now?». International Journal of Human Resource Management 18.3 (2007): 387-400.

Fletcher, Joyce and Rhona Rapoport. «Work-Family Issues: A Catalyst for Organisational Change». In The Work-Family Challenge: Rethinking Employment. Eds. Suzan Lewis and Jeremey Lewis. London: Sage. 142-158. Gambles, Richenda, Suzan Lewis, and Rhona Rapoport. The Myth of Work-Life Balance. Chichester: John Wiley \& Sons Ltd, 2006.

Gregory, Abigail, and Susan Milner. «Editorial: Work-life Balance: A Matter of Choice?» Gender, Work and Organization 16.1 (2009): 1-12.

Guerrina, Roberta. «Socio-economic Challenges to Work-Life Balance at Times of Crisis». Journal of Social Welfare and Family Law 37.3 (2015): 1-17.

Haas, Linda, and Philip C. Hwang. «Policy is not enough -the influence of the gendered workplace on fathers' use of parental leave in Sweden». Community, Work \& Family 22.1 (2019): 58-76.

Haas, Linda, Philip C. Hwang, and Graeme Russell, eds. Organizational Change and Gender Equality: International Perspectives on Fathers and Mothers in the Workplace. London: Sage, 2000.

Hegtvedtz, Karen, Jody Caly-Warner, and Elizabeth D. Ferrigno. «Reactions to Injustice: Factors Affecting Workers' Resentment toward Family-Friendly Policies». Social Psychology Quarterly 65.4 (2002): 386-400.

Kanter, Rosabeth Moss. When Giants Learn to Dance: Mastering the Challenge of Strategy Management and Careers in the 1990s. New York: Routledge, 1989.

Kelliher, Clare, and Deidre Anderson. «Doing more with less? Flexible Working Practices and the Intensification of Work». Human Relations 63.1 (2010): 83-106.

Kelliher, Clare and Lillian M. de Menezes. Flexible Working in Organisations: A Research Overview. London: Routledge, 2019.

Kersley, Barbara, Carmen Alpin, John Forth, Alex Bryson, Helen Bewley, Gill Dix, and Sarah Oxenbridge. Inside the Workplace: Findings from the 2004 Workplace Employment Relations Survey. London: Routledge, 2006.

Kossek, Ellen, Suzan Lewis and Leslie Hammer. «Work-Life Initiatives and Organizational Change: Overcoming Mixed Messages to Move from the Margin to the Mainstream». Human Relations 63.1 (2010): 3-19.

Lewis, Jane, and Mary Campbell. «UK Work/Family Balance Policies and Gender Equality, 1997-2005». Social Politics 14.1 (2007): 4-30. 
Lewis, Suzan. «Rethinking Employment: An Organization Culture Change Framework». In The Work-Family Challenge: Rethinking Employment. Eds. Suzan Lewis and Jeremy Lewis. London: Sage, 1996. 1-19.

Lewis, Suzan. «Family friendly policies: Organisational change or playing about at the margins?». Gender, Work and Organisations 4.1 (1997): 13-23.

Lewis, Suzan, Deidre Anderson, Clare Lyonette, Nicola Payne, and Stephen Wood. «Public Sector Austerity Cuts in Britain and the Changing Discourse of WorkLife Balance». Work, Employment and Society 21.4 (2017): 586-604.

Lewis, Suzan, and Anne Laure Humbert. «Discourse or reality?: Work-life balance, flexible working policies and the gendered organization». Equality, Diversity and Inclusion: An International Journal 29.3 (2010): 239-254.

Lewis, Suzan, and Jeremy Lewis. «Rethinking Employment: A Partnership Approach». In The Work-Family Challenge: Rethinking Employment. Eds. Suzan Lewis and Jeremy Lewis. London: Sage, 1996. 159-168.

Lewis, Suzan, and Janet Smithson. «Sense of entitlement to support for the reconciliation of employment and family life». Human Relations 55.11 (2001): 1455-1481.

Lombardo, Emanuela, Petra Meier, and Mieke Verloo. The Discursive Politics of Gender Equality: Stretching, Bending and Policymaking. London: Routledge, 2009.

McDonald, Paul, Kerry Brown, and Lisa Bradley. «Explanations for the provision-utilisation gap in work-life policy». Women in Management Review 20.1 (2005): 37-55.

Perrons, Diane. «Flexible Working Patterns and Equal Opportunities in the European Union». The European Journal of Women's Studies 6 (1999): 391-418.

Pyper, Doug. Flexible Working, 2018. House of Commons Library. https://commonslibrary.parliament.uk/research-briefings/sn01086/

Putnam, Linda, Karen Myers, and Bernadette Gaillard. «Examining the tensions in workplace flexibility and exploring options for new directions». Human Relations 67.4 (2013): 413-440.

Raabe, Phyllis Hutton. «Constructing Pluralistc Work and Career Arrangements». In The Work-Family Challenge: Rethinking Employment. Eds. Susan Lewis and Jeremy Lewis. London: Sage, 1996. 128-141.

Smithson, Janet, Suzan Lewis, Cary Cooper, and Jackie Dyer. «Flexible working and the gender pay gap in the accountancy profession». Work, Employment and Society 18.1 (2004): 115-135. 
Teasdale, Nina. «Fragmented Sisters: Fragmented Sisters? The Implications of Flexible Working Policies for Professional Women's Workplace Relationships. Gender, Work and Organization 20.4 (2013): 397-412.

Tomlinson, Jennifer. «Perceptions and negotiations of the "business case" for flexible careers and the integration of part-time work». Women in Management Review 19.8 (2004): 413-420.

Wajcman, Judy. Managing like a Man: Women and Men in Corporate Management. Cambridge: Polity Press. 1998.

Wise, Sarah, and Sue Bond. «Work-life Policy: Does it do exactly what is says on the tin?». Women in Management Review 1/2 (2003): 20-31.

Woodland, Stephen, Nadine Simmonds, Marie Thornby, Rory Fitzgerald, and Alice McGee. The Second Work-Life Balance Study: Results from the Employers' Survey - Main Report. Employment Relations Series, No. 22. London: Department of Trade and Industry, 2003.

Working Families. The Modern Families Index 2018. https://workingfamilies.org. uk/publications/mfindex2018/

Yeandle, Sue, Andrea Wigfield, Rosemary Crompton, and Jane Dennett. Employers, Communities and Family-Friendly Employment Policies. Bristol: Policy Press, 2003. 

To link to this article / Para enlazar con este artículo:

https://doi.org/10.14198/fem.2020.35.07

To cite this article / Para citar este artículo:

Steinpórsdóttir, Finnborg Salome y Einarsdóttir, Porgerður. «Jumpstart, potentials and hindrances: collaboration projects in gender mainstreaming and gender budgeting». En Feminismo/s, 35 (junio 2020): 179-205. Monographic dossier / Dossier monográfico: A critical practice of thinking otherwise: Bacchi, Gender and Public Policy Analysis, coord. Angela O'Hagan, DOI: 10.14198/fem.2020.35.07

\title{
JUMPSTART, POTENTIALS AND HINDRANCES: \\ COLLABORATION PROJECTS IN GENDER MAINSTREAMING AND GENDER BUDGETING
}

\section{ESTÍMULO, POTENCIALES Y OBSTÁCULOS: PROYECTOS DE COLABORACIÓN EN TRANSVERSALIDAD Y PRESUPUESTOS CON ENFOQUE DE GÉNERO}

\author{
Finnborg Salome STEINPÓRSDÓTTIR \\ University of Iceland, Reykjavík \\ finnborg@hi.is \\ orcid.org/0000-0001-9581-0310 \\ Porgerður EINARSDÓTTIR \\ University of Iceland, Reykjavík \\ the@hi.is \\ orcid.org/0000-0001-8906-0760
}

\begin{abstract}
Many European organisations have committed to and formally adopted gender mainstreaming and gender budgeting strategies; however, their implementation has not been as effective as anticipated. The Department of Gender Studies at the University of Iceland has been collaborating with public sector organisations in Iceland, a City and a University, to advance implementation of these strategies. The collaboration entails post-graduate students analysing the problem representation and gendering of public activities and providing policy actors with research-informed advice on how to integrate a gender perspective in their management procedures and processes. Drawing on interview data with the policy actors involved in the collaboration projects, we found organisational noncommitment to gender mainstreaming and gender
\end{abstract}

Los contenidos de la revista se publican bajo una licencia de Creative Commons Reconocimiento 4.0 Internacional (CC BY 4.0)

Feminismo/s 35, junio 2020, pp. 179-205 
budgeting, lack of knowledge about these issues and a superficial approach to implementing the strategies. Based on the findings, we explored the potential explanations and the hindrances related to using collaboration projects to jumpstart structural transformative gender+ equality work.

Keywords: Gender budgeting; Gender mainstreaming; Public policy; Jumpstart; Structural transformation.

\section{Resumen}

Muchas organizaciones europeas se han comprometido y adoptado formalmente la transversalidad de género y los presupuestos con enfoque de género; sin embargo, la implementación de las estrategias no ha sido tan efectiva como se había anticipado. El Departamento de Estudios de Género de la Universidad de Islandia ha estado colaborando con organizaciones del sector público, una ciudad y una universidad, para avanzar en la implementación de estas estrategias. La colaboración implica que el alumnado de postgrado realiza análisis de actividades públicas desde la perspectiva de género e identifica oportunidades para integrar la perspectiva y reformar los procedimientos y procesos para avanzar en la construcción de la igualdad. A partir de datos de entrevistas con actores políticos involucrados en los proyectos de colaboración, hemos encontrado ausencia de compromiso organizativo con la transversalidad de género y los presupuestos con enfoque de género, falta de sensibilidad de relaciones de género y enfoque superficial en la implementación de las estrategias. Los resultados del estudio nos han dado la oportunidad de explorar las posibilidades y los obstáculos en el uso de proyectos de colaboración para estimular el trabajo de transformación estructural en igualdad de género.

Palabras clave: presupuestos con enfoque de género; transversalidad de género; políticas públicas; estímulo; transformación estructural.

\section{INTRODUCTION}

Today, in many European countries, public institutions have adopted gender mainstreaming and gender budgeting. However, implementation has not been as effective as desired (Bendl and Schmidt 375; Bacchi and Eveline, «Mainstreaming» 52; O'Hagan and Klatzer 7; Scala and Paterson 208; Sharp and Broomhill 21). Because the efficiency of gender mainstreaming is contested (Bacchi and Eveline, «Mainstreaming» 53; Eveline and Todd 544), our interest is in providing knowledge about the institutional, attitudinal and 
conceptual constraints for the successful implementation of gender mainstreaming and gender budgeting. In particular, we examine how policy actors interpret and respond to gender mainstreaming and gender budgeting obligations in their day-to-day work, an aspect that has not received much attention in the literature on the implementation gap (Scala and Paterson 209).

This article draws on semi-structured interview data with policy actors from public sector organisations, the City of Reykjavík (hereafter the City) and the University of Iceland (hereafter the University), that are obliged by Icelandic law and regulations to implement gender mainstreaming (Act on the Equal Status and Equal Rights of Women and Men no. 10/2008). Iceland has a reputation as an international frontrunner in gender equality (World Economic Forum 6). However, its portrayal as a gender paradise has been contested (Einarsdóttir 1-2) and the country is trapped in the paradox of «strong equality policy, weak practice» (Johnson, Einarsdóttir and Pétursdóttir 175). In other words, extensive formal acceptance and adoption of gender equality measures, but only «partial and variable institutionalization in terms of impact on institutional practices, norms, and outcomes» (Mackay, Monro and Waylen 254-255). Scala and Paterson (228) include gender analysts in their research on the micro-levels of implementation. As the Icelandic legislation taking a "change everything by everyone» (Benschop and Verloo 284) approach, it is particularly meaningful to examine how regular policy actors at different levels engage with gender and enact those obligations in their work.

At the policy level, the organisations included in this analysis demonstrate a commitment by formally adopting gender mainstreaming and gender budgeting strategies to facilitate gender equality (Háskóli Íslands, University of Iceland Equality Action Plan; Reykjavíkurborg, Kynjajafnrétti; Reykjavíkurborg, Mannréttindi; Steinpórsdóttir et al. 182-183). They have instituted gender equality infrastructures, such as equality and diversity departments, taskforces and coordinators (Háskóli Íslands, Equality and diversity; Reykjavíkurborg, Human Rights Office). Moreover, in order to take steps towards implementing gender mainstreaming and gender budgeting measures, the organisations have been collaborating with the Department of Gender Studies at the University since 2005 (Einarsdóttir and Pétursdóttir 18). This has been done in the belief 
that if the scholarly community collaborates with organisations together they «can jumpstart progress toward gender equality» (Correll 745).

The collaboration, which was initiated by the Gender Studies programme at the University, is based on the idea that the connection between research and action (Eveline and Todd 551-554) and the critical engagement of external actors (Sharp and Broomhill 8) can facilitate implementation. The collaboration entails the jumpstart of structural transformative gender equality work in which post-graduate students take on real, practical projects from policy actors under the supervision of gender experts, i.e. teachers. In the projects, the students use Bacchi's (2) critical analytical strategy, «what's the problem represented to be?» (WPR), to assess the problem representation and the gendering of certain activities (e.g. policies, resource distribution), and they provide research-informed advice on how to integrate a gender perspective into the management procedures and processes to ensure more gender equitable outcomes. In recent years, a growing number of students have approached their projects with a gender+ perspective. In doing so, they are «recognising that gender inequality and other inequalities are connected and are thus best addressed with those intersections in mind» (Verloo et al. 27). This is in line with increased efforts to incorporate different social and power relations into gender mainstreaming and gender budgeting practices, such as the GBA+ approach in Canada (Her Majesty the Queen in Right of Canada 1), and addresses previous criticisms of the strategies for not including intersectionality (Benschop and Verloo 284).

The collaborative projects addressed three categories of issues across public services: range and design of public service; organisational management and internal processes; public facing communication and information on services. The first category on services provided (by the City and the University) included a range of service provision: recreational centres, services for senior citizens, programmes for museum events and exhibitions, course catalogues, student psychological services, student disability services, student exchange programmes, and lastly, fees and charging policy for services and activities, e.g. children's participation in sports. The second category consists of organisational issues (in the University), including internal grants, the working conditions of, for example, PhD students, and academic housework (Heijstra et al. 211), student supervision and committee work. The third 
category consists of public relations (in the City and the University), such as accessibility to information about the services provided, news produced by the organisations, promotional material and awareness campaigns.

Correll (726) points out that while there has been extensive theoretical and empirical knowledge production on inequalities and how they are reproduced, it has not sufficiently enabled positive change. Furthermore, there is a lack of research on how to change those inequalities effectively, which she believes is because the "changes we can realistically make in any one instance are often small and imperfect» (Correll 726-727). The objective of the collaboration projects was to give the students an opportunity to engage in practical projects that simultaneously contribute to structural transformation and promote gender+ equality. Based on a cursory examination of the course evaluations, in general, the students were satisfied with the projects; however, for the collaborating partners, our intuition and subjective impression was that while the outcome of the projects was the generation of knowledge on gender+ inequalities, the projects did not result in any significant structural change that facilitates equality. Inspired by Correll, the study discussed in this article aimed to more systematically assess how organisations respond to the advancement of gender equality through public policy and legislation; that is, the government's objective to implement gender mainstreaming and gender budgeting, and specifically gain insight into the outcomes of the collaboration projects.

Drawing on semi-structured interviews with policy actors that participated in the collaboration projects, we found an organisational noncommitment to gender mainstreaming and gender budgeting. Moreover, the policy actors have inadequate knowledge about the strategies and their approach to implementing them is superficial. Based on the findings of our analysis, we explore the potential for and hindrances of using collaboration projects to jumpstart structural transformative gender+ equality work. Before elaborating on the study's findings and conclusions, we begin with a review of the literature that backgrounds the study, and then we present the methodology used in our research. 


\section{GENDER MAINSTREAMING AND GENDER BUDGETING}

Gender mainstreaming and gender budgeting are structural transformation strategies that are used to facilitate gender equality. Both strategies are most commonly defined as an integration of gender analysis in all aspects and all stages of the policy-and decision-making process (Council of Europe, Gender 12) and the budgetary process (Council of Europe, Recommendation). This definition has been criticised for being too technocratic (O'Hagan 29). Hence, drawing on Benschop and Verloo (283) and O'Hagan (20-21), we approach gender mainstreaming and gender budgeting as strategies that aim to challenge the supposed gender-neutral policies, programmes and resources that re/produce gender biases and inequalities and change organisational processes to ensure that they promote gender equality. This approach shifts the attention from individuals and their rights, and from comparing stereotypical characteristics of women and men, to the structural dimensions that produce and maintain gender inequalities, such as gendered institutions, systems, policies, processes, norms, expectations, etc. (O'Hagan 20; Benschop and Verloo 283; Bendl and Schmidt 364; Eveline and Todd 537).

In the research context, gender mainstreaming and gender budgeting are perceived to be interrelated. Some feminist scholars and activists have contested the association between the strategies because the application and implementation of gender mainstreaming are not comparable in all respects (O'Hagan 29). O'Hagan argues that gender budgeting goes further than gender mainstreaming, because «gender budgeting activates gender mainstreaming by including gender analysis of revenue and expenditure in all aspects of policy and programmes, and should result in gender-aware proposals across all policy domains» $(31)^{1}$. In the following sections, we discuss several of the shortcomings of and potentials for positive outcomes of gender mainstreaming and gender budgeting, as documented in the application of the strategies within organisations.

1. Original emphasis.

Feminismo/s 35, junio 2020, pp. 179-205 


\section{SHORTCOMINGS OF AND POTENTIALS FOR POSITIVE OUTCOMES}

While gender mainstreaming and gender budgeting are believed to have the potential to facilitate structural change, their implementation has several shortcomings, including, for example an organisation's ineffectiveness in using these strategies to bring about change that promotes equality and how the strategies are approached and applied. In general, feminist researchers have drawn attention to challenges, such as the «strong equality policy, weak practice» paradox (Johnson, Einarsdóttir and Pétursdóttir 175), and that the implementation of gender mainstreaming has been depoliticised. Feminist advocates have been removed from the process, and the strategies have become an overly technical and bureaucratised issue (see e.g. Powell, Ah-King and Hussénius 129; Klatzer, Brait and Schlager 147-151). A depolitisation of gender mainstreaming is manifested in the way in which power relations are ignored. It is further undermined by the prevailing idea that gender equality work should avoid conflict and not be carried out from a feminist perspective, as such a perspective would be seen as «being in opposition to professionalism and legitimate political issues» (Andersson 203). In her research on attitudes towards gender mainstreaming at the local government level in Sweden, Andersson (214-216) finds that discussion on (male) privileges and actions to improve women's position are avoided, which, in turn, weakens the transformative potential of gender mainstreaming. Moreover, it delegitimizes feminist perspectives or the actions of «femocrats», that is «bureaucrats with a feminist agenda» (Woodward 66).

Our study is especially interested in the day-to-day level of implementation. Benschop and Verloo (284) argue that the ambitious goal of «changing everything everywhere by everyone» is risky. By requiring policy actors at all levels to implement these strategies, there is the possibility that the transformative aspect of gender mainstreaming will fail due to the lack of understanding about the strategy, the problem or gender perspectives. In Woodward's (69) opinion the term «mainstreaming» is open for interpretation and «the further away from the femocrat centre, the more frequent the misunderstanding of the term [gender mainstreaming] and its specific connotations». Another 
issue that must be anticipated is the risk that the policy actors will resist the promotion of gender equality (see e.g. Lombardo and Mergaert 307).

The ongoing tendency to dismantle formal gender equality infrastructures further undermines the implementation process, as research shows they are essential for positive outcomes of gender mainstreaming and gender budgeting. However, these infrastructures must have authority and clear responsibilities, competence and resources to initiate, support and monitor the implementation (Klatzer, Brait and Schlager 152; Benschop and Verloo 284-287; Eveline and Todd 551-554). Scala and Paterson's research on local gender analysts enacting gender mainstreaming in Canada reveals how programme cuts and internal reorganisation of government agencies has left gender machineries isolated from the policy making; thus, they are disempowered. To advance gender and diversity work within their organisation, gender analysts have to compromise and appeal to the dominant neoliberal managerial discourses (Scala and Paterson 228-230).

Organisational obligation does not necessarily lead to organisational commitment, especially if the relevance of gender to policies and programmes is questioned within the organisation (Eveline and Bacchi 306-308). To ensure commitment among policy actors, and overcome the idea of the irrelevancy of gender, Eveline and Bacchi (306-308) suggest collaborative research projects, where internal policy actors gain hands-on experience with gender analysis to ensure long-term learning and commitment by organisations. Such collaboration is in line with Sharp and Broomhill's (8) arguments that without the critical engagement of external actors, gender budgeting efforts might not be effective. Moreover, such collaboration contributes to the accountability of the organisation.

Correll (735-737) argues for a «small wins» model of change in order to encourage action to facilitate equality, and believes it can enable larger organisational transformation. However, Bacchi and Eveline (Approaches 131) warn against the 'project trap', that is, when we are only generating knowledge on how gender inequality is produced and maintained in a narrow context instead of taking a broader approach toward examining the social organisational contexts (Bacchi and Eveline, Mainstreaming 52). To break out of the project trap, they suggest that the starting point of gender analysis is problematisations and the application of Bacchi's (2) WPR critical analytical strategy.

Feminismo/s 35, junio 2020, pp. 179-205 
WPR acknowledges that the policies, and how the problem is represented in them, can shape and produce social and power relations, including gender relations; therefore, they are gendering, that is, they (re)produce gender as a relation of inequality (Bacchi and Eveline, «Approaches» 131). Genderneutral policy and decision-making that does not recognise men's and women's different social positions and conditions will reproduce gendered power relations and male bias, resulting in gendered processes and outcomes (Bacchi and Eveline, «Mainstreaming» 52; O'Hagan and Klatzer 5). This also applies to other social and power relations; hence, policies can be heteronorming, racialising, classing and (dis)abling (Bacchi and Eveline, «Approaches» 112).

In the collaboration between the Department of Gender Studies, the City and the University, researchers aimed to put into practice the recommendations presented in the literature to encourage positive outcomes of gender mainstreaming and gender budgeting. The following section discusses the methodology and semi-structured interview data used in this study, before addressing the potentials for and hindrances of using collaboration projects to jumpstart structural transformative gender+ equality work.

\section{METHODOLOGY}

This research is part of a feminist transformative project that aims to find ways to progress gender+ equality within the City of Reykjavík and the University of Iceland. To assess the collaboration and determine the extent to which it achieved its objectives, the paper draws on semi-structured interview data with policy actors from the City and the University that participated in the collaboration projects with the Department of Gender Studies at the University from 2016 to 2018. The data were collected in October and November 2018. The aim of the interviews was twofold. First, we aimed to gain insight into how organisations respond to public policy and legislation (in this case, the government's objective to implement gender mainstreaming put forward in the Act on the Equal Status and Equal Rights of Women and Men No. 10/2008), and if policy actors at different levels embrace or reject the responsibility of doing this work. The interview frame was designed to gain insights using the following questions: How do the policy actors understand their responsibilities regarding equality work? How do they 
understand gender mainstreaming and/or gender budgeting? Is feminism present or excluded in their understanding of the strategy? Or is there any conflict relating to that? Second, we aimed to gain insight into the status of the implementation of gender mainstreaming in relation to the collaboration projects and the jumpstart it aimed to initiate. The questions that guided this part were: What do the policy actors take from these learning exercises? Has it impacted how they approach gender mainstreaming in their everyday work? Do the policy actors implement the suggested measures? If not, why not? Have the projects resulted in «spill-over effects»; in other words, has the gender perspective been integrated into other activities? If not, then why not?

To select the participants, the collaboration projects that were completed from 2016 to 2018 were mapped, including information on the project's creator, the participating policy actors from the collaborating organisation and the teacher's grade of the project (in order to assess its quality). In total 33 collaboration projects were completed in that period, with the participation of 17 policy actors from those organisations. The interviewees were selected based on the following criteria: a) the policy actor's position within the organisation (we wanted to interview people that still work within the same division as the policy area); b) the idea of the project originated with the policy actors, their division or the equality machinery of their organisations (not the teachers); and c) the quality of the project (the poorest projects were excluded). Although the initiative for the projects came from the policy actors or their organisations, some of the students still encountered resistances, such as the lack of access to information and data and being disregarded by the policy actors. The supervision by the teachers consisted of responding to these hindrances by guiding the students in finding relevant information and data from other sources and supporting them in dealing with the policy actors. The students were encouraged to consider the lack of information as data that they could use as part of their research-informed advice on how the policy makers could advance the implementation of gender mainstreaming and gender budgeting. This pushed the students to be resourceful and to think creatively. While encountering and dealing with resistance can be challenging, it is a valuable part of the students' learning process, as gender equality experts frequently have to deal with these types of issues in their work (Lombardo and Mergaert 307; Andersson 203; Scala and Paterson 230).

Feminismo/s 35, junio 2020, pp. 179-205 
Semi-structured interviews were conducted with 11 policy actors, six from the University and five from the City. Nine women and two men were interviewed, reflecting the frequent gender imbalance among policy actors that take on gender+ equality work (see e.g. Eveline and Bacchi 307). The position of the policy actors in the management structures was classified into two groups at two levels. Six of the participants are management policy actors, a position that includes management directors, head of divisions and deans. Five of the participants are mid-level policy actors (project managers and managers), and one is a gender policy actor, that is, a person that has gender equality responsibilities. The length of the interviews depended on the policy actors' commitment and interest in the collaboration projects. The shortest interviews lasted 10 minutes and the longest interviews lasted up to 30 minutes. The interviews were digitally recorded and transcribed using qualitative methods. To ensure the confidentiality and anonymity of the participants, at once challenging and important in a small community like Iceland, we decided to only describe the interviews using the previously mentioned classification method. Therefore, we only occasionally distinguish between the City and the University in the thematic discussion.

The interview data were analysed according to the thematic analysis, which is consistent with the systematic phases of the grounded theory approach (Glaser and Strauss) with the assistance of Atlas.ti. The first author coded the data using an inductive approach to identify meaningful dimensions in the data. The author's experience, especially scholarly, influences the assignment of codes (such as Bacchi and Eveline on the project trap and Andersson on the question of feminism being present or absent in gender mainstreaming). In the first step of the analysis, 13 codes were identified. In the second step, which aimed to clarify the complexity of the findings in a more fitting manner, the authors reorganised the codes into three themes in the final phase of the analysis: Organisational noncommitment, inadequate knowledge and superficial approach. Organisational noncommitment included the codes: reject responsibility, not taking action, aura of gender equality and indifference. Inadequate knowledge included the codes: lack of knowledge and feminism excluded. Superficial approach included the codes: embrace responsibility, perceived important, evidence of practice, feminism present, superficial implementation, creating knowledge and lack of resources. In the next 
section, we present the findings from the analysis by the themes identified. Firstly, we discuss the organisational commitment to gender mainstreaming and gender budgeting. We then discuss the policy actors' understanding of and knowledge about the strategies and how they approach the implementation of the strategies.

\section{ORGANISATIONAL NONCOMMITMENT}

Equality, gender mainstreaming and gender budgeting are concepts that the policy actors accepted and frequently used. However, organisational noncommitment also exists because most of the interviewed policy actors do not apply these strategies in their work. The reasons for this include: implementation of gender-related strategies are a low priority, they are dependent on individuals taking action, they receive little support, there is an «aura of gender equality» (Pétursdóttir 3) in the organisation and there is a lack of gender+ awareness.

The interviews allowed us to delve into the paradox of «strong equality policy, weak practice» (Johnson, Einarsdóttir and Pétursdóttir 175). Despite the existence of gender equality machinery and the formal adoption of gender mainstreaming and gender budgeting within the organisations, as discussed above, the participants often disregard the responsibility for the gender mainstreaming processes. Furthermore, it was not clear to them who should have that responsibility. Only four of the 11 policy actors perceived the strategies, including an intersectional perspective, to be part of their job. One mid-level policy actor had never heard of the strategies, nor the City's responsibilities according to the law, even though her division and her tasks were part of the collaboration projects. This is in line with Benschop and Verloo's (284) warning that the implementation of gender mainstreaming will fail if all the organisational actors are expected to enact gender mainstreaming. Another mid-level policy actor stressed that the organisation needs to clarify the staff's responsibilities towards equality issues and establish a clear action plan if it is serious about implementing the strategies: «I think that, generally, people do not perceive working on gender equality as a part of their job».

In cases were equality issues are on the agenda, they seem to be low in terms of the organisation's priorities, as can be seen in this response from a 
mid-level policy actor: «Many people see [equality] as a pet project; therefore, they [the equality projects] usually go to the bottom of the list [of priorities]».

Similar to Scala and Paterson's (230) findings, according to some of the policy actors that were interviewed, the progress of equality issues depends on the interest and endurance of the individual policy actor and the support of their superiors and colleagues. Some policy actors described how the lack of interest in and discussion about these issues can be a significant hindrance to equality work. Attitudes within their division, especially men's approval, is a lever for equality work. This can be seen in the statement below, in which a mid-level policy actor at the University gives credit to her male colleagues for the (alleged) success of the workplace with gender mainstreaming: «We have, thankfully, a few male feminists within our unit that are conscious. So, [application of gender mainstreaming] has proven to be easy for us».

The need for men's gender awareness and support for progress echoes previous accounts of the conflict around gender equality work (Andersson 203). Moreover, it reflects the gendered power relations within the workplace; without support from men, no progress will be made.

The aura of gender equality, in other words the perception of gender equality despite practical evidence indicating otherwise (Pétursdóttir 3), was evident among the responses of some of the policy actors. They perceived themselves and their workplaces to be working hard to realise gender equality and that they had mainstreamed gender into their policies and decision-making processes. However, the lack of evidence of practice demonstrates how the transformative aspect of the strategies can easily fail to materialise (Benschop and Verloo 284). For example, as seen in the comment below, a management policy actor at the University not only exaggerates the proportion of the academic staff that have gender expertise, but also believes that having a gender perspective in some of the research activity within the school automatically results in gender and equality perspective being present in the school's policies and decision-making process: «I think that at least one-third of the staff are in some way experts in equality issues, especially gender equality, so it impacts all their work whether it being administration or teaching».

Closely related is the lack of gender+ awareness and the perception that all individuals are equal; thus, meeting the needs of different groups is seen 
as discrimination. A management policy actor who provides services directly to students at the University noted:

[Gender and diversity] are definitely not a perspective that we have been systematically incorporating because we are somehow just looking at the group of students. Gender doesn't matter, and it just, we just want to service the students and period. You know, that is the way it is.

This individualistic approach is also apparent at the City. A collaboration project revealed a gendered patter in how people sought services, that is men sought information on «masculine» issues and women on «feminine» issues, and that marginalised people, such as foreigners and disabled people, used the services to a very small extent. However, when a management policy actor was asked if her division has taken any measures to reach different groups of citizens with their services, she responded as if everyone had the same needs: «Everybody gets the same service. Everybody. It is our motto that everybody gets the same service. There is no one that gets more service than the other, or more or less service».

Bacchi and Eveline («Approaches» 131) warn against approaching the problem in a narrow context, that is, by focusing on individuals and leaving out broader gender and social relations. The lack of understanding about gender and social relations and how they can be reproduced in the decision-making process is linked to inadequate knowledge. This is discussed in the next section.

\section{INADEQUATE KNOWLEDGE}

Two of the policy actors interviewed had an educational background in gender studies, and they have a clear vision and understanding of the application of gender mainstreaming and gender budgeting, both in general and within their field of work. Their knowledge of gender theory influences their approach, which includes a feminist perspective, as can be seen in the comments from a policy actor from the City:

[Gender budgeting] is a strategy that the City, as an authority, is using to facilitate equality. That is the point. However, I think too often the very objective gets left behind, that is, that we are doing this because of inequality, and we are trying 
to change that. And I think it is an important reminder that the precondition for doing [gender budgeting] is acknowledging that there is inequality.

The policy actor criticises the focus on an increasingly bureaucratized process, and stresses that policy actors need to remember that the purpose of gender budgeting is transformative. Apart from these two policy actors, there is a general lack of knowledge on gender mainstreaming and gender budgeting, that reflects Woodward's (69) observations about the risk of gender mainstreaming being compromised when applied by non-femocrats. When asked if they had taken any measures to correct the representation of diverse groups in their public facing communication material, a mid-level policy actor with a gender background ponders if a lack of knowledge about and understanding of how to include the gender and diversity perspective should be expected:

I wonder what we can expect from the staff, even though we are all very bright here [in this division]. But if you consider it in general, that everybody must have a clear understanding. Because I sometimes feel that it isn't even clear in the literature. We must have it well defined.

The lack of knowledge among policy actors can be manifested in their perspective that gender mainstreaming and gender budgeting: a) cannot be applied to the particular services provided by the City or the University, nor can they be applied to their particular area of work; and b) are (only) accomplished through equal gender representation and equal pay.

The general understanding that gender mainstreaming and gender budgeting cannot be applied to all the services provided by the City and the University stems from the general lack of knowledge about how public policy and public spending and revenue can maintain and even produce inequalities -that is, the policies can be inherently gendering and heteronorming, racializing, classing and (dis)abling (Bacchi and Eveline, «Approaches» 112). The comments below from a management policy actor from a service-focused division at the City stand out as she sees gender and other social and power relations as important factors because of the obligation of equity in public administration. According to her, all decisions are built on assessments of the need for and use of services and monthly monitoring:

We assess if the services [provided by the City] are in accordance with regulations and procedures, and of course we must include an equality perspective, 
whether it is gender equality or other equality perspectives. So, we are constantly assessing if the services are consistent with if you are a man or a woman, poor or rich, because everybody is supposed to have access to the same services. [...] Our procedures must ensure equity.

Other policy actors disconnected the gender equality perspective from the policy and the spending and revenue; hence, gender is not mainstreamed into their decision-making processes. This is seen in the comments made by a management policy actor: «Well, [gender budgeting] is more like a project, because the day-to-day tasks are more focused on the operation, the finances and the services».

The disconnection between the gender+ perspective, finances and the decision-making process can be reflected in the assumption that decision-making is gender neutral (Bacchi and Eveline, «Mainstreaming» 52; O'Hagan and Klatzer 5). The perceived gender neutrality of decision-making, such as providing services to citizens or students, maintains the idea that gender mainstreaming is a separate task or project. The «project trap» (Bacchi and Eveline, «Mainstreaming» 52) can be reflected in the words of a management policy actor:

[Gender mainstreaming] is not exactly one of my tasks, simply because we are first and foremost here to provide services to citizens. But of course, I spend a lot of time each month thinking how I can even the gender balance within the workplace.

This management policy actor sheds a light on a common misunderstanding, held by half of the participants, that gender mainstreaming and gender budgeting mean equal pay or encouraging equal representation of men and women employed in the workplace and participating in decision-making processes. This can be seen in the comments made by another management policy actor at the University, whose division has participated in a number of collaboration projects on organisational issues that revealed gendering practices, e.g. in terms of workloads for student supervision, internal support grants for teaching assistance and the position of the PhD students. When asked if gender perspectives are included in his division's policy-making efforts, he said: «Yes. Well, only to the extent that we make sure that there is equal gender representation in the decision-making processes». 
The idea that gender mainstreaming is simply counting bodies is widespread among the policy actors, despite their participation in the collaboration projects, and despite the fact that gender mainstreaming has been obligatory since 2008 (Act on the Equal Status and Equal Rights of Women and Men no. 10/2008) and gender budgeting has been on the agenda since 2010 at the City and 2013 at the University (Steinpórsdóttir et al. 179). Even though gender representation is an important aspect of gender equality, it is not enough to eliminate gender biases in decision making (see e.g. Stainback, Kleiner, and Skaggs 130; Childs and Krook 145). The same can be said about equality policies. Having a gender equality policy is often considered to be gender mainstreaming, as seen in the comments from a management policy actor when asked if gender and diversity are mainstreamed in their decision-making process:

Well yes, we have a special equality or policy against discrimination or whatever. It was of course the integration of the equality policy and a policy on other discrimination, and of course [a feminist] lead the work.

This management policy actor reveals his lack of knowledge about gender mainstreaming, and his comment about a gender expert being on board appears to be an alibi. This approach -having an equality policy but not taking any action- is unlikely to result in transformative action.

However, one mid-level policy actor is aware of these problems, and she emphasised the need to increase awareness among financial directors and other policy actors to facilitate the implementation of gender budgeting:

I believe that training is part of the implementation. The aim of the training is to make people aware that the reason we are doing this is to facilitate equality and it is our responsibility. Also, The City, as a workplace and as an authority, is working towards facilitating equality. Because that is something we want to do. Always. And that it becomes part of people's consciousness.

\section{SUPERFICIAL APPROACH}

Our findings substantiate findings from the literature on the implementation gap (e.g. Bendl and Schmidt 375; Bacchi and Eveline, «Mainstreaming» 52; O'Hagan and Klatzer 7; Scala and Paterson 208; Sharp and Broomhill 21). There are few signs of gender being mainstreamed systematically into the 
policy actors' decision-making processes. In general, the approaches of the policy actors that considered themselves to be implementing gender mainstreaming and gender budgeting were superficial. This includes a) confusing the «awareness» of inequality and performing a gender impact assessment with implementation of the strategies; and b) taking no action, which maintains the social and political status quo.

The objective of gender mainstreaming and gender budgeting is commonly understood simply to be the production of knowledge about the gender+ dimensions of society or specific activities. In general, most of the policy actors believed that a gender+ impact assessment, as well as the outcome of the collaboration projects, represented the full implementation of the strategies. This can be seen in the comments made by a management policy actor from the City when discussing the outcomes of a project on participation in services provided by the senior community centre, revealing the need to encourage men's participation: «I think the main goal is that [the collaboration project] gave us something to think about. And that is a very big step».

When the policy actors were asked about how they apply the strategies in their work, awareness of inequality (e.g. they «should be thinking about» and "should always be checking» the gender perspective) was a common reference point. However, as a management policy actor noted, this approach tends to omit gender issues from the agenda: «I should always think about [gender]. I am not sure I have always done that, but I try. But I need to be reminded about [including that perspective]».

Contrary to Sharp and Broomhill's (8) suggestions that critical engagement with external actors could facilitate implementation, the policy actors did not demonstrate accountability for correcting or responding to the gendering processes and outcomes of the gender+ impact assessments. Gender biases are seen as something that one needs to be aware of or forwarded to some other accountable unit. They are not necessarily something to be acted on by oneself or to be addressed as a matter of institutional or strategic importance. This belief is seen in the comments made by a University management policy actor when asked about action taken following collaboration projects revealing gender stereotypical committee representation and lack of diversity in their promotion material: «[The findings] are useful and need to be delivered 
to the Equal Rights Committee. Not that the committee must act on it, more just to keep us aware [of the problems]».

It is common that the policy actors that have accountability refer the findings of a gender impact assessment to committees without this resulting in further action. One of the mid-level policy actors participating in a project on internal grants revealing gender imbalances in favour of men criticised:

I remember one example. We got this good report, an assessment of funds, and it was not possible to get a decision [on how to react to its findings] from the committee. [They should have] sent the recommendations to the governing bodies of the funds to do something about the applications system, the decisions, because these were the issues referred to [in the report]. This was wiped off the table. And I said: Why are we doing these projects and not using the findings for improvement? I don't know if they have done anything.

When the policy actors discussed evidence of practice to correct imbalances or biases, their approach usually disregarded gendered power relations. They approached the problem in gender-neutral terms; that is, the aim was to even out differences between women and men rather than looking at the factors that produce those differences. Action is taken when the service is believed to be biased against men, reflecting a narrow approach to the problem and ignoring the power and social relations (Bacchi and Eveline, «Mainstreaming» 52). Two examples illustrate this «project trap», both from management policy actors who have been overly focusing on balancing the gender representation within their female-dominated fields (that is, increasing the number of men). One policy actor works in administration at the University and the other works in elderly care for the City. This shows how men are prioritised in gender equality work, and it demonstrates a lack of understanding of gendered power relations.

When asked about how she works towards equality, a management policy officer replied that she gives all the staff at her division, men and women, permission to leave during the Women's Day Off, which is the Icelandic Women's strike for equal pay (Kvennafrí). Since the policy officer could not refer to any other evidence of practice, this insinuates that this action is symbolic, being used as an alibi. Moreover, giving both women and men a day off depoliticises the strike, which aims to demonstrate how society and workplaces would not 
function without women's under-recognised contribution -and it reflects the tendency to avoid conflict in gender equality work (Andersson 203).

According to a mid-level policy actor, the collaboration projects are important in order to counteract the gender-neutral approach, and they take into account gendered power relations in a gender impact assessment and when implementing gender mainstreaming and gender budgeting:

When we are collaborating with the students, they are assessing things that we often do not see. And yes, I believe they create good knowledge. What is more, I think we do not necessarily look critically at what we are doing. We do not often take a step back and look at the whole picture, or look at it from a different perspective, and that is why I believe it is very good to get these students' projects.

Not all the policy actors were as positive; there were many times when the policy actors had not even looked into the findings from the collaboration projects or had forgotten about them. None of the cases of students' collaboration projects resulted in action being taken despite the findings from a gender impact assessment of a policy or if a decision revealed gender imbalances and biases. Hence, despite the engagement of external actors, the projects did not result in chains of accountability, as suggested by Sharp and Broomhill (22). Some policy actors said the lack of resources, such as time, staff and money, hinders them from doing any reform work. However, the lack of action sometimes stems from indifference, as seen in the response of a management policy actor who participated in projects on internal grants and academic housework (Heijstra et al. 211): «Well, no. Our feeling is that our system is rather good». In this instance, he relied more on his own intuition about the system rather than evidence of the outcome of the project, which would require correction of gendered imbalances and biases.

Many policy actors find it difficult to respond to gender biases because they do not perceive themselves as having the power to make decisions and change the processes to ensure more equal outcomes. There were contradictions in the discussions about taking action at the University. Many of the policy actors said the mandate must come from the central administration and the top management at the University. At the same time, the policy actors from the central administration claimed that they do not have any power over the policy and the decision-making process at lower organisational levels. Even high-ranking policy actors talked about the lack of a mandate 
to take action towards ensuring more equal outcomes. This is interesting because, as previously mentioned, equality is a well-recognised policy goal at the University. These perspectives about taking action indicate that these policies are essentially window dressing. Thus, there is a general reluctance to take responsibility for equality issues. This perspective further undermines the resolve towards the possibility of taking action, as seen in the comments from a mid-level policy actor who participated in the public relation projects: «We have a rather big set-up, so it is difficult to steer some issues and... yeah, just impossible».

\section{DISCUSSION AND CONCLUSION}

The objective of this research was to study how organisations respond to public policy and legislation on gender mainstreaming and gender budgeting. We studied the outcomes of implementation projects performed within two organisations, the City and the University, in collaboration with the Department of Gender Studies at the University. Drawing on the findings, in this section we discuss the potential for and hindrances of using such collaboration projects to jumpstart transformative gender+ equality work within organisations.

The national legislation and organisational policies require organisations to integrate gender into all their policies and decision-making processes. However, as seen from the interviews with the policy actors, there is little indication that gender mainstreaming and gender budgeting are being fully delivered within the City and the University. This is in line with Bacchi and Eveline's (306-307) findings that organisational obligation does not necessarily lead to organisational commitment. Assessing the status of the implementation of the strategies from the technocratic perspective, the policy actors interviewed revealed that if they apply the strategy, they do not go beyond the gender analysis of specific activities. In general, gender analysis is not integrated into their policies and decision-making processes. In terms of the collaboration projects, the students performed the analysis and provided research-informed advice on how to integrate the gender perspective into decisions on the activity in question. However, similar to Andersson (215216), actions that could improve gendering policies, decisions or processes 
are avoided. Moreover, there is hardly any evidence that the policy actors had taken action to improve the position of women. Hence, at best, the collaboration projects managed generate knowledge about the alleged gender-neutral activity. This almost always only resulted in knowledge production for the policy actor in question, as most of the findings and suggestions from the collaboration projects were not presented to other members of the organisation. Moreover, the gender analysis findings and the research-informed advice produced in the collaboration projects rarely led to transformation of organisational processes to ensure more gender equal outcomes, which is the objective of gender mainstreaming and gender budgeting (Benschop and Verloo 283; O'Hagan 20-21).

Legislation and policies, as well the theoretical idea of gender mainstreaming, make all the policy actors responsible for mainstreaming gender into all policies and decision-making processes. Benschop and Verloo (284) voice concerns about this approach because of the misunderstanding about gender and gender mainstreaming among the policy actors. Our findings support this lack of understanding of the problem and of the gender perspective was common among the policy actors. Some of them remained in the aura of gender equality (Pétursdóttir 3) and had difficulties seeing the relevance of gender (Eveline and Bacchi 306-308). They had a tendency to fall into the project trap, and in their approaches they overlooked the social and power relations that have been identified as central in other literature (Bacchi and Eveline, «Mainstreaming» 52; O'Hagan and Klatzer 5). One example of the project trap was when policy actors approached the service users (students or citizens) in gender-neutral terms, superficially aiming to even out the differences between men and women. In line with Andersson (2015), approaching the issues from a feminist perspective was not seen as legitimate or professional (Andersson 215). Nonetheless the policy actors who had an understanding of gender and other social relations approached their work from a feminist perspective and tried to challenge and change the gendering processes. However, their power to transform the system is limited. This confirms Benschop and Verloo's concerns (284) that by making the strategy everyone's responsibility can result in the strategy failing all together.

The focus on management and mid-level policy actors within the organisations rather than high-level management, is both a strength and a limitation 
of our study. It is a strength, because it reveals the understanding and perspectives that the policy actors, who are regularly involved in implementation, have about gender mainstreaming and gender budgeting. This is an aspect that has not received much attention in the literature (Scala and Paterson 209). It is a limitation because the systematic implementation of the strategies might be done elsewhere in the organisations but these policy actors might not be aware of it. Hence, we suggest that future research conducts a more comprehensive assessment of the status of the implementation within organisations. The findings of our study suggest that implementation of gender mainstreaming and gender budgeting processes and procedures are lacking in the organisations under study, echoing the established perspectives in the literature in relation to this problem. Consequently, the equality infrastructures need to be strengthened with formal authority and resources, and gender mainstreaming and gender budgeting processes and procedures must be formalised (Klatzer, Brait, and Schlager 152; Benschop and Verloo 284-287; Eveline and Todd 551-554).

The collaboration projects clearly reveal the weaknesses and the shortcomings of gender+ equality work. However, if we can overcome certain hindrances, we believe collaboration projects on gender mainstreaming and gender budgeting have the potential to facilitate change. To increase the organisational commitment, the policy actors need to be more involved in the collaboration projects, as suggested by Eveline and Bacchi (306-308). In other words, the policy actors need to be given more hands-on experience conducting gender analysis, so they can see how the problems are created. Learning by doing will enhance the policy actors' knowledge about and understanding of the problem and the gender+ perspective.

Presenting and sharing project outcomes within the organisations increase the likelihood that the knowledge production will benefit other policy actors within the organisations and would also increase awareness of the gendering of the policy and decision-making processes. Chains of accountability need to be established. This could be done by making the students' reports publicly available. These reports could be employed by external actors, such as feminist advocates, that might be excluded from the implementation processes (Powell, Ah-King and Hussénius 129; Klatzer, Brait and Schlager 147-151), to hold the organisations accountable. 
Gender analysis is important, but in order for the implementation to be successful, organisations must make the effort to take action and change their organisational processes to promote the production of equality (O'Hagan 20; Benschop and Verloo 283; Bendl and Schmidt 364; Eveline and Todd 537). To support the policy actors in taking action to implement gender mainstreaming and gender budgeting, the collaboration has to be extended beyond the collaboration projects. This could be done with follow-up support from the experts at the Department of Gender Studies. More follow-up support on the collaboration projects is likely to result in positive outcomes, or small wins, in line with Correll's model, which has the potential to motivate further action (Correll 735-737). This will reinforce the idea that the strategy needs to be an ongoing process of analysis and re-visioning (Eveline and Todd 551-554). Resources, which are often lacking, are most likely needed for that support to be realised. However, in the literature, it is well-documented that organisations benefit from collaboration with gender experts and research (Benschop and Verloo 284-287; Eveline and Todd 551-554).

In this article, we explored the collaboration projects between students in the Department of Gender Studies and policy actors at the University and the City. The collaboration projects are based on the idea of a jumpstart along with a «small wins» model of change. Identifying the potentials for and the hindrances of the collaboration projects has generated knowledge about the conditions required to fully jumpstart and implement structural transformative gender+ equality work.

\section{REFERENCES}

Act on Equal Status and Equal Rights of Women and Men No. 10/2008 (Icel.).

Andersson, Renée. «The Question of Feminism in Gender Mainstreaming -a

Case of Non-Conflict in Local Politics». NORA-Nordic Journal of Feminist and Gender Research 23.3 (2015): 203-19.

Bacchi, Carol. Analysing Policy: What's the Problem Represented to Be? Frenchs Forest, N.S.W.: Pearson, 2009.

Bacchi, Carol, and Joan Eveline. «Mainstreaming and Neoliberalism: A Contested Relationship». In Mainstreaming Politics: Gendering Practices and Feminist Theory. Eds. Carol Bacchi, and Joan Eveline. Adelaide: University of Adelaide Press, 2010. 39-60.

Feminismo/s 35, junio 2020, pp. 179-205 
Bacchi, Carol, and Joan Eveline. «Approaches to Gender Mainstreaming: What's the Problem Represented to Be?». In Mainstreaming Politics: Gendering Practices and Feminist Theory. Eds. Carol Bacchi, and Joan Eveline. Adelaide: University of Adelaide Press, 2010. 111-38.

Bendl, Regine, and Angelika Schmidt. «Gender Mainstreaming: An Assessment of Its Conceptual Value for Gender Equality». Gender, Work \& Organization 20.4 (2013): 364-81.

Benschop, Yvonne, and Mieke Verloo. «Gender Change, Organizational Change, and Gender Equality Strategies». In Handbook of gender, work and organization. Eds. Emma Jeanes, Daid Knights, and Patricia Yancey Martin. West Sussex: Wiley, 2011. 277-90.

Charmaz, Kathy. Constructing Grounded Theory: A Practical Guide through Qualitative Analysis. London: Sage Publications, 2006.

Childs, Sarah, and Mona L. Krook. «Analysing Women's Substantive Representation: From Critical Mass to Critical Actors». Government and Opposition 44.2 (2009): 125-145.

Correll, Shelley J. «Sws 2016 Feminist Lecture: Reducing Gender Biases in Modern Workplaces: A Small Wins Approach to Organizational Change». Gender E Society 31.6 (2017): 725-50.

Council of Europe. Gender Mainstreaming: Conceptual Framework, Methodology and Presentation of Good Practices. Final Report of Activities of the Group of Specialists on Mainstreaming. Strasbourg: Directorate General of Human Rights, 1998.

Council of Europe. Recommendation 1921. Strasbourg: Council of Europe, 2010. Einarsdóttir, Porgerður. «All that Glitters is Not Gold: Shrinking and Bending Gender Equality in Rankings and Nation Branding». NORA - Nordic Journal of Feminist and Gender Research (2020): 1-13.

Einarsdóttir, Porgerður, and Gyða M. Pétursdóttir. «Meðbyr og ágjöf: próun kynjafræðináms í íslensku samhengi». Íslenska pjóðfélagið 10.3 (2019): 5-29.

Eveline, Joan, and Carol Bacchi. «Obeying Organisational 'Rules of Relevance': Gender Analysis of Policy». In Mainstreaming Politics: Gendering Practices and Feminist Theory. Eds. Carol Bacchi and Joan Eveline. Adelaide: University of Adelaide Press, 2010. 283-310.

Eveline, Joan, and Patricia Todd. «Gender Mainstreaming: The Answer to the Gender Pay Gap?». Gender, Work E Organization 16.5 (2009): 536-58. 
Glaser, Barney, and Anselm Strauss. The Discovery of Grounded Theory: Strategies for Qualitative Research. New York: Aldine, 1967.

Háskóli Íslands. Equality and Diversity. 25 January 2020. <https://english.hi.is/ equality>

Háskóli Íslands. University of Iceland Equality Action Plan 2018-2020, 2018. <http://english.hi.is/university/equal_rights_policy>

Heijstra, Thamar M., Porgerður Einarsdóttir, Gyða M. Pétursdóttir, and Finnborg S. Steinpórsdóttir. «Testing the concept of academic housework in a European setting: Part of academic career-making or gendered barrier to the top?». European Educational Research Journal 16.2-3 (2017): 200-214.

Her Majesty the Queen in Right of Canada. Gender report. Budget 2019. 19 May 2020. <https://www.budget.gc.ca/2019/docs/gba-acs/gbs-acs-en.pdf>

Johnson, Janet, Porgerður Einarsdóttir, and Gyða Margrét Pétursdóttir. «A Feminist Theory of Corruption: Lessons from Iceland». Politics E Gender 9.2 (2013): 174-206.

Keisu, Britt-Inger, Lena Abrahamsson, and Malin Rönnblom. «Entrepreneurship and Gender Equality in Academia -a Complex Combination in Practice». Nordic Journal of Working Life Studies 5.1 (2015): 69-92.

Klatzer, Elisabeth, Romana Brait, and Christa Schlager. «The Case of Austria: Reflections on Strengthening the Potential of Gender Budgeting for Substantial Change». In Gender Budgeting in Europe: Developments and Progress. Eds. Angela O'Hagan and Elisabeth Klatzer. New York, London: Palgrave Macmillan, 2018. 137-157.

Kvennafrí. Kvennafrí. 26 January 2020. <https://kvennafri.is/en/front1-en/> Lombardo, Emanuela, and Lut Mergaert. «Gender mainstreaming and resistance to gender training: A framework for studying implementation». NORA-Nordic Journal of Feminist and Gender Research 21.4 (2013): 296-311.

Mackay, Fiona, Surya Monro, and Georgina Waylen. «The Feminist Potential of Sociological Institutionalism». Politics E Gender 5.2 (2009): 253-262.

O'Hagan, Angela. «Conceptual and Institutional Origins of Gender Budgeting». In Gender Budgeting in Europe: Developments and Progress. Eds. Angela O'Hagan and Elisabeth Klatzer. New York, London: Palgrave Macmillan, 2018. 19-42.

O'Hagan, Angela, and Elisabeth Klatzer. «Introducing Gender Budgeting in Europe». In Gender Budgeting in Europe: Developments and Challenges. Eds. Angela O'Hagan and Elisabeth Klatzer. New York, London: Palgrave Macmillan, 2018. 3-19.

Feminismo/s 35, junio 2020, pp. 179-205 
Pétursdóttir, Gyða Margrét. Within the Aura of Gender Equality: Icelandic Work Cultures, Gender Relations and Family Responsibility. A Holistic Approach. Diss. University of Iceland, 2009.

Powell, Stina, Malin Ah-King, and Anita Hussénius. «'Are We to Become a Gender University?' Facets of Resistance to a Gender Equality Project». Gender, Work E Organization 25.2 (2018): 127-43.

Reykjavíkurborg. Mannréttindi [Human Rights]. 25 January 2020. <https://reykjavik.is/mannrettindin>

Reykjavíkurborg. Kynjajafnrétti [Gender Equality]. 25 January 2020. <https:// reykjavik.is/jafnretti-1>

Reykjavíkurborg. Human Rights Office. 25 January 2020. <https://reykjavik.is/ city-reykjavik-human-rights-office>

Scala, Francesca, and Stephanie Paterson. «Stories from the front lines: making sense of gender mainstreaming in Canada». Politics \& Gender 14.2 (2018): 208-234.

Sharp, Rhonda, and Ray Broomhill. A case study of gender-responsive budgeting in Australia. London: Commonwealth Secretariat, 2013.

Stainback, Kevin, Sibyl Kleiner, and Sheryl Skaggs. «Women in Power: Undoing or Redoing the Gendered Organization?». Gender E Society 30.1 (2016): 109-35.

Steinpórsdóttir, Finnborg S., Katrín Anna Guðmundsdóttir, Thamar Melanie Heijstra, and Halldóra Friðjónsdóttir. «Gender Budgeting in Iceland». In Gender Budgeting in Europe: Developments and Challenges. Eds. Angela O'Hagan and Elisabeth Klatzer. New York, London: Palgrave Macmillan, 2018. 179-98.

Verloo, Mieke, and the Quing consortium. Final Quing Report. Vienna: Institute for Human Sciences, 2011. <https://www.iwm.at/projects/quing/www.quing. eu/files/QUING_Final_Report_Jan\%2012.pdf>

Woodward, Alison. «European Gender Mainstreaming: Promises and Pitfalls of Transformative Policy». Review of Policy Research 20.1 (2003): 65-88.

World Economic Forum. The global gender gap report. Geneva: WEF, 2020. 

To link to this article / Para enlazar con este artículo:

https://doi.org/10.14198/fem.2020.35.08

To cite this article / Para citar este artículo:

O'Hagan, Angela. «Bacchi as pedagogy: Surfacing equality and human rights in public policy teaching». En Feminismo/s, 35 (junio 2020): 207-232. Monographic dossier / Dossier monográfico: A critical practice of thinking otherwise: Bacchi, Gender and Public Policy Analysis, coord. Angela O'Hagan, DOI: 10.14198/ fem.2020.35.08

\title{
BACCHI AS PEDAGOGY: SURFACING EQUALITY AND HUMAN RIGHTS IN PUBLIC POLICY TEACHING
}

\author{
BACCHI COMO PEDAGOGÍA: LA IGUALDAD Y \\ LOS DERECHOS HUMANOS EN LA ENSEÑANZA DE \\ LAS POLÍTICAS PÚBLICAS.
}

\author{
Angela O'HAGAN \\ Glasgow Caledonian University, Glasgow \\ Angela.OHagan@gcu.ac.uk \\ orcid.org/0000-0002-6130-8186
}

\begin{abstract}
Understanding the structural dimensions of inequality, and reflecting on our own assumptions and the presuppositions and knowledge basis of the institutions we work in is key to a critical approach to management and to learning. That is the central argument of this article which demonstrates the application of Bacchi's 'What's the Problem Represented to be?' framework in the learning, teaching and assessment in a post graduate programme on Citizenship and Human Rights. Based on critical theories in feminism, disability, racism, globalisation and human rights, the programme aimed to support «practitioner students» in acquiring new theoretical knowledge and applying that to their organisational practice. Reflecting on current practice and procedures and thinking backwards from current ways of thinking and doing, students were encouraged to «critically engage in thinking otherwise», as exhorted by Bacchi. Through this critical engagement with theory and practice, student practitioners could then «surface» the equalities and human rights dimensions and tensions in their work.
\end{abstract}

Keywords: Equality; Human rights; Public policy; Social justice; Feminism.

Los contenidos de la revista se publican bajo una licencia de Creative Commons Reconocimiento 4.0 Internacional (CC BY 4.0)

Feminismo/s 35, junio 2020, pp. 207-232 


\section{Resumen}

Comprender las dimensiones estructurales de la desigualdad y reflexionar sobre nuestros propios supuestos y las presuposiciones a la base de conocimiento de las instituciones en las que trabajamos es necesario para un enfoque crítico de la gestión y el aprendizaje. Ese es el argumento central de este artículo, que demuestra la aplicación del marco Bacchi «¿Cómo se ha representado el 'problema'?» en el aprendizaje, la enseñanza y la evaluación en un programa de posgrado sobre Ciudadanía y Derechos Humanos. Basado en teorías críticas sobre feminismo, discapacidad, racismo, globalización y derechos humanos, el programa tuvo como objetivo apoyar a los «estudiantes practicantes» en la adquisición de nuevos conocimientos teóricos y aplicarlos a su práctica organizacional. Al reflexionar sobre la práctica y los procedimientos actuales y «pensar hacia atrás» desde las formas actuales de pensar y hacer, se alentó a los estudiantes a "comprometerse críticamente a pensar de otra manera», como lo exhortó Bacchi. A través de este compromiso crítico con la teoría y la práctica, los estudiantes practicantes podrían entonces «hacer surgir» las dimensiones y tensiones de igualdad y los derechos humanos en su trabajo.

Palabras clave: igualdad; derechos humanos; políticas públicas; justicia social; feminismo.

\section{INTRODUCTION}

In 2010, Glasgow Caledonian University (GCU) introduced an MSc in Citizenship and Human Rights. This programme was developed to meet a need among social justice practitioners working in civil society and public sector organisations to support in-work practice by enhancing the underpinning analytical capacity and conceptual knowledge base of practitioners. At the time there were a number of positive drivers for a programme of this type. The Public Sector Equalities Duties were being introduced under the Equality Act 2010, building on the previous positive duties and emphasising the transformational potential of engaging institutional policy and decision making processes in equalities analysis (Hepple 19). Furthermore, the underpinning for the new legislation drew heavily on the capabilities approach (Burchardt and Vizard 91), which was also featured in the course content and design of the MSc syllabus and learning outcomes.

This innovative programme at GCU was international in scope and intent, reflecting the global commitments around the Millennium Development 
Goals (MDGs) initially and then moving to the SDGs from 2015. There was also a significant domestic content within the programme as the devolution of powers to the Scottish Parliament created an ongoing process of policy development and structural change. This local context of the development of a small nation, growing its autonomous (devolved) competences since 1999, and building a distinctive discursive narrative around equality and human rights reflected ambitions of transformational and alternative policy making (O'Hagan, «Favourable» 234). The domestic political discourse was framed around aspirational policy objectives to integrate equality and human rights, and from the inception of the Scottish Parliament, a rhetorical drive in public policy on basing practice and improved outcomes on social justice goals (Scott and Mooney 380; O'Hagan, «Perspectives» 229). This was increasingly reflected in the rhetoric and service design in public and third sector organisations and their expressed desire for changes in practice.

Emma Coles et al. describe this approach as «a whole policy/whole country implementation and national transformational change agenda» (336). For these scholars, the focus is specifically in relation to the wellbeing of children, but the aspirations ranged across all social, and to some degree economic policy domains as

Scotland has attempted to further its aspirational agenda based on the desire to create a socially democratic society while at the same time addressing Scottish needs and the Scottish national interest and following principles of social justice (339)

This policy context and the drive to improve practice in equality and human rights, locally and globally, was the background for the MSc in Citizenship and Human Rights. The programme was designed for and with policy analysts, client-facing service managers, equality and diversity officers, and other policy advocacy roles within third and statutory organisations, initially with the support of the Scottish Council for Voluntary Organisations (SCVO). The first cohort also attracted funding support through the European Social Fund to facilitate participation from practitioner students based in the Scottish Highlands and Islands. The post-graduate students on this programme were not recent graduates. Some had no first degrees, and for others their first degrees had been achieved 20-plus years ago. All of the students were in work 
in a range of roles across third sector service delivery, civil society advocacy, local and statutory authorities, and even one student from an industry professional body with members largely located in the private sector. In recognition of that experience, and that this programme was designed as a «work-based» programme, when referring to «students» throughout this article, I characterise them as «practitioner students».

This article sets out the application of feminist theoretical and policy analysis as a core theoretical pillar of the MSc programme and discusses the theoretical concepts in play in relation to feminist analysis. Feminism was not the only critical theoretical framework in the programme, but is the principal focus of this article. Following a brief introduction to the programme structure, the article introduces Bacchi's What's the Problem Represented to be (WPR) framework as a structure for applied learning for practitioner-students. The main evidence presented and discussed here are the findings from student coursework and reflexive journals. The article focuses on the use of WPR as an analytical process that reveals androcentric and other normative approaches to organisational practice and policies and the implications of the established ways of thinking and doing of governmental policy for implementation in diverse social policy related organisations. The article concludes with observations on the application of the WPR framework as a heuristic within reflexive pedagogy in the context of critical management education.

The principal contribution of this article is the presentation of how practitioner-students in a post-graduate programme on Citizenship and Human Rights acquired new knowledge that both challenged and reaffirmed some of their existing knowledge on equality and human rights from a range of critical theoretical perspectives. Core to the principles of the programme, as a form of critical management education, was a framework of critical theory on gender, race, disability, globalisation and migration, and human rights. This article describes the approach in two modules to learning, teaching, and doing through engaging students in reflexive processes that revealed what Bacchi and Goodwin (13) describe as different ways of thinking about «commonly accepted categories and governing practices». 


\section{CREATING A CRITICAL LEARNING COMMUNITY}

In designing a post-graduate curriculum for work-based learning for students from social policy and social service organisations, learning, teaching and assessment had to be cognisant of the wealth of experiences such students bring from their personal and professional lives. As established in the critical management education literature summarised by Hibbert «the effective learning of such processes seems to depend on students having substantial experience to explore, critique, and reconsider in order to facilitate critical reflection on their own management lives» (805).

With students from Scotland and other countries; from third, statutory and private sectors, perspectives were mixed and organisational focus varied considerably. From the outset then, the aim of the programme was to be inclusive in relation to age, disability, location, gender and ethnic identity, and educational background. This range of perspectives brought a wealth of knowledge and practical experience to the programme and to the individual modules in the real and virtual classrooms. This diversity of experience and perspective was an important element in establishing a critically engaged community of learning, consistent with what Hibbert (808) and others have described as a «community feel» in the physical and virtual classroom. A further challenge in creating a community of learning and practice was that the programme was a combination of on-line and face-to-face delivery. The majority of «lecture» and learning material was provided through an online blackboard, supplemented by use of other accompanying technologies such as wikis, virtual discussion boards, and on-line journals. Each module included four full days of face:face engagement with students and tutors at the start and towards the end of the module.

\subsection{Citizenship and Human Rights in a work-based context}

The rationale for the Masters was to create a programme for learning that would underpin the principles of social justice that practitioners in third and statutory sectors aimed to be working to by providing both theoretical structure and challenge to establish norms. There was an explicit intention to link human rights principles to management and organisational practices 
that not only was consistent with expressed institutional commitment to the «common good» and the UN Global Compact Principles of Responsible Management Education (PRME) but which more substantively stemmed from an epistemological view of the world and an awareness of the unequal lived effects as a consequence of dominant economic paradigms and political structures.

The MSc in Citizenship and Human Rights was initiated in 2010, just as the effects of the politically constructed austerity measures in response to the financial crash of 2008 were beginning to be enacted by governments in the UK and globally. A central pivot of austerity measures was the systematic withdrawal of public spending from public services, social security and social protection measures, and an emphasis on such as a means of reducing levels of national debt and the deficits in public finance.

This context provided multiple pathways for policy analysis and interrogation within classroom discussion. It also meant that as public services were dismantled and existing inequalities exacerbated, practitioners in the third and statutory sectors came under increasing pressure to deliver services and augment their advocacy. At the same time, their training and professional development budgets were lost, resulting in small numbers accessing a programme like this masters, however innovative it was at the time. The programme ran for almost ten years, albeit with small student cohorts but whose ability and levels of engagement compensated for the lack of numbers.

Our MSc in Citizenship and Human Rights was developed to meet a need among social justice practitioners working in civil society and public sector organisations. A core intention of the programme design and content, was to surface what Bacchi (Women 7) describes as «lived effects», that is, the diverse ways in which people experience how policy makers represent problems and policy decisions in their everyday lives. Drawing on critical theories of disability, race, feminism, globalisation, and the application of alternative theories of social, legal and economic justice such as the Capabilities Approach (Sen; Nussbaum) and Fineman's conception of vulnerability, students were encouraged to engage in what Bacchi and Goodwin describe as the «critical practice of thinking otherwise» (21). 


\section{INTRODUCING BACCHI}

Central to the learning and teaching on the programme was a very clearly expressed intent to encourage learners in the critical practice of «thinking otherwise» as Carol Bacchi exhorts policy analysts and others to do in her What's the Problem Represented to be (WPR) framework. The WPR framework was not used in all modules in the programme: it structured work-related change projects and reflexive journals in the modules on Human Rights and Leadership for Equality. The structure of learning and applying the Bacchi framework and the insights from practitioner-student coursework form the central focus of this article.

\section{DEVELOPING CRITICAL THINKING IN SOCIAL JUSTICE PRACTICE}

This next section locates the feminist theoretical approaches that underpinned the learning, teaching in the modules that used the Bacchi WPR approach for assessments. Other critical theories structured the MSc programme, but as a feminist academic activist, my teaching is informed and shaped by an overarching framework of feminist theory from a mainly radical feminist perspective. As a gender budgeting and feminist policy analyst, the curriculum I delivered within Leadership for Equality and Human Rights modules predominantly featured an applied feminist economics and feminist institutionalist approach to analysis and representation of the intersectional lived effects of policy decisions on people's everyday lives.

Foundational concepts for an approach to orientate students towards critical theory with a focus on the transformational intent and potential of a radical feminist approach, included returning to Squires (7), the discursive dimensions of gender equality (Lombardo, Meier, and Verloo), and further Bacchi («Intentionality») including her propositions of «reflexive framing».

\subsection{Feminisms and transformational change}

Thinking about feminism as a «travelling concept» Lombardo, Meier and Verloo (1) remind us that the concept and practice of «feminism» is open to and reflective of different meanings, experiences and perspectives. The discursive exploration of gender equality meanings, institutional structures, policy making and framing, aligns with Bacchi's WPR approach and her discussion 
of «reflexive framing» in advocacy and policy making around gender equality. Bacchi encourages «reflexive introspection on the systems of thought ('discourses') influencing 'ways of arguing' ('frames'), or 'reflexive framing' as necessary to prevent the development of agendas and proposals that may well help some women at the expense of others» (Bacchi, «Intentionality» 28).

Our approach to learning, teaching, assessment and research overall in the MSc programme could be characterised as an attempt to encourage students to «catch oneself 'in the act of seeing in particular ways'-[where] it is crucial to ensure that the perspectives and embodied experiences of diverse and often under-represented groups are foregrounded» («Intentionality» 29). Central to this analytical approach from a feminist theoretical and policy analysis perspective was what Squires has characterised as a strategy of «displacement» (8). In what is a caveat for those engaged in governing -at a political or organisational level-, Squires cautions us to be alert to the implicit peril of losing a focus on voice (recognition) and the potential for «marginalizing rights-based gender equality arguments and side-lining more democratic participatory approaches to its pursuit» (2). Squires' challenge is that gender equality analysis and policy making needs to avoid the pitfalls that can arise within the «pursuit of equal treatment and the recognition of difference» (9). The presumption of equal treatment still persists within androcentric norms, potentially resulting in a less transformative assimilation of women into established institutional norms, rather than the second option of a 'strategy of reversal' through asserting difference. Squires calls for a third strategy. Her proposition for «displacement» (10) aims to break down existing institutional norms; the ways of thinking and doing established in the path dependencies of political and governmental institutions. The transformation of norms and institutions themselves, is central to wider, more diverse and democratic engagement. Twinned with the WPR and «reflexive framing» from Bacchi, students were supported in revisiting their professional experience and unpicking, even unpacking, some of their own established practice and ways of thinking.

In deconstructing Squires' theoretical challenges, it was useful to draw on the more didactic explanations of different approaches, generations, even of gender equality policy analysis. What Rees described as «tinkering, tailoring 
and transforming» (19) in relation to equal treatment, equal opportunities, and gender mainstreaming, Bagilhole further breaks down as

- Equality of opportunity is the «equal access to institutions and social positions among social groups;

- Equality of condition, the starting point determining access to opportunity, the life circumstances question;

- Equality of outcome, is concerned with alternative approaches and arrangements for different social groups «in order to transform inequalities of condition at the beginning into equalities at the end.» This may require special measures, so-called 'favourable treatment', or positive action as allowed in equality legislation. (141)

Hepple moves us on conceptually into the era beyond formal equality before the law, into an aspirational era of transformation whereby institutions, rather than those with particular characteristics, are the central focus of change. This conception of equality, and particularly of the function of legislation emerging from the mid 2000's is for a transformative equality, whereby systemic and structural inequalities are broken down and poverty and other disadvantage are eliminated.

This development of legal thinking and treatment beyond the basis for unequal or discriminatory treatment to consideration of the impact of decisions or actions was the basis of the Equality Act 2010 in Great Britain, which is broadly similar to the Ley de Igualdad 2007 in Spain. Both place a duty on public authorities to reflect on their own practices and what information and knowledge informs decision making. Such reflexive legislation had -and continues to have-significant transformational promise, should the political will and institutional competence exist to support further community participation in public service design (Conley).

\subsection{Vulnerabilities}

Situating the lived and discursive effects of policy decisions upon everyday lives and diverse circumstances is central to a university social and economic justice programme. The curriculum and learning outcomes clearly evidence an approach that sought to balance content on the institutional frameworks and levers for the realisation of human rights through international and domestic law with theoretical and conceptual underpinning on 
theories of justice. In addition to the overviews of Rawls' Theory of Justice, Sen's Capabilities Approach, and Nussbaum's developments in 'Gender and Social Justice', Martha Fineman's «vulnerability approach» was introduced as another route in to thinking backwards from current policies and the problem representations therein. As a feminist legal scholar, Fineman expands from the protection of rights and the role of the state to a reconceptualization of human rights, with the emphasis on the human. Fineman encourages us to think about human life and experiences as vulnerable, whereby there is a constant possibility of «harm, injury or misfortune» (28).

As Bjørnholt and McKay discuss (8), vulnerability is both universal and constant, and particular. As individual humans we experience vulnerability differently depending on the inter-related «webs of economic and institutional relationships» and «the quality and quantity of resources we possess or can command» (Fineman 31). Our vulnerabilities are complex and one form can cause further harm in other ways, such as economic collapse or illness that leads to unemployment and subsequent poverty. Vulnerability also manifests and has different implications for individuals on the basis of other societal institutions and behaviours, such as different and unequal treatment on the grounds of disability, gender, race, age and other characteristics. It is the role of law and state institutions, Fineman argues, to prevent the harm from such actions, to which we are all vulnerable in different degrees and at different times. Consistent with concepts of capabilities and functionings from Sen and Nussbaum, Fineman suggests that individuals can build resilience to these harms through «having some means with which to address and confront misfortune» (32). These means are to a large extent provided by societal institutions and include assets or resources: physical resources, human resources, social assets or resources, ecological resources and existential resources. Fineman is concerned with «privilege and favor conferred on limited segments of the population by the state and broader society through their institutions» (23), including the labour market, the family, education systems and other institutional frameworks, which Bjørnholt and McKay emphasise as «institutions [that] play a core role in allocating resources, and are pivotal in the production of privilege and disadvantage» (8).

These conceptual perspectives support the assertion that gender is a social construct, which Bradley explains as

Feminismo/s 35, junio 2020, pp. 207-232 
the varied and complex arrangements between men and women, encompassing the organization of reproduction, the sexual divisions of labour and cultural definitions of femininity and masculinity. It therefore is, at one and the same time, a set of social arrangements determining how women and men live, and a way of thinking which divides people up into two (or sometimes more) social categories. (16)

Recognising and understanding the effects of these multiple social categories and the gendered relations within formal and informal institutions which create the «structural constraints» that Folbre has described, were central to the curriculum. The theoretical background summarised in this section, formulated the analytical approach to learning, reflection and assessments using the WPR approach, in two specific modules, as explained in the following section.

\section{APPLICATION OF THE WPR FRAMEWORK IN COURSEWORK}

We wanted, and still desire, our students to be able to describe theory as well as apply it and critically analyze it. In this way, our approach was consistent with the Bacchi WPR framework and its aim of opening «a new space for the active involvement of policy workers or analysts in contestation over the substantive content of policies» as described by Bacchi and Goodwin (61). The WPR approach is a "way of thinking differently about commonly accepted categories and governing practices» (Bacchi and Goodwin 13) and, as they suggest, is relevant to students of sociology, social policy, and social work. The WPR, therefore provided a theoretical and analytical framework consistent with critical study and engagement in social justice policy and practice, relevant for practitioner students from a range of social policy, service and advocacy perspectives.

We used the WPR framework on our Human Rights (HRts) and Leadership for Equality (L4E) modules to support student enquiry into their workplace practices to reveal and explore the equality and Human Rights dimensions within. The aim was to surface these as not only central to the practice of our student-practitioners, but to reveal that equality and human rights issues are integral to the purpose, function and design of public services delivered through public sector and third sector organisations. Working through theories of equality, justice, human rights, we developed and delivered a syllabus 
that aimed to move operational practice of equality beyond the more superficial organisational practices of equality of opportunity to bring to the surface an understanding of the structural causes of inequality, discrimination, and their daily manifestations in workplace practice and the systemic absence of an equality analysis informing public policy at all levels.

In using case study as pedagogy in a work-based programme, our aim was to approach teaching and building practice in policy analysis from a post-positivist perspective, looking to the discursive context of decision-making on policy at different levels of organisational and institutional governance. Case study examples were certainly used to illustrate theoretical points, but case studies were a central approach to practical assessed coursework, especially relevant for a work-based, blended learning programme. Again, consistent with a critical management education approach, we used case study in the way described by Foster, McBeth and Clemons, as based on a «broader epistemology» combining political insight, value conflict, subjectivity, and ambiguity with other skill development» (518). As a work-based change project, our students were directed to take an approach, applying Bacchi's WPR framework to a «situation [that] revealed a problem that needed to be solved» (518).

Our approach was one of praxis, where we simply mean «theory guided action», which in turn simply means that students were requested to construct cases that promoted active learning and critical thinking. We used this process in the way that cases may be used to illustrate a process or theory, or they may provide a decision dilemma in the form of a problem to be solved.

Bacchi and Goodwin's contention (16) that «the manner in which 'problems' are constituted shapes lives and worlds» was central to the teaching and to the courses assignments and exercise in which our students engaged in these modules. In a programme on Citizenship and Human Rights, the core focus is on the structural -legal, social, and economic- constraints and conditions that impact different groups of people differently resulting in greater or lesser social, economic, political and civil inequalities.

Formulated as a change project, students were directed to use the WPR framework to formulate a work-based project to develop an area of practice that revealed, or surfaced, an equality and human rights dimension that they had identified as lacking in the existing «representation» of the problem or organisational practice. By taking the WPR, «working backwards» approach

Feminismo/s 35, junio 2020, pp. 207-232 
to problem representation from Bacchi and Goodwin (20), students were to unpick how current organisational practice had been formulated, consider what the «problem» was and how that representation had been arrived at, and what silences and alternative representations had been overlooked in that formulation. As they phrase it: «what we propose to do about something indicates what we think needs to change and hence what we think the «problem» is (16).

\subsection{Applying theory to practice in organisational change case studies}

This was a work-based problems solving exercise, of the approach described by Foster, McBeth and Clemons as the «ability to analyse the political basis of public policy provides them with the necessary analytical skills they need to secure and perform jobs as public administrators and analysts» (519). Students were directed to use and amended and expanded version of the 6-question formulation of the WPR Framework from Bacchi (Bacchi, Women; «Intentionality»; «Problematizations»). Bacchi's framework is set out in Table 1 below.

Table 1. WPR Chart: What's the Problem Represented to be? (WPR approach to policy analysis)

Question 1: What's the problem (e.g. of "gender inequality», «drug use/abuse», «economic development», «global warming», «childhood obesity», «irregular migration», etc.) represented to be in a specific policy or policies?

Question 2: What deep-seated presuppositions or assumptions (conceptual logics) underlie this representation of the "problem»(problem representation)?

Question 3: How has this representation of the «problem» come about?

Question 4: What is left unproblematic in this problem representation? Where are the silences? Can the "problem» be conceptualized differently?

Question 5: What effects (discursive, subjectification, lived) are produced by this representation of the «problem»?

Question 6: How and where has this representation of the «problem» been produced, disseminated and defended? How has it been and/or how can it be disrupted and replaced?

Step 7: Apply this list of questions to your own problem representations.

(Adapted from: C. Bacchi and S. Goodwin)

Feminismo/s 35, junio 2020, pp. 207-232 
The specific instructions for the Human Rights coursework are set out in Table 2.

Table 2: Bacchi WPR Adapted for Human Rights Module Handbook

Assessment 2: Presentation,

'What's the problem represented to be»: Apply Carol Bacchi's policy analysis approach to the relevant work-based issue/problem

Assessment 4: Case study report.

You will need to address the following questions in your case study:

1. What is the problem and how can it be described using the language of human rights?

2. What is the incidence of the problem and what possible data exist?

3. What elements/proportion of the population are affected?

4. How could this problem be justified as a human rights issue using the following three traditions: natural rights, states obligations and the constructed rights tradition?

5. What «cultural relativism» arguments or dilemmas can be associated with this problem and associated human rights? How could these be overcome?

6. How do the problem and the associated rights relate to various structures and discourses of oppression, such as gender, race, class, sexuality, age and (dis) ability?

7. What international instruments exist to safeguard human rights in respect of the problem?

8. What national instruments exist to safeguard human rights in respect of the problem, and how far do they match international instruments?

9. How could this problem be addressed using human rights tools/instruments? What is the scope for, and the limitations of, human rights interventions at the different levels (micro, meso, macro) and with the different orientations/ approaches (remedial, preventative, developmental)?

10. What can be your role and the role of your organisation in addressing this problem?

The Leadership for Equality guidance in Table 3 below draws on the Bacchi framework and the dimensions of interrogating policy representation, the surfacing of the lived realities and subjugated knowledge and silences, and the requirement to reflect on own analytical processes and proposals for change. The work-based change project here extends the reflexive element of the WPR process by including a requirement for self-reflection on the students' proposals in the form of a reflexive journal. The assignment was a four-step process set out in Table 3. Firstly, students were to engage in

Feminismo/s 35, junio 2020, pp. 207-232 
internal inquiry, looking within their own organisation at an issue of interest to them, in the context of how the "problem» was currently represented in terms of what Bacchi and Goodwin (16) call «unexamined ways of thinking around what the organisational response formulated in policy and practice» reveals about how the focus of action had been framed. Using the WPR questions to interrogate and peel back existing assumptions as the knowledge base for action, students applied new learning and epistemological perspectives (feminist, social justice) to explore and interrogate assumptions and presuppositions that had resulted in organisational representations of the problem, asking if the problem could be conceptualized differently. Bacchi and Goodwin argue that this approach helps to «identify the particular combination of practices and relations that give a "problem» a certain shape in a particular context, and indicate that different practices can produce contrasting problematizations» (23).

Following from this understanding, students were to explore with an equalities and human rights lens what was not included or what vulnerabilities, lived effects, or voices had been silenced or rendered invisible in the process that resulted in specific policies, and begin a process of formulating alternatives. This process of considering what had previously not been considered, left unproblematized, is the essential purpose of the exercise, to engage in Bacchi and Goodwin's «critical practice of thinking otherwise» (22). For student practioners this was central to their learning and the application of new knowledge and reflective practice, following what Bacchi and Goodwin present as an «opportunity to be inventive, to imagine worlds in which a specific confluence of circumstances is either not problematized or problematized differently» (22).

Consistent with creating a community feel and reflexive practice within a development community of practice, students presented the outline of their inquiry and early thoughts on reformulation for discussion with students and tutors in face: face sessions. In a supplementary exercise to support the process of revealing the «effects» that Bacchi signals (discursive, subjective, lived), students were encouraged to work through theoretical and practical considerations of research methodology -participative, feminist, reflexive. The purpose of this was to identify the effects of the actual policy 
representation and consider suitable processes to lead to a more inclusive, and accurate, alternative approach to the particular policy or service under consideration.

The fourth and final step comprised two elements:

i. A full report on their analysis of the problem representation, and an exploration of alternative analytical approaches and changes to ways of working and with whom in order to produce policies and services that revealed and engaged with mitigating and limiting the negative effects of previous representations.

ii. A reflexive journal, encouraging reflection on the student learning around knowledge acquisition, alternatives to practice and surfacing values within their organisation, and the potential differences in outcomes of their proposed alternative approach.

\section{Table 3. After Bacchi's WPR - Change for Equality Project}

(1): Outline Project Proposal

This assessment requires you to identify a specific action for change within your work-place, an organisation of which you are a member or an issue where you have identified the need for and potential benefits of change. You are required to outline the specific issue, for example a change in procedure around equality impact assessment; mitigating the impact of policy change -internally or externally imposed; or questions of representation of minority or excluded groups, or representation of equality issues in the media, or a specific action in which you are involved. You are required to set out how you will evidence that your issue, or change project, is of substantive concern. You are required to set out your case for change and the key stakeholders and influencers you are seeking to target. You should also identify the resources -financial, personnel, time, data, information, that you will draw upon in conducting your project.

(2): Presentation of Change Project and Progress Update

Verbal presentation of the change project - objectives, resources, stakeholders involved, and progress to date.

(3): Critical Reflection on Values in Research

This assignment is a short written piece outlining your understanding of the values underpinning research, consultation, and involvement with communities of interest, or local communities in general. 
(4): Portfolio of evidence and reflective learning report. This is the final report of your change project and should evaluate the progress made, levers for change and barriers to progress. It should also include reflective discussion on the theoretical concepts and frameworks explored over the course of the Module and the extent to which they did -or did not- inform and influence your thinking in evaluating your change project. You will not be assessed on the final outcome of your change project as it is to be assumed that some aspects may be beyond your control, and the project takes place within a short period of time. However, you will be assessed on your methodology, structure, use of theoretical constructs and concepts of equality and leadership as discussed throughout the Module.

This application of the WPR framework as a learning and practice development tool exemplifies the principles of critical management education as set out by Hibbert; using a reflexive pedagogy to combine Bacchi's process of critical thinking and working backwards to alternative policy representations. The structure of the assessment and the use of face: face class sessions illustrate Hibbert's four principles:

- Preparing and making space for reflection in the particular class context;

- stimulating and enabling critical thinking through dialogue, in particular in relation to diversity and power issues;

- unsettling comfortable viewpoints through the critical reappraisal of established concepts and texts; and

- supporting the development of different, critical perspectives through ideological explorations and engagement with sociological imagination (804).

\section{EXPLORATIONS, CONTESTATIONS AND REFLECTIONS FROM PRACTITIONER STUDENTS USING WPR}

Students on the programme came from a variety of organisations. These included local authority social work and housing departments, national civil society organisations on refugee and asylum and LBGTQI advocacy and health condition-specific advocacy and service delivery, alongside local third sector organisations for mental health, local volunteering, learning disability support, and other statutory sector organisations at national and regional level in Scotland. Not all their practical coursework was focused on gender equality

Feminismo/s 35, junio 2020, pp. 207-232 
per se, but was informed by the Bacchi framework and wider theoretical underpinning.

This section presents the projects and reflections presented by students. These have been anonymised and other identifying markers including the name of the organisation and year of submission have been removed. The following is a summary in two parts of a selection of the diverse range of project activity in which students engaged, and the reflections on their learning and the application of the Bacchi framework. The project outlines below are summarised from the students' work.

\subsection{Project outlines}

- Amend the data collection to expand our data capture in order to improve equalities monitoring for mental health service design, as identified through Equality Impact Assessment (EQIA) process. The services of the organisation were to be accessible and available across the local community, including to students in secondary (high school) education. However, the proposals to make apparently small changes in criteria of administrative data to reflect diverse gender identities had been challenged by local religious (Catholic) organisations who regarded such questions as inappropriate for secondary school students. The challenges then for the organisation and Student $M$ as service manager were to work backwards from these assumptions and the existing knowledge basis of the opponents, and work collaboratively to reveal and resolve discrimination (Student $\mathrm{M}$ ).

- Building networking capacity across community sector in coalition against welfare reform by examining the «problem representation» of the necessity for cuts to welfare spending. Student $S$ set out to «identify the silences within, including the absence of intersectional gendered analysis of poverty, the causes and lived effects for disabled people; lack of analysis of inter-related/connections between benefits, housing, precarious employment, childcare and other caring roles; and the assumptions evidenced in the UK government's framing of welfare reform» (Student S). 
- Amend educational regulations in Scotland to allow asylum-seeking young people the same access to full-time further and higher education as other young people in Scotland. By working backwards from the regulatory framework and policy statements, Student $C$ sought to reveal the presumptions and assumptions and providing alternative perspectives including the economic case for participation, in addition to social justice arguments and realisation of rights to education, elimination of discrimination and the advancement of capabilities (Student C).

- Through critical engagement with theories of «authentic leadership» and working backwards from the representation of leadership roles and functions within the organisation, Student A aimed to reveal silences about persistent discrimination against women (individuals presenting as female) within an LBGTQ organisation. The approach sought to explore assumptions of inclusivity of leadership programmes which aim explicitly to support diversity and self-realisation within organisational cultures which assume inclusive characteristics but which are not visible in usual practice (Student A).

- In reviewing policy and practice response to diagnosis and support of young people with autism in Scotland, Student P undertook an historical analysis of the representation and public perception of autism. The approach was theoretically complex, engaging in the discursive effects of concepts such as the persistence of «mother blame», and exploring the effects of the role of professional class privilege in problem representations and assumptions that result in granting professionals credibility and the power not to be challenged in their diagnostic, rather than giving voice to the lived experience of the people being diagnosed. Student P's aim was to highlight institutional practices that «distance disabled people from the public sphere and therefore from participation within it». Surfacing these lived and discursive effects, Student $\mathrm{P}$ proposed, should enable their organisation to move to a social model of disabled people's rights through recognising the social construction of oppression of disability through a discursive analysis of the language used about disability (challenge, overcome, tragedy, resilience...). Working backwards from the representation of 
the «problem» of long term conditions revealed a policy in practice that considers disability a problem to be managed by the individual with high (and therefore undesirable) levels of cost to be borne by the state (Student P).

- Review of local training and organisational practice for social work staff working in the protection of vulnerable adults. Student F's approach was working backwards to reveal the assumptions and knowledge base that shaped National Working Group advice on service and training design for Adult Social Work Protection. Applying Bacchi's framework and Fineman's construction of the vulnerable self, this student revisited and subsequently reformulated guidance and staff training on supporting vulnerable adults within the protection of social work services. Using Bacchi's framework to analyse the problem, Student F structured an approach that «shifts the problem from the staff and their training to the state and societal distribution of power and inequality. This has an impact on how identities are constructed» (Student F).

- Student H developed proposals for addressing the «problem» and reconfiguring representation towards making LGTBQ people with dementia visible and their care appropriate to their needs. The approach to surfacing the equalities and human rights issues for practice -and the lived effects for service users-involved revisiting organisational policies so that practice would better recognise diversity among patients and service users in dementia care; and through revealing heteronormative assumptions about people's lives, revise practices to include the diverse sexual orientation and partnerships of individuals. In this way, Student $\mathrm{H}$ was revealing the negative lived effects of discrimination and re-focusing the organisation on the positive altered everyday experience when the lived effects of gay, lesbian, and couples of other sexual identities were included in organisational practice. Using lived effect approach expressed as «The Problem Illustrated Through Practice Experience», Student $\mathrm{H}$ presented vignettes of experience of dementia care of different individuals, «bringing out the silences of unexpressed lived effects of people's lives and the subjugated knowledge and oppression of

Feminismo/s 35, junio 2020, pp. 207-232 
their realities as LGBTQ people who now have dementia and read across with experiences of stigma and discrimination in their lives pre-dementia diagnosis». The findings from these engagements across different members of the staff and services team were used to inform and re-shape client services and family engagement (Student $\mathrm{H}$ ).

- Integrating intersectional and socio economic inequalities into the training and organisational practice guidance of an anti-racism educational charity, for Student M, revealed that using Bacchi's framework identified the significance of poverty in shaping lived experiences. This contrasted with national government and media discourse that pitted «worklessness» against «scroungers» and «migrants», thereby creating conditions of division and inequality (Student M).

- Exploring the impact of Welfare Reform on people with disabilities from a Human Rights perspective by working backwards from the stated aims of the UK Government to introduce a fairer system, Student W aimed to reveal the problem representation by the UK government and how it contrasted with the intention of human rights legislation and practice. Deconstructing the stated policy aims, Student W analysed government texts and the deployment of human rights framing in welfare policy making. The analysis foregrounded the contrasting alternative representations of the problem and the policy response from the UN Committee on Economic, Social and Cultural Rights (Student W).

\subsection{Student reflections}

This section offers some insights into the learning and re-learning that students, some with almost 30 years' professional experience, reflected upon in the informal (not assessed) learning journals that accompanied the project activity. It is clear from these snapshots that students applied a process of critically thinking otherwise about the «problem» they were sighted upon, and worked backwards from their own and their organisation's assumptions. In this way, they developed knowledge to identify alternative practices that were more responsive to the lived effects experienced by their clients or colleagues. 
I critically reflected on the challenges and I have gained new and valuable insights into leading a complex change project. I started out on this equalities change project with a sense of injustice, anger and passion around the issue of welfare reform, and a sense of urgency for networking the third sector. Through learning gained from this module I have now channelled this into a clear and focussed priority action plan which will enable me to lead on change... I was initially overly outcome focused. My understanding of the interconnection between state delivered welfare and the sector's increasing role has been enhanced but I now have a better understanding of welfare reform as an equalities issue and how I can provide strong leadership and encourage third sector ownership of this change agenda... (Student S)

These reflections from Student $S$, are consistent with Bacchi's challenge that formal education on policy making has been overly focussed on «trying to produce students who are problem solvers» (Bacchi, «Problematizations» 23). The focus instead, Bacchi argues, should be on «"problem'-questioning as a form of critical practice» (23) which is what we can see emerge from further student reflections, as explicitly stated in the example from Student $\mathrm{H}$ and Student $\mathrm{F}$ here.

Carol Bacchi's «what's the problem represented to be?» (WPR) approach to analysing policy was particularly useful in helping me to understand the problematisation of inequality in dementia care. This approach validated the feelings of unease and disillusion I had about how [in] equality within health and social care is often represented as something we are trying to fix/ address. It can often seem like 'equalities' work happens in isolation, usually in «addition to» and not in «conjunction with». How we frame what we intend to do to achieve meaningful equality will determine our success. This needs careful consideration and the key to this is co-production. (Student $\mathrm{H}$ )

How a problem is represented and framed has a bearing on the subjectivity of the research. I have informed and influenced my thinking in problem representation using Carol Bacchi's, what's the problem approach? By reframing my research problem, I have deepened my understanding and reconsidered how to take the research forward. Bacchi's approach involves «a commitment to include oneself and one's thinking as part of the 'material' to be analysed» (Bacchi in Bletsas \& Beasley 2012 22). My understanding of the research problem was something I had yet to consider and in order to effectively support staff to work in an empowering and person centred way with adults who are at risk of harm, it was important to get the design of evidence based learning right. Deep routed societal issues can be enhanced

Feminismo/s 35, junio 2020, pp. 207-232 
or exacerbated by policy development and the way that policy is enacted by staff in practice. Public sector workers are powerful conductors of policy who can inadvertently perpetuate an unequal distribution of power. Without «reflexively of one's own representation of the «problem», I risked doing this myself.» (Student F)

Using questions in WPR framework to identify scope of «problem», where «power» lies in relation to decision making on resources where, Student P argued

People with autism are subjectified as users of services while professionals are cast in the position to take action. People with Autism and their families are subjects, to be consulted with at best. Similarly, the vision of the strategy portrays individuals with Autism as passive bystanders in their own lives by stating «our vision is that individuals on the autistic spectrum are respected, accepted and valued by their communities and have confidence in services to treat them fairly so that they are able to have meaningful and satisfying lives». This vision implies that individuals are only able to fully realise their lives while being in receipt of services and makes no mention of individual capacity or agency to affect chance. There also are tensions present in the document between a conception of the «autism community» and individual needs». Citing Bacchi («Policy»), student P concluded that «representation of policy solutions to the 'problem' lie with the individual and not with society or the structures of the labour market or other institutions, and the dominant silence is that of the voices of people with autism».

\section{DISCUSSION AND CONCLUSION}

In this article, I have engaged in a detailed presentation and discussion of a specific set of coursework assignments that were structured around Bacchi's What's the Problem Represented to be? framework. As an approach to critical thinking for students, and critical pedagogy in management education, it is clear that reflexivity as working backwards as part of the Bacchi process, is what Hibbert has described as

a critical examination of our pattern of personal norms and taken-for-granted assumptions, translates something from being used for thinking to being that which we think about. If the patterns of our foundational assumptions change as a result of the process of reflexivity (and if they do not, the process is futile), then the actual process of thinking is also changed (805). 
In encouraging students to engage from a feminist perspective in the endeavour of what Bacchi and Goodwin describe as a «more expansive understanding of politics» (14), students revealed their own established assumptions and those of their organisations. In their learning and practical application, they explored how «problems» are produced by established governing practices at the level of organisation and political institutions. Following Fineman, this approach engaged students in analysis of policy and practice as a means of «interrogating the institutional practices that produce the identities and inequalities in the first place» (13), as Student F above, among others, reinforced in her reflections.

The overall objectives of this Masters programme and the constituent modules was to bring concepts of social and economic justice, equality, rights and freedoms to the centre of learning, teaching and practice for student practitioners to develop a critical underpinning to their management and organisational practice. The approach to assessment and practical application of the critical theories in play produced analysis through the WPR approach that directly mirrored Fineman's exhortation that

The promise of equality must not be conditioned upon belonging to any identity category, nor should it be confined to only certain spaces and institutions, be they deemed public or private. Equality must be a universal resource, a radical guarantee that is a benefit for all. We must begin to think of the state's commitment to equality as one rooted in an understanding of vulnerability and dependency, recognizing that autonomy is not a naturally occurring characteristic of the human condition, but a product of social policy (23).

In undertaking the responsibility of educating social policy professionals, our approach, as this article has demonstrated, sought to develop student practitioners' approach to thinking critically. In the Leadership for Equality and Human Rights modules, through theoretical and conceptual learning and through reflexivity -essential in the Bacchi WPR approach-students and tutors were engaged in a process of surfacing equalities and human rights issues akin to what Hibbert has described as «intrinsic to the emancipation of thinking and the overcoming (or at least recognition) of the most deeply hidden influences and constraints: those hidden within our own assumptions» (804). 


\section{REFERENCES}

Bacchi, Carol Lee. Women, policy and politics: The construction of policy problems. London: Sage, 1999.

Bacchi, Carol. «Policy, theory, politics: Problem representations in drug and gambling policy.» International Summer School on Inequality and Addictive. 2006. http://hdl. handle. net/2440/57267.

Bacchi, Carol Lee. «The Issue of Intentionality in Frame Theory: The Need for Reflexive Framing». In The Discursive Politics of Gender Equality: Stretching, Bending and Policymaking. Eds. Emanuela Lombardo, Petra Meier \& Mieke Verloo (eds.). London: Routledge. 2009. 19-36.

Bacchi, Carol. «Why study problematizations? Making politics visible.» Open journal of political science 2.01 (2012): 1.

Bacchi, Carol, and Susan Goodwin. Poststructural Policy Analysis: A Guide to Practice. New York: Palgrave Macmillan. 2016.

Bagilhole, Barbara. Understanding equal opportunities and diversity: the social differentiations and intersections of inequality. Bristol: The Policy Press, 2009.

Beasley, Chris, and Angelique Bletsas. Engaging with Carol Bacchi. Strategic interventions and exchanges. Adelaide: University of Adelaide Press, 2012.

Bjørnholt, Margunn, and Ailsa McKay, eds. Counting on Marilyn Waring: New advances in feminist economics. Bradford, ON: Demeter Press, 2014.

Bradley, Harriet. Gender. 2nd ed. Cambridge: Polity Press, 2013.

Burchardt, Tania, and Polly Vizard. «'Operationalizing' the capability approach as a basis for equality and human rights monitoring in twenty-first-century Britain.» Journal of Human Development and Capabilities 12.1 (2011): 91-119. Coles, Emma, Helen Cheyne, Jean Rankin, and Brigid Daniel. «Getting It Right for Every Child: A National Policy Framework to Promote Children's Well-being in Scotland, United Kingdom.» The Milbank Quarterly 94. 2 (2016): 334-365.

Conley, H. «Gender equality in the UK: Is reflexive and responsive legislation the way forward?». In Gender and Diversity Studies in European Perspectives. Eds. Ingrid Jungwirth \& Carole Bauschke-Urban. Verlag Barbara Budrich. 2016.

Fineman, Martha Albertson. «The Vulnerable Subject: Anchoring Equality in the Human Condition». Yale Journal of Law E Feminism 20.1 (2008): 1-23.

Folbre, Nancy. Who pays for the kids?: Gender and the structures of constraint. London/ New York: Routledge, 1994. 
Foster, Richard H., Mark K. McBeth \& Randy S. Clemons. «Public Policy Pedagogy: Mixing Methodologies Using Cases». Journal of Public Affairs Education, 16.4 (2010): 517-540.

Hepple, Bob. Equality: The legal framework. Oxford: Hart Publishing, 2014.

Hibbert, Paul. «Approaching reflexivity through reflection: Issues for critical management education». Journal of Management Education 37.6 (2013): 803-827. Lombardo, Emanuela, Petra Meier, and Mieke Verloo (eds.). The discursive politics of gender equality. London: Routledge, 2009.

Nussbaum, Martha. «Capabilities as Fundamental Entitlements: Sen and Social Justice». Feminist Economics 9. 2-3 (2003): 33-59.

O'Hagan, Angela. «Perspectives on gender equality in Scotland.» In Poverty in Scotland: The Independence Referendum and Beyond. Edinburgh: Child Poverty Action Group, 2014. 229-235.

O'Hagan, Angela. «Favourable Conditions for the Adoption and Implementation of Gender Budgeting: Insights from Comparative Analysis». Politica Economica/ Journal of Economic Policy (PEJEP) XXXI. 2 (2015): 233-252.

Rees, Teresa. "Mainstreaming equality» in Engendering Social Policy. Buckingham: Open University Press. 1999.

Scott, Gill, and Gerry Mooney. «Poverty and social justice in the devolved Scotland: neoliberalism meets social democracy?». Social Policy and Society 8.3 (2009): 379-389.

Sen, Amartya. «Equality of what?». In Tanner Lectures on Human Values. Ed. Sterling McMurrin. Vol. I. Cambridge: Cambridge University Press; Salt Lake City: University of Utah Press, 1980.

Sen, Amartya. Inequality Reexamined. Oxford: Oxford University Press, 1992. Squires, Judith. The new politics of gender equality. Basingstoke: Palgrave Macmillan, 2007. 


\section{Miscellaneous section / Sección miscelánea}



To link to this article / Para enlazar con este artículo:

https://doi.org/10.14198/fem.2020.35.09

To cite this article / Para citar este artículo:

Garrido Carrasco, Vicenta. «Los arquetipos masculinos de los cuentos de Perrault: modelos de masculinidad que aprender o desaprender desde la infancia». En Feminismo/s, 35 (junio 2020): 235-262.

\title{
LOS ARQUETIPOS MASCULINOS DE LOS CUENTOS DE PERRAULT: MODELOS DE MASCULINIDAD QUE APRENDER O DESAPRENDER DESDE LA INFANCIA
}

\author{
THE MALE ARCHETYPES IN PERRAULT'S TALES: \\ MODELS OF MASCULINITY TO LEARN OR UNLEARN \\ FROM CHILDHOOD
}

\author{
Vicenta GARRIDO CARRASCO \\ Universidad de Jaén, Jaén \\ garrido@ujaen.es \\ orcid.org/0000-0001-6491-4483
}

\section{Resumen}

Charles Perrault escribe sus cuentos dentro del preciosismo, movimiento de reivindicación femenina que nace y se desarrolla en los salones de París en la segunda mitad del siglo XVII. Las preciosas, que primero cuentan y después escriben cuentos de hadas en los salones, harán que el cuento se consolide como género literario y pase de la forma oral a la escrita. El interés que en los últimos años ha suscitado el estudio de la masculinidad en numerosas disciplinas científicas, refleja la necesidad social de que se instaure en la realidad cotidiana de hombres y mujeres una nueva masculinidad. El análisis de lo masculino en los cuentos de Perrault, de todos conocidos, pone de manifiesto que estos contribuyen a la formación de una identidad de género masculina la cual no se corresponde con las necesidades de nuestra realidad actual. Se impone la deconstrucción del concepto de masculinidad que presentan tales cuentos para implantar, desde la infancia, nuevas masculinidades. 
Palabras clave: masculinidad; arquetipos; identidad de género; cuentos de hadas; Perrault.

\begin{abstract}
Charles Perrault writes his tales within the preciosity, a movement of female assertion born and developed in Parisian salons during the second half of the 17th century. Précieuses, who first tell and then write fairy tales in salons, will consolidate fairy tales as a literary genre as well as their transition from the oral to the written form. The interest elicited by the study of masculinity in many scientific disciplines in recent years reflects the social need that a new masculinity be established in the everyday reality of men and women. An analysis of the masculine in the tales by Perrault, known to all, reveals that they contribute to creating a male gender identity that does not match the needs of our current reality. Deconstructing the concept of masculinity presented by such tales becomes thus essential in order to establish new masculinities since childhood.
\end{abstract}

Keywords: Masculinity; Archetypes; Gender identity; Fairy tales; Perrault.

\title{
1. INTRODUCCIÓN
}

La masculinidad en el mundo actual es objeto de estudio y de interés social debido a las transformaciones de los roles de género de hombres y mujeres. Poner de manifiesto lo que significa la masculinidad es algo complejo porque supone relacionarla con los conceptos que sobre lo masculino tiene una sociedad y los diferentes grupos que la integran en una cultura determinada. En su significado aparecerán conectados multitud de aspectos -época histórica, edad, clase social o cultura-, que pueden ser diferentes de un grupo a otro, de una sociedad a otra y de una cultura a otra (Jociles Rubio 2).

Lo masculino y lo femenino están unidos al sexo y al género. El sexo alude a las diferencias biológicas entre hombres y mujeres, mientras que el género se refiere a la construcción cultural y social del sexo que cada sociedad tiene de lo femenino y de lo masculino (Sau y Jayme 60-65), que, desde la infancia, se adquiere a través del aprendizaje y de la socialización.

Cuando Simone de Beauvoir dice «no se nace mujer, se llega a serlo» (Beauvoir 13), habla de género. Esta afirmación podría utilizarse refiriéndose 
a los hombres diciendo que «no se nace hombre, se llega a serlo». Para Connell la masculinidad «es al mismo tiempo la posición en las relaciones de género, las prácticas por las cuales los hombres y las mujeres se comprometen con esa posición de género y los efectos de estas prácticas en la experiencia corporal, en la personalidad y en la cultura» (35). Connell (31-48) o Bonino Méndez (7-35) definen como «masculinidad hegemónica» la que otorga mayor valoración a lo masculino que a lo femenino, asocia a los hombres comportamientos como la competitividad, la demostración de virilidad, la búsqueda del riesgo, la heterosexualidad o el uso de la violencia (parámetros que interactúan con la raza y con la clase) y legitima el poder masculino a través de las organizaciones sociales y la cultura. Ellos serán activos, fuertes, jefes del hogar y proveedores de la familia, responsables y autónomos y no deberán expresar sus emociones ni demostrar miedo.

Hemos escogido los cuentos de Perrault para analizar la masculinidad que transmiten por dos razones: primero, porque han sido traducidos al español y forman parte de nuestro acervo cultural; y, segundo, porque lo que narran estos cuentos tendrá importantes consecuencias cuando se reproduzcan, desde la infancia, los arquetipos masculinos que contienen. Nuestro objetivo es revisar el modelo de masculinidad que presentan, que ha generado, a su vez, un modelo de feminidad determinado, para constatar si se corresponden con las necesidades del mundo actual.

\section{EL CONTEXTO SOCIAL Y CULTURAL EN EL QUE PERRAULT ESCRIBE SUS CUENTOS}

Charles Perrault (1628-1703) vive y desarrolla su obra literaria en la corte Luis XIV, el «Rey Sol», donde llega a ser Inspector General de Obras del Rey, cargo que le otorga un despacho en Versalles. La vida en la corte influirá y se reflejará en las cuarenta y seis obras que escribe el autor, que alcanzará la fama por sus cuentos. Participa de la Querella entre Antiguos y Modernos tomando partido por los últimos (Soriano 267-294, 295-307). Escribe dos tipos de cuentos diferentes en cuanto a forma y estilo: por un lado, tenemos tres cuentos en verso en los que utiliza una retórica afectada ( «La marquesa de Saluses o La paciencia de Grisélidis» (1691), «Los deseos ridículos» 
(1693) y «Piel de asno» (1694)); y, por otro, ocho cuentos en prosa ( $« \mathrm{La}$ bella durmiente», «Caperucita roja», «Barba azul», «El gato con botas», «Las hadas», «Cenicienta» y «Riquete el del copete»), donde se aborda el problema de la autoría entre Perrault y su hijo Pierre (Henriot 424-441). La colección completa se publica en 1697 bajo el título Historias o Cuentos de antaño. La crítica literaria ha puesto de manifiesto las diferencias entre los cuentos escritos en verso y en prosa, destacando la calidad de los segundos sobre los primeros. Soriano, gran conocedor de Perrault y su obra, manifiesta sobre este tema:

La participación de Perrault en ellos no fue ocasional, ya que forman un conjunto que posee una unidad y una estructura sólida y uniforme, y si no fue su autor pudo reescribirlos dándoles su sello característico, aunque ninguna de las ediciones, que aparecen en vida de Perrault, lleven su nombre, y la dedicatoria y el permiso de imprimir aparezcan a nombre del tercer hijo del académico. (Soriano 74)

Charles Perrault es uno de los pocos autores de la época que participa en el movimiento de reivindicación femenina del preciosismo (1650-1703). Los salones franceses, donde este nace y se desarrolla, se constituyen como ámbitos de socialización y de aprendizaje femenino (Garrido Carrasco 54-59). Destacó por su gran influencia, entre otros, el salón de la marquesa de Rambouillet, que tuvo la habilidad, por un lado, de mezclar en él los dos sexos como iguales, convirtiéndolo en un espacio pedagógico para que hombres y mujeres conversaran de temas intelectuales y científicos, animando sin descanso a sus amistades femeninas a cultivarse para poder estar a la altura en todas las discusiones, y, por otro lado, reunir a los artistas que destacaban en el momento con los miembros de la aristocracia (Anderson y Zinsser 126). Y lo que comenzó como un agradable pasatiempo para las clases nobles se constituyó en una institución social, donde hombres y mujeres aprendieron nuevas formas de pensar y comunicarse y nuevos patrones de comportamiento.

La mujer preciosa sigue una rígida disciplina y actúa siguiendo los dictados de la razón, enseñando a los hombres a dominar las pasiones y los sentimientos que podían provocar desorden en el ánimo, favoreciendo un equilibrio de pensamiento donde prevalecía el sentimiento de la ternura y la 
dulzura, según se recoge en La Carte de Tendre, representación topográfica y alegórica de la conducta y la práctica amorosa que moldeaba las relaciones galantes incluida en el primer volumen de la novela Clélie (1654) de Mlle de Scudéry (Garrido Carrasco 57, 77). El amor, convertido en la preocupación por excelencia, y la mujer, en objeto de conquista y no de placer, solo podían conseguirse por medio del ritual de la galantería (Denis 179-189).

Como consecuencia de este cambio de posición de las mujeres que reclamaban igualdad, respeto y buen trato, se fragua, dentro del preciosismo y en el ámbito del salón, el nuevo ideal de honnête homme: hombre de bien o cortés (Dens 69-82), cultivado, moderado, con sentido de las conveniencias sociales y que gusta de la vida mundana de la época. Poseía sentimientos nobles, agrado, urbanidad y amenidad en la conversación, como recoge Faret en su tratado L'honnête homme ou L'art de plaire à la cour (1630), inspirado en El Cortesano de Castiglione.

La obra Astreé (primera novela-río de la literatura francesa 1607-1627) de Honoré d'Urfé tuvo gran influencia en las preciosas y en el ambiente del salón y contribuyó a separar el amor de la sensualidad vulgar y de la pasión ciega, transmitiendo el mensaje del neoplatonismo que ponía el amor por encima de todo, pero no el amor concupiscente sino el que refleja la belleza ideal a la que aspira el alma.

El rechazo de los matrimonios acordados y la defensa de la libre elección fue un punto clave de las reivindicaciones de las preciosas. El amor y el matrimonio ocupaban el centro del debate; marido y amante eran dos conceptos disociados en la época: «marido» significaba sometimiento social y sexual y «amante», amar y ser amada (Mongrédien 149-150). Las preciosas negaban lo carnal en el amor, por lo que se las llamó «gazmoñas» o «puritanas», mojigatería que critica Molière en Las Preciosas ridículas. Saint-Évremond y Ninon de Lenclos las denominaron «jansenistas del amor» (Soriano 260) debido a lo estricto de este movimiento religioso que influyó en la época y del que Perrault participa por la educación inculcada por su padre. Esta austeridad se acompañaba de coquetería y del amor galante y cortés en el que se podían saborear, en toda su amplitud, los matices del sentimiento. Mme de La Fayette, en su frase « ¡Adiós al amor que no perdura tras la posesión!» (Dulong 446), lo pone de manifiesto. Asidua del salón de la marquesa de 
Rambouillet, publicó, al principio de forma anónima, su novela La Princesse de Clèves, donde expone su idea del amor que defiende la virtud por encima de la pasión.

Otras preciosas utilizaban su propia sexualidad en vez de negarla, por lo que se dudaba de su autenticidad como tales: eran las salonières (Anderson y Zinsser 127). En el salón podían obtener mayores beneficios estableciendo, más que rechazando, una relación sexual con un hombre de título o talento. A finales del siglo XVII y durante el XVIII estas salonières eran famosas por sus asuntos amorosos y sus matrimonios con hombres importantes. Como ejemplo tenemos el salón de Ninon de Lenclos (1620-1705), famosa cortesana de la época. Si una salonière mantenía la castidad era criticada sin piedad. La creencia era que las relaciones entre los sexos, por muy intelectuales o artísticas que pudieran parecer, no podían permanecer platónicas.

Resumiendo, podemos decir que:

El preciosismo, heredero del feminismo francés que arranca de la Edad Media (las cortes de amor) y del Renacimiento (con Christine de Pisan, Louise Labé y otras famosas literatas) es, ante todo, uno de los primeros movimientos feministas de Occidente. Se construye sobre dos axiomas: la igualdad entre hombre y mujer en el amor, con el derecho de las mujeres a elegir su pareja en igualdad y la aportación del hombre a esta de un conjunto de cualidades capaces de convertir el amor no solo en una realización física, sino también en una realización intelectual, imaginativa y estética. El segundo axioma defiende el derecho de las mujeres a acceder a los bienes del espíritu, compartiéndolos, o no, con su condición de esposas y madres sin recibir a cambio ningún menosprecio. (Prado Biezma 123-147)

Para Soriano, Perrault «se mueve en su obra entre un preciosismo y antipreciosismo constante» (255-266) y sus cuentos no son una excepción. Con ellos obtuvo un gran éxito, aunque la verdadera creadora del género de los «cuentos de hadas» fue Madame d'Aulnoy cuando publicó «La Isla de la Felicidad»-primer cuento de hadas literario francés- dentro de la novela Historia de Hipólito, conde de Duglas en 1690 (Defrance 145-152). La expresión «la moda de los cuentos de hadas» aparece en la dedicatoria de Finette de Mademoiselle L'Héritier, sobrina de Perrault, cuando escribe: «c'est la mode: vous les aimez [les contes]: je m'accommode à l'usage avec plaisir» (LHéritier 230). Esta moda, que se relaciona con la cantidad, con 
el apasionamiento por el tema y con la concentración del fenómeno en un periodo concreto -segunda mitad del siglo XVII y el primer cuarto del siglo XVIII en Francia- llevó a la crítica a hablar de «la moda de los cuentos de hadas» (Yllera Fernández 421-422).

Los destinatarios de estos cuentos eran los adultos: preciosas y preciosos que se reunían en los salones de París y exploraban nuevas formas de pensamiento y de comunicación por medio de la conversación y la palabra con el objetivo de que las mujeres pudieran conseguir nuevas posibilidades de ser y de realizarse. Entre otras actividades competían contando cuentos, llegando a tal perfección que comenzaron a escribirlos. De esta forma, el cuento alcanza la categoría de género literario con carácter femenino y precioso (Garrido Carrasco 89-90). Las preciosas expresan en sus cuentos sus reivindicaciones y eligen al hada -figura femenina de poder- como su valedora, demostrando que pueden escribir y publicar como los hombres.

Aunque al principio los destinatarios de sus cuentos eran los adultos, Perrault comienza a presentarlos como narraciones para niños ${ }^{1}$ por las enseñanzas que recogían las moralejas que colocaba al final de cada cuento. A partir del didactismo del siglo XVIII comienzan a considerarse un género adecuado para facilitar el aprendizaje y contribuir a la educación en la infancia. Generalmente los contaban madres, abuelas, ayas o niñeras, como se recoge en la moraleja de «Piel de asno», lo que podría llevar a pensar que a las mujeres se les otorgaba el papel de guardianas y transmisoras de los valores que se recogen en ellos. Cuentos como «Cenicienta», "Caperucita» o «La bella durmiente», contados y leídos de generación en generación, han influido en la construcción de la identidad de género de los hombres y de las mujeres; de ahí nuestro interés por descubrir su modelo de masculinidad.

\section{LOS PERSONAJES MASCULINOS DE LOS CUENTOS DE PERRAULT}

Para descubrir cómo se manifiesta la masculinidad en los cuentos de Perrault, analizaremos el discurso de los textos y las diferentes informaciones que conforman los arquetipos de masculinidad que contienen. Revisar también

1. En este artículo el masculino genérico siempre engloba ambos sexos.

Feminismo/s 35, junio 2020, pp. 235-262 
las imágenes que apoyan los textos contribuirá a enriquecer y completar nuestro análisis. Hemos tomado como criterio para el análisis la importancia del personaje masculino dentro de cada cuento.

Debemos relacionarlos con el contexto del autor, expuesto brevemente en el apartado anterior, y con lo que narra cada cuento sobre la masculinidad en su contexto social, político y cultural porque «las convenciones sociales del contexto recogen un conjunto de sucesos que presentan un estado inicial, un estado intermedio y un estado final» (Van Dijk 273-274) que podrían corresponderse con el planteamiento, nudo y desenlace del cuento. Investigar desde una óptica feminista cómo aparece la masculinidad en los cuentos de Perrault va a permitir constatar si la construcción social de género que contienen es la propia del patriarcado, donde son los hombres quienes ejercen la jerarquía, el estatus y el poder sobre las mujeres. Como apunta Bourdieu, «El orden social funciona como una inmensa maquinaria simbólica que tiende a ratificar la dominación masculina en la que se apoya. [...] El análisis científico de una forma de dominación tiene efectos sociales [...] y puede contribuir a neutralizarlo» $(22,137)$.

Por tanto, a la hora de llevar a cabo el análisis de la masculinidad en los cuentos de Perrault, no podemos perder de vista que fueron recopilados y escritos en un momento histórico determinado, que incluían la ideología del patriarcado y las condiciones sociales, económicas y culturales del mundo occidental, en el que el cristianismo ha tenido una influencia trascendental, y que, además, arrastraban un sustrato cultural e ideológico ancestral. Por otra parte, tampoco podemos obviar que los modelos y contenidos de esos cuentos, que se aprenden y se reproducen desde la infancia, generarán relaciones de poder, como indica Fairclough (179-201), en un mundo que ya no es el mismo, pero donde se ofrecen siempre los mismos modelos de masculinidad y las mismas alternativas de lo que significa ser hombre.

Tomando como corpus para nuestro análisis los Cuentos de antaño $o^{2} \mathrm{de}$ Perrault, exponemos en la siguiente tabla el título de cada cuento, los personajes masculinos que aparecen en cada uno de ellos y la función que realizan.

2. La edición utilizada es la que figura en el apartado final de «Referencias bibliográficas».

Feminismo/s 35, junio 2020, pp. 235-262 
Los arquetipos masculinos de los cuentos de Perrault: modelos de masculinidad que aprender o desaprender desde la infancia

\begin{tabular}{|c|l|}
\hline \multicolumn{3}{|c|}{ Personajes masculinos en los cuentos de Perrault } \\
\hline \multicolumn{2}{|c|}{ Cuentos en prosa } \\
\hline Cuento & Personaje/es masculinos:Función \\
\hline $\begin{array}{c}\text { "La bella durmiente" } \\
\text { (BD) }\end{array}$ & - El rey, padre de La belladurmiente \\
- El príncipe que busca una esposa bellay durmiente
\end{tabular}

Feminismo/s 35, junio 2020, pp. 235-262 
Lo primero que llama la atención observando la tabla es que reyes, príncipes y señores nobles son los personajes masculinos que aparecen en casi todos los cuentos de Perrault; las clases sociales más bajas están menos representadas. También merecen destacarse las actuaciones del ogro -personaje masculino mitológico-y las de los animales que desarrollan papeles masculinos.

En los siguientes apartados vamos a exponer los aspectos más significativos que sobre la masculinidad hemos recogido en nuestro análisis, reproduciendo de forma escueta los fragmentos del texto que corroboran lo que relata cada cuento. Para evitar redundancias, siempre que citemos un cuento haremos referencia a su título con las iniciales que aparecen debajo de su nombre en la tabla anterior, seguidas de la página correspondiente.

\section{LOS REYES COMO ARQUETIPO MASCULINO DE PODER QUE SOSTIENE EL PATRIARCADO}

El personaje masculino del rey que aparece en los cuentos de Perrault ofrece escasas descripciones físicas y psicológicas. Aunque encarna el máximo poder en la escala social como rey y como hombre, nunca aparece como protagonista ni da título a ningún cuento. Su ámbito de acción es externo. Uno de los cuentos en los que se manifiesta el poder del rey de forma más absoluta es «Piel de asno», en el que el rey es tan "amable en la paz como terrible en la guerra» (PA 233). Las grandes posesiones que respaldan su poder se detallan en el cuento. La más preciada era un asno que, «en lugar de boñigas, cada mañana, soltaba buenos Luises y Escudos» (PA 234). Otro ejemplo lo encontramos en «La bella durmiente»: «El rey mandó que le dieran un cubierto [de oro y piedras preciosas al hada]» (BD 11).

Sin embargo, a pesar de ostentar el máximo poder, el rey pide ayuda a las hadas para tener descendencia, escucha sus consejos y se muestra galante siguiendo las reivindicaciones de las preciosas de la época, que reclaman buenos modales y galantería para las mujeres: «El rey le ofrece la mano [al hada], cuando bajaba de la carroza» (BD 15). Acepta sus predicciones y las tiene muy en cuenta -como vemos en «La bella durmiente»-cuando ordena publicar un edicto bajo pena de muerte para impedir que la princesa se pinche el dedo y duerma cien años (BD 13). 
El matrimonio y la paternidad son dos aspectos íntimamente relacionados con el personaje del rey que revelan muchos aspectos sobre la masculinidad.

\subsection{Reyes y matrimonio}

El amor y las riquezas son los motivos que llevan a los reyes a contraer matrimonio en los cuentos de Perrault. El autor introduce el amor como sentimiento de pareja de una forma sutil siguiendo las reivindicaciones de las preciosas. Así lo encontramos en «Piel de asno», donde se refiere que el matrimonio del rey era dichoso por las cualidades de su esposa: «fiel, bella, encantadora, de carácter dulce, delicado, y acomodado» (PA 233), entendido como «fácil de contentar» (RAE 33). Otra razón de peso para casarse son las riquezas que pueda aportar al matrimonio la elegida. En «La bella durmiente» «[el rey] la temía [a la reina] porque era de raza de ogros, y se había casado con ella por sus muchas riquezas» (BD 25).

En estos matrimonios el sexo no se manifiesta de forma explícita, sino que aparece como necesario para tener descendencia. «Piel de asno» define el matrimonio del rey como casto: «De casto himeneo» (PA 233). En la definición de incesto que aparece en el DRAE encontramos que este término viene del latín incestus («incasto», «no casto»): «Relación carnal entre parientes dentro de los grados en que está prohibido el matrimonio» (DRAE 1260). Por tanto, este matrimonio se entiende como «casto» porque entre los cónyuges -el rey y la reina- no existe consanguinidad. Fruto de este casto matrimonio nacerá una hija tan excepcional como la madre. Tras morir esta, en la trama del cuento se presenta el deseo incestuoso del padre, el rey, hacia su hija, la princesa.

Aunque en algunos cuentos los reyes se manifiestan apenados por la muerte de sus esposas, pronto piensan en volver a contraer matrimonio. «Piel de asno» es un buen ejemplo: el rey, ante la muerte próxima de su esposa, le promete que no se casará más, pero ella le hace jurar que solo se casará de nuevo si encuentra una mujer «más bella y mejor hecha que yo, buena y prudente» (PA 235). Al enviudar, el rey manifiesta un gran duelo que le dura poco y se pone a buscar esposa, pero no encuentra ninguna que iguale a la reina muerta. Solo la supera su hija, y el rey -su padre- quiere casarse con ella. 


\subsection{Reyes y paternidad}

Los reyes de los cuentos de Perrault aparecen preocupados por tener descendientes a quienes dejar su reino y sus bienes. Así, en «La bella durmiente» encontramos al rey afligido, junto a la reina, por no tener hijos. Cuando consigue tener una princesita, invita a las hadas para celebrar el bautizo: «todos los invitados volvieron al palacio del rey» (BD 11), pero ahora no se alude a la reina, madre de la princesa, tal vez porque ya ha cumplido con su función procreadora.

En los cuentos de Perrault el derecho de primogenitura se impone de forma desigual entre hombres y mujeres, tanto en la realeza como en las clases bajas. Si la primogénita es una mujer, esta no podrá hacerse cargo de los bienes ni de los derechos que legítimamente le corresponden. Aunque sea princesa, no reinará cuando herede la corona, sino que necesitará un príncipe que se case con ella para reinar y su función será, exclusivamente, la de esposa y madre. El rey de «El gato con botas» ostenta el poder de su reino, pero consiente en casar a la princesa, su heredera, con el hijo del molinero para dar continuidad a su estirpe, creyendo que este -gracias a la astucia de su gato- es el marqués del Carabás, que posee un castillo y muchas tierras (Propp 493-495).

Llama la atención el incesto que se plantea en «Piel de asno» entre el rey y su hija, justificándose en el cuento porque «[...] era más bella / y un juvenil encanto poseía / que la difunta [su madre, la reina] al fin ya no tenía» (PA 236). Para reforzar su posición de poder y justificar su deseo incestuoso, el rey recurre a un «casuista» que, «resolviendo el caso a simple vista / juzgó posible tal proposición» (PA 236). La figura del casuista se entiende como «un experto en teología moral, especializado en casos de conciencia o conducta a seguir» (Perrault 287). Según el texto, todos los deseos del rey se satisfacen aunque no sean correctos, moral o socialmente, pero además son validados por un «experto», otra figura masculina, que otorga al deseo real legalidad, moralidad y refrendo social.

Solo la figura femenina del hada madrina, que atiende las razones de la negativa de la princesa, se atreve a contrariar el deseo real: «Sería un gran pecado / acceder a las locas pretensiones, / mas sin contradecirle, con mis trazas, / hay un modo de darle calabazas» (PA 239). Para conseguir su objetivo 
el rey accede a todas las peticiones de la princesa, incluso a regalarle la piel de su preciado asno; piel con la que, disfrazada, ella escapará. Ante la realidad de su fuga, el rey enviará a sus criados a buscarla, pero no la encontrarán. Al final del cuento, el padre de Piel de asno, que había superado su pasión por ella, asiste a su boda. Para Bettelheim «el deseo incestuoso se resuelve desplazando el vínculo amoroso desde el padre hacia el amante» (206) o el enamorado. Para ello la protagonista debe pasar por una serie de experiencias que la conducirán hacia su madurez psicológica.

\section{LOS PRÍNCIPES: HEREDEROS Y CONTINUADORES DEL SISTEMA}

Aunque en los cuentos de Perrault la figura del príncipe aparece como protagonista junto a otro personaje femenino, ninguno da título a sus cuentos -excepto Riquete-, dejando esta prerrogativa a La bella durmiente, Cenicienta, Caperucita, Piel de asno o Grisélidis. Ellas cobran importancia en el planteamiento y desarrollo de la acción narrativa, convirtiéndose, en la mayoría de los casos, en las verdaderas protagonistas. Los príncipes aparecen gobernando su reino a la muerte de sus padres y realizando actividades que recuerdan a las de los nobles de Versalles: cazan, bailan o disfrutan del carnaval o del teatro, todo en un ámbito de acción externo. Y para asegurar la continuidad de su dinastía y del reino buscan una esposa bella que posea unas cualidades adecuadas.

En Perrault encontramos príncipes apuestos, como el de «Piel de asno»: «bello, de noble porte y aspecto marcial» (PA 247), o grotescos, como Riquete: «feo, muy desagradable pero magníficamente vestido, [...] cortés y respetuoso» (RC 123). El príncipe de «Grisélidis» era «valiente, hábil, vigoroso, guerrero, impetuoso, y ama las Bellas artes. [...] Le gustaba el combate, la victoria, / [...] hacer al pueblo suyo venturoso. [...] Pero un humor sombrío oscurecía / este temperamento valeroso / que triste y melancólico le hacía / ver en su pecho siempre receloso, / al bello sexo infiel y mentiroso» (G 181182). Estas características de masculinidad se corresponden con el canon que imperaba en las cortes medievales y en la propia época del autor. Vamos a repasar a continuación tres aspectos que aportan mucha información sobre el concepto de masculinidad que transmiten los príncipes de los cuentos de Perrault. 


\subsection{Los príncipes como enamorados}

Una de las reivindicaciones de las preciosas es conseguir un matrimonio por amor. Los príncipes de los cuentos de Perrault siguen, en líneas generales, las normas sociales que responden al trato galante que impera en el salón del preciosismo: «La bella durmiente» recoge que «El príncipe ayudó a la princesa a levantarse [...] pero él se guardó de decirle que iba vestida como su abuela» (BD 24). Es galante pero miente para conseguir sus objetivos. Si ejercen el poder como príncipes, la galantería del preciosismo no se impone. Así lo podemos constatar en «Cenicienta» cuando, tras la prueba del zapato, el príncipe no va a recogerla y envía un lacayo: «La llevaron al príncipe, ataviada como estaba y la encontró más bella que nunca» (C 110). Por tanto, él no se comporta como enamorado sino como príncipe y no la considera su igual.

Ellos tienen la prerrogativa de elegir pareja y ellas deben esperar a ser elegidas: en «La bella durmiente», «La princesa cae en un profundo sueño que durará cien años al cabo de los cuales [...] la despierta el hijo de un rey, a quien estaba destinada» (BD 13, 19). Este príncipe quiere una esposa bella y durmiente, que acepte todas sus iniciativas y que lo espere eternamente. Características propias del patriarcado que las quiere «bellas» $\mathrm{y}$ «durmientes», como dice Fernández Rodríguez (64-66). Así lo vemos en «Cenicienta», «Las hadas», «El gato con botas», «Grisélidis», «Piel de asno» o «Riquete el del copete».

La pasión que experimentan estos príncipes no aparece explícita en los cuentos. La excepción es «La bella durmiente», donde encontramos que el príncipe la besa y, después de haber celebrado la boda, «El joven príncipe se sintió arder de pasión [...]. Creyó sin vacilar que él llevaría a cabo tan bella aventura, empujado por el amor y la gloria. [...] un príncipe joven y enamorado siempre es valiente» (BD 19, 21). El texto revela que para él este matrimonio es un lance, una conquista. En el mismo cuento también encontramos demostraciones de amor: «le aseguró que la quería más que a sí mismo» (BD 23). Pero, aunque la quería más que a sí mismo, tras la boda «la dejó por la mañana para volver a la ciudad, donde su padre estaba inquietándose por él» (BD 24). En realidad podríamos decir que la boda para este príncipe es una aventura, tras la cual la princesa se queda sola, casada con un príncipe que, 
de nuevo, la hace esperar y la oculta hasta que sus circunstancias varíen. Ella simplemente acepta la situación.

En los cuentos de Perrault la cualidad indispensable para ser elegida como esposa por el príncipe será la belleza. Las descripciones de las protagonistas femeninas no escapan a los cánones de belleza estereotipados establecidos que arrancan del canon medieval, según el cual ser bella es tener poder sobre el hombre que cae rendido a sus pies, ya que su deseo prevalece sobre su razón (Delumeau 305-345). También encontramos elementos del modelo de belleza renacentista que se mantendría sin alteraciones durante casi 300 años: «Piel blanca, pelo rubio, labios y mejillas rojos, cejas negras. El cuello y las manos debían ser largos y finos; los pies pequeños, la cintura graciosa. Los pechos debían ser firmes, redondos y blancos, con pezones rosados. El color de los ojos podía variar [...], y eventualmente podían hacerse concesiones al pelo oscuro» (Matthews Grieco 79).

En el Renacimiento, siguiendo la línea de pensamiento neoplatónica que establecía la belleza como signo exterior visible de bondad interior invisible, ser bella es un atributo relacionado íntimamente con la moralidad y la posición social. Así, podemos establecer el parámetro bella-buena-noble/aristócrata, en contraposición con la fealdad, que se asociaba a la maldad, al vicio y a la pobreza. Como ejemplo, veamos la descripción de la princesa Piel de asno que luce espléndida sin la piel del animal:

Su rubios cabellos fascinantes / sembrados de diamantes, / cuya luz deslumbrante e irisada / despedía mil rayos, comparables solo a sus ojos admirables, / azules, grandes, dulces y rasgados, / que, de orgullosa majestad cargados, / jamás podrían mirar / sin herir y agradar; / y su cintura, en fin, menuda y fina / que dos manos pudieran abarcar, / mostraron su gentil gracia divina / [...] el buen rey no cabía en sí de gozo / viendo los atractivos de su nuera; / también la reina estaba entusiasmada, / y el príncipe, su amante, sucumbía, / con el alma de júbilo inundada, / al peso de su arrobo y alegría. (PA 257)

Aunque despierta su ardor, su pasión, este príncipe no sucumbe ante su deseo y rechaza la idea de forzar la puerta de la estancia donde ella está, respetándola como reivindican las preciosas. Se retira a palacio y suspira, «llora, hipa, gimotea», actitudes consideradas por el patriarcado más propias de las mujeres que de la masculinidad de un príncipe. «Solo desea un pastel hecho por la mano de Piel de asno»; y la reina madre consiente porque «hay 
que darle gusto y satisfacerle en todo» (PA 251). Los médicos de la corte le diagnostican mal de amores, enfermedad también considerada femenina, y le recomiendan el «himeneo» (el matrimonio) para su cura; él acepta, pero pone como condición que solo lo hará con la que sea dueña del anillo que encontró en el pastel. Este anillo - «estrecho aro de oro» (PA 253)-, que Piel de asno introduce en el pastel, es una variación del zapatito de cristal de Cenicienta y podría representar la vagina, que está íntimamente relacionada con la virginidad, valor deseable en las mujeres. Para Bettelheim:

La sutileza de Perrault queda patente en el detalle de que la zapatilla sea precisamente de cristal, material que no cede, extraordinariamente frágil y que se rompe con facilidad. Un diminuto receptáculo en el que un miembro del cuerpo debe deslizarse e introducirse hasta quedar bien ajustado puede considerarse como un símbolo de la vagina. Algo frágil, que no debe maltratarse porque podría romperse recuerda al himen; algo que se puede perder fácilmente después de una gran fiesta, cuando el amante intenta retener a su pareja, parece una imagen sumamente apropiada para definir la virginidad. [...] Ajustarse la chinela y sobre todo colocarse el otro zapatito, significa aceptar el compromiso del matrimonio y Cenicienta es una novia virgen. (273)

Riquete se enamoró de su princesa por la belleza que mostraba su retrato (RC 123). Esta costumbre medieval se utilizaba en los matrimonios acordados cuando los cónyuges no se conocían y se recoge, por ejemplo, en los Lais de María de Francia y en otros cuentos de hadas, como «La princesa Rosette» de Madame d'Aulnoy. Riquete quiere casarse con esta princesa por su belleza, aunque se la describa como «estúpida» en el cuento (RC 123) (adjetivo que debe entenderse como carente del conocimiento al que aspiraban las preciosas), y le ofrece inteligencia (conocimiento). Este intercambio lo propició el hada que les otorgó los dones al nacer. Riquete tiene como cualidades ser de buena cuna, tener buen carácter, poseer inteligencia (conocimiento) y buenos modales; la belleza que le falta, según vaticinó el hada (RC 129-130), se la otorgará ella si le ama lo suficiente.

En el cuento hallamos otros príncipes que desean casarse con esta princesa; llamó su atención uno "poderoso, rico, inteligente y bien plantado» (RC 126), pero se casó con Riquete. Al final del cuento se recoge que ella hasta lo veía apuesto «con las gafas del amor» (RC 130) y todo termina -según narra el cuento- tal como Riquete había previsto. Este final podría indicar que el

Feminismo/s 35, junio 2020, pp. 235-262 
protagonista masculino cuenta con todas las prerrogativas para alcanzar sus objetivos aunque sea feo y contrahecho, mientras que la princesa tiene que conformarse con responder a las necesidades de Riquete ignorando sus propios deseos. Su voluntad no cuenta, ella solo podrá conseguir lo que Riquete quiera otorgarle. Desde el punto de vista familiar o social, ella no recibe ningún apoyo ni estímulo que la ayude a decidir en libertad.

En «Las hadas» se relata que, además de la belleza, una buena dote es un incentivo para que el príncipe se case con la protagonista, aunque no sea de sangre real: «El hijo del rey que volvía de caza se encontró con ella y, viéndola tan hermosa, le preguntó qué hacía allí sola. [...] Vio salir de su boca cinco o seis perlas y otros tantos diamantes [...] [regalo del hada por ser amable y cortés], se enamoró de ella y, considerando que tal don valía más que todo lo que pudiera aportar al matrimonio, [...] se casó con ella» (H 87-88).

El tema del cuento «Grisélidis» es la paciencia, virtud que deben practicar únicamente las mujeres. El príncipe de este cuento se niega al matrimonio porque tiene una opinión muy negativa de estas. Tras la lectura del texto podemos definirlo como un gran misógino, maltratador psíquico y celoso en extremo. Para él ninguna mujer es digna de ser su esposa porque desconfía de su fidelidad. Considera el matrimonio una atadura necesaria para tener descendencia y piensa que en él siempre debe prevalecer la opinión del marido. El texto es muy claro: se casará si «le encuentran una beldad / joven y sin orgullo y vanidad, / de obediencia acabada, / y de paciencia probada, / y que no tenga propia voluntad» (G 186).

Yendo de caza en el bosque se enamora de una pastora de nombre Grisélidis por su frescura, su aspecto juvenil, recato y discreción, que él considera prueba de un alma pura: «joven tímida, sencilla, dulce y sincera, de piel fresca, ojos azules y boca que conservaba el encanto de la infancia. Cuidaba su rebaño, hilaba, y vivía en su casa del bosque y se hacía su propia ropa» (G 188). Coser e hilar son dos actividades que este príncipe misógino valora, tal vez porque las mujeres las realizan en el ámbito íntimo del hogar.

Su masculinidad, en consonancia con la tradición patriarcal, se pone de manifiesto cuando responde a su Consejo, «voy a tomar esposa / [...] bien nacida, discreta y muy hermosa, / como antaño hicieron mis abuelos» ( $G$ 192). Acuerda el matrimonio con el padre de la pastora y se lo anuncia a esta como un hecho consumado, no sin antes pedirle que le jure que «no tendrá

Feminismo/s 35, junio 2020, pp. 235-262 
jamás ninguna voluntad más que la suya». Ella jura y lo toma por «esposo y señor» (G 196-197).

«Cenicienta» recoge en la escena del baile la prerrogativa del príncipe, del hombre, de elegir esposa entre muchas candidatas; ellas no podrán elegir y tendrán que esperar siempre a ser las elegidas.

\subsection{Los príncipes como esposos}

Salvo «Caperucita roja», los cuentos de Perrault terminan de forma feliz con la boda de ambos protagonistas. Pero no todo es felicidad. Pasados los primeros momentos de la boda y tras el nacimiento de su hija, el príncipe de «Grisélidis» comienza a dudar de su esposa. La espía y, como no consigue pruebas que empañen su virtud, la somete a mil formas de maltrato riguroso: recluirla, desposeerla de su estatus, arrebatarle a su hija, encerrarla en un monasterio, repudiarla y pedirle que instruya a su nueva esposa para que lo complazca, descubriéndole que la elegida es su propia hija. Todo esto para «consolidar sus virtudes innegables» (G 201). El peor aprendizaje que puede generarse de este cuento es que Grisélidis se lo justifica todo porque ella piensa que él busca: «ejercitar mi fe y mi paciencia» (G 202).

Tras la boda, el príncipe de «La bella durmiente» miente y oculta su matrimonio cuando dice a sus padres que «se había perdido cazando en el bosque» (BD 24). Así vivió con la princesa más de dos años y tuvo con ella dos hijos. Solamente hace público su matrimonio cuando es rey, a la muerte de su padre, y marcha a la guerra dejando la regencia a su madre. En la moraleja se da a entender que esperar con paciencia es una virtud que deben poseer las mujeres (BD 29-30), pero el autor nada dice de los hombres.

\subsection{Los príncipes como padres}

El príncipe de «Grisélidis» desea un hijo varón, pero nace una niña que lo conquista por su aire dulce y fascinante y que, sin ningún motivo, él arrebata a su madre. Cuando es adulta, la niña se enamora de un caballero y el padre, que envidia su dicha, traza un pérfido y retorcido plan «para probar el amor de los enamorados» (G 209-220) presentándola a Grisélidis -su madre-como la mujer con la quiere contraer segundas nupcias. El final es feliz, pero el 
modelo de masculinidad y de paternidad que trasmite es nefasto incluso para la época que relata el cuento.

\section{LOS NOBLES: DUEÑOS Y SEÑORES DE SUS ESPOSAS}

Barba azul aparece en el cuento del mismo nombre como un hombre rico. Lo llamaban «Barba azul» por el color de su barba, que causaba el rechazo femenino por el aspecto terrible que le daba. Sus posesiones se describen con detalle en el cuento. Exhibe un modelo de masculinidad que se caracteriza por la fuerza, la violencia, la agresividad, la astucia y el engaño. Se considera dueño de la vida de sus esposas si no cumplen con sus expectativas: «señora, habéis de morir» (BA 54) y propone en el cuento una idea de matrimonio muy particular: «Él le pidió a la madre a una [de sus dos hijas] en matrimonio y dejó a su elección que le diera la que quisiera. [...] las dos eran sumamente hermosas. [...] ya se había casado con varias mujeres y no se sabía nada de ellas» (BA 49). El texto confirma que él quiere una víctima, no una esposa. Invita a su casa a la madre, a las hijas y a sus amigas para impresionarlas con sus riquezas. La que sea su esposa dependerá de él en todos los sentidos (porque no posee conocimientos, ni riqueza, ni tiene una profesión que le dé autonomía) y será envidiada por las demás por su posición en un matrimonio donde él ordena y manda y es dueño incluso de su vida. Por su parte, ella debe obedecer en todo. Esta concepción del matrimonio recuerda a la del príncipe de «Grisélidis».

«Barba azul» incide en las tentaciones sexuales de las mujeres y en la infidelidad que provoca la curiosidad. Para Bettelheim, este cuento gira en torno a dos emociones: una, el amor celoso que está dispuesto a destruir al ser amado para que no lo traicione; y, otra, la fascinación del deseo sexual y el peligro que conlleva caer en él. La infidelidad conyugal representada por la sangre de la llave-que no desaparece- hace que el protagonista masculino castigue a sus esposas con la muerte. La llave, que abre la puerta de la habitación secreta, puede relacionarse con el órgano sexual masculino que desgarra el himen y hace aparecer la sangre -igual que en la llave-, provocando gran angustia a la protagonista, que se estremece al descubrir los cadáveres de las anteriores mujeres asesinadas por cometer esa misma falta (Bettelheim 
309-310). Pero en el cuento no se recoge que exista ningún castigo para las infidelidades masculinas.

Para salvarse, la esposa de Barba azul depende de sus hermanos, que eran dragón y mosquetero respectivamente. Este cuento relata la lucha de hombres contra hombres: por un lado, los hermanos, que se perfilan como «valedores» de las mujeres, capaces de matar por defender a una mujer que es de su familia: «los dos hermanos le persiguieron [...] le traspasaron el cuerpo con la espada y le dejaron muerto» (BA 59); y, por otro, Barba azul, que lucha por lo que considera su propiedad.

En la moraleja, Perrault pretende corregir la curiosidad femenina -considerada un defecto de las mujeres- y sus consecuencias; paradójicamente, la curiosidad asociada con el deseo de saber se entiende como una virtud masculina. La segunda parte de la moraleja dice que la historia que refiere el cuento «es de tiempos remotos, que ya no existen maridos abominables que piden lo imposible; y aunque se sientan insatisfechos o celosos actúan amablemente con sus esposas» (BA 60). Si la protagonista femenina de este cuento fuera respetada en todos los sentidos, como reivindicaban las preciosas, no necesitaría a nadie que la defendiera.

En resumen, el modelo de masculinidad que contiene «Barba azul» es muy negativo porque resalta la importancia que tienen para él el deseo sexual malsano y la posesión de su pareja, aspectos íntimamente relacionados con las emociones violentas y destructivas que no tienen nada que ver con el amor.

El padre de Cenicienta es un gentilhombre viudo que se deja dominar por su nueva esposa y se desentiende de su hija, dejándola a merced de la madrastra, que es orgullosa, altiva y descortés. Esta introduce en el cuento la lucha entre mujeres de la misma generación cuando apoya a sus dos hijas frente a Cenicienta para conseguir que alguna sea elegida por el príncipe, lo que resolvería sus necesidades económicas al beneficiarse de la cercanía al poder masculino. Cabe destacar que en la trama de estos y otros cuentos no aparece la rivalidad entre los hermanos -pero sí aparece entre las hermanas, como podemos ver en este cuento o en «Las hadas»-y los hombres no figuran como padrastros porque no están obligados a proteger a sus hijos para que compitan entre ellos, ya que gozan de autonomía económica por su trabajo o sus riquezas. 


\section{PROTAGONISTAS MASCULINOS DE CLASE SOCIAL BAJA}

Pulgarcito -el menor de siete hermanos- es el protagonista del cuento del mismo nombre. Es pequeño como un pulgar, pero valiente, sagaz, callado, observador y generoso. Su astucia se pone de manifiesto cuando le dice a la ogra que su marido le dijo «que me dieseis todo lo que tiene valor» (P 161). Por sus cualidades hizo fortuna, consiguió ser «correo del rey y con su trabajo compró cargos para que trabajaran su padre y sus hermanos» (P 163), lo mismo que hacían las clases altas cercanas a la corte o la familia de Perrault.

El personaje de Blas, protagonista del cuento «Los deseos ridículos», es leñador de profesión y vive en una choza en el bosque (DR 269). Se queja de que «jamás el cielo empedernido / ningún deseo le había concedido» (DR 268). Desesperado, desea abandonar el monte para descansar y morir. A las quejas de este pobre personaje masculino responde Júpiter, padre de los dioses en la mitología romana, que vive en el cielo y «aparece rayo en mano [...] / pues soy del mundo dueño y soberano» (DR 268), mostrando su gran poder. El leñador intenta que la conversación entre ambos sea de igual a igual, pero Júpiter mantiene la distancia y le concede tres deseos, indicándole que sea prudente en la elección.

Blas está casado con Paquita y, aunque le pide parecer para elegir los deseos, al mismo tiempo sigue la corriente misógina de la época y la insulta, la trata de mala, pécora o charlatana porque no quiere reconocer las consecuencias que ha tenido su descuido al elegir. No en vano, Blas aparece descrito en el cuento como «bebedor de vino, imprudente y torpe» (DR 270). Casi está a punto de pedir como deseo quedarse viudo, ante los improperios de Paquita, cuando desea que una morcilla se pegue a la nariz de ella. Finalmente se impone la cordura y el amor que siente por ella y, despreciando la riqueza, utiliza su tercer deseo para quitarle la morcilla de la nariz y hacer feliz a su esposa. En el cuento no aparece ningún dato de la experiencia amorosa de esta pareja, que no tiene hijos. En la moraleja se incide en que los hombres a la hora de elegir son miserables, ciegos, atolondrados y variables. 


\section{LOS PADRES DE LAS CLASES POBRES COMO PERSONAJES MASCULINOS}

Los padres de las clases pobres que encontramos en estos cuentos siguen la misma línea de actuación que los de las clases nobles, con las diferencias propias de su nivel social y económico. Guillermo -el padre de Pulgarcitoes leñador y tiene siete hijos. Amenaza con pegar a su esposa porque ella le recrimina que consienta perder a sus hijos por no tener con qué alimentarlos. Él toma las decisiones pero no asume sus responsabilidades como padre y «encuentra inoportunas a las mujeres que siempre han tenido razón» (P 145).

El molinero de «El gato con botas» reparte su herencia entre sus tres hijos favoreciendo al mayor. El pequeño solamente heredará el gato, pero conseguirá riqueza y ascenso social gracias a la astucia del animal (GB 67). La figura del padre no aparece en «Caperucita». Está representado simbólicamente por los leñadores que hacen que el lobo posponga sus planes ante su cercanía (Bettelheim 186).

\section{LOS OGROS DE «EL GATO CON BOTAS»Y DE «PULGARCITO»}

El ogro es un «Ser fantástico y gigantesco parecido al hombre que se alimenta de carne humana; persona insociable, cruel o de mal carácter» (DRAE 1469). Pérez-Rioja dice que «en su origen [el ogro] se remonta al mito de Saturno devorador de sus hijos y personifica, simbólicamente, al padre terrible» (322). En «Pulgarcito» el ogro se manifiesta como un ser desconfiado, cruel, violento, que se come a los niños, se erige como rey y señor de su familia y de su mujer - la ogra- a quien manda y ordena como a una sirvienta: «dame rápidamente las botas de siete leguas» (P 159). Por su parte, el ogro de «El gato con botas» aparece como un ser egoísta que vive solo. Su vanidad le pierde cuando, tentado por la astucia del gato, para mostrar su poder se convierte en ratón y este se lo come.

\section{PERSONALES MASCULINOS ANIMALES: EL LOBO DE «CAPERUCITA»Y EL GATO DE «EL GATO CON BOTAS»}

Caperucita roja es la protagonista que da título al cuento. El color rojo simboliza las emociones violentas, sobre todo las de tipo sexual, y la caperuza, su sexualidad incipiente para la que aún no está madura (Bettelheim 181-182). 
En la mitología el lobo se relaciona con la astucia, la crueldad y el mal (Pérez Rioja 274). El protagonista masculino del cuento «Caperucita» es un lobo que planea comérsela. Este lobo no es un animal de presa, sino que encarna, de forma simbólica, a un seductor masculino, egoísta, asocial, activo, atrevido, astuto, listo, tramposo y violento en extremo. Reúne las peores tendencias asociales y primitivas y se guía por sus instintos para destruir a esta niña espontánea, ingenua, tierna, crédula, débil y sin iniciativa.

El lobo vive en el bosque -ámbito externo- y a Caperucita, que vive en su casa con su madre -ámbito interno-, salir para visitar a su abuela enferma le parece algo extraordinario. Cuando el lobo la encuentra en el camino no se la come, sino que la engaña. Escoge el camino más corto para llegar antes a casa de la abuela, la elimina y se hace pasar por ella para poder disponer de la nieta. «Al pasar por el bosque [...] tuvo ganas de comérsela [...] [instintos que reprime] porque andaban por el monte algunos leñadores» ( $C$ 37), que frenan sus planes. En el dualismo propio del cuento, lobo y leñador aparecen como figuras opuestas: el lobo representa la maldad masculina y el leñador simboliza la responsabilidad o el cuidado del padre, la protección y la salvación.

En «Caperucita» se hace hincapié, de forma directa, en la satisfacción sexual masculina: «ven a acostarte conmigo [...], Caperucita se desnudó y se metió en la cama» (C 41). En la moraleja se recoge que el autor identifica a los hombres con los lobos melosos y los considera «peligrosos» (C 42), dando a entender que el objetivo de los hombres es conseguir su satisfacción sexual de cualquier forma o, como el lobo, de forma astuta y complaciente.

El gato era venerado en el antiguo Egipto y considerado en la Edad Media como un animal diabólico. Simboliza la pereza y la lujuria y se le relaciona con lo femenino, la hipocresía, la habilidad y la astucia (Pérez Rioja 221). En «El gato con botas», él es la herencia que le corresponde al hijo pequeño de un molinero que la reparte según el derecho de primogenitura. Este personaje animal con comportamiento masculino es astuto, audaz, estratega, pero a la vez marrullero, pícaro, mentiroso e ingenioso. Con su astucia conseguirá para su amo las posesiones del ogro, ascenso social y el amor de la princesa por los regalos que hace al rey de parte de su amo. 


\section{LA MASCULINIDAD EN LOS CUENTOS DE PERRAULT}

Los personajes masculinos de los cuentos de Perrault transmiten un concepto de masculinidad que concede mayor valor a lo masculino que a lo femenino. Tanto si son protagonistas del cuento como si no lo son, ejercen el poder económico, social, político y cultural sobre los personajes femeninos. Están asociados a cualidades como la fuerza, la inteligencia, la valentía, el conocimiento, la violencia, el poder, la autoridad, el dominio, la agresividad o la necesidad sexual, todos eligen esposas bellas y ellas deben esperar ser las elegidas. Entre ellos se incentiva la competitividad, la demostración de virilidad innecesaria, la búsqueda del riesgo y el uso de la violencia en determinadas circunstancias.

Para satisfacer este modelo de masculinidad las mujeres elegidas deben ser bellas, débiles, torpes, bondadosas, dependientes, pasivas, tiernas, sumisas, pacientes, abnegadas, volubles y grandes sufridoras, complacer y solventar las necesidades del marido y atender al hogar y a los hijos. Una buena dote es otra razón de peso para ser elegida como esposa. Aunque cumplan con todos los requisitos exigidos, los personajes masculinos tienen un concepto negativo de las mujeres -sexo débil o bello sexo, según convenga-, considerándolas vanidosas, perezosas, falsas, perversas, torpes, astutas, curiosas o coquetas. Pueden disponer de ellas a su antojo porque se consideran sus dueños y señores -incluso de su vida, como hemos visto en «Barba azul»-, y así deben ellas aceptarlo.

Algunos se resisten al matrimonio, o lo aceptan como obligación para dar a la corona un heredero que perpetúe su linaje, considerando que pierden su libertad al casarse. Paradójicamente, las mujeres no pierden nada cuando se casan: ellas ganan el espacio privado del hogar porque ese es el destino para el que se han preparado desde pequeñas.

Los personajes masculinos valoran en ellas la fidelidad y la virginidad y satisfacen sus necesidades sexuales dentro del matrimonio, ya que van encauzadas a la procreación. Si nace una niña, aunque le corresponda por linaje, no reinará: se mantendrá en el hogar cuidando de su familia y necesitará un consorte masculino para hacerlo rey. En los cuentos se habla de matrimonio, de pasión, de conquista y de boda, terminando con el «Y vivieron felices...» como fórmula de cierre, pero los protagonistas masculinos no expresan 
sentimientos de amor verdadero. Confunden amor con deseo, posesión o conquista, sufren celos patológicos y son grandes misóginos, como hemos visto en «Grisélidis» o en «Barba azul». En «Piel de asno» el incesto entre padre e hija -que no se da entre madre e hijo- se justifica moral, política y socialmente y se resuelve bien gracias a la ayuda del hada.

Los protagonistas masculinos aparecen como héroes, con profesión definida y con el campo de acción siempre fuera del hogar. Ejercen de padres distantes socialmente aceptados, reconocidos y bien valorados, capaces de tomar decisiones, que las protagonistas femeninas siempre deberán acatar. Nunca aparecen realizando tareas domésticas ni compartiendo la crianza de la prole con sus esposas.

El concepto de masculinidad hegemónica, asociada a los valores del patriarcado, que impera en estos cuentos, contribuye a perpetuar e institucionalizar las estructuras de dominación y las desigualdades de género, reproduciendo siempre los mismos roles y manteniendo de forma continuada un discurso homogeneizante que no tiene en cuenta a las mujeres como sujetos históricos, niega su diversidad y sus vivencias propias y no plantea otras alternativas. El patriarcado alienta desde dentro, porque lo ayuda a mantenerse, la competencia entre las mujeres para conseguir al príncipe. Esta competencia las desune y provoca envidia y falta de solidaridad ente ellas porque solo una será la elegida. El resultado será la subordinación constante de la mujer al hombre, basándose siempre en parámetros de obediencia y dominación. A cambio, si cumplen con lo establecido, ellas obtienen -como en el cuento- el premio del matrimonio y un final «feliz», que consiste en vivir por y para el hombre el resto de su vida, ofreciendo una imagen inamovible de sí mismas que lleva implícita la falta de autoestima, el convencimiento de no sentirse completas por no tener pareja o por no tener hijos y la dependencia emocional, parámetros sobre los que se construyen las relaciones malsanas o el maltrato.

\section{CONCLUSIONES}

Aunque los cuentos de Perrault son un acierto de recopilación y de creación, los arquetipos masculinos que encontramos en ellos y el concepto de masculinidad que transmiten no responden al concepto de masculinidad 
que necesitamos en la actualidad. El aprendizaje que estos cuentos generan, desde la infancia, perpetúa un concepto de masculinidad patriarcal que se retroalimenta de la información del cuento y ayuda a sostener las desigualdades entre hombres y mujeres presentes en nuestra sociedad. No queremos decir que no se lean o no se cuenten los cuentos de Perrault, pero sí que, al menos, se explique que contienen un perfil de masculinidad que responde a otra época y se establezca, de forma clara, la diferencia entre el concepto de masculinidad que manifiestan y el que se necesita en la actualidad para conseguir una correcta socialización de género.

La cultura de la desigualdad está íntimamente relacionada con el control que se ejerce sobre el otro, por lo que podemos utilizar el cuento como herramienta de socialización que, desde la infancia, contribuya a eliminar las inequidades que se establecen a partir de la diferenciación en base al sexo o al género. Podemos introducir en los contenidos de los cuentos, en sus imágenes o en la forma de contarlos otros arquetipos que apoyen nuevas masculinidades carentes de sesgos que respondan a nuestra realidad social, para que en ella se favorezca el intercambio de roles buscando la conciliación del mundo laboral, de la vida personal y familiar, de forma que hombres y mujeres se impliquen por igual.

Es importante revindicar la expresión de los afectos y las emociones masculinas para mejorar las relaciones de hombres y mujeres en su vida cotidiana, así como incluir nuevos conceptos sobre el amor, el matrimonio, la confianza o la autoestima. Buscaremos siempre deslegitimar la violencia como norma general, en particular la física, la sexual o la psicológica y utilizar como método de resolución de conflictos el dialogo pacífico y la negociación.

Para ello debemos repensar los modelos de masculinidad que aprendemos a partir de los cuentos a fin de contribuir a desaprender este modelo de masculinidad que conocemos y aprendemos desde la infancia y contar o leer cuentos que presenten otras alternativas. Para conseguirlo proponemos deconstruir los cuentos de Perrault o escribir otros nuevos que generen nuevas masculinidades, de forma que los hombres hagan suyas las reivindicaciones femeninas y reafirmen su compromiso con un nuevo concepto de masculinidad donde la igualdad, el respeto y la inclusión sean una realidad. 


\section{REFERENCIAS BIBLIOGRÁFICAS}

Anderson, Bonnie S., y Judith P. Zinsser. Historia de las mujeres: una historia propia. 2 vols. Barcelona: Crítica, 1992.

Beauvoir, Simone. El segundo sexo. Buenos Aires: Siglo veinte, 1981.

Bettelheim, Bruno. Psicoanálisis de los cuentos de hadas. Barcelona: Crítica, 1999.

Bonino Méndez, Luis. «Masculinidad hegemónica e identidad masculina». Dossiers feministes 6 (2002): 7-35.

Bourdieu, Pierre. La dominación masculina. Barcelona: Anagrama, 2000.

Connell, Robert W. «La organización social de la masculinidad». Ediciones de las Mujeres 24 (1997): 31-48.

Defrance, Anne. «De la caverne matricielle au tombeau: L'Ile de la Félicité de Madame d'Aulnoy, premier conte de fées littéraire français». Cahiers du C.R.L.H. 11 (1997): 145-152.

Delumeau, Jean. «Les agents de Satan. III : La femme». La peur en Occident. XIV au XVIII ${ }^{e}$ siècle. París: Fayard, 1978. 305-345.

Denis, Delphine. «'Sçavoir la carte': voyage au Royaume de la Galanterie». Études littéraires 34. 1-2. (2002): 179-191.

Dens, Jean-Pierre. «Honnête homme et esthétique du paraître». Papers on French Seventeenth Century Literature 6 (1976-1977): 69-82.

Dulong, Claude. «De la conversación a la creación». Historia de las mujeres: del Renacimiento a la Edad Moderna. Dras. Arlette Fargue y Natalie Zemon Davis.

T. 3. Madrid: Taurus, 1992. 425-451.

D’Urfé, Honoré. L'Astrée. París: Gallimard, 1996.

Fairclough, Norman. «El análisis crítico del discurso como método de investigación en ciencias sociales». Método de análisis crítico del discurso. Comps. Ruth Wodak y Michael Meyer. Barcelona: Gedisa, 2003. 179-201.

Faret, Nicolas. L'honnête homme ou L'art de plaire à la cour. Ed. M. Magendie. Ginebra: Slatkine, 1970.

Fernández Rodríguez, Carolina. La bella durmiente a través de la historia. Oviedo: Universidad de Oviedo, 1998.

Garrido Carrasco, Vicenta. Mujeres y hadas: desde el cuento a las reivindicaciones femeninas. Jaén: Universidad de Jaén, 2015.

Henriot, Émile. «De qui sont les Contes de Perrault?». Revue des Deux Mondes. 43 (15 de enero de 1928): 424-441.

Jociles Rubio, María José. «El estudio sobre las Masculinidades: panorámica general». Gaceta de Antropología 17 (2001). 1 de julio de 2019. Granada: 
Universidad de Granada <http://www.ugr.es/ pwlac/G17_27MariaIsabel_ Jociles_Rubio.html>

La Fayette, Madame de (Marie-Madeleine Pioche de La Vergne, comtesse de). La Princesse de Clèves. París: Flammarion, 2008.

L'Héritier de Villandon, Marie-Jeanne. OEuvres mêlées. París: Jean Guignard, 1696.

19 de marzo de 2018. Gallica <http://gallica.bnf.fr/ark:/12148/bpt6k62376r> Matthews Grieco, Sara F. «El cuerpo, apariencia y sexualidad». Historia de las mujeres en occidente. Dras. Arlette Fargue y Natalie Zemon Davis. T. 3. Madrid: Taurus, 1992. 68-109.

Mongrédien, Georges. Les précieux et les précieuses. París: Mercure de France, 1939.

Pérez Rioja, José Antonio. Diccionario de símbolos y mitos. Madrid: Tecnos, 1971.

Perrault, Charles. Cuentos de antaño. [Histoires, ou Contes du temps passé, avec des moralités, Grisélidis, nouvelle, avec le conte de Peau d'asne, et celuy des Souhaits ridicules] Il. Gustavo Doré. Trad. pról. y not. J. Evheramonno y E. Pascual. 3. ${ }^{a}$ ed. Madrid: Gaviota, 1996.

Prado Biezma, Javier del. «El feminismo ambiguo de Molière». Thélème: Revista Complutense de Estudios Franceses 23 (2008): 123-147.

Propp, Vladimir. Las raíces históricas del cuento. Madrid: Fundamentos, 1998.

Real Academia Española. Diccionario de la lengua española. Vigésimo segunda ed. 2 vols. Madrid: Real Academia Española, 1992.

Sau Sánchez, Victoria, y María Jayme. Psicología diferencial del sexo y el género. Barcelona: Icaria, 2004.

Soriano, Marc. Los cuentos de Perrault. Buenos Aires: Siglo XXI Argentina Editores, 1975.

Van Dijk, Teun A. Texto y contexto. Madrid: Catedra, 1993.

Yllera Fernández, Alicia. «El siglo XVII». Historia de la literatura francesa. Coord. Javier del Prado. Madrid: Cátedra, 1994. 421-422. 
To link to this article / Para enlazar con este artículo:

https://doi.org/10.14198/fem.2020.35.10

To cite this article / Para citar este artículo:

Johnson, María Cecilia. «Las TRHA y los debates en la academia feminista sobre reproducción: relaciones de poder y tecnología». En Feminismo/s, 35 (junio 2020): 263-289. DOI: 10.14198/fem.2020.35.10

\title{
LAS TRHA Y LOS DEBATES EN LA ACADEMIA FEMINISTA SOBRE REPRODUCCIÓN: RELACIONES DE PODER Y TECNOLOGÍA
}

\author{
ARTS AND THE DEBATES IN THE FEMINIST \\ REPRODUCTION ACADEMY: POWER RELATIONS AND \\ TECHNOLOGY
}

\author{
María Cecilia JOHNSON \\ CIECS-CONICET. Universidad Nacional de Córdoba, Córdoba (Argentina) \\ cecilia.johnson@unc.edu.ar \\ orcid.org/0000-0002-5102-2504
}

\section{Resumen}

Este trabajo tiene como objetivo reconstruir los debates que desde la academia y los activismos feministas se han planteado sobre la reproducción humana asistida. Mediante un recorrido histórico se abordan estos debates que comienzan en el norte global, desde los debates de la segunda ola, los feminismos queer y los desafíos para los feminismos en Latinoamérica. Se advierte una tensión sobre algunos ejes centrales para el feminismo: desde la pregunta por las nuevas formas de opresión sobre los cuerpos, hasta quiénes debaten por las posibilidades de agencia y autonomía reproductiva. Estas tensiones adquieren matices diferentes que no pueden disociarse de las diferentes posturas epistemológicas sobre cuerpo, autonomía y poder que proponen, así como tampoco se pueden separar de los escenarios globales y regionales que suponen entender el trabajo reproductivo de forma estratificada.

Palabras clave: feminismos; reproducción asistida; poder; autonomía; América Latina. 


\begin{abstract}
This work aims to reconstruct the debates from the academy and feminist activists have been raised about assisted human reproduction. From a historical point of view, these debates that begin in the global north are addressed, from the debates of the second wave feminism, queer feminisms and the challenges for feminisms in Latin America. A tension is noticed on some central axes for feminism: from the question about the new forms of oppression on the bodies to those who debate the possibilities of agency and reproductive autonomy. These tensions acquire different nuances that cannot be separated from the different epistemological positions on body, autonomy, and power they propose, nor can they be separated from the global and regional scenarios that involve understanding reproductive work in a stratified way.
\end{abstract}

Keywords: Feminisms; Assisted reproduction; Power; Autonomy; Latin America.

\title{
1. INTRODUCCIÓN
}

El estudio de las experiencias de personas usuarias de la medicina reproductiva no siempre fue abordado por el feminismo de la misma manera. Podría pensarse que desde los años setenta las Técnicas de Reproducción Humana Asistida (TRHA) han reactivado algunos debates históricos dentro del feminismo, así también han planteado nuevos interrogantes fuera de este campo.

En el marco de una investigación doctoral en Estudios de Género que estudia las experiencias de mujeres usuarias de reproducción asistida en Argentina, este trabajo se propone como objetivo principal reconstruir algunos debates en clave historiográfica dentro de la academia y los activismos feministas sobre las TRHA. Ello supone identificar en primera instancia algunos nudos críticos de discusión dentro de este movimiento y sobre el que continúan existiendo desacuerdos y tensiones entre posiciones epistémicas y geopolíticas al pensar la reproducción. La maternidad constituye un primer nudo crítico de discusión, sobre el que han existido miradas contrapuestas en los feminismos. Se identifican dentro de una compleja discusión dos grandes posturas que podrían resumirse entre aquellos sectores que ponen el acento en su carácter opresivo de la maternidad y entre quienes consideran que las opresiones son producto de una sociedad patriarcal. De este planteamiento se desprende el interrogante sobre las posibilidades de construir autonomía sexual y reproductiva: ¿es posible pensar la autonomía reproductiva

Feminismo/s 35, junio 2020, pp. 263-289 
solamente cuando se elige no maternar o también se construye autonomía cuando se elige la maternidad?

Un segundo nudo que atraviesa de forma transversal estas discusiones en los estudios feministas es la pregunta por el sujeto del feminismo, encabezado por las posiciones críticas feministas en ruptura con el feminismo blanco, universal y heterosexual, posición cuestionada desde otras intersecciones.

Reconocer estos nudos críticos permite comprender la genealogía de ciertas discusiones en los feminismos, las cuales se reeditan cuando hablamos de las TRHA. De esta manera la pregunta por la maternidad y poder se traduce en la pregunta por la tecnología reproductiva y el poder: ¿La tecnología reproductiva constituye una forma de opresión patriarcal o puede ser pensada como fuente de liberación de las mujeres en su reproducción?

Para desarrollar estas discusiones luego de esta introducción -sección primera-, este artículo desarrolla las diferentes posiciones en el debate. En una segunda sección se recuperan las diversas posiciones que desde la teoría y el activismo feministas han pensado críticamente la maternidad y las tecnologías reproductivas. Este análisis supone un paralelo con las posiciones y aportes de la teoría feminista sobre la maternidad que permiten adentrarse al pensamiento y crítica feministas sobre las TRHA. Así mismo estos interrogantes permiten presentar las primeras fracciones dentro del feminismo sobre las TRHA.

En una tercera sección se desarrollan los debates que fueron atravesando los feminismos de la segunda ola del norte global, y la discusión con otras posiciones del feminismo queer de los años noventa y contemporáneos que plantean otra relación con la tecnología como dispositivo de poder.

Los debates presentes en estas secciones dan cuenta de un primer antagonismo: para algunas feministas radicales, las TRHA fueron identificadas como una forma más de opresión patriarcal sobre los cuerpos de las mujeres, mientras que desde otras posiciones se plantearon distintas maneras de apropiación, resistencia y hasta consideraron a las TRHA como una plataforma de liberación utópica.

El desarrollo de los estudios de la sexualidad y de la biopolítica modificó la mirada sobre las THRA, ahora entendidas como parte del creciente proceso de control biopolítico y medicalización de los cuerpos (Armstrong 393; Foucault 17; Rose 10). Así mismo, el desarrollo de estudios feministas que 
comienzan a disputar el campo de la salud y las experiencias de usuarias en el campo biomédico generó nuevas discusiones. Más aún, otros sectores del feminismo encuentran en la tecnología reproductiva una fuente utópica de liberación o de subversión del género.

En una cuarta sección, se retoman algunas producciones de Argentina que discuten sobre las TRHA y los debates situados desde los feminismos del sur y decoloniales como otro espacio situado para pensar estas intersecciones, donde las experiencias y discusiones de los feminismos sobre las TRHA resultan más recientes.

Respecto a los aspectos metodológicos, el análisis de las diferentes secciones es producto de una revisión de literatura enfocada en los debates de los feminismos sobre las TRHA. Se trabajó con fuentes secundarias, seleccionándose artículos y libros especializados en las perspectivas feministas sobre las TRHA, así mismo se complementó el análisis con fuentes audiovisuales.

Partiendo de las autoras referentes en las discusiones feministas sobre reproducción, se fueron reconstruyendo diferentes posturas tomando como primer criterio de búsqueda las referencias intertextuales entre las autoras en sus debates. Así mismo, la dimensión temporal determinó la búsqueda de fuentes y también constituye un organizador del artículo. Es por ello por lo que se intenta en su desarrollo respetar cierta genealogía de las discusiones, las llamadas «olas del feminismo», las cuales implicaron miradas y epistemologías diferenciales sobre la reproducción. Ello supone situarse en primer lugar en las autoras feministas europeas y norteamericanas, siendo Inglaterra el país pionero en su desarrollo, rápidamente sucedido por Estados Unidos y otros países de Europa. En este sentido, la dimensión geográfica es otro criterio presente, por lo que se partirá principalmente de las autoras feministas europeas y principalmente anglosajonas por ser estas últimas no sólo pioneras en su experiencia sino también promotoras de los primeros análisis sobre los desafíos de las TRHA para las mujeres.

\section{FEMINISMOS Y TRHA: UNA RELACIÓN «INCÓMODA».}

Desde el feminismo y los estudios de género, el debate sobre la maternidad, la reproducción y el control del sistema médico hegemónico sobre los cuerpos de las mujeres tiene un amplio recorrido desde diversas perspectivas 
feministas filosóficas, antropológicas y sociológicas. Desde el punto de vista de las mujeres y sus decisiones reproductivas, ha cuestionado históricamente el control del cuerpo de las mujeres así como la maternidad obligatoria. Podría decirse parafraseando a Irati Fernández Pujana que la relación entre la maternidad y el feminismo es una relación incómoda (149), tensión que se puede trasladar también a los estudios sobre TRHA, por reactualizarse algunas tensiones y preguntas sobre la maternidad como opresión patriarcal.

Si bien a continuación no se desarrollarán exhaustivamente las diferentes visiones del feminismo sobre la maternidad, estos debates atraviesan las tensiones de las posiciones feministas sobre TRHA. Una de las preguntas que atraviesa la teoría feminista se vincula a la autonomía sexual y reproductiva, específicamente si las tecnologías refuerzan la opresión patriarcal o posibilitan mayor autonomía reproductiva.

Para las feministas de la segunda ola, la maternidad constituía sin dudas una forma de opresión patriarcal, donde la experiencia de las mujeres indicaba que la decisión por la maternidad era muy restringida en algunos contextos y la sexualidad estaba confinada a la heterosexualidad, al matrimonio y donde la procreación era solo legítima en ese marco. Es por ello por lo que las luchas del feminismo estaban orientadas a la ruptura de la naturalización de la maternidad como destino para las mujeres en la sociedad (Chodorow 6; De Beauvoir 3).

Para Simone De Beauvoir, al igual que para otras feministas contemporáneas, el desafío estaba en disputar y deconstruir la idea del instinto materno por constituir una idea que sustentaba la opresión patriarcal hacia las mujeres (Saletti Cuesta 175). Enfatizando el papel de socialización patriarcal sobre la maternidad, la apuesta de Simone De Beauvoir se orientaba a la deconstrucción de la «mujer», como bien señala con la afirmación de que «mujer no se nace, se hace». Al mismo tiempo concebía los procesos reproductivos como una experiencia de alienación para las mujeres, que hacía sentir el cuerpo como algo ajeno «fatigoso» y que le exige a la mujer «pesados sacrificios» (De Beauvoir 12-13).

Así también las feministas de la segunda ola (Chodorow 11; De Beauvoir 12) cuestionaron la maternidad como identidad femenina. Cuando Nancy Chodorow se pregunta «¿Por qué las mujeres maternan?» analiza un conjunto de argumentos que históricamente han sustentado y naturalizado la

Feminismo/s 35, junio 2020, pp. 263-289 
división sexual del trabajo (11). Así también, otro aspecto central que plantea Chodorow es el cuestionamiento de la categoría «maternaje» ${ }^{1}$, noción que naturaliza el lugar de la mujer como cuidadora. De esta manera se produce, según la autora, la circularidad de la reproducción de género: «La división sexual del trabajo produce tanto las diferencias de género a la vez que es reproducida por ellas» (38). Para Chodorow, la división sexual no es solo un aprendizaje en el marco de la socialización de género, sino que forma parte de la conformación psíquica femenina en una sociedad patriarcal. Estas posiciones que cuestionan la maternidad como identidad femenina continúan presentes en desarrollos más recientes del feminismo francés, donde se critica la naturalidad del instinto maternal, las ambivalencias y opresiones en la experiencia de maternar (Badinter 19), entendiendo a las TRHA como nuevas formas de opresión sobre las mujeres (Laborie 5; Tubert, «Los ideales culturales» 161, «Demanda de hijo» 351).

Una posición que será controvertida en los años setenta es la de Shulamith Firestone, feminista radical, quien, al igual que De Beauvoir, planteaba que la maternidad era una experiencia victimizante para las mujeres (En Rich 174). Su postura es novedosa en cuanto ella consideraba que la tecnología podía contribuir a eliminar la diferencia sexual como origen de la opresión. La división sexual del trabajo y la tiranía de la familia biológica pueden resolverse con la reproducción artificial, decía Firestone como un planteamiento utópico (11). Desarrollos como el de Donna Haraway buscarán en la tecnología algo similar a lo que Firestone señalaba en la década de 1970 y que fue ampliamente criticado: la tecnología puede volverse una herramienta de liberación para las mujeres (Haraway, «Manifiesto para cyborgs» 7) (Franklin, «Transbiology» 19), idea que se retomará posteriormente ${ }^{2}$.

Una década después del planteo de Firestone y con el desarrollo de las TRHA, algunas feministas radicales como Gena Corea y Christine Crowe traerán estas discusiones para criticar las consecuencias de las tecnologías reproductivas para las mujeres. Crowe señala que las TRHA constituyen una

1. La autora señala que la categoría «paternaje» no existe, lo cual refleja esta naturalización de la división sexual del trabajo.

2. Puede rastrearse este paralelo teórico entre Firestone y Haraway en la conferencia brindada por Sarah Franklin en Barnard College. Consultar referencias. 
solución tecnológica para la ausencia de hijos pero que en lugar de apuntar a sus causas continúan reforzando la maternidad biológica como modelo deseable (547). La autora, en debate con aquellos argumentos que apuntan al derecho a decidir de las mujeres sobre su reproducción, cuestiona que la decisión no resulta autónoma en cuanto está mediada por circunstancias sociales como el estigma y la condena social por no tener hijos.

Otra exponente del feminismo radical, Janice Raymond, señala estas técnicas como una forma de violencia hacia las mujeres por degradar sus cuerpos (5) vinculándolas a formas de abuso sexual. Así también agrega la dimensión geopolítica trasnacional, analizando la gestación subrogada en países del sur global. En relación a las usuarias, Raymond también cuestiona la idea de elección de las mujeres sobre las TRHA, como valor que ha legitimado otras «opciones opresivas» tales como la prostitución y la pornografía. Al igual que Crowe, critica los argumentos que enfatizan la autonomía reproductiva de las mujeres, señalando que no puede haber elección si no hay autonomía, salud y justicia social (8). También critica cómo la reproducción asistida presenta al feto como un ente aislado e independiente del cuerpo de la mujer (9), la cual pasa a ser un mero ambiente y un envase, principalmente en la gestación subrogada.

Otro argumento crítico de la autora se vincula a la idea de que la infertilidad es producida por la reproducción tecnológica. En este sentido Janice Raymond argumenta que su creciente uso no solo se debe a que la definición de la infertilidad se ha expandido, sino a la oferta de especialistas y la consecuente visita a estos especialistas (39).

Desde el ecofeminismo Mies y Shiva señalan que las tecnologías de reproducción forman parte de los desarrollos y conquistas patriarcales y coloniales del hombre blanco sobre la naturaleza. Las autoras contrastan cómo las políticas de población intentan reducir los nacimientos en el «Tercer Mundo» mediante políticas de esterilización forzosa a las mujeres pobres, mientras que se busca la fertilidad en el «Primer Mundo». También subrayan una continuidad entre las políticas eugenésicas, el racismo y fascismo de la política nazi y las TRHA. Señalan que las tecnologías reproductivas también constituyen una política sexista, ya que permiten la selección del sexo, lo que tiene consecuencias graves particularmente en los cuerpos de las mujeres del «Tercer Mundo»(8). 
Desde otras posiciones políticas, algunas autoras contemporáneas sostienen críticas similares que van en la misma línea que el feminismo radical, particularmente la coincidencia se vincula a la relación entre las TRHA y el mercado reproductivo neoliberal y patriarcal. En la actualidad, algunas de estas críticas cuestionan la donación y mercantilización de los gametos y la gestación subrogada como otra práctica donde el escenario neoliberal da cuenta de un entramado del trabajo reproductivo realizado de manera desigual (Wichterich 17; Waldby y Cooper 21; Blázquez-Rodríguez 11). Estas autoras reconocen otras intersecciones vinculadas a la posición social, racial y territorial, que configuran diversos modos de desigualdad para las personas involucradas. Las autoras señalan que a nivel global es posible identificar una verdadera geopolítica de la mercantilización de la reproducción que reproduce las desigualdades globales, en consonancia con lo planteado por el feminismo radical en los años setenta. Aquí se denuncia que algunas sustancias biológicas tendrían más valor que otras (gametos de alta calidad y de baja calidad) vinculadas a color de piel, ojos y cabello, inteligencia, y educación, argumento vinculado a los debates sobre el racismo en la construcción del parentesco.

En sintonía con algunas críticas del feminismo radical, Sarah Franklin también cuestiona estas formas de trabajo reproductivo desigual y señala que uno de los grandes desafíos de las TRHA se remite a que nos encontramos con un campo desregulado, con las consecuencias que ello acarrea: la comercialización y la creación de un mercado reproductivo así como la perpetuación de las normas de género, raciales y de parentesco, mientras que ideas asociadas al fundacionalismo biológico están colapsando (8).

Así también se advierte que el contexto neoliberal posibilita y enfatiza la lógica de elección de las personas usuarias. Como señala Marylin Strathern, no es casual que esta idea de elección en el ámbito de la reproducción y el parentesco surja en Inglaterra en una sociedad capitalista donde priman una mirada individualista del ciudadano y una mirada emprendedurista del sujeto (Reproducing the future 38).

De esta manera, algunas de las críticas del feminismo radical, vinculadas a la conexión entre la mercantilización de la reproducción y el mercado neoliberal global y colonial, son compartidas por diferentes posiciones y continúan vigentes en los desarrollos posteriores. 
Es preciso también señalar otras dimensiones en las que es posible marcar algunas divisiones y fragmentaciones que se dieron dentro del feminismo tanto frente a algunas posturas críticas sobre las TRHA, como por plantear miradas divergentes sobre la maternidad.

Una de las feministas que presenta una postura diferente de la maternidad es Adrienne Rich, quien plantea que el problema no es la reproducción ni la maternidad en sí, sino la manera patriarcal en que se instituye la maternidad en nuestras sociedades (175). En sintonía con lo planteado por De Beauvoir, en estas circunstancias la maternidad alienaba a las mujeres y se convertía en un trabajo forzado. Sin embargo, diferenciaba esta opresión de la experiencia misma de maternar, entendiendo que podía convertirse en espacio de poder femenino más allá de las estructuras patriarcales. En esta misma línea, desde el feminismo de la diferencia como se plantea la importancia de recuperar el orden simbólico femenino, la genealogía femenina y las relaciones entre mujeres en una sociedad falogocéntrica (Irigaray 5; Saletti Cuesta 179)

En una lógica similar, es posible pensar algunas de estas tensiones y fragmentaciones del feminismo sobre la maternidad como en relación a las tecnologías reproductivas. Tanto Sarah Franklin como algunas autoras del feminismo radical como Gena Corea y Christine Crowe formaron parte de la red FINRRAGE ${ }^{3}$, el primer movimiento que dentro del feminismo planteó una postura crítica a las nuevas tecnologías reproductivas (Strathern, A Antropologia e o advento 9). Dentro del mismo se trazaron diferentes posiciones donde un sector disidente -que incluía a la ya mencionada Sarah Franklin- cuestionaba la mirada de un sector del feminismo radical, que entendía a las mujeres como víctimas, cómplices del sistema patriarcal o inocentes -en inglés dupes ${ }^{4}$ - frente a estas nuevas tecnologías (Franklin, The Politics of Reproduction). Esta forma de comprender la relación entre la autonomía de las mujeres y las tecnologías, provocó un conjunto de disputas internas que llevaron a la posterior fragmentación del movimiento (Franklin, «Transbiology» 2).

3. FINRRAGE: Feminist International Network of Resistance to Reproductive and Genetic Engineering

4. Hace referencia a la expresión de Renata Klein, la cual fue intensamente discutida en la organización. Para ver más información consultar la Conferencia brindada por Sarah Franklin, en Referencias.

Feminismo/s 35, junio 2020, pp. 263-289 
De esta manera, un primer punto en tensión que se puede señalar en el debate del feminismo sobre las TRHA, tuvo que ver con una concepción de sujeto y particularmente con la posibilidad de agencia de las mujeres frente a las tecnologías reproductivas. Estas posturas, sin desconocer algunas de las críticas planteadas por el feminismo radical, delimitaron otra relación posible con las tecnologías reproductivas desde una óptica que se desplazaba de la mirada de opresión, lo que suponía revisar la concepción de poder que sustentaba las otras posturas (Luna, Reproducción asistida 20).

Un aspecto relevante y novedoso de estas nuevas posiciones feministas parte del reconocimiento de aquello que Sarah Franklin denomina como una «incómoda ambivalencia» del feminismo frente a las TRHA y que suponía llevar adelante otra línea de acción. La autora señala que:

[...] paradójicamente contar con mayor información y mayor elección reproductiva podría ser opresivo y desempoderante. Esta ambivalencia no fue usada como base para rechazar la tecnología, sino para habilitar a las mujeres a negociar sus demandas de forma más efectiva» (Franklin, «Transbiology» 2) [la traducción es propia].

Siguiendo a Franklin, en lugar de rechazar las TRHA, el hecho de poder identificar las particulares maneras en que se desarrolla la opresión en el campo biomédico permitiría entonces pensar qué estrategias pueden fortalecer la autonomía reproductiva de las personas. Desde allí que las visiones de las usuarias de estas tecnologías fueran centrales para disputar estas relaciones de poder.

Es por ello por lo que un segundo punto en tensión con el feminismo radical se vincula a la crítica de que sus desarrollos teóricos se encuentran desconectados de las experiencias de las mujeres con las tecnologías reproductivas (Luna, Reproducción asistida 20). A partir de ello se advierte el desarrollo de estudios centrados en las experiencias concretas de las mujeres con las tecnologías, por ello algunas de estas autoras se involucraron con un estudio crítico del sistema de salud (Franklin, «Transbiology» 3).

De esta manera, el desarrollo de un movimiento por la salud de las mujeres en los años ochenta, conjuntamente con el desarrollo de estudios sobre diversas experiencias de mujeres con la tecnología reproductiva -de visualización, la amniocentesis y la hormonización- dieron lugar a un conjunto de análisis feministas sobre el sistema médico hegemónico y los efectos de la 
biomedicina sobre la reproducción de las mujeres. Entre ellos se encuentra una línea en análisis que desde el feminismo puso en cuestión el sistema médico hegemónico, como Robbie Davis-Floyd referente en los estudios sobre los procesos de medicalización de los nacimientos y el parto (294).

Entre los trabajos que desarrollaron estudios particulares sobre las TRHA en el campo biomédico, se destacan algunas autoras ya mencionadas como Sarah Franklin, Charis Thompson y Rayna Rapp. Otra autora que plantea un estudio empírico es Elaine Denny, quien también cuestiona la manera en que el feminismo radical ha utilizado la noción de elección de forma diferenciada, cuando se debate aborto o maternidad. Denny señala que siempre existe un conjunto de variables que en ambas opciones pueden mitigar la autonomía reproductiva de las mujeres y en este sentido entiende que el feminismo no debería oponerse a la tecnología sino a la manera en que está organizada (77).

La relevancia que estos aportes del feminismo tuvieron respecto al campo de estudio del cuerpo, la medicina y la reproducción, suelen ser desestimados desde la academia. Como señala Rayna Rapp y en coincidencia con otros análisis (Franklin, «Transbiology» 5; Tarducci 110), la antropología feminista desde los años setenta y aquellas inscritas dentro del movimiento de la salud de las mujeres de los ochenta, tuvieron un papel central al renovar el interés por la reproducción y el parentesco como aspectos centrales de debate en la academia que pocas veces es reconocido (Rapp, Gender, Body, Biomedicine 467). Otra área que se ve transformada en sus discusiones se vincula al estudio de los efectos de esta tecnología en la cultura y cómo permea en la construcción de las familias y las relaciones de parentesco (Yanagisako y Collier 34), donde las propuestas de las antropólogas feministas (Franklin, Embodied Progress; Strathern, After nature 35) renovaron los debates que se abrían en este campo antes dominado por el funcionalismo. Particularmente las TRHA y las modificaciones en el parentesco desafiaron las nociones de lo «lo social»y «lo natural» tan relevantes a la hora de la definición occidental sobre la familia (Luna, Pessoa e Parentesco 390) como del género (Stolke 79).

Dentro del campo de la antropología feminista, el trabajo de Rayna Rapp como el de Rosalind Petchensky fueron aportes centrales para dar algunas respuestas a esta «incómoda ambigüedad» frente a las TRHA (Franklin, «Transbiology» 5). Estas discusiones permitieron desarrollar dentro de los 
feminismos otras lecturas y posiciones diferentes donde la biotecnología dejo de ser vista como sinónimo de disciplinamiento del patriarcado.

Rosalind Petchesky, en su estudio sobre las tecnologías de visualización, señala esta misma tensión particularmente analizando el papel del ultrasonido. Si bien es crítica acerca de cómo las mismas refuerzan la subjetivización del feto, por presentarlo como un ente aislado, individual y funcional al control de los cuerpos de las mujeres, también señala la importancia de conocer las perspectivas de las mujeres ya que en general las mismas no se sienten ni víctimas ni pasivas frente a las tecnologías (279). En este sentido, se interroga sobre la tensión que se produce entre lo que el feminismo decodifica como opresión y las diversas experiencias de las usuarias. Petchensky también cuestiona la idea de que las mujeres usuarias de las tecnologías reproductivas reproducen de forma automática los modelos hegemónicos de familia heterosexual, conyugal, biológica (276).

Del mismo modo, Rayna Rapp es crítica sobre los efectos que han tenido las tecnologías de visualización, las cuales nacidas como una tecnología naval hoy resultan de uso cotidiano y tienen efectos en la relación médico-paciente y médico-mujeres: presenta la ilusión de un feto independiente, autónomo, descorporeizado de la mujer, donde el conocimiento y la interpretación de esta información es únicamente potestad médica. Sin embargo, cuando la autora estudia las decisiones de las mujeres frente a las biotecnologías, analiza las experiencias buscando comprender los obstáculos de las usuarias («Real-time fetus» 630). Partiendo de la decisión compleja que supone para las mujeres utilizar la amniocentesis ${ }^{5}$ durante el embarazo, Rayna Rapp utiliza el concepto de «pioneras morales» para hacer alusión a la manera en que las mujeres accionan en sus decisiones frente a este estudio prenatal (Testing Women 306).

Como se señaló anteriormente, estos desarrollos que dan cuenta del compromiso por comprender las experiencias de las mujeres con las tecnologías parten de y tienen un anclaje en su propia subjetividad: la autora comienza esta investigación a partir de su propia experiencia de aborto después de realizarse un estudio de amniocentesis, comprendiendo la complejidad de este escenario para las mujeres en el campo biomédico.

5. Punción mediante la cual se busca diagnosticar durante el embarazo, la presencia de una anomalía cromosómica o genética en el feto. 
Estos estudios, alejándose de miradas de la tecnología como necesariamente negativa, permiten comprender que las mujeres frente a estos nuevos desarrollos biomédicos comenzaron a encontrarse en situaciones de decisión en que las consecuencias de los tratamientos no se encontraban definidos de antemano. De esta manera, la autora entiende que esto lleva a que las personas como protagonistas de procesos reproductivos, sean cada vez más reflexivas. Como señala Rayna Rapp, existe una mayor autoconciencia de la manipulación de las categorías de parentesco y biología por parte de las personas usuarias, quienes transitan estos procesos como analistas de sus propias prácticas ( «Gender, Body, Biomedicine» 470).

Así también, lejos de evadir las relaciones de poder y desiguales en el campo biomédico, se propusieron nociones como la de «reproducción estratificada» (Colen 80) que permitieron comprender cómo ciertos desarrollos biomédicos reforzaron la patologización de la personalidad, el género y el parentesco (Rapp, «Gender, Body, Biomedicine» 469). Esta reproducción ahora entendida como problemática y patológica es la que posibilita la mercantilización de la reproducción con la vigilancia del estado (Rapp, «Gender, Body, Biomedicine» 469). Sin embargo, estas críticas no desconocen la ironía en estos procesos: a la vez que patologizan y estigmatizan ciertas formas de reproducción, dan lugar a la conformación de nuevas políticas identitarias (Rapp, «Gender, Body, Biomedicine» 469).

Volviendo a la tensión planteada por las autoras, no se puede desconocer cómo las TRHA han abierto nuevas opciones de elección, las cuales tienen un costo que se vincula a la creciente medicalización de los cuerpos, de la sexualidad y a la responsabilización de las mujeres por la gestión «eficiente» de su reproducción. A su vez, esta tensión entre elección-responsabilización reformula la pregunta por el poder y la agencia de las mujeres en relación a estas técnicas.

A continuación se planteará un conjunto de posturas divergentes dentro del feminismo que no solo repercutirán en la manera en que se entiende la tecnología reproductiva, sino que propone desde el feminismo otra manera de vincularse con la «naturaleza» y la «tecnología», o más bien de deconstruir esta falsa oposición. 


\section{FEMINISMOS, PODER Y TECNOLOGÍA ¿OTRA RELACIÓN ES POSIBLE?}

Al mismo tiempo que algunos sectores del feminismo radical en la década de los noventa reafirmaban su oposición a las TRHA, desde otros sectores de feminismo se comenzó a pensar de otra manera las relaciones entre tecnología y reproducción, donde el cuerpo constituyó un eje importante para entender las relaciones de poder.

Al igual que Firestone, quien en la década de los setenta pensaba que la tecnología permitiría romper con la opresión de la diferencia sexual, algunas feministas como Donna Haraway propusieron nuevas formas de alianzas utópicas entre feminismo y tecnología («Las promesas» 141). Sin desconocer las relaciones de poder patriarcales y neoliberales, estas nuevas posiciones comenzaron a cuestionar cierta relación lineal donde la tecnología es entendida como villana y las mujeres se encuentran desagenciadas (Franklin, «Transbiology» 3; Haraway, «Manifiesto para cyborgs» 7; Preciado, Testo Yonqui 40; Rapp, Testing Women 86).

Como señala Sarah Franklin, la pregunta por la relación entre la reproducción y la tecnología es una pregunta por el poder. Es por ello por lo que las posiciones presentadas previamente han permitido pensar desde otra óptica otras relaciones de poder entre las mujeres, su reproducción y la tecnología (7).

Si hay una única lección para llevar de este cuerpo entero de académicas feministas, es que la relación entre tecnología y reproducción nunca puede separarse de cuestiones más amplias sobre el estatus y el empoderamiento de las mujeres. En el borroso margen entre las opciones limitadas y el hecho de no-tener-más-opción-que-elegir-entre-ellas se encuentra la paradoja característica del debate feminista sobre las nuevas tecnologías reproductivas (Franklin, «Transbiology» 2) [la traducción es propia y el énfasis original de la autora]

Una dimensión donde se ancla esta mirada del poder y se piensa la autonomía reproductiva es la dimensión corporal, la cual puede ser vista como plataforma de control pero también como un eje de resistencia y transformación. Aquí el feminismo y los estudios queer traerán discusiones críticas sobre la existencia de la biología, la naturaleza y la noción de «sexo» como base material. La radicalidad de estos debates no es menor, dado que plantean que no 
hay una «vuelta atrás» hacia la naturaleza para pensar la reproducción. Como señala Donna Haraway, desde estas perspectivas la naturaleza es discursiva, es un lugar retórico común pero ya no entendida como aquel lugar estable de certezas, sino que es el lugar del cambio:

La naturaleza es también un trópos, un tropo. Es figura, construcción, artefacto, movimiento, desplazamiento. La naturaleza no puede preexistir a su construcción. Esta construcción se articula sobre un determinado movimiento, un tropos o «giro». Fieles a los griegos, en tanto que trópos, la naturaleza tiene que ver con cambiar. (Haraway, «Las Promesas» 122-123)

Esto supone, a diferencia de las primeras posturas feministas analizadas, que la construcción de una mirada crítica y feminista sobre la biología constituye un giro radical, entendiéndola como un artefacto y un discurso sustentado por el aparato científico. Ello modifica la forma de comprender los cuerpos de las personas gestantes, los fetos y los embriones, ya no como un ente natural diferente a la tecnología, sino como parte de la misma.

En esta línea de análisis que incorpora los efectos de la biomedicina sobre los cuerpos, se puede señalar el trabajo de Emily Martin, quien puso de relieve la construcción socio política y patriarcal de la sexualidad y la reproducción (45). Ello le permitió a la autora advertir en los discursos médicos la reproducción de representaciones de género sobre los cuerpos femeninos, discursos que eran reproducidos por las mismas mujeres. Así también su trabajo señala la sensación de enajenación de las mujeres sobre el propio cuerpo, percibiéndolo como un ente-objeto que es animado pero operado por otros, como una máquina, en un proceso de alienación que De Beauvoir ya señalaba décadas atrás.

Si con Emily Martin podemos pensar en el cuerpo como máquina (61), con Haraway hablamos del cuerpo como sistema ( Manifiesto para cyborgs» 7), metáforas que no sólo expresan posiciones filosóficas sobre el cuerpo, sino que tienen consecuencias políticas sobre la capacidad de agencia. Haraway a su vez propone la idea de cyborg como una construcción hibrida, de organismo y máquina, donde las tecnologías y sistemas de comunicación constituyen un lugar a disputar («Las promesas» 2). Las ideas de cyborg de Haraway y de una transbiología son nociones que permiten romper con visiones generizadas de la biología, a la vez que proyectar irónicamente otras formas de convivencia 
de la biología y la tecnología, que no son parte de lo natural, sino metáforas que permiten pensar su transformación (Franklin, «Transbiology» 7).

Donna Haraway, dialogando con Sarah Franklin, cuestiona ese lugar de apropiación de aquello construido discursivamente como naturaleza, donde la gestión del feto es un ejemplo que da cuenta de lo que es naturaleza y humano, constituyendo uno de los planos -interno le llama la autora- que el sistema científico capitalista busca controlar («Las promesas» 146). Sarah Franklin en la misma línea analiza las nuevas formas de control y de gestión de la biología, cuyo propósito está puesto en hacerla más confiable a través del «control del riesgo» de estos procesos («The Cyborg Embryo»178).

Marilyn Strathern por su parte señala que si bien las nociones de cuerpo y máquina fueron conectadas por analogía, ya no funcionan más en los sentidos que se le asigna a la tecnología actualmente. Por el contrario, como sucede en el caso de las TRHA, se entiende que la tecnología ayuda a la vida a funcionar, en el sentido cultural de «asistir a la naturaleza» (Reproducing the future 60). Por ello, desde la visión de Strathern, naturaleza y tecnología no evocan distintos dominios de la vida, por lo que no sirven de metáfora la una a la otra (Reproducing the future 60).

Otro aspecto que constituye una visión divergente dentro del feminismo para pensar las tecnologías reproductivas se vincula a la manera en que se piensa el poder y la agencia desde concepciones micropolíticas. Tal es el caso de Teresa De Lauretis, quien, siguiendo a Foucault, desarrolla la noción de «tecnologías de género». Para ella, la resistencia al poder y la agencia se pueden comprender desde los intersticios del poder (De Lauretis 33) y no desde el planteamiento clásico de resistencia.

Paul Preciado, como referente de los estudios queer, parte de una mirada del cuerpo que pone en cuestión la tradicional mirada del feminismo que sitúa en el sexo como la naturaleza o base material y el género como la cultura o la interpretación de esa naturaleza. La ruptura de este binarismo le permite comprender una idea maleable del cuerpo que puede ser transformado desde las propias tecnologías médicas como la hormonización. Para Preciado, el «tecnobiopoder» opera a nivel micro y forma parte de las subjetividades de tal manera que este poder es voluntariamente inserto en el cuerpo, como sucede en la autoadministración de hormonas (Testo Yonqui 40). La propia 
experiencia de autoadministración de la testosterona da cuenta de otros procesos impensados como la apropiación de la biotecnología por parte de los sujetos.

El planteamiento de Paul Preciado, en línea con lo que expresa Donna Haraway, abre otro juego para pensar la relación con la tecnología y permite entender a los cuerpos de las personas usuarias no como un ente previo, natural y diferente a la tecnología, sino como un «tecnocuerpo» que no es «ni organismo ni máquina» (Preciado, Testo Yonqui 40) proyectando de esta manera otro orden de relaciones y diferentes a las primeras posiciones del feminismo.

La perspectiva queer permite cuestionar en la actualidad no solo los sentidos sobre cuerpo y tecnología, sino también la construcción social y política de la reproducción. Como advierte Preciado, es el mismo Estado quien define quiénes pueden acceder a las TRHA, donde la heterosexualidad continúa siendo el régimen político y la tecnología social con los que se piensa la reproducción («Procreación» 67). De esta manera, esa perspectiva sitúa el acceso a las TRHA como una disputa política y un proceso de despatologización de aquellas personas que han sido privadas históricamente y políticamente de su reproducción. Sin embargo, es interesante cómo Preciado, tomando los aportes de Silvia Federici, señala cómo el útero continúa siendo central en el proceso de acumulación capitalista y colonial («Procreación» 74).

En el marco de la reconstrucción de estos debates, es interesante pensar que estas tensiones hasta aquí analizadas dan cuenta de que estas fracciones políticas son contextuales, donde los planteamientos de las feministas radicales que denunciaban la mercantilización y colonialidad de la biotecnología aún resuenan en los desafíos y disputas actuales por la regulación de las tecnologías reproductivas a nivel global, como analizaremos a continuación.

\section{FEMINISMOS Y TRHA EN LATIONAMÉRICA Y ARGENTINA: DEMANDAS REPRODUCTIVAS ACTUALES.}

En Latinoamérica son recientes las producciones que desde el feminismo han analizado las TRHA y están directamente vinculadas a la agenda política y la discusión pública. Como señalan Cardaci y Sánchez Bringas para el caso mexicano, más allá de algunas denuncias realizadas desde los feminismos contra 
estas técnicas como nuevas formas de opresión, han permanecido más bien ajenos a estos debates y tampoco han realizado investigaciones sistemáticas al respecto, a excepción de algunas autoras (271).

El caso brasilero ha retomado estos debates en su producción por ser relevante a nivel de las experiencias: es el país latinoamericano donde se realizan más tratamientos ${ }^{6}$. Sin embargo no es la opresión o la autonomía su principal eje de análisis, sino que sus trabajos se han centrado en las transformaciones sobre el género y el parentesco (Fonseca 781; Grossi, Uziel y Mello 9; Luna, Pessoa e Parentesco 389; Ramírez-Gálvez 4) dialogando con los debates del norte global sobre las TRHA. Así también se destacan trabajos de Uruguay (Viera Cherro 351) como investigaciones situadas en Ecuador de corte antropológico (Roberts 15).

Particularmente en Argentina, país en el que se centra este trabajo, existe una regulación desde el año 2013 que habilita el acceso de forma universal a las TRHA y define su cobertura, pero aún quedan diversos vacíos por regulación: la gestación subrogada, el tratamiento de los embriones in vitro y la regulación de la donación de gametos. En estos temas el feminismo no constituye la voz más visible, sino que son abordados a «nivel de expertos» (Fraser 8).

Por este motivo, los debates en Argentina no transcurren sobre los efectos de los cuerpos de las mujeres como principal eje, sino sobre cómo las mismas «funcionan» y cómo deben ser reguladas. De esta manera se encuentran algunos trabajos que desde las ciencias sociales incorporan la perspectiva de género (Garay 30) pero principalmente se encuentran trabajos desde la sociología (Ariza, «La construcción» 43; Straw, Scardino, y Pérez 3) y los estudios de la ciencia y la tecnología centrados en estos temas (Ariza, «Cuerpos abstractos» 363) analizando el papel de diferentes actores en su regulación (Ariza, «La regulación» 8; Farji Neer 351; Irrazábal 113). Algunas autoras parten desde enfoques etnográficos sobre la experiencia de donantes de gametos (Ariza, «No pagaras» 240), sin perder de vista las condiciones sociales

6. De acuerdo con un informe de la RED LARA (Registro Latinoamericano de Reproducción Asistida), Brasil es el país latinoamericano con mayor cantidad procedimientos de reproducción asistida realizados en ese año, seguido por Argentina y luego México. Ver referencias Zegers-Hochschild, Schwarze, Musri, Crosby y Urbina. 
y globales en que se desarrolla este trabajo reproductivo pero aportando a comprender este escenario desregulado.

Fundamentalmente en Argentina la demanda por la legalización del aborto, como un tema de debate social y fuerte impacto en la opinión pública, aparece de forma espejada frente a este vacío normativo respecto al tratamiento del embrión no implantado, aspecto que es analizado principalmente desde la sociología y las ciencias jurídicas (Jadur, Duhalde y Wainstein 33; Lamm 2; Straw, Scardino y Perez 3). En este sentido, desde los feminismos en Argentina se encuentran análisis acerca de los discursos conservadores sobre el embrión, politizando las consecuencias que tienen en la criminalización del aborto (Morán Faúndes 151; Vacarezza 71) pero sin abordar los efectos sobre la misma practica de las TRHA.

Por todo ello, las voces más presentes en Argentina sobre las TRHA son las disciplinas jurídicas, que retoman discusiones del feminismo pero se centran más bien en los derechos reproductivos y la discusión por las nuevas formas de filiación (Herrera y Lamm 5; Lamm 3) y la gestación subrogada.

Los términos en que se plantea la discusión no se vinculan a la maternidad, como pasaba en los primeros debates, sino que el tema que polariza posiciones en los feminismos latinoamericanos es el debate «trabajo sexual versus prostitución». La gestación subrogada es una práctica sobre la que no existe consenso en los feminismos a nivel global ni regional. Como señala Olavarría para el caso mexicano, tanto legisladores, juristas como activistas buscan «puntos de intersección o modelos que permitan su comprensión» (3) ante un tema que es comparado con otras prácticas presentes en el imaginario social, tales como la figura de la «gestante madre», «gestante donante», «gestante cuidadora»y «gestante prostituta». Estos paralelos se establecen ya que todos los debates ponen en juego la pregunta por la autonomía corporal de las mujeres en un mercado reproductivo y sexual global atravesado por formas de «reproducción estratificada» (Colen 82; Rapp, «Gender, Body, Biomedicine» 469).

Esta noción resulta clara para comprender las jerarquizaciones que atraviesan «todas las formas posibles de convertirse en padres, ya sea a través de la procreación, la adopción o la reproducción médicamente asistida, así como el ejercicio mismo de la parentalidad» (Olavarría 16). Pero así también esta estratificación da cuenta de diferentes formas de care o de cuidados, donde la

Feminismo/s 35, junio 2020, pp. 263-289 
gestación constituye el último escalón en esta estratificación de tareas reproductivas que no son reconocidas generalmente como un trabajo.

Particularmente en Argentina los sectores que defienden su regulación están confirmados por colectivos juristas especializadas en el tema (González Magaña 5; Herrera y Lamm 5), en alianza con colectivos biomédicos y organizaciones de personas usuarias y de diversidad sexual (Rodríguez Iturburu y Notrica 2$)^{7}$. El último proyecto legislativo supone reconocer la existencia de una práctica que ya existe en Argentina junto con el reconocimiento de la identidad de las personas nacidas de la misma; pero al mismo tiempo busca evitar condiciones que habiliten la creación de un mercado reproductivo como en otros países donde ocurre a niveles de explotación.

Sin embargo, desde los feminismos y la academia también existen posturas críticas a esta técnica y que denuncian este trabajo reproductivo como opresivo, como es el caso de Dora Barrancos, quien cuestiona esta práctica por su carácter eugenésico y racista. La autora, sin embargo, diferencia el trabajo sexual y reproductivo de la práctica de la gestación subrogada porque no implica a una tercera persona, así como también lo diferencia del aborto porque lo entiende como una demanda que se basa en la dignidad del propio cuerpo, aspecto que en la gestación subrogada se vulnera. A diferencia de las juristas argentinas, Barrancos sostiene que no es argumento suficiente que una práctica exista para que deba ser regulada (156). Como se anticipó, lo que sucede en este escenario es que el eje de fractura está dado por la pregunta por la regulación/prohibición como estrategia política de incidencia sobre la reproducción.

\section{RECAPITULANDO UN DEBATE INCONCLUSO}

A modo de cierre, y retomando la experiencia que nos dejan las primeras posiciones del feminismo sobre las TRHA, se pueden revisar algunos caminos ya transitados para continuar repensando el aporte teórico y político del feminismo. Esta reconstrucción realizada permite advertir que ciertas tensiones, en apariencia irreconciliables en los primeros debates, hoy se amalgaman de diferentes formas a la luz de los desafíos actuales. Así mismo permite

7. En Argentina existen dos proyectos de Ley que buscan su regulación, pero con diferentes énfasis e impulsados por distintos actores.

Feminismo/s 35, junio 2020, pp. 263-289 
reconocer que los debates sobre las THRA visibilizan el trabajo reproductivo, históricamente naturalizado y estratificado, que hoy se identifica en las diversas prácticas de donar gametos, gestar, cuidar y criar. Sin embargo, las formas de explotación del cuidado también se reinventan en diferentes momentos históricos y mediante otras tecnologías políticas, si pensamos en el trabajo de nodrizas, amas de leche, ejerciendo la crianza y el cuidado de sectores acomodados. Estos aspectos que se producen de forma disociada en las diferentes conformaciones familiares y de cuidado, dan cuenta de condiciones de explotación desigual en diversas sociedades, más allá de la existencia de las TRHA.

Así también, esta reconstrucción nos señala la importancia de atender a las experiencias situadas que las TRHA generan en tanto opresión como posibilidad de agencia, para evitar caer en sentidos universalizantes sobre la experiencia «femenina» que tan cuestionados han sido dentro del pensamiento feminista.

Atender a la experiencia de las personas no nos debe distraer de un mapa mayor del cual las feministas radicales advirtieron desde un primer momento: el análisis de estas experiencias no es posible si no se tiene en cuenta la división del trabajo sexual, reproductivo y de cuidados a nivel global, para develar estratificaciones reproductivas que operan en diferentes espacios sociales.

Desde los feminismos latinoamericanos es posible plantearse otras disputas epistemológicas. La mirada que proponen las epistemologías del sur resulta una intersección de poder poco explorada para pensar estas nuevas formas en que se produce la reproducción. Siguiendo a Andrea Torrano y Natalia Fischetti, es posible pensar las tecnologías desde el «Buen Vivir», entendiendo que existe «una relación co-constitutiva entre lo humano, lo técnico y lo tecnológico y la naturaleza» (275), miradas que alientan a no reproducir lógicas extractivistas sobre los cuerpos que gestan y llevan adelante el cuidado.

A partir de estos debates, los feminismos nos permiten responder a la pregunta por las TRHA y el poder, con otras herramientas y nuevas preguntas. Por un lado, se pueden pensar las TRHA desde los feminismos sin recurrir a la sacralización de la maternidad ni la naturaleza. Así mismo nos interpelan cuando dan voz a las experiencias situadas y pueden fortalecer las formas de resistir y construir agencia que las/os sujetas/s encuentran en los lugares más 
inesperados. Sin embargo, no podemos perder de vista que estos procesos se producen en un escenario capitalista, patriarcal y colonial que se reinventa y donde no existen respuestas definitivas sobre la tecnología como dispositivo social y político, dejándonos en una constante incomodidad y búsqueda.

\section{REFERENCIAS BIBLIOGRÁFICAS}

Ariza, Lucía. «La construcción narrativa de la infertilidad. Mujeres que narran la experiencia de no poder concebir». Sexualidad, Salud y Sociedad. Revista Latinoamericana 18 (2014): 41-73.

Ariza, Lucía. «Cuerpos abstractos, riesgos concretos: Dispositivos clínicos y la salud de las donantes de óvulos en la medicina reproductiva Argentina». Salud Colectiva 12.3 (2016): 361-382.

Ariza, Lucía. «'No pagarás': el Consentimiento Informado como productor de solidaridad en la medicina reproductiva». Ciencia, Docencia y Tecnología 27.52 (2016): 240-268.

Ariza, Lucía. «La regulación de las tecnologías reproductivas y genéticas en Argentina: análisis del debate parlamentario». Dossiêr: Conservadorismo, Direitos, Moralidades e Violência 50 (2017): e175005.

Armstrong, David. «The rise of surveillance medicine». Sociology of Health $\mathcal{E}$ Illness 17.3 (1995): 393-404.

Badinter, Elizabeth. La mujer y la madre. Un libro polémico sobre la maternidad como nueva forma de esclavitud. Madrid: La esfera, 2012.

Barrancos, Dora. «Dilemas éticos de la reproducción tecno-mediada: una reflexión más allá de la cosmovisión religiosa». Sociedad y Religión: Sociología, Antropología e Historia de la Religión en el Cono Sur 25.44 (2015): 155-179.

Blázquez-Rodríguez, María Isabel. «Aproximación a La Antropología De La Reproducción». AIBR. Revista de Antropología Iberoamericana 42 (2005): 1-25.

Cardaci, Dora, y Ángeles Sánchez Bringas. «Hasta que lo alcancemos... Producción académica sobre reproducción asistida en publicaciones mexicanas». Alteridades 19.38 (2009): 21-40.

Chodorow, Nancy. The Reproduction of Mothering. Psychoanalysis and the Sociology of Gender. Berkeley, Los Angeles: University of California Press, 1978.

Colen, Shelee. «Like a mother to them». Conceiving the new world order. The global politics of reproduction. Eds. Faye D. Gynsburg y Rayna Rapp. California: University California Press, 1995. 78-102. 
Corea, Gena. «The Mother Machine: reproductive technologies from Artificial Insemination to Artificial Wombs». The American Journal of Maternal/Child Nursing 32.1 (1985): 357-363.

Crowe, Cristine. ««Women want it»: In-vitro fertilization and women's motivations for participation.» Women's Studies International Forum 8.6 (1985): 547-552.

Davis-Floyd, Robbie. "Obstetric Training as a Rite of Passage». Obstetrics in the United States: Woman, Physician, and Society 1. 3 (1987): 288-318.

De Beauvoir, Simone. El segundo sexo. Los hechos y los mitos. La experiencia vivida. Buenos Aires: Siglo XXI, 1949.

Denny, Elaine. «Liberation or oppression? Radical feminism and in vitro fertilization». Sociology of Health E Illness 16.1 (1994): 62-80.

De Lauretis, Teresa. «La tecnología del género». Revista Mora 2 (1996): 6-34.

Farji Neer, Anahí. «Cuerpo, derechos y salud integral: Análisis de los debates parlamentarios de las leyes de Identidad de Género y Fertilización Asistida (Argentina, 2011-2013)». Salud Colectiva 11. 3 (2015): 351-365.

Fernández Pujana, Irati.«Feminismo y maternidad: ¿una relación incómoda? Conciencia y estrategias emocionales de mujeres feministas en sus experiencias de maternidad.». País Vasco: Emakunde/Instituto Vasco de la Mujer, 2014.

Firestone, Shulamith. The dialectic of sex: The case for feminist revolution. New York: Farrar, Straus and Giroux, 2003.

Fonseca, Claudia. «Homoparentalidade: novas luzes sobre o parentesco». Revista Estudos Feministas 16. 3 (2008): 769-783.

Foucault, Michel. Historia de la sexualidad. La voluntad de saber. Buenos Aires: Editorial Siglo XXI, 2008.

Franklin, Sarah. Embodied Progress. London: Routledge, 1997.

Franklin, Sarah. «The Cyborg Embryo: Our Path to Transbiology». Theory, Culture E Society 23. 7-8 (2006): 167-187.

Franklin, Sarah. «Transbiology: A Feminist Cultural Account of Being After IVF». Critical Conceptions: Techonology, Justice, and the Global Reproductive Market. New York: Bernard Center for Research on Women, 2009.

Franklin, Sarah. The Politics of Reproduction: New Technologies of Life. Conferencia brindada en Barnard College en ocasión de The Scholar \& Feminist Conference, 2009. 25 marzo 2020. https://vimeo.com/4635010. 
Fraser, Nancy. «La lucha por las necesidades: Esbozo de una teoría crítica socialista-feminista de la cultura política del capitalismo tardío». Debate feminista 3 (1991): 3-40.

Garay, Ricardo. «El destino de ser madres: la ideología de la maternidad como soporte discursivo de las nuevas tecnologías reproductivas». Maternidades en el siglo XXI. Ed. Mónica Tarducci. Buenos Aires: Editorial Espacio, 2008. 29-59.

González Magaña, Ignacio. «La tácita inclusión de la gestación por sustitución en el nuevo Código Civil y Comercial de la Nación. Preámbulo necesario de una norma expresa que la regule». La Ley 181 (2014): AR/DOC/3853/2014. 13 abril 2020.

Grossi, Miriam, Anna Paula Uziel, y Luiz Mello. Conjugalidades, parentalidades e identidades lésbicas, gays e travestis. Río de Janeiro: Garamond, 2012.

Haraway, Donna. «Manifiesto para cyborgs: ciencia, tecnología y feminismo socialista a finales del siglo XX». Ciencia, Cyborgs y Mujeres: La Reivindicación de La Naturaleza. Madrid: Ediciones Cátedra, 1995. 251-311.

Haraway, Donna. «Las promesas de los monstruos: Una política regeneradora para otros inapropiados/bles». Política y Sociedad 30 (1999): 121-164.

Herrera, Marisa, y Elenora Lamm. «Un valiente fallo del TEDH sobre gestación por sustitución. Prohibir, silenciar, regular o fallar». La Ley 122 (2014): 1-8. Irigaray, Lucy. An Ethics of Sexual Difference. New York: Cornell University Press, 1993.

Irrazábal, Gabriela. «Bioeticistas católicos en contra de las técnicas de reproducción asistida. Implicancias para la futura Reforma del Código Civil». Revista de Derecho de Familia 57 (2012): 113-134.

Jadur, Silvia, Constanza. Duhalde, y Viviana Wainstein. «Efectos emocionales de la criopreservación de embriones y su transferencia». Reproducción 25 (2010): 33-39.

Laborie, Françoise. «New reproductive technologies: news from France and elsewhere». Reproductive and Genetic Engineering 1.1 (1988): 77-85.

Lamm, Eleonora. «El status del embrión in vitro y su impacto en las técnicas de reproducción humana asistida. Aclarando conceptos para garantizar derechos humanos». La Ley 43 (2015): AR/DOC/1297/2015. 13 abril 2020.

Luna, Florencia. Reproducción asistida, género y derechos humanos en América Latina. San José: Instituto Interamericano de Derechos Humanos, 2008. 
Luna, Naara. «Pessoa e parentesco nas novas tecnologias reprodutivas». Revista Estudos Feministas 9. 2 (2001): 389-413.

Martin, Emily. The Woman in the Body. A Cultural Analysis of Reproduction. Boston: Beacon Press, 2001.

Mies, Maria, y Vandana Shiva. La Praxis Del Ecofeminismo. Biotecnología Consumo y Reproducción. Barcelona: Icaria Antrazyt. Mujeres, voces y propuestas, 1998. Morán Faúndes, José Manuel. «La valoración de la vida, la subjetivación del embrión y el debate sobre el aborto: aportes desde una perspectiva crítica». Acta bioethica 20. 2 (2014): 151-157.

Olavarría, María Eugenia. «La gestante sustituta en México y la noción de trabajo reproductivo». Revista Interdisciplinaria de Estudios de Género de El Colegio de México 4 (2018).

Petchesky, Rosalind. «Fetal Images: The Power of Visual Culture in the Politics of Reproduction». Feminist studies 13. 2 (1987): 263-292.

Preciado, Paul B. Testo Yonqui. Madrid: Editorial Calpe, 2008.

Preciado, Paul B. «Procreación políticamente asistida». Parole de queer (2014). 8 marzo 2020.

Ramírez-Gálvez, Marta Celia. Novas Tecnologias Reprodutivas conceptivas: fabricando a vida, fabricando o futuro. Diss. Universidade Estadual de Campinas, 2003.

Rapp, Rayna. Testing Women, Testing the Fetus: The Social Impact of Amniocentesis in America (Anthropology of Everyday Life). New York: Routledge, 1999.

Rapp, Rayna. «Gender, Body, Biomedicine: How Some Feminist Concerns Dragged Reproduction to the Center of Social Theory». Medical Anthropology Quarterly 15.4 (2001): 466-477.

Rapp, Rayna. «Real-time fetus: the role of the sonogram in the age of monitored reproduction». Beyond the body proper: Reading the Antropology of Material Life. Eds. Margaret Lock y Judith Farquhar. Durham, London: Duke University, 2007. 608-622.

Raymond, Janice. Women as Wombs. Reproductive Technologies and the Battle Over Women's Freedom. Melbourne: Spinifex Press, 1994.

Rich, Adrianne. Of Woman Born: Motherhood as Experience and Institution. New York: WW Norton, 1995.

Roberts, Elizabeth. God's laboratory: assisted reproduction in the Andes. California: Berkeley, 2012. 
Rodríguez Iturburu, Mariana, y Federico Notrica. «La figura de la gestación por sustitución, otra vez en boca de todxs». Microjuris (2017). 31 marzo 2020.

Rose, Nikolas. The Politics of Life Itself. Biomedicine, Power and Subjetivity in the Twenty First Century. New Jersey: Princeton, 2007.

Saletti Cuesta, Lorena. «Propuestas teóricas feministas en relación al concepto de maternidad». Clepsydra. Revista de Estudios de Género y Feminista 7 (2008): 169-183.

Stolke, Verena. «La mujer es puro cuento: la cultura del género». Estudos feministas, Florianápolis 12. 2 (2004): 77-105.

Strathern, Marylin. After nature: English kinship in the late twentieth century. Cambridge University Press: Lewis Henry Morgan Lectures 1989, 1992.

Strathern, Marylin. Reproducing the future. Antropology, Kinship, New Reproductive Technologies. Manchester: Manchester University Press,1992.

Strathern, Marylin. «A Antropologia e o advento da Fertilização In Vitro no Reino Unido: uma história curta». Cadernos Pagu 33 (2009): 9-55.

Straw, Cecilia, Marisa Scardino, y Agustina Pérez. «La mirada de usuarios de técnicas de reproducción asistida con donante o gestante en relación con los embriones». Rev. IUS 11.39 (2017): 1-26.

Tarducci, Mónica. «Adopción y parentesco desde la antropología feminista». Revista de Estudios de Género. La Ventana 4.37 (2013): 106-145.

Thompson, Charis. Making parents. The Ontological Choreography of Reproductive Technologies. Cambridge. London: MIT Press books, 2005.

Torrano, Andrea y Natalia Fischetti. «Apuestas del feminismo: Ciencia/ Técnica/ Latinoamérica. Nuevas urdimbres desde el Sur. (Hacia un buen vivir feminista)». RevIISE - Revista De Ciencias Sociales Y Humanas 11.11 (2018): 267-279.

Tubert, Silvia. «Demanda de hijo y deseo de ser madre». Debate Feminista 8 (1993): 349-377.

Tubert, Silvia. «Los ideales culturales de la feminidad y sus efectos sobre el cuerpo de las mujeres». Quaderns de Psicologia 12. 2 (2010): 161-174.

Vacarezza, Nayla. «Los fetos de otra manera. Reflexiones sobre afectos, aborto y políticas reproductivas a partir de obras de Zaida González y Felipe Rivas San Martín». Afectos políticos. Eds. D. Losiggio y C. Macón. Buenos Aires: Ensayos sobre actualidad, 2017. 71-91. 
Viera Cherro, Mariana. «Sujetos y cuerpos asistidos: un análisis de la reproducción asistida en el río de la plata». Civitas-Revista de Ciências Sociais 15. 2 (2015): 350-368.

Waldby, Catherine, y Melinda Cooper. «The Biopolitics of Reproduction: PostFordist Biotechnology and Women's Clinical Labour». Australian Feminist Studies 23. 55 (2008): 57-73.

Wichterich, Chista. Sexual and Reproductive Rights. Vol.11. Berlin: Heinrich Böll Foundation, 2014.

Yanagisako, Silvia y Jane Collier. «Género y Parentesco Reconsiderados: Hacia un Análisis Unificado». Assessing Cultural Anthropology. Ed. Robert Borofsky. Honolulu: Hawaii Pacific University, 1994.

Zegers-Hochschild, Fernando, Juan Enrique Schwarze, Javier Musri, Carolina Crosby, y María Teresa Urbina, «Assisted Reproductive Techniques in Latin America: The Latin American Registry 2015». JBRA Assisted Reproduction 23. 2 (2018): 143-153. 

To link to this article / Para enlazar con este artículo:

https://doi.org/10.14198/fem.2020.35.11

To cite this article / Para citar este artículo:

Merlyn, Marie-France. «Dime lo que escuchas y te diré quién eres. Representaciones de la mujer en las 100 canciones de reggaetón más populares en 2018». En Feminismo/s, 35 (junio 2020): 291-320. DOI: 10.14198/fem.2020.35.11

\title{
DIME LO QUE ESCUCHAS Y TE DIRÉ QUIÉN ERES. REPRESENTACIONES DE LA MUJER EN LAS 100 CANCIONES DE REGGAETÓN MÁS POPULARES EN 2018
}

\author{
TELL ME WHAT YOU LISTEN TO AND I WILL TELL YOU \\ WHO YOU ARE. REPRESENTING WOMEN IN 100 OF THE \\ MORE POPULAR REGGAETON SONGS IN 2018
}

\author{
Marie-France MERLYN \\ Pontificia Universidad Católica del Ecuador, Quito \\ MFMERLYNS@puce.edu.ec \\ orcid.org/0000-0001-6171-2691
}

\section{Resumen}

El propósito del presente trabajo es analizar y caracterizar el rol de la mujer en las representaciones de los vídeos, letras y lugar de las intérpretes dentro del reggaetón. Se analizan 100 vídeos y letras de canciones más populares en 2018; se utiliza para el análisis de los vídeos la observación detallada con registro y para las letras el análisis temático, que consta de seis fases: familiarización con los datos, generación de categorías o códigos iniciales, búsqueda de temas, revisión de temas, definición y denominación de temas e informe final. Los resultados evidencian que la mujer en estas canciones es sexualizada, objetivada, descrita a través de modelos relacionales tradicionales y negativos, lo que convierte el reggaetón en un espacio que transmite principalmente el modelo de la identidad del disfrute.

Palabras clave: reggaetón; mujer; identidad; modelos; representaciones. 
Dime lo que escuchas y te diré quién eres. Representaciones de la mujer en las 100 canciones de reggaetón más populares en 2018

\begin{abstract}
The purpose of this work is to analyze and characterize the role of women in the representations in the videos, lyrics, and the place of the women performers within the reggaeton rhythm. One hundred videos and lyrics of most popular songs in 2018 are analyzed; the detailed observation with registration is used for the analysis of the videos and for the lyrics the thematic analysis is used, which consists of 6 phases: familiarization with the data, generation of categories or initial codes, search of topics, review of topics, definition and denomination of topics and final report. The results show that women are sexualized, objectified, described through traditional and negative relational models, which makes reggaeton a space in which the model of the identity of enjoyment is transmitted.
\end{abstract}

Keywords: Reggaeton; Woman; Identity; Models; Representations.

\title{
1. INTRODUCCIÓN
}

La música, más allá de ser un arte, es una expresión cultural dependiente del contexto histórico, geográfico y social. Además, es un potente medio de comunicación, a través del cual un individuo o un grupo puede llegar con su mensaje a miles de receptores; a diferencia de otros medios, la música está presente sin ningún tipo de censura en espacios públicos como restaurantes, buses, centros comerciales, vía pública, etc.

Si bien las melodías pueden ser únicamente instrumentales, en los últimos dos siglos se han popularizado aquellas con letras, y desde los años 80 del siglo anterior, se acompañan con vídeos. La música per se no transmite un mensaje en particular, el mensaje es dado por las letras y las imágenes que se le asocian (Vernallis 16). Para Sedeño, el vídeo es el mensaje «más definidor de la cultura posmoderna», ya que posee una variedad formal y narrativa cercana a la de la publicidad (2-3). Según el Informe del Task Force on the Sexualization of Popular Music (TFSPM 9), la primera investigación sobre los contenidos de las canciones se realizó en 1969, y desde entonces muchos se han interesado en el análisis de contenidos y vídeos de tipo sexual en las canciones, así como de su impacto en los individuos. Sus resultados evidenciaron que la música es el medio de comunicación que más contenidos sexuales incluye comparado con otros (TFSPM 10). Un análisis por décadas (entre 1959 y 2009) del Top-100 en USA muestra que el aumento de la

Feminismo/s 35, junio 2020, pp. 291-320 
sexualización en la música ocurrió entre 1990 y 2000 (Hall, West y Hill 111), con un incremento de casi tres veces de los contenidos sexuales en las canciones de intérpretes masculinos (pasando del $11.1 \%$ al $32.1 \%$ ) y apareciendo en las canciones de intérpretes femeninas (del $0 \%$ al 14.3\%).

El impacto que tienen los contenidos sexuales de las canciones es analizado en el Informe (TFSPM 3-4), donde se evidencia que la música sexualizada influye en las actitudes y conductas de manera negativa, aunque existen algunas investigaciones que llegan a resultados contrarios en este aspecto (Sprankle, End y Bretz 36). El Informe de la TFSPM (6-7) se refiere esencialmente a la música en lengua inglesa escuchada en los Estados Unidos y Australia, en donde los géneros musicales con mayor sexualización son el rap, pop, hip hop y soul.

América Latina no escapa de esta tendencia sexualizadora de la música y sus géneros se imponen a nivel mundial. Así, en 2018, del Top-10 de las canciones más escuchadas en YouTube ocho fueron latinas, de estas, seis pertenecieron al género reggaetón (Unidad Editorial Información Deportiva). Si bien América Latina posee varios géneros musicales propios (salsa, cumbia, merengue, bossa nova, música andina, etc.), lo que se vuelve popular obedece a las mismas leyes de globalización y mercado que regulan lo que se produce y se escucha a nivel mundial. La tendencia global indica que lo más escuchado en español es reggaetón. En Ecuador este ritmo es aún más popular, ya que entre las 10 más escuchadas del 2018, 9 pertenecieron a este género (Redacción El Comercio).

El reggaetón surgió en las barriadas de Puerto Rico en los años 80. Otros ritmos como la salsa habían entrado en crisis, permitiendo el surgimiento de un género que en un inicio circuló de manera encubierta («underground»), expresando temas populares y marginales sin restricción alguna (Rodríguez Rivera 27-29). Censurado inicialmente por sus contenidos, desafiantes de la moral y el orden político, la popularidad y el éxito comercial hicieron que poco a poco se insertara en la cultura del país; el reggaetón «era real» y «hacía referencia a las condiciones sociales del país: tasas de desempleo de hasta $65 \%$ en algunas zonas, escuelas descalabradas, corrupción gubernamental y una violencia rampante vinculada al narcotráfico» (Negrón-Muntaner y Rivera 33). Los intentos de censura lo hicieron más popular, ya que las canciones con letras más depuradas lograron difundirse mejor. Paulatinamente

Feminismo/s 35, junio 2020, pp. 291-320 
se abrió al mercado, combinándose con ritmos como el rap y adquiriendo un tinte más comercial, perdiendo el carácter contestatario inicial (Rodríguez Rivera 28-29). En los años noventa, agotada esta vena comercial, se mezcló con el reggae jamaiquino y regresó a sus raíces «underground» retomando los temas callejeros (violencia y sexo). El momento de auge a nivel internacional del reggaetón ocurre en el siglo XXI, con los éxitos comerciales de las canciones «Pobre Diabla» de Don Omar (2003) y «Gasolina» de Daddy Yankee (2004), que tienen letras de contenido sexual pero son menos violentas, más románticas y más cantadas (Rodrigues Morgado 33). El reggaetón entonces puede definirse como «un sanchocho de rap y reggae en español, que llegó a su punto en los barrios y caseríos de Puerto Rico» (NegrónMuntaner y Rivera 30). Finalmente, los mercados internacionales terminaron validándolo y forzando su aceptación como producto de exportación y atractivo hacia la isla (Negrón-Muntaner y Rivera 36-37). El reggaetón logra así consolidar una nueva identidad del puertorriqueño, una comunidad imaginada subalterna, basada en tres elementos fundamentales: vivencia de una sexualidad libre, reivindicación de la ilegalidad o la extralegalidad y la propuesta de una nueva ética de vida focalizada en el disfrute (drogas, sexo y alcohol) (Rodríguez Rivera 32-34). Para entender un producto cultural se debe mirar la cultura dominante, y esto es válido para otros géneros. Así, Adams y Fuller (941) señalan que la misoginia presente en las letras del rap es un producto de los valores misóginos correspondientes a la historia de la cultura norteamericana.

Sin embargo, más allá de ser el producto de grupos sociales y la expresión de las protestas de un pueblo, la música ha pasado a formar una gran Industria Cultural que genera miles de millones de dólares. Horkheimer y Adorno (165) introdujeron la noción de Industrias Culturales refiriéndose a esas instituciones que emplean modos de producción y organización de las corporaciones industriales para producir y difundir símbolos como bienes culturales; se afirma que esto aplica para la música, situándola como una Industria Cultural, al decir que «entre las industrias Culturales, la industria musical tiene un creciente mercado» y que «el consumo no solamente se refiere a las mercancías sino también a estilos y formas de vida» (Martínez Noriega 22). 
Al globalizarse, el reggaetón pasa a ser parte del mercado y a obedecer, como los otros ritmos musicales, a las leyes del consumo. Así, el género representa hoy «una de las historias más impresionantes de triunfo económico» (Negrón-Muntaner y Rivera 37). Objetivamente hablando, la exportación masiva del género hacia otros países disminuyó el interés de producir canciones con contenidos de protesta, y aumentó la producción de contenidos que «venden» mejor, como ha pasado con todos los géneros musicales. Connor (en Aguilar Barreto y Peñaloza Figueroa 111) dice que «para la música comercial lo importante es ser vista y escuchada. Existe en cuanto es visible como representación y por tanto está mediada y administrada por las estructuras y ritmos del espectáculo y del consumo que acompaña la visibilidad».

Así, lo que trasciende las fronteras ya no es reggaetón de protesta y resistencia, sino comercial, donde los contenidos relacionales y altamente sexualizados han desplazado completamente a los otros que estas canciones tenían en su origen. Actualmente, el mensaje musical no se transmite únicamente por la letra de las canciones sino también por las imágenes de los vídeos que los acompañan y hasta por la que transmiten los intérpretes con su actitud.

El mensaje que emite el reggaetón es casi único en este sentido: mantiene un énfasis en la «sexualidad libre», en la que se entretejen relaciones de género eufemísticamente definidas como «interesantes» (Rodríguez Rivera 34). Cabe destacar que la sexualidad que propone es sexista y violenta, y en ella colaboran y participan mujeres, convirtiéndose en «objeto y sujeto al mismo tiempo» (Rodríguez Rivera 35). La idea que subyace a este razonamiento es que existe un empoderamiento de la mujer dentro de su rol sexual sobre todo a través del llamado «perreo», baile asociado al reggaetón. Por su parte, Rivera (4) piensa que no hay posibilidad de acuerdo porque el espacio del perreo se maneja con las leyes del sexismo; incluso Rodríguez Rivera (34) admite la reproducción de modelos patriarcales en el reggaetón.

Con el argumento del empoderamiento de la mujer en el perreo, el reggaetón es defendido desde distintas perspectivas, entre ellas el activismo feminista (Sosa, en Feliciano 1; Sosa, en Noisey Colombia 1; Alcaraz 1-23), la lingüística (Dávila 59-65), la sociología (Negrón-Muntaner y Rivera 30-37; Rodríguez Rivera 26-37), el género (Rodrigues Morgado 38-44) y el arte

Feminismo/s 35, junio 2020, pp. 291-320 
(Caycedo, en Rivera 2-4). Sin embargo, también hay posturas de que este empoderamiento de la mujer a través de una imagen sexualizada en los medios, no es más que un nuevo «empaque» para su objetivación sexual (Levy, en Harvey y Hill 54).

Se observan dos tendencias frente a la sexualización: la que se opone y aquella a favor. Según Harvey y Hill (53-54), dentro del propio movimiento feminista se están polarizando las posturas, estableciendo dos posiciones: una que sostiene que la proliferación de representaciones de mujeres como deseables y sexuales representa un cambio positivo en la manera de ver la sexualidad femenina, mientras que otras manifiestan que estas mismas imágenes están al servicio del capitalismo de consumo patriarcal.

Harvey y Hill (54-55) proponen una nueva lectura del tema, no binaria, que trata sobre la construcción subjetiva de la persona en un contexto social dado. Retomando la noción de subjetivización sexual de Gill, las autoras suman la de la «tecnología de la sensualidad» de Radner (en Harvey y Hill 54-55) y añaden a esto los discursos del nuevo ejercicio sexual femenino, para generar una nueva noción, a través de la cual las mujeres están construyéndose, la del «emprendimiento sexual». La nueva mujer tiene que ser:

Obligatoriamente sexy y estar siempre «a la altura», al ser interpelada a través de discursos en los que el sexo es laborioso y requiere trabajo constante y reafirmación [...] La belleza, deseabilidad y el rendimiento sexual constituyen sus proyectos en curso y se la exhorta a llevar una vida sexual «condimentada» cuyos límites -entre ellos la heterosexualidad y la monogamia- se controlan estrictamente, incluso cuando se borran o desaprueban a través de discursos de juego y experimentación. (Harvey y Hill 55).

Estas consideraciones generales conducen a analizar el papel de la mujer en el reggaetón actual. El objetivo del presente estudio es analizar y caracterizar el rol de la mujer en las representaciones de los vídeos y letras, y el lugar de las mujeres en el género (intérpretes y compositoras), en las 100 canciones de reggaetón más populares del 2018, bajo el supuesto de una posible sexualización y objetivación de la mujer en sus contenidos. 


\section{METODOLOGÍA}

\subsection{Muestra}

Se escogieron 100 canciones que cumplieran con los siguientes cuatro criterios de inclusión: fecha de publicación, género reggaetón, popularidad y tener vídeo oficial ${ }^{1}$.

En cuanto a la fecha de publicación, se seleccionaron vídeos oficiales publicados en YouTube entre el 12/01 y el 21/12 de 2018 y/o clasificados en VEVO con fecha 2018. Para todos se verificó la pertenencia al reggaetón de acuerdo a: (1) estar clasificado como tal en VEVO o (2) ser citado en uno al menos de los diez primeros links de Google como reggaetón o (3) hablar de reggaetón o contener en su letra la palabra reggaetón.

El criterio de «popularidad» hizo referencia al posicionamiento en las listas de Spotify, como las más escuchadas, o propuestas como tal en YouTube en los listados o canciones referenciadas en sitios especializados de reggaetón como «las mejores». Finalmente, las canciones debían tener vídeo oficial publicado en YouTube, eliminando aquellas que tenían solo vídeos de concierto o con letras.

Los vídeos analizados han permanecido en YouTube en promedio 168 días, alcanzando un poco más de 1.200 .000 visualizaciones por vídeo por día. En relación al género de los intérpretes en la muestra, ochenta y seis canciones son interpretadas por hombres, cuatro por mujeres y en diez ambos géneros comparten el micrófono (llamamos a estas «reggaetón mixto»). En los resultados distinguiremos las canciones que provienen de cada una de las fuentes cuando sea pertinente.

\subsection{Procedimiento}

En la presente investigación se decidió hacer un análisis de la representación de la mujer en el reggaetón desde tres ejes: análisis de los vídeos, de las letras, y de la presencia femenina en el género (imagen de las intérpretes y presencia como compositoras). Las investigaciones, en general, abordan por separado

1. Por razones de espacio, no se incluye la lista total de las canciones analizadas con sus títulos e intérpretes; la muestra analizada está disponible para las personas que quieran confirmar o refutar la investigación bajo pedido al correo del autor corresponsal.

Feminismo/s 35, junio 2020, pp. 291-320 
Dime lo que escuchas y te diré quién eres. Representaciones de la mujer en las 100 canciones de reggaetón más populares en 2018

estos componentes. Así, hay algunas que se han centrado en analizar el vídeo clip (Aubrey y Frisby 482; Rodríguez-López y Caldeiro- Pedreira 65; Sedeño 4); otras han puesto el énfasis en el análisis del contenido de las letras (Adams y Fuller 950); algunas han considerado como opción analizar el contenido de vídeos producidos por mujeres (Pérez-Rufí 206); algunas analizan no solo a la mujer representada, sino a las intérpretes también (Aubrey y Frisby 482; Pérez-Rufí 216; Rodríguez-López y Caldeiro-Pedreira 67-77), y en otros se analiza a los intérpretes masculinos (Aubrey y Frisby 483; Sedeño 8). El presente estudio contempla simultáneamente varios parámetros para el análisis.

\subsubsection{Vídeos}

La metodología empleada en el análisis de los vídeos fue la observación detallada con registro en una matriz de la presencia/ausencia de las categorías creadas para el análisis (tabla 1).

Tabla 1: Categorías de codificación de las imágenes

\begin{tabular}{|l|l|}
\hline Información general & - Nombre de la canción. \\
& - Nombre del/la/los intérpretes. \\
& - Fecha de publicación en la web. \\
& - Género del/la/los intérpretes. \\
& - Compositores/as. \\
\hline $\begin{array}{l}\text { Tipo de baile } \\
\text { representado }\end{array}$ & - Baile provocador: baile con movimientos pélvicos y \\
& sugerentes sin pareja. \\
& - Perreo: movimientos pélvicos en posturas de perreo \\
& solas o acompañadas. \\
& - Perreo «duro» o marroneo: imitación de actos sexuales \\
& de manera casi pornográfica pero con ropa. \\
& - Otro tipo de baile: grupal/ coreográfico \\
& - No baile: ausencia de baile femenino en el vídeo \\
\hline Presentación de las & - En ropa corta o pegada. \\
mujeres & - En ropa interior. \\
& - En terno de baño. \\
& - Desnudos femeninos (parcial o total). \\
& - Vestida/vídeo sin mujer. \\
\hline
\end{tabular}

Feminismo/s 35, junio 2020, pp. 291-320 
Dime lo que escuchas y te diré quién eres. Representaciones de la mujer en las 100 canciones de reggaetón más populares en 2018

\begin{tabular}{|c|c|}
\hline Objetivación de la mujer & $\begin{array}{l}\text { - Fragmentada: enfoques de cámara en senos, nalgas, } \\
\text { pelvis. } \\
\text { - Ornamental: número de mujeres sobrerrepresentadas en } \\
\text { relación a varones, adornando o rellenado las escenas } \\
\text { (intercambiables y anónimas). } \\
\text { - No objetivada: mujer presentada como protagonista } \\
\text { principal de una historia no sexual, sin enfoques } \\
\text { fragmentados al cuerpo }\end{array}$ \\
\hline Mujer sexualizada & $\begin{array}{l}\text { - Provocativa: bocas abiertas con lenguas, piernas } \\
\text { abiertas al sentarse, lamiendo objetos, moviéndose } \\
\text { explícitamente paradas o sentadas. } \\
\text { - Lasciva: acariciándose lascivamente. } \\
\text { - Del goce: parejas o grupos de mujeres en poses sexuales } \\
\text { o interactuando sexualmente. } \\
\text { - No sexualizada: mujer presentada en todo el vídeo en } \\
\text { interacciones no sexuales ni seductoras }\end{array}$ \\
\hline $\begin{array}{l}\text { Tipo de ambiente } \\
\text { representado }\end{array}$ & $\begin{array}{l}\text { - Sexualizados: Nocturno de fiesta con alusiones eróticas/ } \\
\text { Diurno de diversión con alusiones eróticas (playas, } \\
\text { piscinas, canchas, etc.)/ Sexual (prostíbulos, clubes } \\
\text { de striptease, palos de pole dance) / Íntimo (camas, } \\
\text { duchas, bañeras). } \\
\text { - No sexualizados: Calle, barrio popular (urbano) } \\
\text { / Aparcamientos, subterráneos, callejones, autos / } \\
\text { Estudio de grabación / Escenarios de películas (vídeos } \\
\text { narrativos) /Mansiones y castillos } \\
\text { - Otros ambientes: aeródromos, hangares, hoteles, jardín, } \\
\text { teatro, etc. }\end{array}$ \\
\hline $\begin{array}{l}\text { Sexualización del } \\
\text { ambiente }\end{array}$ & $\begin{array}{l}\text { - Besos, caricias, contacto corporal. } \\
\text { - Imitación de posturas, escenas íntimas. } \\
\text { - Caricias explícitamente sexuales o acto sexual. }\end{array}$ \\
\hline Consumo de sustancias & $\begin{array}{l}\text { - Alcohol. } \\
\text { - Cigarrillo/vaporizadores/pipas. } \\
\text { - Pastillas. } \\
\text { - No consumo }\end{array}$ \\
\hline
\end{tabular}

Fuente: elaboración propia (2019)

\subsubsection{Letras}

Para el estudio del contenido de las canciones, se utilizó el método de análisis temático de Braun y Clarke (87), que consta de 6 fases: (1) familiarización con los datos, (2) generación de categorías o códigos iniciales, (3) búsqueda

Feminismo/s 35, junio 2020, pp. 291-320 
de temas, (4) revisión de temas, (5) definición y denominación de temas y (6) informe final.

En la fase 1, las letras de las canciones interpretadas por hombres, mujeres y mixtas, fueron retomadas en tres documentos diferenciados; se completaron las palabras incompletas para facilitar la lectura (ej.: pa', vamo', e', ere', entre otras), se buscó en la Internet el significado de palabras desconocidas, que correspondían al léxico caribeño y propias de reggaetón. En esta primera familiarización se identificaron temáticas generales, que fueron una guía para las fases 2 y 3 .

Las fases 2 (generación de códigos iniciales) y 3 (búsqueda de temas) fueron realizadas con el procesador cualitativo Nvivo; se realizó una codificación inductiva de la información, reagrupando aquella que tenía un mismo significado, a la vez que se buscaron temas generales por prevalencia en el discurso de palabras y narraciones similares.

En la fase 4, se revisó y reorganizó la información en categorías más inclusivas. Así mismo, se generaron tres nuevas categorías. En la fase 5, se definieron y denominaron los temas definitivos, que fueron los siguientes: Representaciones del hombre y de la mujer, Relaciones de Pareja, Ruptura, Sexo, Sexualidad, Ambiente.

Se debe recalcar que en la codificación no se eliminaron las repeticiones de un mismo estribillo o parte de la canción. Se considera importante dejar la letra en su totalidad y codificarla enteramente puesto que, a nivel cognitivo, la repetición garantiza la memorización de un mensaje.

\section{RESULTADOS}

Los resultados expuestos se refieren principalmente a las representaciones de la mujer; no se expondrán ni analizarán resultados referentes a las otras categorías.

Las descripciones de la mujer serán expuestas y analizadas siguiendo el siguiente esquema: representaciones de la mujer en los vídeos, letras, y tipo de presencia femenina en el género (intérpretes, compositoras). 
Dime lo que escuchas y te diré quién eres. Representaciones de la mujer en las 100 canciones de reggaetón más populares en 2018

\subsection{Representaciones de las mujeres en los vídeos}

\subsubsection{Imágenes}

Las mujeres están presentes en casi la totalidad de los vídeos de reggaetón (99), generalmente con ropa corta, pegada, ropa interior, terno de baño o incluso se puede llegar a verlas parcialmente desnudas. Dos vídeos no presentan mujeres de estas maneras: en uno solo está el intérprete masculino y en otro la mujer usa un vestido de noche durante todo el vídeo (tabla 2).

Tabla 2: Categorización de las imágenes de mujeres en los vídeos analizados

\begin{tabular}{|l|c|}
\hline \multicolumn{1}{|c|}{ Presentación de mujeres } & Número de vídeos \\
\hline Ropa corta o pegada & 80 \\
\hline Ropa interior & 45 \\
\hline Terno de baño & 26 \\
\hline Desnudos femeninos & 10 \\
\hline Vestida/vídeo sin mujer & 2 \\
\hline
\end{tabular}

Fuente: elaboración propia (2019)

Cabe recalcar que en los vídeos, una categoría no excluye a otra; por el contrario, la mayoría de vídeos tienden a presentar varias simultáneamente (tabla 3).

Tabla 3: Número de categorías en un mismo vídeo

\begin{tabular}{|c|c|}
\hline $\begin{array}{c}\text { Categorías presentadas } \\
\text { en un mismo vídeo }\end{array}$ & Número \\
\hline Ninguna & 2 \\
\hline Una & 45 \\
\hline Dos & 40 \\
\hline Tres & 11 \\
\hline
\end{tabular}

Fuente: elaboración propia (2019)

Las mujeres en los vídeos del reggaetón analizados, aparte de estar presentes con estos diversos tipos de indumentarias, también se encuentran 
representadas a través de su actuar. Este actuar será expuesto como: la mujer que baila, la mujer objeto y la mujer sexual.

\subsubsection{La mujer que baila}

La mujer realiza principalmente tres tipos de baile: provocador, perreo y perreo «duro», en solitario o en algunos casos grupalmente (35 vídeos), con o sin coreografía. En algunos vídeos no hay baile de ningún tipo por parte de las mujeres, puesto que narran historias (tabla 4); cabe recalcar que varios tipos de baile pueden presentarse en un mismo vídeo.

Tabla 4: La mujer que Baila

\begin{tabular}{|l|c|}
\hline \multicolumn{1}{|c|}{ Tipo de baile } & Número de vídeos \\
\hline Baile provocador & 49 \\
\hline Perreo & 40 \\
\hline Perreo duro & 16 \\
\hline Perreo o baile grupal/coreográfico & 35 \\
\hline No baile & 35 \\
\hline
\end{tabular}

Fuente: elaboración propia (2019)

\subsubsection{La mujer objeto}

En las imágenes se observó que la mujer es objetivada, en la medida que en varias tomas es presentada como un fragmento de mujer (solo se ven lo senos, nalgas o pelvis). Por otro lado, en casi la mitad de los vídeos es presentada en sobrenúmero en relación al varón, alrededor o detrás de él, lo que la pone en el rango de un objeto ornamental, intercambiable y anónima. Sin embargo, en algunos vídeos la mujer es protagonista de una historia, generalmente romántica, y no hay enfoques de cámara fragmentados (21 vídeos) (tabla 5). De la misma manera, varias representaciones pueden estar presentes en un mismo vídeo. 
Dime lo que escuchas y te diré quién eres. Representaciones de la mujer en las 100 canciones de reggaetón más populares en 2018

Tabla 5: La mujer objetivada

\begin{tabular}{|l|c|}
\hline \multicolumn{1}{|c|}{ Tipo de objetivación } & Número de vídeos \\
\hline Fragmentada & 63 \\
\hline Ornamental & 49 \\
\hline No objetivada & 21 \\
\hline
\end{tabular}

Fuente: elaboración propia (2019)

\subsubsection{La mujer sexual}

En 70 vídeos, se presentan varios tipos de representaciones sexualizadas de la mujer: provocativas, deseosas y lujuriosas, ya sea adoptando poses que evocan el deseo o los actos sexuales, acariciándose o interactuando de manera sexual en pareja o grupos. Solo un número reducido de vídeos no sexualiza directamente a la mujer (tabla 6).

Tabla 6: La mujer sexual

\begin{tabular}{|l|c|}
\hline Tipo de sexualización & Número de vídeos \\
\hline Provocativa & 58 \\
\hline Lasciva & 48 \\
\hline Del goce & 21 \\
\hline No sexualizada & 13 \\
\hline
\end{tabular}

Fuente: elaboración propia (2019)

Estas mujeres, ademá,s se encuentran en ambientes erotizados, de fiesta o de diversión, lo que está acorde con el tipo de música, puesto que se trata de un baile movido, o en ambientes directamente sexuales o íntimos. Los ambientes sexualizados son los más representados en los vídeos analizados; ambientes no sexualizados están presentes en menor grado; entre ellos destacan los callejeros y populares. Los ambientes más representados se presentan en la tabla 7; se debe tomar en cuenta en los datos presentados a continuación que varios ambientes pueden estar presentes en un mismo vídeo. 
Dime lo que escuchas y te diré quién eres. Representaciones de la mujer en las 100 canciones de reggaetón más populares en 2018

Tabla 7: Ambientes más representados en los vídeos analizados

\begin{tabular}{|l|l|c|c|}
\hline \multicolumn{1}{|c|}{ Tipo } & \multicolumn{1}{|c|}{ Desglose } & Número & $\begin{array}{c}\text { Total } \\
\text { por tipo }\end{array}$ \\
\hline \multirow{5}{*}{ Sexualizados } & Nocturno de diversión erotizado & 34 & 94 \\
\cline { 2 - 4 } & Diurno de diversión erotizado & 24 & \\
\cline { 2 - 4 } & Íntimos & 28 & \\
\cline { 2 - 5 } & Sexuales (prostíbulos y afines) & 8 & \\
\hline \multirow{5}{*}{ No sexualizados } & $\begin{array}{l}\text { Calle, graffitis/ barrio popular/ ventas } \\
\text { callejeras }\end{array}$ & 16 & 65 \\
\cline { 2 - 5 } & $\begin{array}{l}\text { Aparcamientos/ subterráneos/ autos como } \\
\text { escenario/ callejón/ paredes }\end{array}$ & 14 & \\
\cline { 2 - 5 } & Estudio & 14 & \\
\cline { 2 - 5 } & Escenarios de película & 13 & \\
\cline { 2 - 5 } & Mansiones/castillos & 25 & 25 \\
\hline \multirow{2}{*}{ Otros } & & & \\
\hline
\end{tabular}

Fuente: elaboración propia (2019)

La sexualización del ambiente se incrementa a través de las conductas representadas relacionadas con el sexo. Así, cuarenta y cinco muestran besos, caricias y contacto corporal, veintiuna presentan imitaciones claras de posturas y escenas íntimas, y nueve exhiben caricias explícitamente sexuales o el acto sexual per se. Si a esto se suman indicadores de vestimenta de la mujer (excluyendo ropa corta o pegada), tipo de baile, tipo de objetivación, tipo de sexualización y ambientes íntimos y sexuales, solo cuatro canciones no contienen ningún indicador de sexualización.

\subsection{Descripciones de las mujeres en las letras de las canciones}

Con las categorías finales generadas se codificó el 97.04 \% de los textos de las canciones interpretadas por mujeres, el $61.64 \%$ de los textos de las interpretadas por hombres y el $88.45 \%$ de los textos de reggaetón mixto. Los resultados indican los «porcentajes de cobertura» del texto codificado, y no del texto original y total. 
Dime lo que escuchas y te diré quién eres. Representaciones de la mujer en las 100 canciones de reggaetón más populares en 2018

$\mathrm{Al}$ analizar las letras, ciertos temas surgieron como principales; de estos, las descripciones sobre el hombre y la mujer ocuparon el $26 \%$ de los textos codificados. Otros temas (no analizados en este artículo) tuvieron los siguientes porcentajes de cobertura: Relaciones de Pareja (36\%), Sexo (21\%), Ruptura (20\%), Ambiente (9\%) y Sexualidad (4\%).

Las descripciones de mujeres están presentes mayoritariamente en las canciones interpretadas por varones ( $26.77 \%$ de los textos codificados) y en las de interpretación mixtas (24.45\%), mientras que solamente en el $7.88 \%$ de los textos de las canciones interpretadas por mujeres. Las canciones de reggaetón hacen alusión a las mujeres de muchas maneras, desde aquellas que proponen alusiones directas a sus atributos físicos, pasando por descripciones más complejas de modelos femeninos, por ejemplo, maneras de actuar, y hasta maneras degradantes de referirse a ella. Un detalle de las expresiones y formas de describir a la mujer se encuentra en la tabla $8^{2}$.

Tabla 8: Porcentaje de cobertura del tema «Descripciones de la mujer» dentro del texto codificado en las 3 fuentes

\begin{tabular}{|c|c|c|c|c|}
\hline TEMA & Sub categoría & Mujeres & Hombres & Mixto \\
\hline \multirow{2}{*}{$\begin{array}{l}\text { Mujer definida por } \\
\text { atributos }\end{array}$} & $\begin{array}{l}\text { Referencias a atributos físicos } \\
\text { femeninos }\end{array}$ & 1.31 & 2.42 & 8.89 \\
\hline & Referencias a otros atributos & - & 0.37 & - \\
\hline \multirow{7}{*}{$\begin{array}{l}\text { Modelos } \\
\text { femeninos } \\
\text { propuestos }\end{array}$} & Preferida/única & - & 2.08 & 1.13 \\
\hline & Libertina/seductora & 1.61 & 5.22 & 7.43 \\
\hline & Liberada del hombre & 4.21 & 2.71 & 0.70 \\
\hline & Doble cara & 0.75 & 1.83 & 0.81 \\
\hline & Mala & - & 4.43 & 0.29 \\
\hline & Hecha la difícil & - & 3.52 & - \\
\hline & Poderosa & - & 3.03 & 3.95 \\
\hline
\end{tabular}

2. Por razón de espacio, no se identifican las piezas citadas de donde surgen algunos de los fragmentos, salvo cuando el fragmento es extenso.

Feminismo/s 35, junio 2020, pp. 291-320 
Dime lo que escuchas y te diré quién eres. Representaciones de la mujer en las 100 canciones de reggaetón más populares en 2018

\begin{tabular}{|l|l|c|c|c|}
\hline \multirow{4}{*}{$\begin{array}{l}\text { Degradación de } \\
\text { la mujer: mujer } \\
\text { deshumanizada }\end{array}$} & Animal & - & 0.29 & - \\
\cline { 2 - 5 } mujer parcial & Diablo & - & 0.54 & - \\
\cline { 2 - 5 } & Partes anatómicas & - & 0.15 & 0.14 \\
\cline { 2 - 5 } & Puta & - & 0.18 & 1.11 \\
\cline { 2 - 5 } & TOTAL & 7.88 & 26.77 & 24.45 \\
\hline
\end{tabular}

Fuente: elaboración propia (2019)

En cuanto a las descripciones sencillas, los atributos físicos son los más cantados de la mujer en todas las fuentes ( $4.2 \%$ en promedio), con innumerables referencias al cuerpo total; los hombres celebran el cuerpo femenino («ese cuerpo me tiene sudando» "estás bien dura») y a la mujer bonita («mujer tan bella») y las mujeres también se autodefinen por ello: "estaba bonita» «todo el mundo loco con mi cinturita». La posibilidad de cirugías es citada en el reggaetón masculino ( "no hay cirugía, ella nació bien completa» «y le pregunté que cual cirujano era ese/me dijo que se operó en $\mathrm{RD} /$ me dijo que siempre quiso ser doble D/ y que el culo no se lo ha hecho»). Estas consideraciones priman sobre las referencias a otros atributos hechas por los varones, como por ejemplo "sencilla», "con esa sensualidad y esa actitud», "toda una dulzura», las que representan solamente el $0.37 \%$.

Entre las descripciones ligadas a modelos femeninos, algunas se presentan como aparentemente valorativas de la mujer. Para mejor ilustración, en las siguientes citas, entre paréntesis se indica la fuente en siglas: reggaetón cantado por hombres (RH), reggaetón cantado por mujeres (RF), y reggaetón mixto (RM).

- Preferida/ única: la mujer escogida por el varón entre varias para ser la receptora de su atención, y que se valora por características especiales, muchas veces la sexual: «es que me gustas tú nada más/no importan las demás» (RH), «es única y solo yo se lo puedo ver» (RH), «tú eres mi baby personal, pegadita, exclusive» (RH).

- Libertina/ seductora: mujer a la que le gusta divertirse y tiene un apetito sexual que necesita ser satisfecho. Los hombres cantan: «la veo en la disco casi todos los weekends/ al parecer en su casa no hay quien la frenelel vacilón de ella comienza desde el jueves» (RH), «es una loca» (RH), «me dijo que quería prender que le llegara/ le llegué y

Feminismo/s 35, junio 2020, pp. 291-320 
se me tiró encima para que la besara» (RH); y las mujeres contestan de la misma manera: «que no se te apague la excitación/tú sabes que yo no te dejo plantado» (RF).

- Liberada del hombre: mujer que decide por su propio destino, que prefiere estar sola y vivir con sus reglas, generalmente después de una decepción amorosa. Los hombres dicen: "Ya está solteral y no espera quien la quiera/ no se mete con cualquiera/ solo con el que ella quiera»(RH), "y todos quieren con ella/ y ella con nadie quiere nada/ porque prefiere estar sola/que mal acompañada» (RH); Las mujeres también se autodefinen así: «de nadie me dejo» (RM), «soy una reina y su destino controla» (RF).

Los otros modelos transmitidos en las canciones presentan claramente a la mujer en sus aspectos negativos: doble cara, mala, hecha la difícil y poderosa.

- Doble cara: este modelo se encuentra en descripciones de la mujer en que esta presenta una actitud aparentemente tranquila pero en el fondo es otra; generalmente, esta doble actitud se refiere a lo sexual. Los hombres del reggaetón cantan que la mujer es: «santa de día, diabla cuando cae la luna» (RH), "ella es decente, pero solo en el díal porque la noche calma las ganas que tenía» (RH), "y tú eres buena pero por dentro tienes tanta maldad», "carita de inocente pero eres bien pervertida» (RH); "no te hagas la santa que tú sabes que tú quieres/ que yo te toque ahì (RM). Al contestar en el reggaetón femenino, la mujer le dice que tiene razón: "siempre he sido una dama/ pero soy una perra en la cama» (RM).

- Mala: se describe en las canciones a una mujer llena de sentimientos negativos, que busca hacer daño al varón: «eres una asesina, un diablo en cuerpo de mujer» (RH), «mala mujer» (RH), «traicionera, no me importa lo que tú me quieras» (RH). La mujer usa al varón ( «tú eres una hipócrita/ un día me amas y otro día me odias» (RH), «mami, tú muy mal me trataste/usaste, tú me utilizaste/ solo te importaba el dinero» $(\mathrm{RH})$ ), maltrata su corazón ( «mi corazón lo maltratastel conmigo en verdad te pasaste/ mataste mi hombría y en un par de días las manos te las ensuciaste»). Llega a ser "más mala que Anabelle» (RM), "te deja marcado como el Zorro» (RM). 
- Hecha la difícil: es un tipo de mujer descrita sólo en el reggaetón de varones, que no cede al deseo masculino inmediatamente, lo tiene esperando, lo ignora, es orgullosa: «solo me buscas cada vez que te conviene/ se pone difícil, su orgullo no hay quien lo frene», "bebé, deja el orgullo», "me mata que tú siempre me trates así/ te haces la difícil». Y el varón no entiende por qué no cede: «por darte tanto puesto es que ya no te cojo en serio/ haciéndote la difícil, pero ¿por qué?».

- Poderosa: describe a la mujer como dotada de poderes, que logra hacer que el varón realice acciones en contra de su voluntad y que escapan de su control: « es una niña de desconocida criatura/de noche ella empaña tu visión/ con solamente mirarla/de magia negra ella me llama/ tiene algo que hipnotiza mamá/ me hechiza» (RH), y usando sus atributos «jugando con mi mente eres experta/entre esas piernas tú tienes poderes» (RH), "hechicera, tú me embrujas cada vez que tú me hablas» (RH), o dándole algo «me tienes enviciado con eso que me has dado» (RH). La mujer le ratifica esto: "Cuidao, porque te vas envolver/ Cuidao, las mujeres tienen poder/ Cuidado, aviso de peligro» (RM)

Finalmente, está la degradación de la mujer, a través de un tratamiento peyorativo en las descripciones en las cuales se ha sustituido la palabra mujer, y los varones usan como sinónimo, directamente, referencias a animales («las gatas son de tres en tres»), al diablo ( hija del diablo», "hija de Lucifer»), partes anatómicas ( «tengo un culo en cada país», «me voy a tirar un par de traseros»), o la palabra "puta» («tengo otras putas nuevas en el menú», "sata en todas las poses»). Cabe recalcar que estas descripciones están ausentes en el reggaetón femenino.

En la figura 1 se ilustra la presencia de las diferentes categorías de descripción en las fuentes y cómo algunas de ellas son compartidas. Al compararlas se encontró que:

1. No existe una categoría exclusiva de autodescripción de las mujeres en sus canciones.

2. Los modelos femeninos con los cuales están de acuerdo las mujeres, presentes en el reggaetón de varones y mixto pero también en el reggaetón exclusivamente femenino, son: libertina/seductora, liberada 
Dime lo que escuchas y te diré quién eres. Representaciones de la mujer en las 100 canciones de reggaetón más populares en 2018

del hombre y doble cara, así como las descripciones por sus atributos físicos.

3. Los modelos femeninos que avalan las mujeres, al cantar con varones en el reggaetón mixto son: la preferida/única, la mala, la poderosa, y aceptan que se las trate de manera degradante como putas y como una parte anatómica.

4. Los modelos que no son compartidos por las mujeres, ni están presentes en el reggaetón mixto y son entonces exclusivos de varones son: la hecha la difícil, las imágenes degradantes como animal o diablo y las referencias a otros atributos femeninos positivos.

Figura 1: Descripciones de la mujer relatadas según cada una de las fuentes

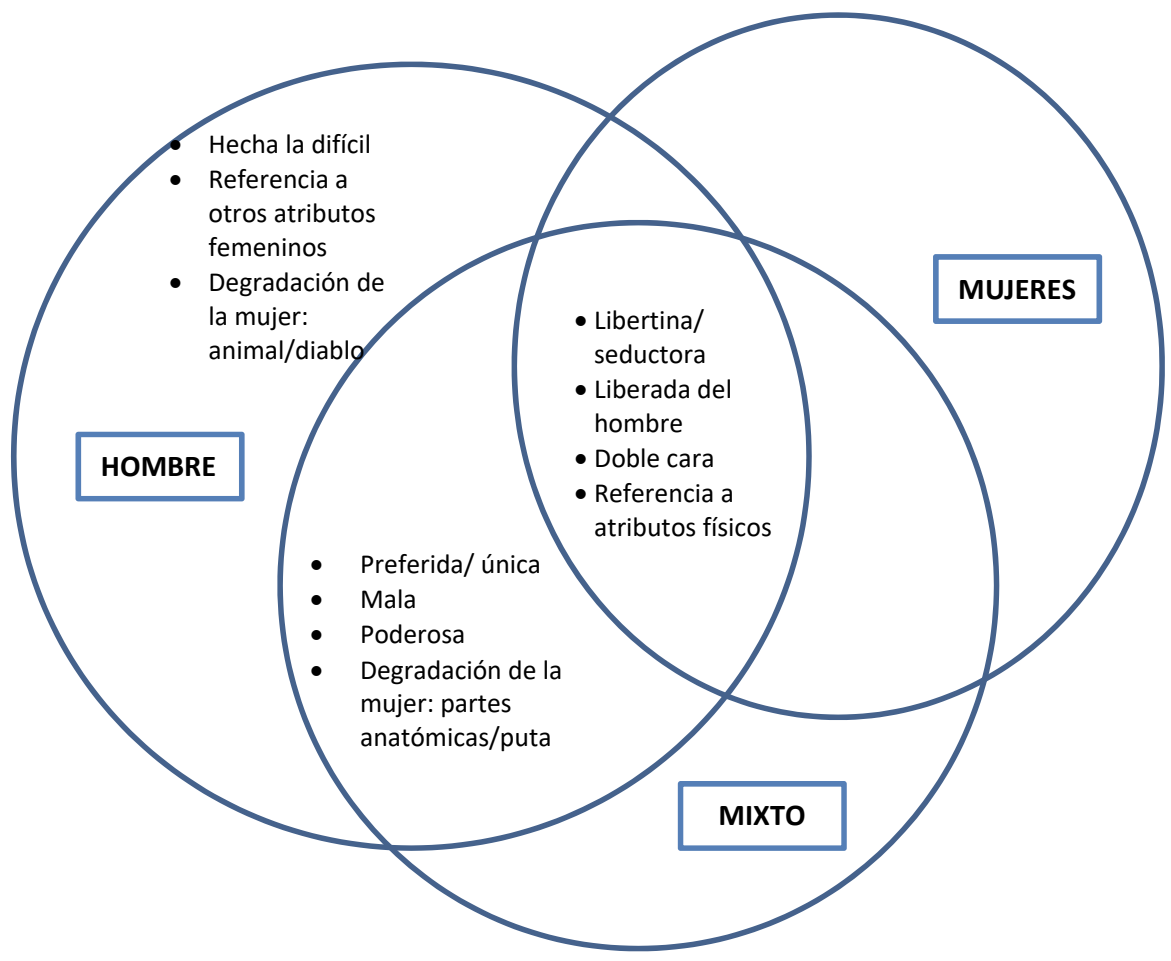

Fuente: elaboración propia (2019)

Feminismo/s 35, junio 2020, pp. 291-320 


\subsection{Representación femenina dentro del género: presencia e imagen como intérpretes y compositoras}

En el análisis realizado, solo 4 canciones son de intérpretes femeninas, lo que deja entrever que el espacio del reggaetón es casi exclusivamente masculino. Si sumamos las canciones mixtas, tenemos que sólo el 14\% del reggaetón popular en 2018 incluyó a mujeres como intérpretes o cointérpretes. El fenómeno se extiende a la composición de las canciones: en el análisis realizado, $79 \%$ son compuestas exclusivamente por hombres y en $17 \%$ se incluye a una o dos mujeres máximo en la composición (en el 4\% la autoría es corporativa); no se encontró ninguna canción analizada de autoría exclusivamente femenina, lo que muestra que la presencia de las mujeres es minoritaria en este plano también.

Lo representado en los vídeos de las cantantes femeninas no difiere de los vídeos de reggaetón mixto y masculino (tabla 9).

Así, las intérpretes femeninas, protagonistas además en sus vídeos, se presentan bailando provocativamente o perreando, en ropa corta o pegada o incluso en ropa interior, permitiendo en ellas mismas los enfoques de cámara en nalgas, senos o pelvis, totalmente sexualizadas (provocativas, acariciándose lascivamente, interactuando entre ellas sexualizadamente), en ambientes de diversión, íntimos o sexuales.

$\mathrm{Al}$ analizar las temáticas generales de estas cuatro canciones, lo que sobresale en los temas son narraciones relacionales, que se encuentran detallados en la tabla 10 . 
Dime lo que escuchas y te diré quién eres. Representaciones de la mujer en las 100 canciones de reggaetón más populares en 2018

Tabla 9: Categorías de análisis de las cuatro canciones de reggaetón interpretadas por mujeres que se incluyeron en este estudio

\begin{tabular}{|c|c|c|}
\hline Categoría & Subcategoría & $\begin{array}{l}\text { Número } \\
\text { de } \\
\text { vídeos }\end{array}$ \\
\hline \multirow{4}{*}{ Tipo de baile } & Baile provocador & 4 \\
\hline & Perreo & 2 \\
\hline & Perreo «duro» o marroneo & 1 \\
\hline & Perreo en grupo o baile grupal & 1 \\
\hline \multirow{2}{*}{$\begin{array}{l}\text { Presentación de } \\
\text { las mujeres }\end{array}$} & Mujer en ropa corta o pegada & 4 \\
\hline & Mujer en ropa interior & 4 \\
\hline \multirow{3}{*}{ Objetivación } & Mujer fragmentada & 3 \\
\hline & Mujer ornamental & 2 \\
\hline & Mujer no objetivada & 0 \\
\hline \multirow{4}{*}{$\begin{array}{l}\text { Mujer } \\
\text { sexualizada }\end{array}$} & Mujer provocativa & 4 \\
\hline & Mujer lasciva & 4 \\
\hline & Mujer del goce & 2 \\
\hline & Mujer no sexualizada & 0 \\
\hline \multirow{3}{*}{ Tipo de ambiente } & Sexualizados & 4 \\
\hline & No sexualizados & 0 \\
\hline & Otros & 1 \\
\hline $\begin{array}{l}\text { Sexualización del } \\
\text { ambiente }\end{array}$ & $\begin{array}{l}\text { Imitación de posturas, escenas } \\
\text { íntimas }\end{array}$ & 1 \\
\hline \multirow{2}{*}{$\begin{array}{l}\text { Consumo de } \\
\text { sustancias }\end{array}$} & Alcohol & 3 \\
\hline & No consumo & 1 \\
\hline
\end{tabular}

Fuente: elaboración propia (2019)

Feminismo/s 35, junio 2020, pp. 291-320 
Dime lo que escuchas y te diré quién eres. Representaciones de la mujer en las 100 canciones de reggaetón más populares en 2018

Tabla 10: Temáticas de las 4 canciones de reggaetón femenino analizadas

\begin{tabular}{|c|c|c|c|}
\hline $\begin{array}{l}\text { Nombre de } \\
\text { la canción e } \\
\text { intérpretes }\end{array}$ & $\begin{array}{l}\text { Temática } \\
\text { narrada }\end{array}$ & Cita de la canción & Compositores \\
\hline $\begin{array}{l}\text { «in } \\
\text { Pijama» } \\
\text { - Becky } \\
\text { G, Natti } \\
\text { Natasha }\end{array}$ & $\begin{array}{l}\text { Narración de } \\
\text { sexo y diversión } \\
\text { bajo pedido del } \\
\text { varón }\end{array}$ & $\begin{array}{l}\text { Si tú me llamas/ Nos vamo' pa' tu } \\
\text { casa/ Nos quedamo' en la cama, Sin } \\
\text { pijama, sin pijama/ Voy pa' contarle } \\
\text { mis secretos a tu almohada/ Mientras } \\
\text { tanto hagamos vídeo llamada/ Me } \\
\text { manda foto', fotico'/Mostrando todo, } \\
\text { todito/ Cuando llegue desbaratamo' } \\
\text { la cama» }\end{array}$ & $\begin{array}{l}\text { Cinco } \\
\text { hombres, } \\
\text { una mujer }\end{array}$ \\
\hline $\begin{array}{l}\text { «No me } \\
\text { acuerdo» } \\
\text { - Thalía, } \\
\text { Natti } \\
\text { Natasha }\end{array}$ & $\begin{array}{l}\text { Narra una salida } \\
\text { a una fiesta; la } \\
\text { protagonista al } \\
\text { día siguiente no } \\
\text { recuerda nada } \\
\text { por consumir } \\
\text { alcohol. } \\
\text { Admite posible } \\
\text { infidelidad, } \\
\text { avalando } \\
\text { fantasía } \\
\text { masculina }\end{array}$ & $\begin{array}{l}\text { «Para mí tan solo hay uno/ Pero si } \\
\text { te hace feliz/ Saber que estuve con } \\
\text { otro/ Vamos a decir que sí/ Pero no me } \\
\text { acuerdo, no me acuerdo/ Y si no me } \\
\text { acuerdo, no pasó». }\end{array}$ & $\begin{array}{l}\text { Cinco } \\
\text { hombres, } \\
\text { una mujer }\end{array}$ \\
\hline $\begin{array}{l}\text { «Mi cama» } \\
- \text { Carol G }\end{array}$ & $\begin{array}{l}\text { Narración } \\
\text { de despecho } \\
\text { sentimental, } \\
\text { en donde la } \\
\text { recuperación se } \\
\text { transforma en } \\
\text { revanchismo y } \\
\text { la protagonista } \\
\text { pasa a ser } \\
\text { promiscua } \\
\end{array}$ & $\begin{array}{l}\text { «Piensas que yo me quedé tranquila/ } \\
\text { Y los tengo haciendo fila/ Mientras } \\
\text { que tu inventas dar pom pom pom } \\
\text { pom/ Mi cama suena y suena/ Mi } \\
\text { cama suena y suena». }\end{array}$ & $\begin{array}{l}\text { Cuatro } \\
\text { hombres, } \\
\text { una mujer }\end{array}$ \\
\hline $\begin{array}{l}\text { «acuzzi» } \\
\text { - Greeicy, } \\
\text { Anitta }\end{array}$ & $\begin{array}{l}\text { Narración } \\
\text { del primer } \\
\text { encuentro entre } \\
\text { la protagonista } \\
\text { y un hombre, } \\
\text { que termina en } \\
\text { sexo. }\end{array}$ & $\begin{array}{l}\text { «Sólo un par de copas y se me prendió } \\
\text { en deseo/ Todo comenzó en la barral } \\
\text { Cuando apagaron la' luces/ Nos } \\
\text { miramos por un rato/ Y así fue que le } \\
\text { propuse/ Yo tengo vino en la casa/ Y } \\
\text { ya va llegando el Uber/ Y dijo vamo' } \\
\text { a ver qué pasa/ Y terminamo' en el } \\
\text { jacuzzi». }\end{array}$ & $\begin{array}{l}\text { Cinco } \\
\text { hombres, } \\
\text { una mujer }\end{array}$ \\
\hline
\end{tabular}

Fuente: elaboración propia (2019)

Feminismo/s 35, junio 2020, pp. 291-320 
Además, se puede observar que las cuatro canciones son compuestas esencialmente por autores varones, lo que en realidad no difiere de lo que sucede en el género en general. En el análisis realizado con la información disponible en la internet sobre los compositores, se observa que cada canción tiene múltiples autores, sin especificar si han intervenido en la composición musical, de las letras o ambas; sin embargo, se ha contabilizado que de los 247 compositores involucrados en las canciones, sólo catorce son mujeres (5.67\%).

\section{DISCUSIÓN}

Al analizar las 100 canciones más populares de reggaetón en 2018 con parámetros claros de inclusión, se evitaron posibles sesgos que pueden introducirse al «escoger» las más representativas de un género. Estableciendo criterios, una ventana temporal amplia (un año) y seleccionando una muestra extensa, se obtuvo un panorama más exacto y objetivo del tema analizado. El estudio realizado tanto de vídeos como de letras e intérpretes/compositores permite que las afirmaciones que se hacen sobre los contenidos tengan un soporte documentado y sólido, evitando críticas como las de Gallucci (84) que sostiene que las afirmaciones que normalmente se hacen sobre el tema no tienen sustento al no analizar realmente los textos.

Si bien se afirma que el reggaetón es un espacio en donde las mujeres están representadas, en este estudio se encuentra evidencia de que esto no ocurre, considerando que en la muestra el $86 \%$ de las canciones más escuchadas son cantadas por hombres, un $10 \%$ son mixtas y solamente el $4 \%$ son interpretadas por mujeres, y que la presencia femenina es minoritaria en la composición de estas canciones (5.67\%). Estos porcentajes claramente ilustran la diminuta representación de las mujeres en el género, ya que aunque las mujeres están presentes en los vídeos y letras, su papel no es protagónico.

El análisis de las letras indica que la mujer es descrita en sus roles de género tradicionales. Es la mujer pasiva, como vemos en las descripciones de la preferida/única, que adquiere valor por la mirada del hombre, o la liberada del hombre que se descubre libre después de una relación nociva, dejando de manifiesto que la mujer no puede ser autónomamente libre sino lo hace momentáneamente y por revanchismo. El modelo valorativo de libertina/ seductora plantea una mujer definida por su sexualidad, espacio que la 
empodera frente al hombre, pero que la sigue definiendo en relación a él, ya que es una sexualidad para ser vista por los hombres y provocativa para ellos; en definitiva, es un «ser-para-los-hombres» (De Toro 90).

Por otro lado, se describen mujeres con actitudes de supremacía. Así, en las canciones analizadas se percibe que la mujer es dicótoma (doble cara), que tiene intenciones ocultas y malvadas (mala), que el vincularse a ella o sentir algo por ella no depende del hombre sino es un ejercicio de poder sobre él (poderosa), y que cuando no cede a sus deseos no es por un desinterés legítimo hacia él sino por hecha la difícil.

En estos discursos existe una reproducción de lo tradicional. Lo que denominamos doble cara es lo que De Toro (91) señala como dicotomía « ¿Ser virgen o ser perra? ¿Ser dulce o gata?». Sin embargo, esta dicotomía es solo aparente puesto que las mujeres intérpretes han tomado ya postura, escogiendo el rol de perras para la intimidad: «siempre he sido una dama pero soy una perra en la cama». Por otro lado, las categorías de hecha la difícil, poderosa y mala corresponden a interpretaciones de la conducta femenina que cuando no se pliega al deseo masculino, ejerce autonomía o voluntad propia, es juzgada por el varón negativamente, como manipulándolo a través del cuerpo o intentando doblegar su voluntad, algo que ha sido subrayado ya por estudios anteriores (Fonseca 103-104). Estas adjetivaciones sobre la mujer no solo se encuentran en la boca del hombre para hablar de ella, sino que la mujer también ya las ha hecho suyas.

En este estudio, la objetivación de la mujer se presenta tanto a nivel de los vídeos como de las letras. La mujer es representada como un adorno del varón, en sobrenúmero en los vídeos, lo que la vuelve anónima y reemplazable: no importa quién está, lo que importa es que estén y que sean bastantes. Adicionalmente, el cuerpo de la mujer se fragmenta en las tomas de cámara, ya que la reducen a un «trozo de mujer» (unas nalgas, unos senos), haciendo lo mismo en las letras al emplear partes anatómicas en reemplazo de la palabra mujer ("a los culos que traigan su cuero»). La mujer en el reggaetón es, así mismo, deshumanizada, al compararla con el diablo o al animalizarla.

Por otro lado, la sexualización de la mujer en el espacio del reggaetón es evidente: se la describe por sus atributos físicos, que son los que la representan, estos atributos se exhiben en los vídeos de hombres y mujeres, las intérpretes femeninas esculpen sus cuerpos para mostrarlos en ropa interior

Feminismo/s 35, junio 2020, pp. 291-320 
o corta. Es evidente cómo las intérpretes a través de sus propios cuerpos representan el modelo femenino estereotipado: cuerpos esculturales, senos y nalgas grandes y perfectos. Todas las intérpretes han pasado por cirugías, y algunas hablan abiertamente de ello: «No quiero que la gente de casa quede mirando a las portadas y hablando '¿por qué no soy así? Y ¡qué vida injusta!' No, solo trabaje, junte su dinero y va a quedar como quiera» (Restrepo). El cuerpo tiene valor en la imagen «siempre cuando sea bello y joven» "y este se representa como un producto social para ser deseado, exhibido, gozado y violentado» (De Toro 94). La sexualización está en el discurso del hombre al describir a la mujer, y en el de la mujer al autodescribirse, asumiendo ambos que el cuerpo sexuado es la parte principal de la identidad desde la cual y sobre la cual comunicar y relacionarse con el otro. La mujer «es objeto de deseo sexual [...] en la medida en que sus atributos físicos siguen siendo el principal requisito para generar una relación afectiva y vinculación con el mundo masculino» (Fonseca 101-102).

Los resultados de este estudio indican que la imagen de «emprendedora sexual» se transmite también en la canciones de reggaetón. Los análisis muestran a una mujer apropiada de un modelo sexualizado, apropiación que se evidencia al mostrar el cuerpo en los vídeos, al perrear, al cantar junto con los intérpretes masculinos canciones que transmiten los mismos modelos, al autodefinirse de la misma manera que las definen los hombres, con un mismo discurso, sin generar nueva categorías descriptivas, sin presentar otros cuerpos, otras maneras de vestirse, otros contenidos que no sean los sexuales y relacionales estereotipados en las canciones. Es de crucial importancia subrayar que esta autobjetivación, según algunos autores, en lugar de empoderar a las mujeres transmite el mensaje de que para el género femenino la única manera de tener éxito en la industria musical es a través de la objetivación de sí mismas (Aubrey y Frisby 496).

Los autores de este estudio concordamos con esta visión y sostenemos que los resultados del análisis muestran que la supuesta «resistencia femenina» en el reggaetón no existe. Lo que es manifiesto en este tipo de música es una propuesta de un modelo de mujer que responde a una estética particular, a una conducta estereotipada, sexualizada, disponible, ligera, que le gusta divertirse. Además, según el hombre del reggaetón, la mujer es poco auténtica con su verdadera naturaleza (la sexual), potencialmente mala y peligrosa, y él

Feminismo/s 35, junio 2020, pp. 291-320 
cede solo en contra de su voluntad. La mujer, en lugar de resistir, toma estas identificaciones y las hace suyas, creyendo «empoderarse» a través de ello, cuando en realidad se moldea a la sugerencia masculina, a sus reglas, límites, conductas y propuestas de relacionamiento; tal como dicen Rodríguez-López y Caldeiro-Pedreira, las mujeres «recogen actitudes tradicionalmente atribuidas a la masculinidad [...] en lugar de crear actitudes propias» (77).

\section{CONCLUSIONES}

En suma, el reggaetón es un espacio esencialmente masculino, en donde lo que se canta, se crea y se transmite representa la visión de un varón sobre lo que es la mujer, independientemente del género del intérprete.

El reggaetón, sin embargo, no es responsable de generar el modelo de mujer sexualizada y objetivada; solo hace lo que otros productos culturales como la publicidad, el cine y otros géneros musicales hacen, transmiten y refuerzan. Las canciones producidas actualmente en el género del reggaetón y que son populares, perpetúan los modelos que obedecen a las leyes del mercado. Como lo subraya Ramos (72) «La música, además de ser una forma de arte, es una industria y un mercado con el objetivo principal de obtener un beneficio»; lo que se vende es lo que se compra y viceversa. La industria de la música es un negocio, que genera miles de millones de dólares y que inculca en audiencias mundiales ideologías dominantes de raza, clase, género, sexualidad y nacionalidad (Hobson y Bartlow, en Ramos 73). Los vídeos que acompañan a las canciones también obedecen a una lógica de mercado: «su objetivo es ayudar a vender una canción y por ello deben recrear un mundo apetecible para el oyente/consumidor deseado» (Guarinos 307).

La representación de la mujer en este género musical es solamente un ejemplo de un fenómeno más amplio que se observa en el mundo del espectáculo, que en las últimas décadas se ha teñido más y más de contenidos sexuales y objetivantes de la mujer. Según Feinman (589-590), estamos en una época en la cual los medios de comunicación ejercen poder sobre el individuo a través del entretenimiento, centrado cada vez más en lo sexual. El género del reggaetón y su popularización entran a formar parte de este juego de sometimiento moderno. 
Los modelos femeninos propuestos por la sociedad posmoderna (y dentro de ellos, los del reggaetón) son incorporados dentro del proceso de construcción de la identidad de las mujeres a través de los mecanismos de identificación. Estos modelos además convergen desde diferentes fuentes hacia uno que los engloba: la mujer del disfrute; la sociedad lo propone y las mujeres construyen identidades del disfrute a través de este modelo, transformándose en mujeres para ser disfrutadas y que tienen que disfrutar el hecho de serlo. En palabras de Guarinos (312): «La mujer sexualizada es un estereotipo pero también un prototipo propuesto por las propias cantantes mujeres para consumidores hombres y que sirven de modelo imitable para consumidoras mujeres».

En conclusión, la nueva imagen femenina no solo construye un ideal del cuerpo, de las actitudes y de la vida sexual de la mujer, sino que transforma internamente a la mujer a través de una subjetivización de su cuerpo, de sus actitudes y hasta de su sexualidad. De todas las consecuencias de la música sexualizada (TFSPM 3-4), en los resultados este estudio se evidencian la autosexualización y autovalidación de la mujer por su imagen física; procesos que van a afectarla durante toda su vida, puesto que se construye internamente y se define externamente con los modelos propuestos, apropiándose de ellos en su cuerpo e imaginario, es decir «convirtiéndose» en lo que la sociedad le va dando como modelo normativo.

La evidencia científica disponible al respecto y reseñada en el informe de la TFSPM (17) apunta a que existe un impacto negativo ya que las mujeres «llegan a percibirse a sí mismas en función de cómo creen que sus cuerpos se parecen a los demás y, por lo tanto, se centran en sus rasgos perceptibles externamente en lugar de sus rasgos internos» (Fredrickson y Roberts, en TFSPM 17). Las consecuencias de esta autobjetivación son dañinas para ellas: sentimientos de vergüenza y ansiedad, incapacidad para experimentar los estados motivacionales y una desconexión entre los cuerpos externos de las personas y sus propias experiencias corporales internas (TFSPM 17).

Con estos antecedentes, y basándonos en lo analizado, concluímos que el reggaetón popular e importado al Ecuador presenta modelos estereotipados de la mujer, a través de sus letras, vídeos y de la imagen de las mujeres intérpretes. La evidencia científica constata que la exposición a cualquier tipo de música sexualizada afecta negativamente a las personas. Se debe resaltar

Feminismo/s 35, junio 2020, pp. 291-320 
Dime lo que escuchas y te diré quién eres. Representaciones de la mujer en las 100 canciones de reggaetón más populares en 2018

el impacto negativo que estos modelos tienen en la construcción interna de las mujeres.

En definitiva, los resultados de este estudio cuestionan seriamente otras posturas (personales, experienciales, de las artistas del reggaetón y de las activistas feministas), que proponen la música sexualizada del reggaetón y su baile como espacios de empoderamiento femenino.

\section{REFERENCIAS BIBLIOGRÁFICAS}

Adams, Terri y Douglas Fuller. "The words have changed but the ideology remains the same. Misoginistic lyrics in rap music». Journal of black studies 36 (2006): 938-957.

Aguilar Barreto, Andrea y Ronal Peñaloza Figueroa. «Reggaetón e identidad sexual: una relación para pensar la política pública en sexualidad». Políticas públicas: desafíos en Colombia y Venezuela. Comps. Modesto Graterol, María Mendoza, Rosemily Graterol, Julio Contreras y John Espinosa. Maracaibo: Universidad del Zulia, 2017. 101-128.

Alcaraz, María. «Fanáticas de mover el culo: twerking y feminismo». Latfem, 2017. Web. 19 marzo 2019.

Aubrey, Jennifer y Cynthia Frisby. «Sexual Objectification in Music Videos: A content analysis comparing gender and genre». Mass communication and society 14 (2011): 475-501.

Braun, Virginia y Victoria Clarke. «Using thematic analysis in psychology». Qualitative research in psychology 3 (2006): 77-101.

Dávila, Verónica. «Acelerando la feminidad en el reggaetón: La chapa que vibra de La Materialista». Perspectives on Reggaeton. Eds. Vigimaris Nadal-Ramos y Dorsía Smith Silva. Puerto Rico: University of Puerto Rico, 2016. 59-66.

De Toro, Ximena. «Métele con candela pa'que todas las gatas se muevan. Identidades de género, cuerpo y sexualidad en el reggaetón». Revista Punto Género 1 (2011): 81-102.

Feinman, José. Filosofía Política del Poder Mediático. Buenos Aires: Planeta, 2013. Feliciano, Omar. «Perrea un feminismo». Animal Político, 2015. 13 enero 2020.

Fonseca, Clara. Dale mi loba que tú eres la killa. Análisis de las marcas valorativas de la imagen femenina en el reggaetón. Diss. Universidad de Cartagena, 2010. Gallucci, María. «Análisis de la imagen de la mujer en el discurso del reggaetón». Opción 55 (2008): 84-100. 
Dime lo que escuchas y te diré quién eres. Representaciones de la mujer en las 100 canciones de reggaetón más populares en 2018

Guarinos, Virginia. «Estereotipos y nuevos perfiles de mujer en la canción de consumo, de la romántica a la mujer fálica». Cuestiones de género: de la igualdad $y$ de la diferencia 7 (2012): 297-314.

Hall, P.Cougar, Joshua West y Shane Hill. «Sexualization in lyrics of popular music from 1959 to 2009: Implications for sexuality educators». Sexuality $\mathcal{E}$ Culture: An interdisciplinary Quaterly 16.2 (2012): 103-117.

Harvey, Laura y Rosalind Hill. «Spicing it up: sexual entrepreneurship and the sex inspectors». New Femininities: Postfeminism, Neoliberalism and Subjectivity Eds. Rosalind Gill \& Christina Scharff. London \& New York: Palgrave, 2011. 52-67.

Horkheimer, Max y Theodor Adorno. Dialéctica de la Ilustración. Fragmentos filosóficos. Madrid: Editorial Trotta, 1998.

Martínez Noriega, Dulce. «Cultura, música y juventud: una reflexión acerca del reggaetón como fenómeno cultural». Cinzontle 7.16 (2015): 18-24.

Negrón-Muntaner, Frances y Raquel Rivera. «Nación Reggaetón». Nueva Sociedad 223 (2009): 29-38.

Noisey Colombia. "El culo como territorio político: asistimos a uno de los Twerkshops de Fannie Sosa». Vice, 2015. Web. 19 marzo 2019.

Pérez-Rufí, José. «Mujeres en el videoclip: la representación de la mujer en los vídeos musicales de Diane Martel». Prisma social n. ${ }^{\circ}$ especial 2 (2017): 202-232.

Ramos, Isabel. "'A ella le gusta agresivo': An analysis of the negative representation of women in reggaeton songs». Social Eyes 6 (2015): 67-75.

Redacción El Comercio. "Estas fueron las canciones más escuchadas en Ecuador en el 2018». El Comercio, 2018. Web. 13 enero 2020.

Restrepo, Wendy.«No niega sus cirugías, así se veía Anitta antes de pasar por el quirófano». Colombian, 30 de Octubre 2018.

Rivera, Raquel. «Perreo \& Power: Explicit Sexuality in Reggaeton Dance». Ponencia presentada en la Conferencia de la Asociación de Estudios Latinoamericanos en Río de Janeiro, Brasil, 2009. 19 de marzo 2019. <https://drive.google.com/ file/d/1kq7VpUXmCWGJ7DWRauR02bhcRCU-k84F/view>

Rodríguez-López, Jennifer y Mari Carmen Caldeiro-Pedreira. «Divas clip: la imagen actual de la mujer en el video musical». Temas de comunicación 31 (2015): 59-80.

Rodrigues Morgado, Carolina. «Reggaetón, mujeres e identidades: "yo quiero bailar... eso no quiere decir que pa' la cama voy”». Diss. FLACSO, 2012. 
Rodríguez Rivera, Ángel. «Acumulación subalterna: cultura, clase, raza y reggaetón». Perspectives on Reggaeton. Eds. Vigimaris Nadal-Ramos y Dorsía Smith Silva. Puerto Rico: University of Puerto Rico, 2016. 26-38.

Sedeño, Ana María. «El cuerpo del cantante en los videoclips: una propuesta de análisis textual». Ponencia presentada en el IV Congreso latinoamericano de investigadores de la Comunicación en Santa Cruz de la Sierra, Bolivia, 2002. <https://studylib.es/doc/239614/el-cuerpo-del-cantante-en-los-videoclips>

Sprankle, Eric, Christian End y Miranda Bretz. «Sexually degrading music videos and lyrics». Journal of media psychology 24 (2012): 31-39.

Task Force on the Sexualization of Popular Music. Washington, D.C.: Division 46 (Society for Media Psychology \& Technology) of the American Psychological Association, 2018.

Unidad Editorial Información Deportiva. «Ocho de las diez canciones más escuchadas en YouTube en 2018 fueron en español», 6 de Diciembre 2018.

Vernallis, Carol. «The functions of lyrics in music video». Journal of Popular Music Studies 14 (2002): 11-31. 
To link to this article / Para enlazar con este artículo:

https://doi.org/10.14198/fem.2020.35.12

To cite this article / Para citar este artículo:

De Riba Mayoral, Silvia. "(Seguir) teorizando los afectos y las emociones en la investigación educativa desde enfoques feministas». En Feminismo/s, 35 (junio 2020): 321-338. DOI: 10.14198/fem.2020.35.12

\title{
(SEGUIR) TEORIZANDO LOS AFECTOS Y \\ LAS EMOCIONES EN LA INVESTIGACIÓN EDUCATIVA DESDE ENFOQUES FEMINISTAS
}

\author{
(TO KEEP) THEORIZING AFFECTS AND EMOTIONS IN \\ EDUCATIONAL RESEARCH FROM FEMINIST APPROACHES
}

\author{
Silvia DE RIBA MAYORAL \\ Universidad de Barcelona, Barcelona \\ sderiba@gmail.com \\ orcid.org/0000-0003-4494-0371
}

\section{Resumen}

Durante las últimas décadas, el debate sobre los conceptos emoción y afecto se ha introducido transdisciplinariamente en investigación, afectando al campo educativo. El objetivo de este artículo es examinar la discusión partiendo de enfoques feministas y desde la experiencia de la investigación Hacia una pedagogía afectiva del movimiento, apoyada en la metodología de Investigación Basada en las Artes desde una perspectiva Feminista Nuevo Materialista. A partir de la generación de los dispositivos visuales realizados por tres grupos del Centro Tariqa y la Escuela Drassanes de Barcelona, se detecta la necesidad de considerar la distinción ontológica entre emoción y afecto. Mientras el afecto permite acceder a los procesos de aprendizaje, la emoción puede limitar las sensaciones a significados culturales. El artículo reclama seguir problematizando el debate y concluye apuntando la necesidad de aportar el potencial del giro afectivo a la investigación educativa para repensar onto-episte-metodologías.

Palabras clave: afecto; emoción; investigación educativa; Investigación Basada en las Artes; feminismo. 


\begin{abstract}
During the last decades, the discussion about the concepts affect and emotion has been introduced in research in a transdisciplinary way affecting educational research. The objective of this article is examining this discussion from feminist approaches and collecting the research experience Towards an affective pedagogy of movement. This research used an Arts Based Research methodology from a Feminist New Materialist perspective. In it, 3 groups of students of Tariqa Center and Drassanes School of Barcelona generated visual devices. The research results underline the need of accounting the ontological distinction between emotion and affect. While affects enable examining the processes of the learning experience, emotion can limit sensations to cultural meanings. The article claims to continue problematizing the debate about the concepts of affect and emotion and concludes underlining that more efforts should be made to enhance the potential of the affective turn in educational research, making possible to rethink onto-episte-methodologies.
\end{abstract}

Keywords: Affect; Emotion; Educational Research; Arts Based Research; Feminism.

\title{
1. INTRODUCCIÓN
}

Durante las últimas décadas, una gran cantidad de líneas de investigación se han centrado en las posibilidades que proporcionan los conceptos de emoción y afecto (Ahmed; Colman; Fox; Hickey-Moody; Illouz; Revelles-Benavente). Diferentes disciplinas, como la pedagogía o las artes, han incorporado estos conceptos en sus procesos de investigación para comprender la complejidad de su impacto en las dinámicas del mundo. Estos conceptos han sido influyentes en tanto que han generado nuevos debates que problematizan y repiensan su significación. En estas discusiones que traspasan disciplinas y generan nuevos modos de pensamiento, han surgido varias perspectivas onto-epistemológicas sobre la comprensión de los conceptos emoción y afecto. Por ejemplo, dependiendo de la genealogía utilizada, se pueden ver líneas de pensamiento como las que entienden estos términos como sinónimos u otras perspectivas que los separan ontológicamente. El propósito de este artículo es explorar cómo el debate contemporáneo sobre el afecto y la emoción se encarna en una investigación educativa y cómo esto puede generar nuevas perspectivas. Esta iniciativa surge fruto de una revisión de la investigación Hacia una pedagogía afectiva del movimiento. Esta investigación fue llevada a cabo en el Trabajo Final de Máster tutorizado por Beatriz Revelles-Benavente

Feminismo/s 35, junio 2020, pp. 321-338 
dentro del programa de Artes Visuales y Educación: Un enfoque construccionista realizado en la Universidad de Barcelona durante el curso 2017-2018. El objetivo era explorar, a partir de una situación pedagógica de movimiento, qué significa una pedagogía afectiva del movimiento y qué posibilidades brinda a la educación. En concreto, se examinaba: 1) cómo circulan los afectos en una situación pedagógica de movimiento; 2) qué papel tienen los afectos en las transformaciones vividas para propiciar el aprendizaje; 3) cómo se traducen los afectos en un lenguaje material y qué potencialidad pedagógica tiene este proceso. En el presente artículo, pues, se busca retomar esta investigación desde la necesidad de abordar el debate sobre los conceptos de afecto y emoción en el campo de la educación.

Para llevarlo a cabo, primero se examinan las distintas líneas de comprensión del afecto y la emoción a partir del conocimiento generado desde enfoques feministas. Después, se mapean los conocimientos sobre pedagogía afectiva surgidos a través de la metodología de Investigación Basada en las Artes desde una perspectiva Feminista Nuevo Materialista aplicada en Hacia una pedagogía afectiva del movimiento (Autora). A partir de los resultados y las conclusiones de la investigación, se pone en relación las tensiones y los encuentros de los conceptos emoción y afecto explorados en la fundamentación. Así, en la discusión se problematiza el debate sobre afecto y emoción desde la experiencia empírica de la investigación, no para buscar respuestas concretas al debate, sino para examinar sus distintos ejes al repensarlo desde la práctica y la investigación educativa.

\section{FUNDAMENTACIÓN}

\subsection{La teoría del afecto}

El giro afectivo de los años noventa permite comprender el afecto desde diferentes perspectivas. Este giro fue inspirado por el concepto de afecto introducido por Spinoza en su obra Ética y recogido más tarde por Massumi, Deleuze y Guattari. Sin embargo, como se ha apuntado anteriormente, la teoría del afecto se distingue en función de la genealogía que se utilice. Siguiendo el trabajo de investigadoras feministas como Hickey-Moody, Revelles-Benavente o Colman, el afecto es una fuerza invisible que cambia los cuerpos en su 
relación: el afecto es la materialización de la capacidad de un cuerpo para cambiar y aumenta o disminuye la capacidad de actuar. Como describe Hickey-Moody:

El afecto es el concepto de asumir algo, de cambiar en relación a una experiencia o encuentro [...] En Spinoza, la Filosofía Práctica Deleuze (1998) describe el afecto como un aumento o disminución del poder de actuar, tanto para el cuerpo como para la mente. Expande esta definición argumentando que el afecto es diferente de la emoción. El afecto es la virtualidad y materialidad del aumento o disminución del poder de acción de un cuerpo [...] El afecto es la materialidad del cambio: 'el paso de un estado a otro' que ocurre en relación con ‘afectar a los cuerpos' (259) ${ }^{1}$.

Los afectos son fuerzas invisibles que circulan a través de los cuerpos, humanos y no humanos, en su relación con el mundo. De esta manera, los afectos se pueden definir como fuerzas invisibles y relacionales que permiten las transformaciones del cuerpo, siendo potencialmente pedagógicos por la posibilidad de devenir que proporciona a los cuerpos. Al ser invisibles, «todo lo que tenemos es su rastro (experimentamos 'momentos pasajeros'). Si el afecto 'es' precisamente la experiencia presente, se podría decir que todo lo que tenemos es una especie de eco» (Man et al. en O'Sullivan 126).

Así, el concepto de afecto proveniente de esta perspectiva forma parte de una ontología relacional en la que la realidad se entiende como un flujo de fuerzas en constante transformación (Deleuze en Baugh, Experimentation 94). Esta perspectiva se caracteriza por ofrecer una visión monista del mundo, donde las dicotomías como mente y cuerpo se desdibujan: desde esta ontología relacional, el cuerpo está siempre en movimiento y en contacto con el mundo. Está definido por las fuerzas en relación con los cuerpos humanos y no humanos (Deleuze en Baugh, Body 35). Por lo tanto, el cuerpo es entendido por su potencialidad de afectar y ser afectado, la cual aumenta cuando este cuerpo está en movimiento (Ahmed 56): el movimiento del cuerpo permite intensificar las experiencias e ir a su potencial. Por ende, la naturaleza relacional del afecto tiene la virtud de reconfigurar ontologías, epistemologías, la ética y metodologías de investigación.

1. Las citas de este artículo están traducidas por la autora.

Feminismo/s 35, junio 2020, pp. 321-338 
Sin embargo, como se mencionó anteriormente, existen diferentes perspectivas sobre la comprensión de la naturaleza del concepto de afecto dependiendo de los referentes teóricos recogidos. Apuntando concretamente los distintos enfoques feministas, se puede ver que se encuentran feministas contemporáneas (Colman; Hickey-Moody; Revelles-Benavente) que entienden la emoción y el afecto como conceptos diferentes y pertenecientes a una lógica distinta (Massumi 88), tal como se ha mostrado en los párrafos anteriores. Por otro lado, otras académicas e investigadoras feministas (Ahmed; Vidiella, Espacios) definen la emoción y el afecto como sinónimos o como términos borrosos entre sí. La siguiente sección del artículo tiene como objetivo explorar los diferentes puntos de vista relacionados con este debate para seguir pensando a través de las contribuciones feministas aportadas en este campo.

\subsection{En el debate contemporáneo sobre emociones y afectos}

Vidiella (Archivos encarnados) define la emoción desde una perspectiva muy similar de lo que entiende por afecto. Ella toma el origen latino de la palabra: emovere. Al hacerlo, afirma que la emoción «implica movimiento, acción, conexiones y contacto» (Archivos encarnados 17) y es una manera cotidiana de entender el mundo. Sobre esta base, la emoción que define Vidiella se asemeja al concepto de afecto: es una transformación relacional que no es individual, sino que se produce en contacto a través de los cuerpos. Sin embargo, afirma que las emociones no son solo estados individuales, sino «construcciones culturales que forman parte de nuestro vocabulario» (Vidiella, Archivos encarnados 16).

La conceptualización de la emoción y el afecto que ofrece Vidiella se extiende ampliamente en los círculos feministas. En el libro Cultural Politics of Emotion, Ahmed muestra un enfoque similar a la autora anterior al utilizar ambos conceptos indistintamente: «Después de todo, las emociones se mueven, aunque no se muevan simplemente entre nosotros. Por supuesto, las emociones no son solo movimiento, sino también apegos o lo que nos conecta con esto o aquello» (11).

Las emociones aquí se refieren a la circulación de las fuerzas relacionales que permiten el movimiento y la acción, cosa que puede remitir al concepto de afecto apuntado anteriormente. De hecho, en la introducción del libro, 
Ahmed da cuenta de que no está respondiendo qué son las emociones sino qué hacen las emociones. Al hacerlo, rastrea cómo circulan las emociones entre los cuerpos, examinando «cómo se 'pegan' y cómo se mueven» (4). Sin embargo, Ahmed afirma que las emociones no son individuales ni sociales, sino que se producen en los límites de las mismas, generando la superficie de los objetos individuales y sociales (10). Entonces, Ahmed propone entender las emociones como relacionales e inregistrables (194), lo cual se asemeja a la definición del afecto aportada en el apartado anterior. Al mismo tiempo (como también sostiene Vidiella) afirma que las emociones son culturalmente mediadas.

Recogiendo la entrevista de Schmitz a Ahmed (Schmitz y Ahmed), Ahmed afirma que utiliza el concepto de emoción porque está interesada en la idea de movimiento que es explícita en su etimología, así como porque es una palabra que usamos en la vida cotidiana. Ahmed argumenta (refiriéndose al debate afecto-emoción) que no quiere dividir teóricamente algo que no tiene una distinción natural: «el mundo que estamos describiendo es desordenado -si tenemos distinciones claras estamos perdiendo nuestra conexión con ese mundo» (Schmitz y Ahmed 98-99). Si bien es cierto que al definir de manera encorsetada podemos caer en desatender la complejidad del mundo, la distinción entre afecto y emoción desde la perspectiva de este artículo no parte de una necesidad de simplificar aquello complejo, pero sí de situar las diferencias ontológicas entre ambos conceptos en tanto que implican un impacto y unas repercusiones en cómo investigamos y cómo nos relacionamos con nuestros campos de estudio. Entonces, la cuestión es: ¿cuáles son las consecuencias de la mediación social de la emoción al entenderla como sinónima del afecto? ¿Al enredar el afecto y la emoción disminuimos la potencialidad intrínseca del concepto de afecto?

Desde la genealogía del afecto referida al inicio del artículo, la posición que desdibuja el afecto con la emoción puede ser problemática. Por una parte, la emoción rompe con la continuidad para registrar un estado ya sentido en tanto que es «un elemento narrativo que mueve la acción hacia adelante, ocupando su lugar en las líneas de acción y reacción socialmente reconocidas» (Massumi 86). Por otra parte, como los afectos son experienciales, invisibles y solo podemos ver su rastro, estos no pueden ser parte de nuestro vocabulario en tanto que hay una imposibilidad en su reconocimiento social

Feminismo/s 35, junio 2020, pp. 321-338 
y cultural (esto muestra una problemática en cómo acercarnos a los afectos en una investigación sin colonizar las relaciones afectivas, una cuestión que en este artículo no tiene cabida pero que es necesario resaltar). Entonces, mientras que las emociones pueden ser visibles y socialmente reconocidas, el afecto es una fuerza experiencial que circula siempre a través de los cuerpos humanos y no humanos. Por esta razón, los afectos no pueden ser mediados sino examinados en su eco. Así, si existe una perspectiva feminista que separa los afectos de las emociones es precisamente porque las emociones pueden ser categorizadas, entendiéndolas como instrumentos y categorías sociales preestablecidas (Illouz).

Enfatizando esta idea, se siguen las aportaciones del concepto de emoción que Illouz da en su libro Intimidades congeladas. La formación del capitalismo emocional. Ella argumenta que la emoción es una energía interna que nos mueve a actuar y que forma parte de los significados culturales. Así, la emoción es a la vez psicológica, cultural y social ya que se define a través de ella (15-16). Illouz explica que, al definir las emociones a través de categorías sociales, hacemos de las emociones objetos encerrados que podemos observar y manipular. Entonces, las emociones pueden configurarse como una economía mercantil (80) que clasificamos y cuantificamos (143). Desde este punto de vista, podemos asentar las emociones en una jerarquía organizada a través de una perspectiva moral y social particular, guiando la acción a través de un conocimiento cultural concreto (15-17). Por lo tanto, la emoción puede ser un instrumento de la política neoliberal para simplificar la complejidad de las relaciones, intensidades y flujos. Esta perspectiva nos permite pensar en el compromiso ético que supone distinguir los conceptos de emoción y afecto. Entendiendo los riesgos que supone hablar de emoción, es necesario que al pensar a través de ellas en una investigación o en la praxis educativa se tome en consideración los componentes políticos, culturales y sociales que esta comporta.

Reduciendo la compleja tensión de estos debates, Fox introduce unas aportaciones que abren nuevas perspectivas a esta discusión:

La emoción [es] una experiencia subjetiva, encarnada y afectiva, [es] la capacidad de un cuerpo, cosa o colectividad para afectar o ser afectado, un 'volverse otro' (Deleuze y Guattari 1988, p. 400). Consecuentemente, mientras que las emociones y los sentimientos pueden ser afectos (que producen

Feminismo/s 35, junio 2020, pp. 321-338 
estados de cuerpos o mentes), solo una minoría de los afectos son emociones o sentimientos (11-12).

A partir de esta distinción, Fox propone tomar las emociones como parte integrante del flujo afectivo (16). Es decir, parafraseando a Fox, la emoción no es un vínculo perdido entre lo biológico y lo social, sino que forma parte del enredo donde los cuerpos son afectados y afectan de manera física, psicológica y social:

El hecho de que una emoción se «sienta» no la diferencia de otras formas en que los cuerpos se ven afectados por otros cuerpos, cosas o ideas. [...] La importancia de una emoción no es como una respuesta corporal a un evento, sino como una capacidad de afectar (Fox 14).

Entonces, se puede entender que las emociones tienen la capacidad de afectar, posibilitando ser partícipes en los flujos afectivos y modificando el poder de actuación de los cuerpos. Aun así, se entienden desde una lógica distinta de los afectos, aunque pueden ser parte de los tránsitos afectivos. Para detallar: estando las emociones enredadas en las relaciones afectivas del mundo, afecto y emoción solo caminan conjuntamente siendo la emoción una posibilidad de los flujos afectivos que conectan las experiencias y que forman parte de una dinámica global mucho más compleja. Y, sin embargo, la problemática de la mediación cultural y social de las emociones sigue presente y puede suponer un riesgo para nuestra práctica.

\section{METODOLOGÍA: PARTIENDO DE UNA INVESTIGACIÓN BASADA EN LAS ARTES DESDE UNA PERSPECTIVA NUEVO MATERIALISTA}

La necesidad de dar cuenta de la compleja relación teórica de las emociones y los afectos se reafirma al llevar esta discusión a una investigación educativa. Como aclama Fox, es importante estudiar empíricamente los flujos afectivos y las capacidades para hacer y sentir, que en conjunto producen un desarrollo de la vida social y la historia humana (17) y, por lo tanto, debemos ser conscientes de cómo se usan de manera empírica las emociones y los afectos en la investigación educativa. Al olvidar la mediación social y cultural de las emociones, se puede correr el riesgo de subestimar la tendencia de algunas metodologías y prácticas educativas a encerrar y categorizar aquello 
que investigan, en este caso los afectos, produciendo una disminución de su capacidad de generación de conocimiento.

Retomando la experiencia de Una pedagogía afectiva del movimiento, los siguientes apartados del artículo tienen como objetivo repensar cómo este debate afecta a la práctica. Para ello, se recogen los conocimientos de la anterior investigación para profundizar en la discusión desde lo empírico. Para contextualizar, en Una pedagogía afectiva del movimiento se usaba una metodología de Investigación Basada en las Artes (VV.AA) desde una perspectiva Nuevo Materialista (Fox y Alldred) para ver los flujos afectivos entre los elementos involucrados en la investigación que ocurrían cuando los conjuntos de investigación se hibridaban con conjuntos de eventos convirtiéndose en un evento en conocimiento (411). Además, la Investigación Basada en las Artes proporcionaba la posibilidad de atender a visiones de la experiencia que no podrían ser generadas de otra manera, entendiendo el conocimiento surgido de la experiencia de los flujos afectivos como parcial y situado (VV.AA 1). Al ser el arte un sitio de circulación de afectos (Deleuze y Guattari), esta metodología permitía materializar las fuerzas del cambio y romper los límites del conocimiento de la experiencia, enredándose con la materia, los contextos y las ideas.

En concreto, esta metodología de investigación se focalizó en la generación de dispositivos visuales como práctica artística que permitía materializar los movimientos y los afectos que se habían vivido en una sesión de psicomotricidad. Como se ha apuntado anteriormente, el objetivo era examinar, a través del proceso de creación, qué significa una pedagogía afectiva del movimiento y qué posibilidades ofrece a la educación, abordando 1) cómo circulan los afectos en una situación pedagógica de movimiento; 2) qué papel tienen los afectos en las transformaciones vividas para propiciar el aprendizaje; 3) cómo se traducen los afectos en un lenguaje material y qué potencialidad pedagógica tiene este proceso.

Los y las participantes de la investigación fueron el alumnado de dos grupos del Centro Tariqa (grupos de entre 3 y 4 personas; un grupo se caracterizaba por tener participantes de entre 7-10 años y otro de 10-13 años) y de un grupo-clase de 19 niños y niñas de primero de primaria (6 años) de la Escuela Drassanes de Barcelona. Concretamente, a estos grupos se les pidió que, después de realizar una sesión de psicomotricidad de una hora 
de duración, reflejaran a través de un dispositivo visual sus momentos de intensidad vividos durante esta sesión. Durante la creación, los participantes mostraron las conexiones y las relaciones surgidas en su movimiento. Así, los resultados de la investigación no fueron los dispositivos visuales generados por los niños y las niñas. Por el contrario, se obtuvieron a través de la reflexividad que surgió de la generación del dispositivo visual. Entonces, el conocimiento de esta investigación se construyó a través de relaciones surgidas del proceso de producción y permitió apuntar miradas sobre el potencial pedagógico del afecto en una situación de movimiento.

\section{RESULTADOS DE HACIA UNA PEDAGOGÍA AFECTIVA DEL MOVIMIENTO}

Para poner detalle al conocimiento referente a una pedagogía afectiva surgido como resultado de la investigación:

1. La circulación de afectos en la situación pedagógica de movimiento. Durante el proceso de generación de los dispositivos visuales, se hizo evidente que habían circulado afectos durante el movimiento. En el caso de Drassanes, no hubo una dificultad para recordar los momentos afectivos y plasmarlos en el papel. En el caso del grupo de 7 a 10 años de Tariqa, los participantes no dejaron de estar estimulados por la circulación de afectos. En el grupo de participantes de entre $10 \mathrm{y}$ 13 años de Tariqa, la circulación de afectos estaba presente pero los participantes se negaron a compartir.

2. El papel y la capacidad de retención de los afectos en las transformaciones. A través de la creación, se demostró la posibilidad de retener los afectos y materializarlos a partir del arte. En el caso de Drassanes, se mostró más facilidad para expresarlos con el dispositivo visual que en palabras. En el grupo de 10-13 años de Tariqa, los participantes estuvieron en constante afectación durante la creación, lo cual no permitió que estos pudieran explorar si los afectos del movimiento se habían retenido. En el caso del grupo de Tariqa de 10 a 13 años, no se pudo afirmar cómo se habían retenido los afectos y qué transformaciones habían ocurrido en el proceso de movimiento, ya que no había una voluntad para compartir de manera gráfica las afectaciones vividas.

Feminismo/s 35, junio 2020, pp. 321-338 
3. La traducción de los afectos en un dispositivo visual. En Drassanes, se pudo ver que el grupo de participantes generó nuevas imágenes relacionadas con lo vivido (Hickey-Moody 261). Es decir, no figuraban literalmente el momento afectivo sino que se permitían reinterpretalo para generar nuevos mundos y posibilidades. En Tariqa, el grupo de 7 a 10 años atendió con ilusión la propuesta, pero hubo una dificultad en la creación: sus dispositivos visuales finales retienen su constante vivencia de intensidad. En el caso del grupo de 10 a 13 años, cada participante se adentró en distintos estados generando nuevos trazos afectivos.

\section{CONCLUSIONES DE HACIA UNA PEDAGOGÍA AFECTIVA DEL MOVIMIENTO}

A partir del análisis de los resultados de la investigación, las conclusiones relativas a los objetivos de significar una pedagogía afectiva del movimiento y las posibilidades que brinda a la educación, fueron las siguientes:

1. Los afectos son parte inherente de una situación pedagógica de movimiento. Al poner el cuerpo en relación con otros cuerpos en un espacio de aprendizaje como las sesiones psicomotrices de la escuela Drassanes y el centro Tariqa se observó cómo este se ve afectado por las relaciones materiales y transformado en sus distintas formas según su especificidad. Sin embargo, para acceder a ellos parece necesario contar con más tiempo de exploración.

2. En el proceso de creación de dispositivos visuales se pudo ver diferentes maneras en que el afecto había circulado y transformado a los cuerpos. En el caso de Drassanes se detectó cómo las transformaciones y aprendizajes provenían de unos afectos producidos en relación. La fuerza de este afecto permitió que los cuerpos de los participantes pudieran recoger aquel momento vivido para reinterpretarlo en un dispositivo visual. Por otro lado, en los casos de los grupos de Tariqa los flujos afectivos del movimiento conllevaron un movimiento difícil de frenar, imposibilitando acceder a aquellos momentos de impresión por una incansable afectación. 
3. La metodología de Investigación Basada en las Artes permitió romper el pensamiento lineal para poder acceder a los afectos y construir nuevos relatos:

- Se pudo ver lo que un cuerpo puede hacer en una situación localizada de aprendizaje. En el caso de Drassanes, los afectos de los cuerpos en movimiento fueron materializados. En el caso de Tariqa, se vió la dificultad por atender los tránsitos afectivos en una situación pedagógica de movimiento.

- La creación visual permitió acercarse a los afectos y reconfigurar el evento, convirtiéndose en un movimiento diferente hacia nuevos tránsitos. En el caso de Drassanes recogieron aquellos momentos relacionales con los/as compañeros/as y/o elementos materiales. En el caso de los niños de Tariqa, hubo disonancias entre aquello vivido y aquello trazado, generando algo totalmente nuevo. Es decir, el material visual no era una traducción figurativa de los momentos de intensidad, sino una reconfiguración de los afectos y las transformaciones.

- A través de la generación de los dispositivos visuales, encarnaron los afectos del movimiento y se impresionaron produciendo transformaciones. Es decir, se retuvieron los momentos afectivos y se exploraron a partir de la creación visual, repensado las afectaciones y la relación con el mundo.

\section{DISCUSIÓN: DEBATIR LAS EMOCIONES Y LOS AFECTOS EN UNA INVESTIGACIÓN EDUCATIVA}

Partiendo de los resultados de la investigación, este apartado tiene el objetivo de atender qué se puede entender por pedagogía afectiva y problematizar qué puede ocurrir al hablar de emoción en el campo de la educación de una manera indistinta con el concepto de afecto. No se buscan respuestas únicas, pero sí llevar al terreno de la educación el debate sobre afecto-emoción fundamentado por las distintas aportaciones teóricas y experiencias empíricas recogidas en este artículo.

Por una parte, una pedagogía afectiva entiende que: 
- Los afectos que surgen de la experiencia tienen la capacidad de retenerse en un cuerpo y transformarlo (Deleuze y Guattari en HickeyMoody 261) en nuevas formas materiales como pueden ser los dispositivos visuales. Entonces, los afectos se materializan de distintas maneras a través de las artes visuales en tanto que la relación entre arte y afectos es intrínseca (Deleuze y Guattari) y facilita los procesos de transformación y aprendizaje. Aunque los afectos son una fuerza invisible y solo podemos ver su eco, la creación artística posibilita aproximarse a una experiencia afectiva en tanto que va más allá del lenguaje. Además, los dispositivos visuales hacen fluir nuevas relaciones afectivas que posibilitan que la experiencia siga modificando la capacidad para actuar de los participantes, hecho que nos remite al potencial pedagógico de los afectos.

- Los afectos son específicos en cada cuerpo (Camps 74) y permiten procesos de aprendizaje que son singulares en la vivencia de cada experiencia. Eso nos recalca la necesidad de atender al potencial de cada cuerpo, guiándonos hacia una visión de generar relaciones pedagógicas basadas en la horizontalidad de las prácticas llevadas a cabo. Entonces, al entender la lógica relacional del afecto, las jerarquías pueden hacerse borrosas para prestar atención a las relaciones pedagógicas horizontales, a los procesos y a los movimientos.

- La pedagogía afectiva puede cambiar las prácticas pedagógicas hegemónicas en tanto que asisten a los procesos y a las relaciones. Proponen dejar de buscar los resultados para atender a la globalidad y la singularidad de cada experiencia, poniendo en el punto de mira las relaciones surgidas en relación al contexto de aprendizaje a la misma vez que dando cuenta de aquellos procesos que transforman, o no, dentro de una práctica pedagógica.

- Una pedagogía afectiva puede desdibujar la dualidad entre cuerpo y mente. Comprendiendo que el afecto remite a una ontología monista, cuerpo y mente son parte de una misma relación afectiva, participando en los procesos pedagógicos por igual y dejando de lado la jerarquía cartesiana que propone la mente en una posición superior a la del cuerpo. De hecho, es el cuerpo en movimiento el que permite intensificar la vivencia de las relaciones afectivas. Así pues, desde una 
pedagogía afectiva, el aprendizaje se entiende como una experiencia corpórea en la que los cuerpos están siempre en devenir, modificándose con el mundo e intensificando la experiencia, entendiendo la «materialidad del conocimiento» (Vidiella, Espacios y políticas culturales 81).

- Una pedagogía afectiva propone aprender a través de eventos localizados que permiten la transformación de la subjetividad (HernándezHernández 16). Son eventos concretos, y es a partir de la contextualización de estos que florece el conocimiento de lo que permiten las relaciones afectivas. Son estos eventos donde las distintas intensidades de los cuerpos en movimiento afectan para transformar y permitir el aprendizaje, proporcionando nuevas capacidades de actuación.

Por otra parte, desde esta onto-episte-metodología afectiva, y recogiendo las contribuciones feministas sobre el debate con la emoción, se entiende que en una investigación educativa se debería tener en cuenta que:

- Tal y como apunta Illouz, acercarse a las emociones puede tener el riesgo de buscar un significado culturalmente definido de las sensaciones que los niños y las niñas viven dentro de los procesos de aprendizaje. Por ejemplo, al plantear qué emociones han vivido los participantes y proponer materializarlas a través del arte, es necesario ser consciente de la definición de emoción que utilizamos. Pero, ¿cómo definirlo? ¿Quién tiene que definirlo? ¿Cómo hacerlo sin generar jerarquías entre profesor/a o investigador/a y alumnado? ¿Existe una manera de hacerlo sin limitar las posibilidades de las sensaciones de los y las participantes o imponer una visión cultural concreta de cada emoción? Si no es así, caemos en el riesgo de seguir generando fronteras y jerarquías entre profesores/as, investigadores/as y estudiantes, dejando a un lado la potencialidad de la perspectiva monista de la ontología afectiva que permite pensar en las relaciones horizontales.

- Se puede tomar la pregunta de Ahmed sobre qué hacen las emociones en una investigación educativa para ver los flujos de sensaciones y los distintos contactos con el mundo. Sin embargo, al ir al campo de trabajo, ¿puede una escapar de la definición cultural de las emociones que organizan nuestros sentimientos en una lógica de causa 
y efecto? Esto nos haría alejarnos del potencial relacional del afecto y nos haría vincularnos con una lógica que pierde el punto medio, es decir, los procesos que permiten entender el mundo desde nuevas perspectivas. Nos desvincularía, pues, de todos aquellos momentos de transformación que proporcionan aprendizaje.

Desde la onto-episte-metodología de este artículo, el uso de las emociones en una investigación educativa relacionada con el movimiento puede tener el riesgo de evaluar las emociones a través de una clasificación caracterizada por el dualismo de bien y mal. Buenas emociones, malas emociones. Buenos alumnos y alumnas, malos alumnos y alumnas. Además, esta clasificación se generaría desde una posición cultural y política concreta, dejando a un lado la posibilidad de atender a la especificidad de cada cuerpo, sus relaciones y sus transformaciones contextualizadas dentro de un evento de aprendizaje. Es decir, al jerarquizar las emociones, promoveríamos pedagogías desiguales donde el alumnado sería clasificado desde un saber cultural concreto, dejando a un lado las relaciones pedagógicas horizontales. Además, al limitar las transformaciones corporales a las definiciones culturales, podríamos perder la oportunidad de explorar las relaciones entre los cuerpos y sus devenires. No solo los humanos, sino también los cuerpos no humanos, ya que se debería empezar a pensar lejos de las visiones antropocéntricas del aprendizaje. Entonces, al categorizar las emociones perdemos la posibilidad de estar atentos a los flujos afectivos y a la complejidad del proceso de aprendizaje. Es decir, el uso de las emociones puede limitar la exploración de procesos, movimientos y relaciones entre cuerpos. En un mundo en constante cambio, el aprendizaje debería alejarse de las categorías construidas socialmente.

\section{APERTURAS}

Este artículo ha revisado las aportaciones de la teoría de los afectos proporcionadas por el giro afectivo iniciado en los años noventa de la mano de Massumi, Deleuze y Guattari, guiados por la filosofía de Spinoza. En él, se han explorado las distintas perspectivas de comprensión del concepto de afecto y su relación con el concepto de emoción, mostrando las tensiones entre las distintas líneas de contribuciones teóricas del pensamiento feminista. En concreto, se ha mostrado el debate contemporáneo de la relación entre el concepto 
emoción y afecto. Por una parte, hay una perspectiva que reclama el uso del concepto de emoción como sinónimo de afecto para su mayor comprensión en la cotidianeidad y, por otro lado, existe una perspectiva que aclama la necesidad política, cultural y social de mantener estos conceptos en lógicas distintas para poder seguir pensando desde las posibilidades de una ontología monista y relacional. Con el objetivo de problematizar este debate dentro del campo educativo, se han recogido los resultados de la investigación Hacia una pedagogía afectiva del movimiento para poner el debate dentro de la praxis y argumentar las tensiones que surgen al desdibujar el afecto con la emoción.

Para concluir, este articulo tiene la intención de abrir nuevos caminos para seguir pensando y problematizando cómo afecta utilizar conceptos como emoción o afecto en una investigación educativa. De hecho, como se ha argumentado en el texto, la inherente capacidad del afecto de cambiar los cuerpos en su relación, también proporciona modificar la forma en que investigamos, aprendemos y enseñamos. Al difuminar la definición del afecto con la emoción, podríamos estar perdiendo los procesos y movimientos de la experiencia y la posibilidad de generar conocimiento sobre el campo educativo través de un pensamiento relacional.

Aunque hooks argumenta que el feminismo académico ha creado una jerga no accesible para todos los públicos con el objetivo de legitimar el pensamiento feminista (22), la introducción de nuevos conceptos en el campo educativo permite nuevos pensamientos y nuevas formas de ver el mundo, lejos de las limitaciones de las categorías reduccionistas (Schulte 146). Además, el uso de nuevas palabras tiene el objetivo de dejar a un lado lo sucio de las palabras antiguas (Schmitz y Ahmed 98). En este punto, parece mucho más efectivo pensar a través del afecto que tratar de cambiar la mediación cultural de las emociones. Sin embargo, reflexionando a partir de la contribución de hooks, se debe hacer esfuerzos para llevar el concepto de afecto a la vida cotidiana o, al menos, al campo de la investigación educativa. Solo así parece posible que la pedagogía afectiva afecte nuestras prácticas educativas a la vez que nos dejamos afectar por ellas. Al hacer esfuerzos para seguir repensando cómo aportar el potencial del giro afectivo en los lugares de aprendizaje es posible modificar prácticas e incrementar nuestra capacidad de actuación.

En resumen, pensar a través del afecto en una investigación educativa es una tarea compleja. Nos lleva a la incertidumbre de las relaciones y procesos 
pedagógicos. Además, el afecto necesita seguir siendo experimentado a través de métodos y prácticas. Sin embargo, es precisamente la apertura del afecto lo que lo hace tan poderoso. Es el poder de transformar los cuerpos y las relaciones. Es el potencial para ver la complejidad de los eventos. Es la posibilidad de repensar las ontologías, epistemologías y metodologías, así como la experiencia dentro del campo educativo. Los afectos facilitan prestar atención al medio excluido ya que conecta lo que normalmente está separado (Massumi 85): las transformaciones de los cuerpos, los movimientos y procesos relacionales que cambian las formas de entender la investigación educativa, los eventos de aprendizaje y la generación de conocimiento. Por lo tanto, como afirma Massumi: «Es crucial [seguir teorizando] la diferencia entre afecto y emoción» (88) para seguir desarrollando nuevas formas de entender el proceso de aprendizaje. Nuevas formas de ver el mundo y de afectar y ser afectado por él.

\section{REFERENCIAS BIBLIOGRÁFICAS}

Ahmed, Sara. The Cultural Politics of Emotion. Edinburgh: Edinburgh University Press, 2004.

Baugh, Bruce. «Body». The Deleuze Dictionary Revised Edition. Ed. Adrian Parr. Edinburgh: Edinburgh University Press, 2010. 35-37.

Baugh, Bruce. «Experimentation». The Deleuze Dictionary Revised Edition. Ed. Adrian Parr. Edinburgh: Edinburgh University Press, 2010. 93-95.

Camps, Victòria. «Spinoza. La fuerza de los afectos». El gobierno de las emociones. Barcelona: Herder, 2011. 65-86.

Colman, Felicity. «Digital Feminicity: Predication and Measurement, Materialist Informatics and Images». Artnodes 14 (2014): 7-17.

Deleuze, Gilles y Piérre-Félix Guattari. ¿Qué es la filosofía? Barcelona: Anagrama, 1993.

De Riba Mayoral, Silvia y Beatriz Revelles-Benavente. «Hacia una pedagogía afectiva del movimiento». Tercio Creciente 16 (2019): 7-30.

Fox, Nick. «Emotions, affects and the production of social life». British Journal of Sociology 66. 2 (2015): 301-318.

Fox, Nick J. y Pam Alldred. «New materialist social inquiry: designs, methods and the research-assemblage». International Journal of Social Research Methodology 18.4 (2015): 399-414. 
Hernández-Hernández, Fernando. «Narrativas en torno a las experiencias de subjetividad en la escuela primaria». Aprender a ser en la escuela primaria. Coord. Fernando Hernández-Hernández. Barcelona: Octaedro, 2010. 9-25. Hickey-Moody, Anna. «A Femifesta for Posthuman Art Education: Visions and Becomings». Posthuman Research Practices in Education. Eds. Carol Taylor y Christina Hughes. London: Palgrave Macmillan, 2016. 258-266.

hooks, bell. Feminism is for everybody: passionate politics. Cambridge, MA: South End Press, 2000.

Illouz, Eva. Intimidades congeladas. Las emociones en el capitalismo. Madrid: Katz, 2007.

Massumi, Brian. «The Autonomy of Affect». Cultural Critique 31 (1995): 83-109. O'Sullivan, Simon. «The Aesthetics of Affect: Thinking Art beyond Representation». Angelaki: Journal of Theoretical Humanities 6.3 (2010): 125-135.

Revelles-Benavente, Beatriz. «Affecting Feminist Pedagogies: Performing Critical Thinking in between Social Networking Sites and Contemporary Literature». Adventurous Encounters. Eds. Edyta Just y Wera Wraggen. Cambridge: Cambridge Scholars University Press, 2017. 131-155.

Schmitz, Sigrid y Sara Ahmed. «Affect/Emotion: Orientation Matters. A Conversation between Sigrid Schmitz and Sara Ahmed». Freiburger Zeitschrift für GeschlechterStudien 22 (2014): 97-108.

Schulte, Christopher M. «Possible worlds: Deleuzian ontology and the project of listening in children's drawing». Cultural Studies-Critical Methodologies 16.2 (2016): 141-150.

Spinoza, Baruch. Ética demostrada según el orden geométrico. Madrid: Orbis, 1980. Vidiella, Judit. «Espacios y políticas culturales de la emoción. Pedagogías de contacto y prácticas de experimentación feministas». Transductores: Pedagogías en red y prácticas instituyentes. Coord. Antonio Collados y Javier Rodrigo. Granada: Centro José Guerrero-Diputación de Granada, 2012. 62-84.

Vidiella, Judit. «Archivos encarnados como zonas de contacto». Efímera Revista de Arte de Acción 5.6 (2014): 16-23.

VV.AA. Investigación (educativa) basada en las artes. Materiales para el Mooc Tendencias emergentes en investigación educativa. La Laguna: Universidad de La Laguna, 2017. 
III. Reviews / Reseñas 



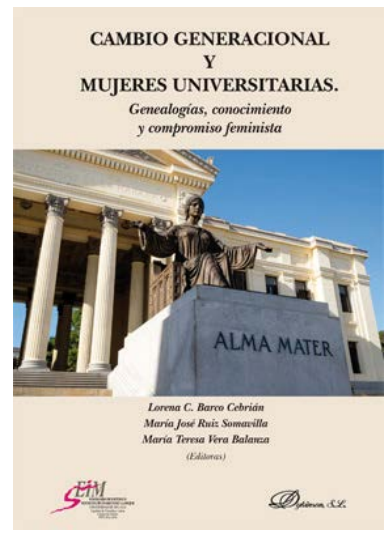

Reseña de: Barco Cebrián, Lorena C., María José Ruiz Somavilla y María Teresa Vera Balanza (eds.). Cambio generacional y mujeres universitarias. Genealogías, conocimiento y compromiso feminista. Madrid: Editorial Dykinson, 2019. 195 pp. ISBN: 978-84-9148-934-4

\author{
Marta Postigo AsEnjo \\ Universidad de Málaga, Málaga \\ martapostigo@uma.es
}

Cambio generacional y mujeres universitarias rinde homenaje a una generación de profesoras e investigadoras de la Universidad de Málaga -como son Rosa Quesada Segura, Marion Reder Gadow, Rosa Romojaro, Francisca M. Sánchez y Merces Vico- que han roto moldes y han desafiado estereotipos en los espacios académicos tradicionalmente masculinizados, durante las primeras décadas del período democrático-constitucional de 1978. A comienzos del siglo XXI, las citadas profesoras culminan sus prolíficas y exitosas carreras académicas con el merecido reconocimiento de haber trazado nuevos caminos y de haber servido de referencia a las generaciones siguientes de universitarias.

Cambio generacional y mujeres universitarias ofrece, asimismo, una rica y amplia ilustración del legado científico de las investigadoras universitarias que, en las cuatro últimas décadas, han contribuido al desarrollo de sus disciplinas académicas y a la incorporación de la perspectiva de género a los estudios universitarios y a los temas de investigación. 
Reseña de: Barco Cebrián, Lorena C., María José Ruiz Somavilla y María Teresa Vera Balanza (eds.). Cambio generacional y mujeres universitarias. Genealogías, conocimiento y compromiso feminista. Madrid: Editorial Dykinson, 2019. 195 pp.

ISBN: 978-84-9148-934-4

Cabe recordar que no fue hasta la Real Orden del Ministerio de Instrucción Pública del 8 de marzo de 1910, firmada por el Rey Alfonso XIII, cuando las ciudadanas españolas pudieron acceder por primera vez a los estudios superiores en igualdad de condiciones, sin permisos especiales ni concesiones individualizadas. Hoy, llegadas las primeras décadas del siglo XXI, las mujeres son mayoría entre quienes acuden a las aulas universitarias -710.743 mujeres matriculadas en las universidades españolas frente a 578.490 hombres en el curso 2017-2018 (según los datos del Ministerio de Ciencia, Innovación y Universidades de 2019). Es esta una transformación que ha sido posible gracias a los valores democráticos y constitucionales de 1978 y a los movimientos feministas, tras la profunda regresión que supuso la dictadura franquista.

Las trayectorias académicas de Rosa Quesada Segura, de Marion Reder Gadow, de Rosa Romojaro, de Francisca M. Sánchez y de Merces Vico son, en fin, un claro reflejo de que la excelencia y la meritocracia no entienden de sexo, pero también de la relevancia de la perspectiva de género para avanzar en la igualdad real, como es la conciliación de la vida laboral y familiar, cuando aún perviven importantes brechas de género en las instituciones académicas.

Las editoras del presente volumen, Cambio generacional y mujeres universitarias, una iniciativa del Seminario de Estudios Interdisciplinarios de la Mujer de la Universidad de Málaga (SEIM), Lorena C. Barco, María José Ruiz y María Teresa Vera, han reunido para este propósito trabajos inéditos de diferentes autoras y autores que ilustran, desde sus respectivas disciplinas, la amplitud y la diversidad de las contribuciones de las mujeres a los diferentes campos del conocimiento, de la ciencia, del arte y de la política, pero también las vicisitudes que han debido experimentar para lograr la igualdad, así como los desafíos que el reconocimiento y la recuperación de dicho legado plantea a la historiografía.

El volumen comienza con un repaso de los cuarenta y cinco años de historia de la Universidad de Málaga (1972-2017) por parte de la profesora Ángela Caballero Cortés, quien se centra fundamentalmente en los estudios de Ciencias de la Educación. La autora narra la historia del nacimiento de la institución universitaria, de un campus (el Campus Universitario de Teatinos) y de una disciplina, aportando asimismo datos que atestiguan el desarrollo y el crecimiento de dicha Universidad a lo largo de estos cuarenta y cinco años.

Feminismo/s 35, junio 2020, pp. 341-350 
Reseña de: Barco Cebrián, Lorena C., María José Ruiz Somavilla y María Teresa Vera Balanza (eds.). Cambio generacional y mujeres universitarias. Genealogías, conocimiento y compromiso feminista. Madrid: Editorial Dykinson, 2019. 195 pp.

ISBN: 978-84-9148-934-4

El resto de las contribuciones a la presente obra se organizan en dos bloques temáticos, coherentes y bien integrados. El primero de ellos pone el acento en las «Genealogías femeninas y feministas. Política, ciencia y arte», con una clara alusión a los desafíos que la recuperación de las biografías femeninas y de la genealogía feminista plantea a la historiografía y a los estereotipos femeninos tradicionales. El segundo bloque de trabajos se reúne bajo el epígrafe de «La creación del conocimiento para la transformación social».

En el primer bloque, la Catedrática de Historia Contemporánea, María Dolores Ramos Palomo, directora del SEIM, y la investigadora del SEIM, Isabel Moyano Ramos, ilustran, en su capítulo «Por una genealogía de mujeres republicanas. Política, cultura y ética en España (1880-1914)», las aportaciones de las mujeres republicanas a la cultura, a la política y al feminismo; contribuciones que han quedado en muchos aspectos ocultas en la memoria histórica y que las autoras rescatan del olvido, ofreciendo con ello una visión más moderna y rica de los intereses y aportaciones femeninas a la cultura, al pensamiento y a los movimientos políticos a finales del siglo XIX y principios del XX.

Por su parte, la profesora de Historia de la Ciencia, María José Ruiz Somavilla, analiza y discute en el capítulo titulado "Activismo feminista de las internas de los hospitales de París, 1885-1914», las estrategias de las mujeres que, a finales del siglo XIX y principios del siglo XX, se incorporaron al Internado de los hospitales de París; una institución prestigiosa y masculinizada, con una clara estructura patriarcal. Analizar la actividad desarrollada por las internas, recuperar la memoria histórica de sus luchas y asociaciones, vicisitudes y logros, proporciona, como señala la autora, «herramientas intelectuales que pueden contribuir a reforzar la respuesta a las prácticas y a los discursos sexistas» (97)

Si la medicina y el activismo político y cultural han sido campos en los que se han librado las luchas de las mujeres por la igualdad y la participación, el mundo cinematográfico es, asimismo, vivo reflejo del olvido de las múltiples facetas y legados femeninos. La investigadora del SEIM, Rosa María Ballesteros García, pone de manifiesto en su capítulo, «El cine no es sólo juego de hombres. (Los comienzos del cine mudo)», la diversidad y la riqueza de las contribuciones femeninas al mundo cinematográfico en los albores del cine mudo, pero también el efecto de los estereotipos sexuales y de las

Feminismo/s 35, junio 2020, pp. 341-350 
Reseña de: Barco Cebrián, Lorena C., María José Ruiz Somavilla y María Teresa Vera Balanza (eds.). Cambio generacional y mujeres universitarias. Genealogías, conocimiento y compromiso feminista. Madrid: Editorial Dykinson, 2019. 195 pp.

ISBN: 978-84-9148-934-4

prácticas de ocultación a la hora de desterrar dicho legado cinematográfico protagonizado por actrices, directoras, guionistas, productoras, etc., de la memoria histórica. «Como consecuencia de este masculino empoderamiento son innumerables los nombres de actrices, escritoras, guionistas...», escribe Ballesteros García, «creadoras, en fin, que duermen en el sueño eterno, bien por esconderse tras un pseudónimo o, lo que es aún más dramático, por haber sido eliminado su nombre de los títulos de crédito» (105). Se trata de un bello capítulo que recupera los numerosos papeles femeninos desempeñados en la industria cinematográfica, no solo como intérpretes sensuales y erotizadas, sino ejecutando pluralidad de funciones tras las cámaras que desmitifican la imagen estereotipada de las mujeres.

El ámbito educativo y el artístico, relevantes como son, no quedan al margen del trabajo genealógico que tiene lugar en la primera parte de la obra. La profesora Carlota Escudero Gallegos y la agente de Igualdad del Centro Municipal de Información a la Mujer, Agustina Hidalgo, estudian en el capítulo, «Recuperando la memoria del magisterio de mujeres en el medio rural de Álora (Málaga)», las barreras a veces insuperables que han padecido las niñas rurales para recibir una educación formal. El foco de atención es la Comarca del Valle del Guadalhorce, en Álora (Málaga), un ejemplo que ilustra cómo la instrucción formal de las niñas ha sido generalmente un asunto secundario, incluso en el reformismo liberal de la segunda mitad del siglo XIX, cuando se acordaban decretos y reformas que reforzaban las oportunidades educativas. Las diferencias en los salarios de maestros y maestras, así como en la dotación de recursos básicos para escuelas primarias de niños y niñas que las autoras documentan, ponen en evidencia la minusvaloración del saber y de la instrucción formal de las niñas, cuyo desarrollo intelectual y profesional ha sido un objetivo secundario para la mayoría de las administraciones del Estado hasta décadas recientes.

Tales barreras no han impedido, empero, que se hayan forjado brillantes talentos femeninos en el mundo de las artes y de las ciencias. Pilar Flores Núñez recupera en el capítulo sobre «Rosa García Faria, la violinista en el escenario», la historia de quien fuera docente de Música de Cámara en el Conservatorio de Música de Málaga, Catedrática de Violín, y exitosa concertista en dicha ciudad hasta 1954. A través del epistolario de la protagonista, el capítulo de Flores Núñez refleja las drásticas consecuencias que el matrimonio

Feminismo/s 35, junio 2020, pp. 341-350 
Reseña de: Barco Cebrián, Lorena C., María José Ruiz Somavilla y María Teresa Vera Balanza (eds.). Cambio generacional y mujeres universitarias. Genealogías, conocimiento y compromiso feminista. Madrid: Editorial Dykinson, 2019. 195 pp.

ISBN: 978-84-9148-934-4

ha tenido para el desarrollo profesional femenino. Al contraer matrimonio con el también violinista, Don Enrique Tolosa Giralt, Flores Núñez abandonó su carrera docente y como intérprete; una circunstancia, la del matrimonio, que lógicamente no tenía el mismo efecto en la carrera profesional de Tolosa Giralt. «Mi deber como esposa», escribía García Faria el 5 de enero de 1954, «me tiene alejada de lo que hasta hoy fue (sic) mi vida...» (157). Por su parte, Pilar Flores contribuye a poner de relieve en sus páginas las ambivalencias y tensiones de García Faria entre su deber e identidad como músico y su deber e identidad como mujer-esposa, a pesar de lo cual concluye «que, efectivamente el conservatorio de Málaga respondió de forma satisfactoria a las necesidades educativas y musicales para las que fue creado, contribuyendo no sólo a elevar el nivel cultural de las mujeres en la sociedad malagueña, sino incluso abriendo un amplio campo de profesionalización a sus pies» (147).

En el ámbito de la ciencia, las circunstancias no han sido diferentes para las mujeres. Así lo pone de manifiesto la profesora de Bioquímica y Biología Molecular, Francisca Sánchez Jiménez, en el capítulo «La Diosa Sarásvati o la utopía de la mujer de científica», escrito con un explícito sentido autobiográfico. Tras treinta y cinco años de experiencia investigadora, la científica y autora sostiene que «a las dificultades estructurales y coyunturales de los proyectos científicos o el desarrollo de tecnología competitiva, hay que añadirles las múltiples características fisiológicas y sociológicas que se comportan como una escala cruel de techos de cristal a distintos niveles» (161).

En su contribución a la obra, Sánchez Jiménez analiza los avances y las brechas de género tomando como referencia los datos de la Facultad de Ciencias de la Universidad de Málaga, en el período que abarca entre 1977 y 2016. Sus resultados ilustran que, si bien el número de doctoras en ciencias y biología se ha multiplicado por un factor superior a 10 desde 1977, siguiendo una progresión ascendente constante, sin embargo, una vez concluidas las tesis doctorales se acentúan las desigualdades de género. ¿Cómo pueden explicarse tales brechas? «¿Qué hay en nuestros cerebros que construye esos techos de cristal, o de cemento a veces, que han estado bloqueando sistemáticamente el progreso profesional medio de las mujeres?», se pregunta la autora. «Sinceramente creo», responde tentativamente, «que no podemos echarle la culpa únicamente a la neurobiología 'estereotípicamente masculina'. Todo es mucho más complicado. ¿Hasta dónde podemos/debemos controlar/dirigir

Feminismo/s 35, junio 2020, pp. 341-350 
Reseña de: Barco Cebrián, Lorena C., María José Ruiz Somavilla y María Teresa Vera Balanza (eds.). Cambio generacional y mujeres universitarias. Genealogías, conocimiento y compromiso feminista. Madrid: Editorial Dykinson, 2019. 195 pp.

ISBN: 978-84-9148-934-4

los comportamientos para conseguir la paridad perfecta? En mi opinión, esa pregunta siendo una pregunta esencial, no tiene aún respuesta irrefutable. Sería necesario tener más conocimiento genético, neurobiológico e incluso psicológico, sociológico y ético» (164).

En el Departamento de Biología Molecular y Bioquímica del que forma parte Sánchez Jiménez, el 50 por ciento de las profesoras no tienen hijos, el 78.6 por ciento de los profesores son padres (167). En definitiva, si «es muy difícil seguir la evolución profesional de las doctoras egresadas [...] Sin embargo, puedo decir que he conocido bastante de cerca a varias doctoras muy inteligentes y capacitadas para la ciencia que han dejado la carrera investigadora por razones familiares. Sin embargo, solo recuerdo el caso de un doctor que no continuó su carrera investigadora por motivos similares» (167).

Como vemos, si la decisión de contraer matrimonio desvinculó definitivamente a Rosa García Faria de los escenarios y del Conservatorio en 1954, las responsabilidades familiares siguen siendo, en muchos casos, un impedimento para el desarrollo de la carrera científica y profesional de las universitarias. En 1963, Betty Friedan lo llamó «la decisión equivocada» y estudió «el problema que no tiene nombre» (Friedan 13-30, 160-181). En el siglo XXI, la maternidad y las tareas de cuidado explican todavía una parte fundamental de las brechas de género que tienen lugar en el ámbito de la investigación y de la competición profesional.

Tras la recuperación de las biografías de intelectuales, políticas, activistas, artistas, violinistas, científicas, productoras y guionistas, la obra da paso a los debates sobre la «creación de conocimiento para la transformación social».

Uno de los logros de la concienciación sobre los problemas derivados de las desigualdades de género es la puesta en marcha de mecanismos de observación, como es el Observatorio Jurídico Laboral de la Violencia de género de la Universidad de Málaga, fundado y dirigido por la Profesora Rosa Quesada. La violencia de género es, sin duda, uno de los fenómenos más crueles del machismo que las asociaciones de mujeres han logrado visibilizar. El capítulo «La integración de la perspectiva de género en la protección jurídica de la mujer víctima de violencia de género» rinde homenaje a la profesora Rosa Quesada y al Observatorio, mediante el análisis jurídico de la sentencia de la Sala de lo Social del Tribunal Superior de Justicia de Canarias de 7 de marzo de 2017, que reconoce el acceso a la pensión de viudedad de una mujer

Feminismo/s 35, junio 2020, pp. 341-350 
Reseña de: Barco Cebrián, Lorena C., María José Ruiz Somavilla y María Teresa Vera Balanza (eds.). Cambio generacional y mujeres universitarias. Genealogías, conocimiento y compromiso feminista. Madrid: Editorial Dykinson, 2019. 195 pp.

ISBN: 978-84-9148-934-4

víctima de violencia de género. Tal y como señalan sus autores, Salvador Perán Quesada, Lucía Martín Rivera, Francisco Vila Tierno, Antonio LópezQuiñones García, María Salas Porras, Miguel Ángel Gómez Salado y Beatriz Cobo Blanco, la sentencia es «simbólicamente importante por dos cuestiones, en primer lugar, porque se basa en una reforma legislativa impulsada por la profesora Quesada y el Observatorio, y en segundo lugar, porque integra la perspectiva de género como fundamento jurídico para el reconocimiento de este derecho» (178).

La perspectiva jurídica se ve complementada y ampliada con la aportación de la investigadora del Observatorio Jurídico Laboral de la Violencia de Género y Profesora Titular de Derecho, Paz Romero Pardo. En el capítulo «A vueltas con la discriminación de la mujer en el ámbito laboral», la autora se centra en las limitaciones del marco legal vigente en España en materia de discriminación laboral derivada de la maternidad y del embarazo. Para ello analiza y discute la sentencia del Tribunal Constitucional 2/2017, de 16 de enero, que se pronuncia sobre la vulneración del derecho a la igualdad protegido en el artículo $14 \mathrm{CE}$ y la aplicación del principio de igualdad de trato y no discriminación contemplado en la Directiva 2006/54/CE. El análisis jurídico permite a la autora concluir que «el entorno laboral de la mujer y en este caso concreto de la mujer embarazada o madre es proclive a provocar situaciones de discriminaciones que solo pueden salvarse por la vía judicial, por lo que el único camino a seguir será la penosa senda de la denuncia» (189).

También desde el ámbito del derecho y con perspectiva histórica analiza la investigadora de la Universidad de Málaga, Elizabeth García Gil, la evolución del concepto del estupro en el tránsito del Medievo a la Modernidad, en su capítulo sobre «Delito contra la honestidad: el estupro en la documentación del tránsito del Medievo a la Modernidad. Algunos casos de estudio». La autora ilustra, contemplando casos documentados, cómo la agresión sexual, el estupro y el honor se articulan en la estructura social y legal patriarcal al final de la Edad Media y los inicios de la España Moderna, principalmente en la Corona de Castilla. La autora aborda históricamente un concepto jurídico, como es el delito del estupro, en el que la separación entre los ámbitos civil, moral y religioso aún no está bien definida. De esta forma, concluye García Gil que «el delito por estupro es un delito que atenta contra la honestidad

Feminismo/s 35, junio 2020, pp. 341-350 
Reseña de: Barco Cebrián, Lorena C., María José Ruiz Somavilla y María Teresa Vera Balanza (eds.). Cambio generacional y mujeres universitarias. Genealogías, conocimiento y compromiso feminista. Madrid: Editorial Dykinson, 2019. 195 pp.

ISBN: 978-84-9148-934-4

y que no sería hasta bien entrado el siglo XVIII cuando se empezase a tratar como un delito por daño físico y psicológico» (209).

Si los delitos sexuales están aún en el centro del debate público en el siglo XXI, no menos controvertidas son las discusiones en torno al cuerpo femenino y a la maternidad. En su contribución a la presente obra, «La lactancia asalariada en la España del siglo XVIII: principio y fin de la destrucción y conservación de expósitos», la profesora Milagros León Vegas pone de relieve la precariedad que caracteriza a las mujeres que recurren a la lactancia asalariada como uno de los pocos medios de vida disponibles a su sexo en la España moderna. Por un lado, las míseras y paupérrimas condiciones de las lactantes, y del otro, los pobres huérfanos desamparados dependientes de la beneficencia. El capítulo de la profesora Milagros León toma como punto de referencia la obra de Antonio Bilbao publicada en 1789 sobre la Destrucción y conservación de los expósitos, que da buena cuenta de la situación de dichos expósitos y de las lactantes en España a finales del siglo XVIII. Tal y como sostiene la autora, el estudio de los expósitos y de las nodrizas pone de manifiesto que «la mujer y su disposición física para la maternidad y la crianza han sido, a lo largo de los siglos, objeto de discusión en tanto exista una transacción económica» (223).

Del debate en torno al uso del cuerpo femenino en beneficio de la crianza de huérfanos y expósitos como medio de vida en el siglo XVIII, el volumen da paso a la ideología franquista sobre los deberes y virtudes domésticas de las españolas. El investigador Sergio Blanco Fajardo, en su capítulo «Ocio, hogar, maternidad y... ipolítica? Los programas femeninos de Radio Madrid durante el primer Franquismo (1939-1959)» refleja cómo han funcionado los instrumentos de socialización doméstica de las mujeres, centrándose en las campañas de la Sección Femenina en la etapa del primer franquismo (19391959), y en concreto, en los programas radiofónicos de temática femenina de la época. La contribución de Blanco Fajardo a la presente obra es doble: por un lado analiza y recupera la memoria de los programas de Radio Madrid dirigidos a la audiencia femenina durante las dos primeras décadas del franquismo; por otro lado, ilustra cuáles han sido los discursos y mensajes de socialización dirigidos a las mujeres, así como la interiorización de sus virtudes y deberes domésticos.

Feminismo/s 35, junio 2020, pp. 341-350 
Reseña de: Barco Cebrián, Lorena C., María José Ruiz Somavilla y María Teresa Vera Balanza (eds.). Cambio generacional y mujeres universitarias. Genealogías, conocimiento y compromiso feminista. Madrid: Editorial Dykinson, 2019. 195 pp.

ISBN: 978-84-9148-934-4

Precisamente para combatir la socialización diferenciada entre los sexos y avanzar en la igualdad, la educación pública juega un papel básico. El capítulo de la investigadora del SEIM, María Remedios García Muñoz, se centra en los «Aportes del feminismo teórico al conocimiento de la política pública educativa». La autora pone de manifiesto que «existe una tensión entre los enunciados discursivos y normativos que la ley promulga en relación a un enfoque de derechos y la práctica educativa materializada en la puesta en acción del currículum oculto en las escuelas» (248). Tomando como referencia el contexto legislativo vigente en España y Argentina, Remedios García propone a la comunidad educativa estrategias para un cambio educativo y para la aplicación de la perspectiva de género tanto en el currículo como en la formación docente (248), con especial énfasis en los «micro-machismos» y en las «micro-violencias» aún latentes en el denominado «currículo oculto». Cabe destacar, por ejemplo, el estudio de Nieves Blanco del año 2000, que constata que, de 56 libros de texto analizados del primer ciclo de la ESO, el 95 por ciento de los personajes históricos referidos son hombres (261).

Por su parte, las profesoras Carmen Romo, Macarena Vallejo y Teresa Vera concluyen la obra con un trabajo dedicado al «Saber, hacer, poder. Género y empoderamiento ciudadano» que, desde el ámbito de la psicología social y de la comunicación, se centra en las prácticas de acción colectiva, en concreto, en la Plataforma de Afectados por la Hipoteca en España y en el Movimiento de Empresas Recuperadas de Argentina. Dichas autoras analizan y discuten las estrategias comunicativas y de acción colectiva de las nuevas organizaciones sociales y movimientos cívico-políticos teniendo en cuenta la perspectiva de género. Concluyen estas que «las mujeres siguen accediendo a la participación social desde la diferencia y la desigualdad enraizada en las asimetrías de género, que no ha sido analizada apenas en el contexto de la política no institucional afectando en definitiva a las estructuras organizativas y a los efectos sociales de los movimientos de protesta» (287). Conviene recordar que, como indican las profesoras, las ciudadanas son, aún así, especialmente vulnerables a los desahucios y a la precariedad; en torno al 82 por ciento de los hogares monoparentales están encabezados por mujeres, según el INE (2015), y la feminización afecta, asimismo, a los hogares encabezados por personas de edad avanzada, el 28,3 por ciento en el caso de las mujeres frente al 6,2 por ciento en el caso de los varones (290).

Feminismo/s 35, junio 2020, pp. 341-350 
Reseña de: Barco Cebrián, Lorena C., María José Ruiz Somavilla y María Teresa Vera Balanza (eds.). Cambio generacional y mujeres universitarias. Genealogías, conocimiento y compromiso feminista. Madrid: Editorial Dykinson, 2019. 195 pp.

ISBN: 978-84-9148-934-4

Con tales datos y reflexiones concluye una obra compuesta por catorce capítulos, cada uno de los cuales aporta biografías, discusiones, reflexiones y metodologías que ayudan a conocer mejor el papel de las mujeres en la historia; un volumen al que han contribuido numerosos docentes, investigadoras e investigadores de la Universidad de Málaga, desde sus diferentes disciplinas y magisterios académicos. Cambio generacional y mujeres universitarias reúne, así, genealogías, conocimiento y el compromiso feminista de quienes, en estas últimas cuatro décadas, han protagonizado el relevo generacional, contribuyendo a hacer de las instituciones académicas espacios más plurales y diversos, e integrado la perspectiva de género en los debates científicos.

\section{REFERENCIAS BIBLIOGRÁFICAS}

Friedan, Betty. The Feminine Mystique. Londres: Penguin Books, 1963.

Ministerio de Ciencia, Innovación y Universidades. Datos y cifras del sistema universitario español 2018-2019, 2019. 24 de octubre de 2019. <https://www. educacionyfp.gob.es/dam/jcr:2af709c9-9532-414e-9bad-c390d32998d4/ datos-y-cifras-sue-2018-19.pdf>

Feminismo/s 35, junio 2020, pp. 341-350 


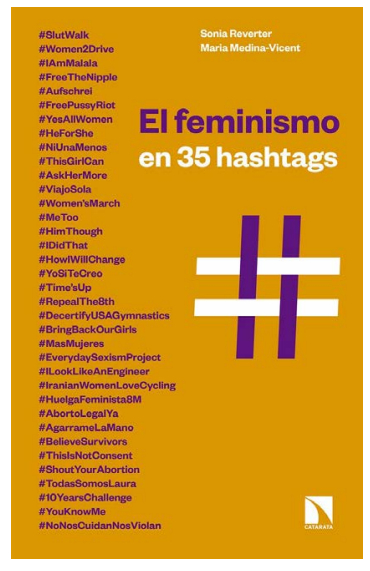

\author{
Reseña de: Reverter, Sonia y María \\ Medina-Vicent. El feminismo en 35 \\ hashtags. Madrid: Los libros de \\ la catarata, 2020. 110 pp. ISBN: \\ 978-84-9097-905-1
}

\author{
Laura MANZANO-ZAMBRUNO \\ Universidad de Sevilla \\ lauramanzam@gmail.com \\ orcid.org/0000-0001-7472-2506
}

Sonia Reverter y María Medina-Vicent comienzan El feminismo en 35 hashtags preguntándose por qué el feminismo ha pasado de ser un tabú a convertirse en un tótem. A ello procuran responder bajo la hipótesis de que una de las principales fuerzas impulsoras de la popularización del feminismo han sido las redes sociales, motivo por el que las autoras exponen los treinta y cinco hashtags representativos que apuntan en esta dirección. El libro se divide en tres partes: una primera, introductoria, con un breve marco teórico y algunas preguntas de investigación; una segunda, recopilatoria y explicativa, que caracteriza cada uno de los hashtags; y una tercera, como conclusión, que reflexiona sobre la implicación de los distintos agentes sociales en las campañas descritas y los temas más populares abordados en ellas.

El libro se acoge a la clasificación estadounidense de olas del feminismo que inició Kate Millet, que sitúa la primera durante el sufragismo y la segunda entre los años sesenta y setenta, continuada por Rebeca Walker con una tercera que comenzó en los años noventa. No obstante, hay una propuesta europea, la de Amelia Valcárcel (56-57), quien localiza la primera ola en la Ilustración, 
así el movimiento sufragista pasa a ser la segunda y aquello que se ha venido denominando «revolución sexual» de los años sesenta y setenta, se traduciría en una tercera ola. Esto puede afectar a la definición de «feminismo liberal»: Valcárcel define así el sufragismo y lo considera en su sentido clásico, aún vigente y caracterizado por ser reformista y albergar las demandas de mujeres de clase acomodada (Heywood 239-240). Siguiendo este razonamiento, hablar de «feminismo liberal o neoliberal» (10) resulta impreciso y confuso, al igual que sucede con la conceptualización del feminismo en las corrientes «adaptativa» $\mathrm{y}$ «revolucionaria» que vienen a reemplazar el ya mencionado feminismo liberal y al feminismo radical, respectivamente (Heywood 228229). Algo semejante se produce al presentar al «posfeminismo», el «feminismo popular»y «feminismo neoliberal» como sinónimos (28-29), cuando cada cual ubica su razón en puntos distintos. El posfeminismo se origina por su rechazo a las demandas de la tercera ola ${ }^{1}$, considerando que ya se ha logrado la igualdad formal y siendo sus características aún difíciles de llevar a consenso científico; mientras que el feminismo popular pone el acento en el resultado, el haberse convertido en un movimiento de masas; y el feminismo neoliberal habla del proceso que le ha convertido en lo que es, un producto de consumo más. Pueden ser estos motivos suficientes para esgrimir por qué estos tres términos no deberían presentarse como intercambiables, aunque sí sea útil para reflexionar sobre la proliferación de conceptos en busca de caracterizar el feminismo actual.

Las preguntas de investigación formuladas son uno de los principales valores de esta obra. No se responde a todas ellas con carácter definitivo, pero se dibujan hojas de ruta interesantes para continuar esta línea de investigación. Se interrogan las autoras sobre si el producto del acomodamiento del feminismo al sistema socioeconómico, el «feminismo neoliberal», es capaz de mantener la esencia subversiva del movimiento. Se señala así directamente al conflicto estructural provocado por esta estrategia neoliberal, siendo incómodo el feminismo que, en su corriente radical, desarrolla una crítica al sistema, caracterizado como neoliberal y patriarcal.

1. La presente reseña se rige por la propuesta de clasificación de olas del feminismo de Amelia Valcárcel de modo que, en adelante, cuando se mencione una de ellas se hará tomándola como referencia, sin que sea necesario precisarlo.

Feminismo/s 35, junio 2020, pp. 351-355 
En esta línea, Reverter y Medina-Vicent proponen «la sospecha como forma de pensamiento crítico» a través de la que constituir la conciencia feminista (16). Cabe destacar la perspectiva interseccional e intergeneracional manifestada en el libro, que caracteriza esta etapa del feminismo por la superación de la diferencia de edad y la confluencia de demandas que evidencian la diversidad del sujeto político «mujer», que se había universalizado soslayando que realmente contaba las experiencias de «una mujer blanca, heterosexual, de clase media, con formación» (Casado Aparicio 100). Reverter y MedinaVicent apuntan aquí al mismo dilema que plantea Patrizia Violi al abordar la complicación necesaria de llegar a un «universal-particular» que reúna las diferencias de las vivencias y las necesidades al tiempo que tenga la entidad suficiente para constituir un sujeto político sólido y operativo (139). Con precisión se indica que la forma de ampliar este sujeto no es recurriendo a la representación, que puede «usurpar la experiencia» (Reigada-Olaizola 60), sino abogando por una reivindicación de redistribución real de los recursos (35). En este sentido, se advierte que «el estado de la igualdad de género no es lo mismo en todos los países, por lo que las repercusiones legales y sociales de participar en una campaña feminista [...] pueden ser muy diferentes dependiendo de dónde nos encontremos» (100), evidenciando esta diversidad de las vivencias en función de la situación geopolítica.

Con la intención de continuar caracterizando el momento actual del feminismo, las autoras concluyen que, aparte de la cuestión intergeneracional e interseccional, destaca su onmipresencia, en el sentido de que no existe a día de hoy un país ajeno a las injerencias del patriarcado (40-41). Se realiza una reivindicación de la validez de clasificar el feminismo en olas por ser «una forma de remarcar que los objetivos para alcanzar la igualdad han de ir revisándose y renovándose de forma continua» (19) y también por afianzar la idea de que «la desigualdad de las mujeres no es un problema puntual de un periodo concreto de la historia» (19). A esta defensa va asociada otra sobre la que no suele hacerse mención: «El antifeminismo también se puede relatar en olas, pues para cada ola feminista hay una reacción organizada en contra» (9). A día de hoy, aseguran Reverter y Medina-Vicent, el feminismo se enfrenta a la lucha contra los discursos de odio, especialmente en las redes sociales.

Los hashtags aparecen como un recurso que lleva las demandas feministas a la agenda política y mediática, y es ahí donde reside su fuerza principal, 
aunque guardan una carga ambivalente. Por un lado, los hashtags permiten dar una idea de la transversalidad de los efectos de los valores patriarcales en la sociedad, abordando temas como la violencia contra las mujeres, el significado de los cuerpos femeninos o la culpabilización de las víctimas; pero por otro, resulta inocente pensar que toda persona que participa en las redes, sumándose a una de estas campañas, lo hace con una conciencia feminista, dificultada si se tiene en cuenta la saturación intrínseca a los entornos digitales, donde una reivindicación acaba «sepultada por un mar de tuits que caducan casi en el instante de su publicación» (105). Igualmente, otras autoras como Stavroula Pipyrou alertan sobre el peligro que una denuncia por redes sociales puede conllevar por el hecho de que el alivio que produce el apoyo de la comunidad sustituya la necesidad de reclamar un aparato político, educativo y judicial que dé solución al problema. La concreción de qué agentes sociales se están involucrando en este tipo de campañas es también relevante. Si bien el éxito de los hashtags depende siempre en última instancia de la participación ciudadana, la sociedad civil no es la única en implicarse, sino que instituciones públicas, marcas y celebridades se han sumado a esta corriente, lo que hace pensar, como indican las autoras, en el valor estratégico del feminismo, que se ha convertido para muchos y muchas en garantía de éxito (97).

La conclusión a la que se llega en este libro es que la desestigmatización del feminismo se ha producido gracias a su popularidad, fortalecida en gran parte por mediación de las redes sociales y los hashtags que enumeran en su segundo capítulo. El feminismo en 35 hashtags es una obra optimista, necesaria para construir un marco teórico e interpretativo que permita analizar el momento actual del feminismo y reflexionar acerca de su relación con las redes sociales, así como sobre las ventajas e inconvenientes que la adscripción inconsciente al movimiento puede tener a largo plazo para la consecución de los objetivos últimos del feminismo.

\section{REFERENCIAS BIBLIOGRÁFÍCAS}

Casado Aparicio, Elena. «La des/reconstrucción de la comunicación en las sociedades de la información». Crítica feminista y comunicación. Eds. María José Sánchez Leyva y Alicia Reigada Olaizola. Sevilla: Comunicación Social Ediciones y Publicaciones, 2007. 82-109. 
Heywood, Andrew. Political ideologies. An introduction. Londres: Palgrave MacMillan, 2012.

Pipyrou, Stavroula. «\#MeToo is little more than mob rule vs. \#MeToo is a legitimate form of social justice». Journal of Ethnographic Theory 3. 8 (2018): 415-419.

Reigada Olaizola, Alicia. «Orientaciones. Comunicación, cultura y sentido». Crítica feminista y comunicación. Eds. María José Sánchez Leyva y Alicia Reigada Olaizola. Sevilla: Comunicación Social Ediciones y Publicaciones, 2007. 56-81.

Valcárcel, Amelia. Feminismo en el mundo global, Madrid: Cátedra, 2008.

Violi, Patrizia. «Feminismo y filosofía del lenguaje. Sujeto lingüístico y sujeto femenino». Feminismo y teoría del discurso. Ed. Giulia Colaizzi. Madrid: Cátedra, 1990. 127-140. 



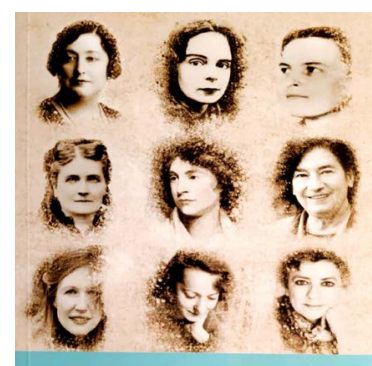

MUJERES CON LUZ

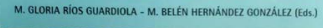

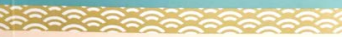
editum
Reseña de: M. Gloria Ríos Guardiola y M. Belén Hernández González (eds.). Mujeres con luz, Murcia: Ediciones de la Universidad de Murcia (edit.um), 2017. ISBN 978-84-17157-41-8

\section{Montserrat PlanELLES IVÁÑEZ \\ Universidad de Alicante, Alicante montserrat.planelles@ua.es orcid.org/0000-0001-8033-7794}

Mujeres con luz es un libro de contenido oportuno en la actualidad, ya que rinde homenaje a doce mujeres, rompedoras en sus respectivas actividades -novela, poesía, filosofía, enseñanza, periodismo, arquitectura-, algunas de ellas incluso desconocidas en nuestro siglo, y que, por tanto, ilumina el universo presente del lugar de la mujer en la sociedad, en particular en la literatura, en la filosofía y en el periodismo.

La presentación de Rosa Peñalver, presidenta de la Asamblea Regional de Murcia, invita a sumergirse en la lectura de este volumen, que verdaderamente arroja luz sobre la valía y la actividad de mujeres especiales, muchas de ellas pioneras, que nos han precedido en la lucha por la igualdad de oportunidades.

Hemos de agradecer a sus editoras, M. ${ }^{a}$ Gloria Ríos Guardiola y M. ${ }^{a}$ Belén Hernández González, la recopilación de trabajos sobre mujeres, unas más conocidas que otras, en un volumen, ya que, de este modo, al plantear la publicación como monografía, la difusión de su actividad, de su talento, de su influencia y de su obra queda asegurada con más eficacia que si cada capítulo hubiera sido publicado en revistas diferentes. Once de los doce capítulos 
contenidos en este libro son de autoría femenina y contribuyen a dar visibilidad a mujeres insignes, a sus ideas y a su producción.

Comienza el volumen con el capítulo «Notas para un ensayo» de Dionisia García, escritora del siglo XX, en el que expone sus ideas sobre la realidad del mundo actual a través de la literatura, disciplina que considera «un buen soldado de la guerra del tiempo» (16).

Isabel de la Campa, en «Mary Wollstonecraft: una vida no convencional», presenta a esta escritora inglesa del s. XVIII como revolucionaria de la educación y defensora de la mujer; de costumbres transgresoras para su época, ya que tuvo dos hijas fuera del matrimonio. Su obra $A$ vindication of the rights of woman sentó las bases del movimiento feminista, que prosperó tres siglos después. Gracias a su actividad se promovieron leyes que contribuyeron a terminar con tradiciones en las que la mujer aparecía subordinada al hombre. Tanto ella como su hija Mary Shelley vivieron conforme a sus principios y de este modo influyeron en la historia de la literatura y de las ideas.

Juana Castaño Ruiz, en «Zoé Oldenbourg cumple 100 años: una escritora en los cafés parisinos», nos habla de esta escritora rusa nacida en 1916. Extranjera en París, vive momentos convulsos de la historia de su país. Al exiliarse a Francia junto a su familia, contribuye a engrandecer las letras de la literatura francesa con obras de novela histórica de la Edad Media y de la Cruzadas -cuajadas de personajes cotidianos más que de personajes históricos- y de historias sobre exiliados rusos. Destacan también sus escritos autobiográficos y sus memorias, en los que influyen de manera especial las lecturas de su infancia y los juegos literarios de su padre. Persona solitaria, escribía para sí misma, aunque paradójicamente, gustaba de hacerlo en los cafés. A pesar de que su obra fue prolífica, cayó injustamente en el olvido por la eclosión del nouveau roman, y, en consecuencia, en la invisibilidad.

Adam Elbanowski nos descubre a la poetisa polaca Wisława Szymbroska, premio Nobel en 1996, en «Wislana Szymbroska: la poetisa y sus traductores». Para ello, se basa en la extensa correspondencia entre Wisława y sus traductores, con quienes trabó una sólida amistad llena de cordialidad, que se refleja en sus cartas. Todos coinciden en destacar sus cualidades humanas de mujer excepcional, maravillosa, cálida y generosa. Gracias a ellos es admirada, conocida y respetada en el mundo entero e incluso el autor sostiene que contribuyen a que se le otorgue el citado y preciado galardón.

Feminismo/s 35, junio 2020, pp. 357-362 
Curiosamente, no hay rastro de la correspondencia que mantuvo con los doce traductores españoles. El corpus epistolar en el que se basa el autor del capítulo, que es inédito y poco conocido, proviene de dos instituciones: por un lado, del Archivo Karl Dedecius en Slubice, en la frontera polaco-alemana que contiene, además de las obras traducidas por Dedecius, 150 carpetas con cartas de escritores polacos y alemanes, y por otro, de la fundación Wisława Szymbroska de Cracovia.

La siguiente escritora, Zénaïde Fleuriot, presentada por Magali Fernández en «L'éducation des jeunes filles en fleurs chez Zénaïde Fleuriot», actualmente es completamente desconocida, a pesar de su prolífica obra en la segunda mitad del siglo XIX y de su éxito en aquella época. Recibe el premio Montyon de literatura de la Académie Française por su obra Aigles et colombes. Es escritora y preceptora de numerosas niñas pertenecientes a la burguesía francesa del XIX. Transmite a través de sus obras los valores de la religión católica y las costumbres de su época. Describe el universo de los prototipos y modelos de jóvenes, que se convierten en guías de las familias burguesas, conservando las cualidades morales y cristianas. Así pues, Fernández presenta a esta escritora como pionera prolífica de literatura dirigida a mujeres, madres e hijas, pero, sobre todo, a las jóvenes, y apela a la importancia de continuar investigando y sacando a la luz obras literarias y autoras dedicadas a este tipo de literatura.

En «Elisabeth Anscombre: razones y acciones», María D. García-Arnaldos rinde homenaje a la filósofa de dicho nombre, que brilló con luz propia como profesora de filosofía en Oxford y Cambridge y siendo discípula de Wittgenstein. Así pues, García-Arnaldos presenta la relevancia y actualidad del pensamiento de esta filósofa centrándose en el análisis del concepto de «acción intencional» en su obra Intention, que da respuestas al problema planteado por el enfoque de Wright, que sostiene que la acción precede a la intencionalidad, pero no llega a demostrarlo.

María Belén Hernández González nos descubre la influencia que el viaje a Italia y a otros países europeos como Francia y Suiza, ejercen en el desarrollo personal, ideológico y profesional de la periodista y maestra Carmen de Burgos en «Impresiones de una periodista por Italia: Carmen de Burgos (Colombine)». Es el ejemplo de cómo su vocación profesional periodística, a la que llegó por necesidad de supervivencia, le sirve para descubrir nuevos planteamientos educativos. De Burgos utiliza el género epistolar para plasmar

Feminismo/s 35, junio 2020, pp. 357-362 
todas sus impresiones y todas las conclusiones de su observación. En una época en la que España se encuentra inmersa en convencionalismos sociales estereotipados y difíciles de resquebrajar -principios del siglo XX-, el testimonio y la obra de esta periodista reconvertida en escritora, marcará un punto de inflexión y de inspiración para las pensadoras y escritoras ulteriores, así como para el desarrollo de ideas del movimiento feminista en ciernes.

Andrea Ladrón de Guevara analiza la obra sobre Medea, de la escritora alemana Christa Wolf, en su capítulo «La Medea de Christa Wolf: una versión feminista». Entre los temas centrales de sus obras se encuentra el feminismo, que impregna las páginas y la intención de su nueva versión de esta obra clásica. De este modo, la autora presenta un personaje que responde a la perfección al nuevo paradigma de mujer feminista de los 90, alterando profundamente los elementos esenciales del mito de Medea. Así pues, en esta versión, Medea es abandonada por Jasón, pero esta no le guarda ningún rencor sino que se va con otro hombre y la venganza de la Medea clásica desaparece. Además, Creonte no muere y Medea tampoco asesina a sus hijos, mientras que en la Medea original ocurre lo contrario. Con todas estas modificaciones, Wolf reivindica en su obra a una protagonista feminista.

El capítulo de Josefa López Alcaraz titulado «De Las olvidadas a Ellas mismas. El universo femenino en la obra de Ángeles Caso», recorre las obras biográficas y de ficción de la escritora en las que defiende el universo femenino, comprometiéndose y empeñándose en mostrar la valía intelectual de la mujer a lo largo de la historia de la humanidad. Así, en Las olvidadas, nos da a conocer personajes femeninos influyentes en la sociedad: religiosas, literatas, músicas ${ }^{1}$, profesoras de universidad, filólogas, pintoras y escultoras. En Ellas mismas, continúa sacando del olvido, profundizando y aumentando la lista de mujeres pintoras y escultoras a las que apenas se alude en los libros de Historia del Arte.

Susanna Nocchi nos muestra el mundo virtual ficticio en 3D en «Bryn Oh: un'artista del metaverso». Artista canadiense, es un exponente de una nueva estética y una nueva forma de expresión artística mediante la tecnología del ciberespacio, creando obras de arte en tres dimensiones. De este modo,

1. La cursiva es de López Alcaraz, que afirma que no existe el femenino de esta palabra cuando se refiere a la «persona que se dedica a la música» (156).

Feminismo/s 35, junio 2020, pp. 357-362 
Nocchi analiza los conceptos de heterotopía y de metaverso o meta-universo, como elementos centrales de la interpretación de la vida del homo technologicus y del ambiente en el que se mueven los artistas virtuales, también conocido como Second Life. Pues bien, Bryn Oh es pionera, referente y una de las artistas más conocidas y prolíficas de este tipo de arte.

En el capítulo «Ausencias presentes: nombres femeninos en una colección erótica española de los años 20», Carmen M. Pujante Segura profundiza en el terreno de las colecciones españolas de relatos breves y en el de la literatura considerada erótica y popular de la Edad de Plata a principios del siglo XX. Según Pujante, es una época de enorme producción literaria, en la que los autores buscan nuevas vías para transmitir reflexiones sobre la libertad. De este modo, la autora se centra en una colección que ha sido poco estudiada: La novela de noche (1924-1926), para analizar una serie de relatos escogidos repletos de secretos y apariencias o, como apunta en el título, de ausencias. La mayoría de los autores de estos relatos cortos son hombres, pero destacan firmas como la de Carmen de Burgos, Clara Isabel de Sade y Encarnación de Viguri. Sus textos son difíciles de encontrar, pero en ellos defienden el feminismo y ellas mismas representan la incorporación de la mujer a ciertas esferas de la sociedad donde estaba vetada. En este capítulo se analizan comparativamente, en concreto, dos obras firmadas por mujeres en la colección española La novela de noche: La confidente, de Carmen de Burgos, y Las simulaciones de Charito, de Clara Isabel de Sade.

El libro termina con el capítulo de Leonor Sáez Méndez titulado «La creación de espacios humanos en Margarete Schütte-Lihotzky», en el que se reflexiona sobre las razones que llevan a esta arquitecta austriaca, diseñadora de la cocina Frankfurt, a su compromiso con la Resistencia en la Segunda Guerra Mundial y a su lucha contra el nazismo. Se analiza su humanismo y, a continuación, sus creaciones de espacios, para concluir que toda su vida estuvo marcada por la apuesta por el cambio del sistema, que fue la base de su epistemología de humanismo radical y existencial.

Solo se echa de menos en este volumen una introducción de las editoras en la que se expongan las motivaciones que les han llevado a promover la recopilación de estos valiosos trabajos, pero, en definitiva, se trata de una obra de referencia obligada para quienes se interesan por devolver la merecida luz a todas las mujeres insignes, que nos han precedido en la defensa de nuestra

Feminismo/s 35, junio 2020, pp. 357-362 
presencia en todas las actividades profesionales y en todos los sectores de la sociedad y que han demostrado capacidad de trabajo, tesón, coraje y liderazgo, dejando su huella para facilitar la presencia igualitaria de la mujer a las generaciones presentes y venideras. 


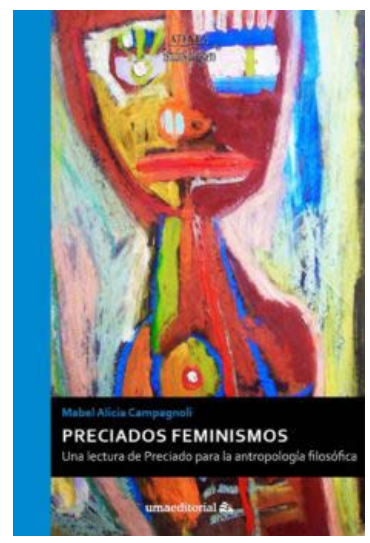

Reseña de: Campagnoli, Mabel Alicia. Preciados feminismos. Una lectura de Preciado para la antropología filosófica. Málaga: UMA, 2018

\author{
Ariel MARTíNEZ \\ Universidad Nacional de La Plata, Buenos Aires \\ amartinez@psico.unlp.edu.ar \\ orcid.org/0000-0002-9883-7911
}

La publicación del presente libro merece múltiples comentarios. En primer lugar, no es menor apreciar su estilo de escritura amigable que sugiere un deseo de transmitir. Desde el inicio, la autora renuncia al estilo oscurantista y críptico que suele adoptarse frecuentemente como mascarada de pseudo-complejidad, tan frecuente en el ámbito de la producción filosófica. Por otra parte, diferentes niveles de profundidad coexisten en sus páginas. La lectora recién iniciada tendrá ocasión de deslizarse en un recorrido que sistematiza y ofrece, muy generosamente, un mapeo de las complejas territorialidades conceptuales que allí se plasman, frecuentemente agrupadas bajo la nomenclatura de estudios de género. Para quien cuenta con una sistematización de las referencias fundamentales dentro del campo, el recorrido que la autora propone incrementa tanto en profundidad como en extensión los territorios conceptuales, al tiempo que nos brinda claves de elucidación teórico-política.

El libro se organiza en seis capítulos que anudan aportes de los feminismos con contribuciones de Paul Preciado. Este entrecruzamiento extrae su fuerza de la potencia analítica de categorías como las de biopolítica y género, y se vuelve original e incluso queer cuando el pliegue analítico de la filosofía

Los contenidos de la revista se publican bajo una licencia de Creative Commons Reconocimiento 4.0 Internacional (CC BY 4.0)

Feminismo/s 35, junio 2020, pp. 363-367 
de Preciado -en franca y paulatina construcción a medida que avanzamos en la lectura del libro- no configura un elemento disolutivo de los feminismos, sino un elemento extraño que se integra a su genealogía y, desde allí, opera sumando complejidad y cuestionando límites frecuentemente establecidos. Indudablemente la lectora asiste a un aporte significativo que redunda en la construcción de una mirada queer dentro del feminismo, mirada imposible de ser pensada, considera la autora, fuera del cruce de relaciones coloniales. Este cruce tenso y complejo de miradas y perspectivas que suelen ubicarse de manera disyunta, configura el gran proyecto teórico y político contenido en las páginas, sugerido, por otra parte, en el título Preciados feminismos.

El resultado plasmado en cada página impresiona por la destreza de la autora, quien reordena y tensa las perspectivas puestas a dialogar en el libro. La concreción de estas ideas se desliza contra la corriente de la fuerte impregnación de aportes norteamericanos, mal digeridos, a los que suele apelarse para sostener la idea de que Paul Preciado es post-feminista. Nuestra autora entrama lo aparentemente incompatible en una argumentación que no es apresurada. La cartografía que nos ofrece no se encuentra trazada en la inmediatez del territorio. Queda claro que este libro es un punto de decantación de una amplia trayectoria de pensamiento y problematización de ideas al calor de un feminismo en primera persona.

Para decirlo sintéticamente, el libro nos aproxima a la producción que Preciado realiza en el transcurso de diez años, bajo la consideración de dos líneas genealógicas: biopolítica, una de ellas, y de género, la otra. La producción de Paul Preciado cabalga entre ambas genealogías, y allí radica una clave para develar uno de sus aportes específicos vinculados con los procesos de producción de subjetividad en su dimensión sexo-generizada. Así, la autora nos conduce por una genealogía de la biopolítica -capítulo 2-, iniciada en ideas de Michel Foucault y siguiendo el cauce de las derivas italianas. También nos ofrece genealogías del género -capítulo 3. Ante la despolitización de esta noción, la autora defiende su potencia epistemológica y política para los feminismos. La sistematización que Mabel Campagnoli realiza en torno a estas genealogías, las vertientes terminológicas allí implicadas y los descentramientos feministas son verdaderamente impactantes. Hace justicia a la complejidad de la producción conceptual feminista, tan frecuentemente borrada por el canon mal intencionado. Por este motivo, Preciados feminismos

Feminismo/s 35, junio 2020, pp. 363-367 
guarda el valor de invocar toda una tradición de pensamiento que lucha contra el artilugio ideológico de la denostación tendiente a deslegitimar la relevancia, la complejidad o incluso la especificidad de todo el campo de estudio que aquí nos (pre)ocupa.

El capítulo 4 -llamado «El imperio sexual»- nos lanza a un campo conceptual que tematiza la sexualidad. Ante la complejidad de un orden de cosas particularmente escurridizo y resistente a ser apresado bajo categorías, encontramos claves «preciadas» que dan cuenta de la producción de subjetividades/ corporalidades bajo el umbral de una ontología histórica de nosotres mismes, ontología del presente que entraña la posibilidad de transformación. Esto nos conduce al dispositivo de género -capítulo 5-, que avanza sobre la potencialidad y los límites de segmentos del pensamiento de Michel Foucault y Judith Butler, entre otras referencias notables. En el capítulo 6 - «La contra-sexualidad»-encontramos claves para pensar una política de la re-territorialización (corporal) subversiva mediante transformaciones positivas de la biopolítica, ahora devenida sexopolítica. El cuerpo se vuelve posibilidades múltiples. Su maleabilidad, a diferencia del construccionismo social que el campo médico-psicológico había esbozado, se concibe de forma plástica, y a la altura de estas páginas, tal vez, ya hemos dejado de ser tan respetuosas con las exigencias normativas que imponen los marcos identitarios.

En suma, la vastedad de las líneas que contiene este libro lo hace estar a la altura de las circunstancias de los debates actuales, contiene múltiples ejes de análisis que atraviesan un denso espesor conceptual, y toda esta complejidad no se organiza en función de una mera sistematización que reúne acumulativamente, como superposición de capas, diversos comentarios de lecturas. Más bien, el ritmo de la presentación de diferentes aportes danza en torno a un compromiso ético-político claro, que no es otra cosa que los feminismos latiendo en cada una de sus páginas.

Me interesa realizar algunos comentarios del posicionamiento subyacente en la mirada de la autora. Las consideraciones teóricas sobre las que el libro avanza involucran problemáticas antropológicas, y a medida que la expansión teórica se produce, no se escatiman consideraciones epistemológicas. Asimismo, en su espectro claramente se encuentran, explícitas o subyacentes, consideraciones que disputan sentidos en un pretendido plano ontológico. Puede detectarse la fuerte pregnancia de Donna Haraway en el proyecto 
teórico-político de Mabel Campagnoli, esto se trasluce en que nuestra autora, a pesar de no ser ajena al problema que entraña el antropocentrismo, no resuelve su posicionamiento en un post-humanismo que iguala todas las formas de agencia. Las relaciones de dominación, poder y diferencia dentro y entre las sociedades humanas no son ignoradas, sobre todo el problema estructural que alimenta y sostiene al Hombre como falso universal. Podemos detectar una apuesta por la agencia humana, en diálogo con otros actantes, a la hora de pensar formas de hacer política, para no reproducir o reciclar los indeseados universales en diferentes niveles de abstracción estéril.

Su posicionamiento foucaultiano también la ubica onto-epistemológicamente de un modo particular. Su propuesta no intenta concebir la totalidad del ser, la búsqueda de un acceso directo e inmediato a la verdad. Más bien abraza la posición siempre precaria y parcial del sujeto epistémico. Asimismo, se mantiene alerta de cualquier reintroducción de una visión neutra, es decir, de una posición privilegiada desde la cual la realidad se revela a sí misma. Las coordenadas ofrecidas en este recorrido reconocen el carácter situado, en tanto sus afirmaciones son relevantes bajo ciertas condiciones históricas de producción. Esta es ocasión para mencionar el capítulo 1 denominado, justamente, «Itinerarios y lecturas en contexto».

El valor del posicionamiento epistémico de la autora radica en sostener la posibilidad de la crítica que toma partido respecto del estatus autoritario de las ciencias. Cada afirmación fuerte del libro puede entenderse como un combate con afirmaciones ontológicas supra-históricas mediante herramientas conceptuales históricamente contingentes, aunque políticamente potentes, que los feminismos han forjado para transformar las múltiples situaciones de subordinación.

Ante la renovada creencia contemporánea en los métodos de la ciencia natural como única vía hacia la verdad, que convoca a la filosofía a adaptarse a las ciencias naturales, Mabel Campagnoli señala que el mundo ya esta conceptualmente articulado por los dispositivos mediante los cuales la ciencia construye normativamente una representación de naturaleza. Entonces, nuestra autora cincela las herramientas que nos enfrentan con los matices de una perspectiva teórica en torno de la subjetividad/sujeción sin alimentar el actual vaciamiento de la agencia humana. Por otra parte, los modos en que la subjetividad se articula en torno al dispositivo de género se intersectan con

Feminismo/s 35, junio 2020, pp. 363-367 
una gama de consideraciones que sopesan las habituales y exclusivas referencias al plano discursivo, propias del posestructuralismo norteamericano. Es decir, la producción del género se entiende simultáneamente como material y discursiva, como semiótico-material en términos de Donna Haraway, y quienes lean el libro ya encontrarán cómo esto se refigura y nomina de forma específica en las conceptualizaciones de Paul Preciado.

Este libro nos enfrenta con un relevante giro crítico dentro de los feminismos, preocupado por conservar su proyecto político. Tan importante como aquello: teniendo en cuenta el avance de nuevas miradas que reclaman una parcela para la biología dentro del feminismo, el posicionamiento de Mabel Campagnoli considera al cuerpo en su dimensión material, pero evitando un retorno a explicaciones ontológicas indeseadas que intentan fundar al sujeto político de los feminismos en una esencia subyacente y eterna. Es en este sentido en el que este libro es fundamental frente a problemas de corte ontológico, epistemológico y antropológico renovados contemporáneamente, puesto que sopesa la forma en que la metafísica, el cientificismo y el post-humanismo amenazan el campo teórico-político de los feminismos. Como Donna Haraway lo diría, este libro -pieza clave del patrimonio político-intelectual de los feminismos- se promete como un embaucador de códigos que nos acerca a la posibilidad de achicar la brecha entre mundos deseables y mundos posibles. 



\section{OPEN-ACCES POLICY}

Feminismo/s offers immediate access to the journal's contents, without any embargo period, and is granted upon the belief that free access to research results can help foster global knowledge exchange. In this sense, Feminismo/s follows the open access policy defined by the Budapest Declaration (BOAI, 2002): « free availability on the public internet, permitting any users to read, download, copy, distribute, print, search, or link to the full texts of these articles, crawl them for indexing, pass them on as data to software, or use them for any other lawful purpose, without financial, legal, or technical barriers other than those inseparable from gaining access to the internet itself.»

Feminismo/s is a non-profit scientific journal and, therefore, does not include the payment of any fee for submission of manuscripts or any other fee for the publication of articles.

\section{HOW TO SUBMIT A MANUSCRIPT}

1. Works shall be the result of an original research and must contain novel conclusions supported by a duly raised and reasoned methodology. Only unpublished works that are not in the process of being assessed by other journals will be admitted.

2. The length of the papers should not exceed 9,000 words, including notes and bibliography.

3. The number and length of footnotes should be reduced to the minimum necessary.

4. Authors should submit their articles in Word format via electronic mail (revistafeminismos@ua.es) along with the following documents, compulsorily:

Feminismo/s 35, junio 2020 
- On a separate sheet: name of the author, home institution, ORCID code, full professional address and e-mail address.

- Text in Word format, ANONYMOUS, stating:

- Title in Spanish and English.

- A 150-word abstract in Spanish and its correct English version. This summary should follow this structure: objectives of the work, methodology and conclusions or thesis.

- Five key words in Spanish and its correct English version.

- Original text.

5. Papers will undergo a process of anonymous selection and a peer review assessment, according to the procedure and criteria published by the journal.

FEMINISMO/S 35

\section{EDITORIAL GUIDELINES AND STYLE}

\section{Author Guidelines}

Feminismo/s publishes two types of work: research articles and book reviews. The Editorial Board establishes the general rules described below.

The journal does not charge any fee for submissions, nor does it charge for the publication of articles.

Papers are accepted in English or Spanish.

In order to submit an article, authors must Login or Register if they have not previously done so.

\section{RESEARCH ARTICLES}

- Research articles must be unpublished with a maximum length of 9,000 words, including notes and tables (except justified exceptions, with prior authorisation from the Editorial Board).

- They must be written in Times New Roman 12. The text must be duly justified, 1.5 line spacing. The first line of each paragraph shall be indented. 
- The different sections of the text should be ordered according to Arabic numbering $(1,2,3, \ldots)$ and the title of section should be written in capitals and bold. Sub-paragraphs should be numbered as follows: 1.1, 1.2, 1.3, etc. and their titles should be in lower case and bold type.

- Footnotes, written in Times New Roman 10, should be reduced to the bare minimun, used only for supplementary information and in no case should they be bibliographic references. Footnote calls should appear before the punctuation mark.

- After the conclusions, the article should end with a section containing a Reference List including all the works cited in the article, following alphabetical and chronological criteria (in case there are several works by the same author). Each bibliographic reference should end with a full stop and a they should include blank line between references. See Citation and Referencing Guidelines.

- Photographs and images will be submitted in digital format, separated from the text, in.tif format, with a quality of 300 points per inch. They must be properly identified in keep with the way they are cited in the text.

- In their first version, the articles must be submitted anonymously (no self-references revealing authorship, no mention of research projects in which the article is included, and no personal information in the document properties), thus ensuring double-blind peer review.

- Should the article be accepted for publication, the final text must be signed on the first page, after the title (right alignment). Author's data and institutional affiliation must appear in this order:

- Author's name.

- Institutional affiliation (with no acronyms) and city in which the institution is located.

- Author's email.

- ORCID identifier. Example: https://orcid.org/0000-0002-18250097. 
- At the beginning of each article, and regardless of the language in which it is written, the title of the work (Spanish or English) and an abstract of a maximum of 150 words (in Spanish and in English) should be added, describing the justification of the study, the objectives, the methodology, the main results and the most relevant conclusions. Also, the article must include between 4 and 8 keywords (in Spanish and English), separated by a semicolon.

- In addition, in a separate file, attach a brief curriculum vitae to the OJS platform («Upload complementary files»), approximately 10 lines long, on the author's academic and professional background, and main research.

- Failure to comply with these basic criteria may be grounds for exclusion from the peer review process.

- Correction of the first papers will be the author's responsibility, and they will have a maximum of 10 days.

\section{BOOK REVIEWS}

- Reviews of recently published books (from the last two years) will have a maximum length of 1,500 words, specifying the author or editor, title, place of publication, publisher, date of publication, ISBN and number of pages.

- The author of the review will provide his/her name and surname, institutional affiliation, e-mail address and ORCID identifier.

- A complementary file, an image of the main cover of the reviewed publication is advisable.

- Authors must follow the instructions of the section Citation and Referencing Guidelines. 


\section{Checklist for preparing submissions}

As part of the submission process, authors are required to check that their submission meets all the elements shown below. Submissions that do not comply with these guidelines will be returned to the authors.

1. The submission has neither been previously published, nor is under consideration for another journal (or an explanation has been provided in Comments to the Editor)

2. The submission file is in OpenOffice, Microsoft Word, or RTF document file format of submissions is Microsoft Word (.DOCX) or Open Document Format (.ODT) format.

3. Whenever possible, Digital Object Identifiers (DOIs) should be provided for reference purposes.

4. The text is 1.5 line spacing; uses a 12-point font; employs italics, rather than underlining (except for URL addresses); and all illustrations, figures, and tables should be placed in the corresponding place within the text, rather than at the end of the article

5. The text adheres to the stylistic and bibliographic requirements outlined in the Authors Guidelines, which appear in About the Journal.

6. If submitted to a peer-reviewed section of the journal, the instructions are in Ensuring Anonymous Review.

7. The text complies with the standards outlined in Citation and Referencing Guidelines.

\section{CITATION AND REFERENCING GUIDELINES}

\section{Citation in text}

\subsection{Bibliographic references for citations in the text should appear in par- enthetical notations in the body of the article, never in footnotes.}

1.2. Extensive citations (four or more lines): they will be highlighted from the text by an indented paragraph, with $11 »$ font size, without quotation marks. In this case, the full stop will go before the parenthesis containing the bibliographic reference and not after it. 


\section{3, Referencing an author's work}

- When referencing an idea of an author whose name is not expressly cited in the text: add author's surname followed by page number. The comma is omitted [,] between the surname and the page number. E.g:

«En la cultura renacentista y humanística italiana este debate sobre los sexos tuvo una muy especial viveza» (Blanco 265).

El debate sobre los sexos fue muy vivo en la cultura del Renacimiento y del Humanismo italianos (Blanco 265).

- When referencing an idea of an author whose name is quoted in the text: only the page number is included in parenthesis. E.g:

Según Moi, «la obra de Kristeva no se puede considerar fundamentalmente feminista» (174).

\subsection{Referencing several works by the same authors}

If more than one work by the same author is mentioned, the name of the author and the short title of each work should be included, in italics or in quotation marks, depending on the type of publication. A comma [,] should be inserted ONLY between the author's name and the title of the work. E.g.:

(Frye, Anatomy 237)

(Haraway, «Manifiesto para Cyborgs» 620)

\subsection{Referencing a work by several authors}

- If the work has 2 or 3 authors, they should all be cited. E.g.:

No podemos olvidar que «estableciendo relaciones igualitarias de poder se contribuye a una democratización de la sociedad y de la vida doméstica» (Orive Álvarez, Asián Chaves y González Limón 525).

- If the work has 4 or more authors, only the name of the first one should appear, adding later «et al. 


\subsection{How to cite a corporate author's work}

The name of the entity or body should be part of the text. If it is entered in the body of the text, known terms should be abbreviated. E.g:

(ONU, Comisión Económica para África 79-86).

\subsection{How to cite an anonymous paper}

The title should be included in italics or in quotation marks, depending on the type of bibliographic reference. E.g.:

(Lineamientos curriculares de la educación preescolar 21)

\subsection{How to cite a work in several volumes}

In addition to the author's last name, the volume number should be included, and adding the page numbers after a spaced colon. If the quotation refers to the whole volume, it is not necessary to include the page(s). E.g:

(Wellek 2: 1-10)

(Wellek, vol. 2)

1.9. Do not use «cfr.», «see», «vine», «see» or «comp. In no case are indications such as «op. cit.», «art. cit.», «loc. cit.», «id.», «ibid.», «supra», «infra», «passim» used.

\section{Final list of cited works}

2.1. Bibliographic entries will appear only at the end of the document. Only resources cited in the preparation of the work shall be included, so that each citation has its corresponding reference in the final reference list.

2.2. The full reference to the authors' and publishers' names should be included (first and last names), and never in capital letters.

2.3. When including a work by several authors, only the first author's name is preceded by the last name.

2.4. Order of references in the final reference list: 
- References must be sorted alphabetically by the author's surname, or by the first author's surname in the case of several authors.

- When more than one work by the same author is included, they must be sorted alphabetically by title. Also, in the second and subsequent entries, if any, the surname and the name of the author or author must be repeated in full. E.g.:

Canales Serrano, Antonio Francisco. «Las mujeres y la enseñanza científico-tecnológica en la España del siglo XX». Clepsydra: revista de estudios de género y teoría feminista 5 (2006): 111-128.

Canales Serrano, Antonio Francisco. «Mujer, franquismo y educación científica». Memorias del IX Congreso Iberoamericano de Ciencia, Tecnología y Género. Madrid: Organización de Estados Iberoamericanos, 2012.

- The works of one author made in collaboration with other authors must be sorted by the second author's surname.

- Individual publications must be placed before collaborative publications.

\subsection{Each reference entry must be organised as follows}

\subsubsection{Books and monographs}

- With only one author, compiler or publisher: Surname, First name. Title of the book in italics. Edition used. Number of volumes [if more than one]. Place of publication: Publisher's name, Date of publication. E.g.:

Bloom, Harold. Poetry and Repression: Revision from Blake to Stevens. New Haven: Yale University Press, 1976.

Moi, Toril, ed. The Kristeva Reader. Oxford: Blackwell Publishers, 1986.

Pardo Bazán, Emilia. Obras completas. Vol. 2. Ed. Federico Carlos Sainz de Robles. Madrid: Aguilar, 1957.

- With several authors, compilers or publishers: Surname, Names; and Names Surnames. Title in Italics. City: Publisher, year. E.g.:

Anderson, Bonnie and Judith P. Zinsser. Historia de las mujeres: una historia propia. 2 vols. Barcelona: Crítica, 1991. 
Martínez Costa, Carme, Amaia Lusa García, María Dolores Calvet Puig, Isabel Gallego Fernández, Olga Pons Peregort, and Marta Tura Solvas. Guía para el diseño y la implantación de un Plan de Igualdad en las universidades. Valencia: Institut Català de les dones, 2006.

Perrot, Michelle, y Georges Duby, eds. Historia de las mujeres. Madrid: Taurus, 1991.

\subsubsection{Journal articles}

In the case of journals, the issue and part numbers should always appear in Arabic numerals.

- With only one author: Surname, First name «Title». Journal in italics volume no. Issue or copy No. (year): pages (without pg./pgs). E.g.:

Valcárcel, Amelia. «El primer ensayo feminista de una teoría del poder». Panorama 9 (1990): 59-64.

Vogel, Lisa. «Erotica, the Academy and Art Publishing: A Review of Woman as Sex Object. Studies in Erotic Art, 1730-1970, New York, 1972». Art Journal 35.4 (1976): 378-385.

- With several authors: Surname, Name; and Name Surname. «Title». Journal in italics volume no. Issue or copy No. (year): pages (without pg./pgs). E.g.:

López-Zafra, Esther and Rocío García Retamero. «Mujeres y liderazgo: ¿discapacitadas para ejercer el liderazgo en el ámbito público?». Feminismo/s 13 (2009): 85-104.

\subsubsection{Book chapters and collaborations in collective works}

Author's surname, author's name. "Title of the work». Title of the book in italics. Ed./Eds. Publisher's name and surname. Number of volumes [if more than one]. Place of publication: Publisher, year of publication. Pages. E.g.:

Smith-Rosenberg, Carroll. «Writing History: Language, Class and Gender». Feminist Studies. Ed. Teresa de Lauretis. Bloomington: Indiana University Press, 1986. 31-54. 


\subsubsection{PhD thesis}

Author's surname, author's name. Title of the PhD thesis in italics. Diss. University awarding the title, year. E.g.:

Gómez Cama, M. ${ }^{a}$ del Carmen. Presencia, evolución y participación de las mujeres en la Universidad: la Universidad de Cadiz. Diss. U. de Cádiz, 2015.

Fullerton, Matilda. Women's Leadership in the Public Schools: Towards a Feminist Educational Leadership Model. Diss. Washington State University. Ann Arbor: UMI, 2001.

\subsubsection{Press quotes}

Author's surname, author's name. «Title of the work». Name of the newspaper in italics Day Month Year: pages. E.g.:

Lara, Fernando. «Victoria Kent, una mujer de suerte». Triunfo 22 October 1977: 62.

\subsubsection{Websites and ebooks}

- References to electronic documents follow the same pattern of printed documents, although additional data must be included.

- They must contain, at least: Surname, First name. Title. Website name. Organisation responsible. Date of query.

- You are not required to include the URL unless the text is difficult to locate. In that case, it must be placed after the date of query. E.g.:

Safa Barraza, Patricia, and Juan Manuel Ramírez Sáiz. «Deterioro urbano y calidad de vida en las grandes urbes: la participación de las mujeres en las organizaciones vecinales». La ventana 54 (2011): 110-145. 20 April 2015.

Naciones Unidas. Informe de la Cuarta Conferencia Mundial sobre la Mujer, 1996. 4 June 2014. http://www.un.org/womenwatch/daw/beijing/pdf/ Beijing\%20full\%20report\%20S.pdf

García Landa, José Ángel, comp. A Bibliography of Literary Theory, Criticism and Philology. U. de Zaragoza, 2008. 77. http://personal.unizar. es/garciala/bibliography.html. 15 May 2008. 


\subsubsection{Reference list using the DOI}

The documents with a DOI must use it at the end of the reference as a URL link. e.g:

Medina Arjona, Encarnación. «Ecofeminismo e interculturalidad». Feminismo/s 34 (2019): 199-214. DOI: https://doi.org/10.14198/ fem.2019.34.09

\section{HOW TO PROPOSE A MONOGRAPHIC SERIES}

The proposal for a monographic series for Feminismo/s journal should be submitted to the editor of the journal (Helena.Establier@ua.es) with the following information:

1. Provisional title of the monographic series.

2. A comprehensive $\mathrm{CV}$ of its coordinator/s.

3. A description of the objectives and justification of the relevance of the dossier topic (300 words).

4. A provisional list of participants in the volume, along with a short biography and bibliographical review of each of them, with the titles of the planned works and a brief summary of each one where the intended objectives are included (150 words).

5. Proposals will be considered by the Editorial Board of Feminismo/s within a maximum period of one month from the date of receipt. 


\section{PEER REVIEW PROCESS}

1) Original papers are firstly assessed by the Editorial Board of the journal on their suitability to the fields of knowledge and the requirements established for authors by the journal.

2) The Editorial Board sends out the original documents (without the name of the author) to two external reviewers. On these views, the Editorial Board decides on rejecting or accepting the article or to apply for modifications by the author. Authors are given a detailed and reasoned notification where the content of original reports (edited) is exposed with specific indications for modifications if appropriate. Feminismo/s can send authors the original reports submitted, either complete or in part and always anonymously.

3) The report submitted by reviewers includes:

h) a global assessment of both the article and abstracts.

i) a quantitative evaluation of quality (good | acceptable | insufficient) according to these five criteria: originality and interest of the topic; relevance in relation to current research in the area; methodological rigour; significant and updated bibliography; clear expository style.

j) a final recommendation: publish | ask for modifications | reject.

\section{COVERAGE DISSEMINATION AND PRESENCE IN DATABASES}

The journal is indexed in ESCI (WOS), DOAJ, REDIB, Gender Watch (Proquest), InDICEs-CSIC, ERIH PLUS, MLA, CIRC, MlAR, Latindex, Dialnet, Ulrich's, Dulcinea, Google Scholar, SHERPA/RoMEO, RUA, DICE, REBIUN, RESH, OCLC WorldCat, Copac, SUDOC and ZDB/EZB. 


\section{PUBLICATION ETHICS AND MALPRACTICE STATEMENT}

The publication of articles in a peer-review journal is a direct reflection of the quality of the work of their authors, and the commitment and qualifications of the researchers who act as reviewers. Therefore Feminismo/s is a publication committed to the ethical principles of scientific activity on the following terms:

\section{Publication and authorship}

All manuscripts must include a list of references, and indicate whether they have received financial support. Works must be free of plagiarism or scientific fraud. Illustrative cases* of plagiarism and scientific fraud can be consulted in a non-exhaustive list below:

- Plagiarism: literal copy without quoting and referencing the source; substantial copying (research materials, processes, tables...); paraphrasing or reproducing ideas without citing the source and/or changing the original meaning; text-recycling (reusing a published own text) without indicating the source, and abusive paraphrasing even quoting the source.

- Scientific fraud: no recognition of all the participating researchers in the study, simultaneous submission to several publications, the division of a work in different parts ('slices') that share the same hypotheses, population and methods, as well as the use of false or unproven data. Finally, the authors should disclose potential conflicts of interest to the journal when a manuscript is sent.

* Source: http://www.ethics.elsevier.com/

\section{Authors' Responsibility}

- The manuscripts submission to Feminismo/s involves reading and acceptance of the journal publishing guidelines, including participation in an anonymous peer-review process. 
- All authors signing a work must have contributed significantly to its development and must agree both with the end result and with the manuscript submission for evaluation.

- Manuscripts must acknowledge all authors who have participated in their elaboration.

- Data used in the article must be real and authentic

- The authors assume the obligation to retract/correct when possible errors are later detected.

- Articles must be original and cannot be sent simultaneously to any other publication.

\section{Review Process}

All articles submitted to the journal are subjected to a peer review process with the following characteristics:

- The selection of reviewers is done according to rules and principles based on both their qualification and the quality of their scientific production.

- The review process will be totally anonymous both for authors and for reviewers. Manuscripts and reviews will be treated confidentially.

- Reviewers will take into account for their evaluation criteria the respect for the ethical principles that are essential in scientific research.

- The judgments expressed in the reviews should be objective.

- Authors and reviewers should disclose all relationships and funding sources that could generate potential conflicts of interest.

\section{Editors' Responsibilities}

- The editorial board has the responsibility and authority to accept or reject a manuscript based on the peer reviews.

- The editorial board will reveal any relationships or funding sources that could potentially be considered conflicts of interest regarding the rejection or the acceptance of manuscripts.

- The journal only accepts manuscripts when reasonably certain of compliance with editorial standards. 
- The editorial team is committed to preserve the anonymity of the reviewers so that they can never be associated with the reviewed manuscripts.

\section{Publishing ethical Issues}

The editorial board is committed to:

- Monitoring and maintaining the publishing ethics.

- Maintaining the integrity of the academic record.

- Avoid publishing plagiarized or fraudulently prepared material.

- Be willing to publish corrections, clarifications, retractions and apologies when needed.

- Provide support in the process of retracting articles.

- Perform all actions required to meet the standards of intellectual and ethical commitment.

\section{Plagiarism policy}

Feminismo/s Editorial Board is responsible for checking that the works submitted are original and do not incur plagiarism. The University of Alicante uses a software programme called Turnitin for this purpose. It is a tool that prevents and avoids academic and professional plagiarism by proving the similarities of a document with multiple sources of information (Internet, scientific articles and its internal database) and identifying non-original content translated from English. Additionally, the Editorial Board has a number of free plagiarism detection programs available on the UA website, such as Copyscape, Plagium, PlagScan, Dupli Checker, Plagiarisma, Article Checker, Viper and Antiplagiarist (https://biblioteca.ua.es/en/research-and-publish/pi/ plagiarism.html)

The Editorial Board reserves the right to withdraw any work received, accepted or already published if plagiarism, falsification or duplicate publication is detected, as well as the various cases of scientific misconduct listed above. Likewise, it promotes the publication of corrections or retractions in the face of detected errors. 


\section{DISCLAIMER}

Regarding the provisions in articles 138-143 of the Spanish Law on Intellectual Property, the publication of a work prejudicial to those rights shall be the responsibility of the author. The editorial board of Feminismo/s is not responsible, in any case, for the credibility and authenticity of the works. In the same way, the opinions and facts expressed in each article are the sole responsibility of the authors and Feminismo/s does not necessarily agree with them.

\section{COPYRIGHT WARNING}

Authors who publish in Feminismo/s agree to the following terms:

1. Authors will retain the rights on their work, even if they will be granting Feminismo/s a non-exclusive right of use to reproduce, edit, distribute, publicly communicate and show their work. Therefore, authors are free to engage in additional, independent contracts for non-exclusive distribution of the works published in this journal (such as uploading them to an institutional repository or publishing them in a book), as long as the fact that the manuscripts were first published in this journal is acknowledged.

2. Authors assure that Feminismo/s is the first medium that publishes their work and guarantee that while it is being assessed for possible publication in our journal, it has not been submitted or will be submitted to other media.

3. Works are published under a 4.0 Creative Commons Attribution license (CC BY 4.0), unless otherwise specified, which means that the material can be shared and adapted as long as it is attributable to the author, the first medium published and a link to the license is provided. Likewise, any modification on the original work must be reported

4. Authors are allowed - and encouraged - to publish their works electronically after publication in Feminismo/s (as well as in institutional repositories, on its website...) in order to achieve fruitful exchanges and more citations of the work (See The Effect of Open Access, in English). 


\section{HOW TO GET THE JOURNAL}

The journal (issues 1-30) is on sale at $€ 12$ through the University of Alicante Publications Service

Sales:

Tel. 965909445

E-Mail: Publicaciones.Ventas@ua.es

The journal exchanges publications with other journals from Spanish and international academic and/or research institutions. 


\section{POLÍTICA DE ACCESO ABIERTO}

Feminismo/s se ofrece a la comunidad investigadora en acceso abierto inmediato a su contenido, sin ningún tipo de periodo de embargo, basado en el principio de que ofrecer al público un acceso libre a las investigaciones ayuda a un mayor intercambio global de conocimiento. En este sentido, Feminismo/s sigue la política de acceso abierto definida por la Declaración de Budapest (BOAI, 2002): «disponibilidad gratuita en la Internet pública, para que cualquier usuario la pueda leer, descargar, copiar, distribuir, imprimir, con la posibilidad de buscar o enlazar todos los textos de estos artículos, recorrerlos para indexación exhaustiva, usarlos como datos para software, o utilizarlos para cualquier otro propósito legal, sin barreras financieras, legales o técnicas, distintas de la fundamental de ganar acceso a la propia Internet».

Feminismo/s es una revista científica sin ánimo de lucro y por tanto no contempla el abono de ninguna tasa por presentación/envío de manuscritos ni tampoco ninguna cuota por la publicación de artículos.

\section{CÓMO PRESENTAR UN ORIGINAL}

1. Los trabajos serán el resultado de una investigación original y deberán contener conclusiones novedosas apoyadas en una metodología debidamente planteada y justificada. Sólo se admitirán trabajos inéditos que no estén en proceso de evaluación por otras revistas.

2. La extensión de los trabajos presentados no excederá de 9000 palabras, incluidas notas y bibliografía.

3. El número y extensión de las notas al pie se reducirá a lo indispensable. 
4. Los autores someterán sus artículos en Word a través del correo electrónico de la revista (revistafeminismos@ua.es) y deberán aportar imprescindiblemente:

- En hoja aparte: nombre del autor o de la autora, institución a la que pertenece, código ORCID, dirección profesional completa y dirección electrónica.

- Archivo del texto en formato Word, ANONIMADO, con:

- El título en español y en inglés.

- Un resumen de unas 150 palabras en español, y su correcta versión inglesa. Este resumen deberá atenerse al siguiente esquema: objetivos del trabajo, metodología y conclusiones o tesis.

- Cinco palabras-clave en español, y su correcta versión inglesa.

- El texto del original.

5. Los trabajos se someterán a un proceso de selección y evaluación anónimo y por pares, según el procedimiento y los criterios hechos públicos por la revista.

\section{NORMAS EDITORIALES Y DE ESTILO}

\section{Directrices para autoras/es}

La revista Feminismo/s publica dos tipos de trabajos: artículos de investigación y reseñas de libros. El Consejo de Redacción establece las normas generales que se describen a continuación.

La revista no cobra tasas por envío de trabajos, ni tampoco cuotas por la publicación de sus artículos.

Se aceptan trabajos en inglés o español.

Para poder enviar un artículo las/los autoras/es deben Iniciar sesión o Registrarse si no lo han hecho con anterioridad. 


\section{ARTÍCULOS DE INVESTIGACIÓN}

- Los artículos de investigación, que deberán ser inéditos, tendrán una extensión máxima de 9.000 palabras con las notas y cuadros inclusive (salvo excepciones justificadas, previa autorización del Consejo de Redacción).

- Deberán estar escritos con letra Times New Roman 12. El texto se presentará debidamente justificado y con un interlineado de 1'5. La primera línea de cada párrafo irá sangrada.

- Los diferentes apartados del texto se ordenarán siguiendo la numeración arábiga $(1,2,3, \ldots)$ y el título de cada uno de ellos irá en letra mayúscula y en negrita. Los subapartados se enumerarán de la siguiente manera: 1.1, 1.2, 1.3, etc. y sus títulos irán en minúscula y en negrita.

- Las notas al pie, escritas con letra Times New Roman 10, se reducirán a lo indispensable, se utilizarán solo para información suplementaria y en ningún caso serán bibliográficas. La llamada en el texto irá antes del signo de puntuación.

- Después de las conclusiones, el artículo finalizará con un apartado de Referencias bibliográficas en el que se coloquen, siguiendo un criterio alfabético y cronológico (en caso de haber varias obras de una misma autora/ un mismo autor), todos los trabajos que se citan a lo largo del artículo. Es importante que cada referencia bibliográfica acabe con un punto y que se deje un salto de línea en blanco entre las referencias. Ver Normas de citación y referencias.

- Las fotografías e imágenes se entregarán en formato digital, separadas del texto, en formato tif, con una calidad de 300 puntos por pulgada. Deben ir identificadas convenientemente según sean citadas en el texto.

- En su primera versión los artículos deberán presentarse de forma anónima (sin autorreferencias que desvelen la autoría, sin menciones a proyectos de investigación en los que se inscriba el artículo y 
sin información personal en las propiedades del documento), garantizando de este modo el doble ciego en el proceso de evaluación externa.

- Si el artículo fuera aceptado para su publicación, el texto definitivo deberá ir firmado en la primera página, después del título (alineado a la derecha) y los datos sobre la autoría y la afiliación institucional tendrán que aparecer en este orden:

- El nombre de la autora/ del autor.

- La institución a la que pertenece (de forma desarrollada y sin siglas) y la ciudad en la que se encuentra la institución.

- El correo electrónico de la autora/ del autor.

- El identificador científico ORCID. Ejemplo: https://orcid. org/0000-0002-1825-0097.

- Al inicio de cada artículo, e independientemente del idioma en el que esté redactado, siempre se añadirá el título del trabajo (en español y en inglés) y un resumen con una extensión máxima de 150 palabras (en español y en inglés), en el que se describa la justificación del objeto de estudio, los objetivos, la metodología, los principales resultados y las conclusiones más relevantes. Se deberá incluir también entre 4 y 8 palabras clave (en español y en inglés), separadas por punto y coma.

- Además, en archivo aparte, que se adjuntará en la plataforma OJS ( «Cargar los archivos complementarios»), se incluirá una breve nota curricular, de una extensión aproximada de unas 10 líneas, sobre la formación académica, situación profesional y labor investigadora de la autora/ del autor.

- El incumplimiento de estos criterios básicos podrá ser motivo de exclusión del proceso de evaluación por pares.

- La corrección de las primeras pruebas correrá a cargo de las/los autoras/es, para lo que dispondrán de un plazo máximo de 10 días. 


\section{RESEÑAS DE LIBROS}

- Las reseñas de libros de reciente publicación (de los dos últimos años) tendrán una extensión máxima de 1.500 palabras, especificándose el autor o la autora o editor/a, título, lugar de publicación, editorial, fecha de publicación, ISBN y número de páginas.

- El autor/la autora de la reseña, facilitará su nombre y apellidos, afiliación institucional, dirección de correo electrónico e identificador ORCID.

- Es aconsejable el envío, como un archivo complementario, de una imagen de la cubierta principal de la publicación reseñada.

- El autor/la autora seguirá las instrucciones del apartado Normas de citación y referencias.

\section{Lista de comprobación para la preparación de envíos}

Como parte del proceso de envío, las autoras/los autores están obligadas/ os a comprobar que su envío cumpla todos los elementos que se muestran a continuación. Se devolverán a las autoras/ los autores aquellos envíos que no cumplan estas directrices.

1. El envío no ha sido publicado previamente ni se ha sometido a consideración por ninguna otra revista (o se ha proporcionado una explicación al respecto en los Comentarios al editor/a).

2. El archivo de envío está en formato Microsoft Word (.DOCX) u Open Document Format (.ODT).

3. Siempre que sea posible, se proporcionan los identificadores DOI para las referencias.

4. El texto tiene interlineado de 1,$5 ; 12$ puntos de tamaño de fuente Times New Roman; se utiliza cursiva en lugar de subrayado (excepto en las direcciones URL); y todas las ilustraciones, figuras y tablas se encuentran colocadas en los lugares del texto apropiados, en vez de al final.

5. El texto se adhiere a los requisitos estilísticos y bibliográficos resumidos en las Directrices del autor/a, que aparecen en Acerca de la revista. 
6. Si se envía a una sección evaluada por pares de la revista, deben seguirse las instrucciones en Asegurar una evaluación anónima.

7. Cumple con las normas recogidas en Normas de citación y referencias.

\section{NORMAS DE CITACIÓN Y REFERENCIAS}

\section{Normas para citar en el texto}

\subsection{Las referencias bibliográficas de las citas en el texto irán entre parén-} tesis en el cuerpo del artículo nunca en las notas al pie.

1.2. Citas extensas (cuatro o más líneas): se destacan del texto mediante un párrafo sangrado, con letra de 11", sin entrecomillar. En este caso, el punto irá delante del paréntesis que contiene la referencia bibliográfica y no después.

\subsection{Cómo citar un trabajo de un/a autor/a:}

- Referencia a una idea de un/a autor/a cuyo nombre no se cita expresamente en el texto: apellido del/de la autor/a seguido del número de página. No se pone coma [,] entre el apellido y el número de página. Ejs.:

«En la cultura renacentista y humanística italiana este debate sobre los sexos tuvo una muy especial viveza» (Blanco 265).

El debate sobre los sexos fue muy vivo en la cultura del Renacimiento y del Humanismo italianos (Blanco 265).

- Referencia a una idea de un/una autor/a cuyo nombre sí se cita en el texto: sólo se recoge la página entre paréntesis. Ej.:

Según Moi, «la obra de Kristeva no se puede considerar fundamentalmente feminista» (174).

\subsection{Cómo citar varios trabajos de un/a mismo/a autor/a}

Si se menciona más de una obra de un/una mismo/a autor/a, debe incluirse el nombre del/ de la autor/a y el título abreviado de cada trabajo, en cursiva o entrecomillado, en función del tipo de publicación de la que se trate. Debe 
insertarse una coma [,] SOLAMENTE entre el nombre del/de la autor/a y el título de trabajo. Ejs.:

(Frye, Anatomy 237)

(Haraway, «Manifiesto para Cyborgs» 620)

\subsection{Cómo citar un trabajo de varios/as autores/as}

- Si el trabajo tiene 2 o 3 autores/as, deben citarse todos/as. Ej.:

No podemos olvidar que «estableciendo relaciones igualitarias de poder se contribuye a una democratización de la sociedad y de la vida doméstica» (Orive Álvarez, Asián Chaves y González Limón 525).

- Si el trabajo tiene 4 o más autores/as, puede citarse sólo el/la primero/a, añadiendo después «et al.»

\subsection{Cómo citar un trabajo de autoría corporativa}

Conviene que el nombre de la entidad u organismo forme parte del texto. Si se introduce en el cuerpo del texto, deben abreviarse los términos conocidos. Ej.:

(ONU, Comisión Económica para África 79-86).

1.7. Cómo citar un trabajo anónimo: debe incluirse el título en cursiva o entrecomillado, dependiendo del tipo de referencia bibliográfica de que se trate. Ej.:

(Lineamientos curriculares de la educación preescolar 21)

\subsection{Cómo citar un trabajo en varios volúmenes}

Debe incluirse, además del apellido del/de la autor/a, el número de volumen separado por un espacio, y las páginas separadas por dos puntos. Si la cita se refiere a todo el volumen, no es necesario recoger la/s páginas/s. Ejs.:

(Wellek 2: 1-10)

(Wellek, vol. 2) 
1.9. No se emplea «cfr.», «véase», «vid.», «ver»o «comp.». En ningún caso se emplean indicaciones como «op. cit.», «art. cit.», «loc. cit.», «id.», «ibid.», «supra», «infra», «passim».

\section{Lista final de obras citadas}

2.1. Las entradas bibliográficas aparecerán únicamente al final del documento. Se incluirán únicamente los recursos citados en la preparación del trabajo, de forma que cada cita tenga su correspondiente referencia en la lista de bibliografía final.

2.2. Los nombres de las/los autoras/es y editoras/es se darán completos (nombres y apellidos), y nunca en mayúsculas.

2.3. Al incluir una obra de varias/os autoras/es, solo en el primero se hace preceder el apellido.

2.4. Ordenación de referencias en la lista de bibliografía final:

- Las referencias se ordenarán alfabéticamente por el apellido del autor o de la autora, o por el apellido del primer autor o de la primera autora en el caso de que sean varios/as.

- Cuando se incluye más de una obra de un mismo autor/una misma autora, se ordenan cronológicamente por el año de publicación. Además, en la segunda entrada y siguientes, si las hay, se debe repetir el nombre completo del autor/de la autora. Ejs.:

Canales Serrano, Antonio Francisco. «Las mujeres y la enseñanza científico-tecnológica en la España del siglo XX». Clepsydra: revista de estudios de género y teoría feminista 5 (2006): 111-128.

Canales Serrano, Antonio Francisco. «Mujer, franquismo y educación científica». Memorias del IX Congreso Iberoamericano de Ciencia, Tecnología y Género. Madrid: Organización de Estados Iberoamericanos, 2012.

Los trabajos de un mismo autor/una misma autora realizados en colaboración con autores/as diferentes, se han de ordenar por el apellido del segundo autor/ de la segunda autora. 
- Las publicaciones individuales se colocan antes que las publicaciones en colaboración.

2.5. Cada entrada se organizará de la siguiente manera:

2.5.1. Libros y monografías

- Con un/a solo/a autor/a, compilador/a o editor/a: Apellido/s, Nombre. Título del libro en cursiva. Número de volúmenes [si más de uno]. Edición utilizada. Lugar de publicación: Nombre de la editorial, Fecha de publicación. Ejs.:

Bloom, Harold. Poetry and Repression: Revision from Blake to Stevens. New Haven: Yale University Press, 1976.

Moi, Toril, ed. The Kristeva Reader. Oxford: Blackwell Publishers, 1986.

Pardo Bazán, Emilia. Obras completas. Vol. 2. Ed. Federico Carlos Sainz de Robles. Madrid: Aguilar, 1957.

- Con varios/as autores/as, compiladores/as o editores/as: Apellido/s, Nombre, y Nombre Apellido/s. Título en cursiva. Número de volúmenes [si más de uno]. Ciudad: Editorial, año. Ejs.:

Anderson, Bonnie, y Judith P. Zinsser. Historia de las mujeres: una historia propia. 2 vols. Barcelona: Crítica, 1991.

Martínez Costa, Carme, Amaia Lusa García, María Dolores Calvet Puig, Isabel Gallego Fernández, Olga Pons Peregort, y Marta Tura Solvas. Guía para el diseño y la implantación de un Plan de Igualdad en las universidades. Valencia: Institut Català de les Dones, 2006.

Perrot, Michelle, y Georges Duby, eds. Historia de las mujeres. Madrid: Taurus, 1991.

\subsubsection{Artículos de revista}

En las revistas, el número de volumen y fascículo se dará siempre con caracteres arábigos.

- Con un solo autor o una sola autora: Apellido/s, Nombre. «Título». Revista en cursiva n. ${ }^{\circ}$ de volumen. N. ${ }^{\circ}$ de fascículo o ejemplar (año): página/s (sin p./pp.). Ejs.: 
Valcárcel, Amelia. «El primer ensayo feminista de una teoría del poder». Panorama 9 (1990): 59-64.

Vogel, Lisa. «Erotica, the Academy and Art Publishing: A Review of Woman as Sex Object. Studies in Erotic Art, 1730-1970, New York, 1972». Art Journal 35.4 (1976): 378-385.

- Con varios autores o varias autoras: Apellido/s, Nombre, y Nombre Apellido/s. «Título». Revista en cursiva n. ${ }^{\circ}$ volumen. N. ${ }^{\circ}$ de fascículo o ejemplar (año): páginas (sin p./pp.). Ejs.:

López-Zafra, Esther, y Rocío García Retamero. «Mujeres y liderazgo: ¿discapacitadas para ejercer el liderazgo en el ámbito público?». Feminismo/s 13 (2009): 85-104.

\subsubsection{Capítulos de libro y colaboraciones en libros colectivos}

Apellido/s del autor o de la autora, Nombre del autor o de la autora. «Título del trabajo». o Título del libro en cursiva. Ed./Eds. Nombre y apellido/s del editor o de la editora. Número de volumen [si más de uno]. Lugar de publicación: Editorial, año de publicación. Páginas. Ej.:

Smith-Rosenberg, Carroll. «Writing History: Language, Class and Gender» Feminist Studies. Ed. Teresa de Lauretis. Bloomington: Indiana University Press, 1986. 31-54.

\subsubsection{Tesis Doctorales}

Apellido/s del autor o de la autora, Nombre. Título de la tesis en cursiva. Diss. Universidad que otorga el título, año. Ejs.:

Gómez Cama, M. ${ }^{a}$ del Carmen. Presencia, evolución y participación de las mujeres en la Universidad: la Universidad de Cadiz. Diss. U. de Cádiz, 2015.

Fullerton, Matilda. Women's Leadership in the Public Schools: Towards a Feminist Educational Leadership Model. Diss. Washington State University. Ann Arbor: UMI, 2001.

\subsubsection{Citas de prensa}

Apellido/s del autor o de la autora, Nombre. «Título del trabajo». Nombre del periódico en cursiva Día Mes Año: página/s. Ej.: 
Lara, Fernando. «Victoria Kent, una mujer de suerte». Triunfo 22 octubre 1977: 62.

\subsubsection{Sitios Web y libros electrónicos}

- Las referencias de los documentos electrónicos siguen el mismo esquema que las de los documentos impresos, aunque añadiendo algunos datos.

- Como mínimo, deben constar de: Apellido/s, Nombre. Título. Nombre del sitio web. Organización responsable. Fecha de consulta.

- No es necesario incluir la URL salvo que el texto sea de difícil localización. En ese caso, debe colocarse después de la fecha de consulta. Ejs.:

Safa Barraza, Patricia, y Juan Manuel Ramírez Sáiz. «Deterioro urbano y calidad de vida en las grandes urbes: la participación de las mujeres en las organizaciones vecinales». La ventana 54 (2011): 110-145. 20 abril 2015.

Naciones Unidas. Informe de la Cuarta Conferencia Mundial sobre la Mujer, 1996. 4 junio 2014. http://www.un.org/womenwatch/daw/beijing/pdf/ Beijing\%20full\%20report\%20S.pdf

García Landa, José Ángel, comp. A Bibliography of Literary Theory, Criticism and Philology. U. de Zaragoza, 2008. Web. http://personal.unizar. es/garciala/bibliography.html. 15 mayo 2008.

\subsubsection{Referencias bibliográficas con DOI}

En aquellos documentos que dispongan de un DOI, este debe figurar al final de la referencia con formato de enlace URL. Ej.:

Medina Arjona, Encarnación. «Ecofeminismo e interculturalidad». Feminismo/s 34 (2019): 199-214. DOI: https://doi.org/10.14198/ fem.2019.34.09 


\section{CÓMO PROPONER UN DOSIER MONOGRÁFICO}

La propuesta de un dosier monográfico para la revista Feminismo/s se hará llegar a la directora de la revista (Helena.Establier@ua.es) y contendrá la siguiente información:

1. Título provisional del dosier monográfico.

2. Un C.V. completo de la coordinadora/del coordinador (o de las coordinadoras/los coordinadores) del mismo.

3. Una descripción de sus objetivos y una justificación de la oportunidad del tema del dosier (300 palabras).

4. Un listado provisional de participantes en el volumen, acompañado de una breve reseña bio-bibliográfica de cada una/uno de ellas/os, de los títulos de los trabajos previstos y de un breve resumen de cada uno donde se incluyan los objetivos previstos (150 palabras).

5. Las propuestas serán consideradas por el Consejo de Redacción de Feminismo/s en el plazo máximo de un mes a partir de la fecha de recepción de las mismas. 


\section{PROCESO DE EVALUACIÓN POR PARES}

1) Los originales recibidos son valorados, en primera instancia, por el Consejo de Redacción de la revista para decidir sobre su adecuación a las áreas de conocimiento y a los requisitos que la revista ha publicado para los/las autores/as.

2) El Consejo de Redacción envía los originales, sin el nombre del autor o de la autora, a dos revisores/as externos/as al Consejo Editorial. Sobre esos dictámenes, el Consejo de Redacción decide rechazar o aceptar el artículo o solicitar modificaciones al autor o a la autora del trabajo. Los/las autores/ as reciben una notificación detallada y motivada donde se expone, retocado, el contenido de los informes originales, con indicaciones concretas para la modificación si es el caso. Feminismo/s puede enviar a los/las autores/as los informes originales recibidos, íntegros o en parte, siempre de forma anónima.

3) El informe emitido por los/las revisores/as incluye:

a) una valoración global del artículo y de los resúmenes.

b) una valoración cuantitativa de la calidad (buena | aceptable | insuficiente) según estos cinco criterios: originalidad e interés del tema; pertinencia en relación con las investigaciones actuales en el área; rigor metodológico; bibliografía significativa y actualizada; pulcritud formal y articulación expositiva.

c) una recomendación final: publicar | solicitar modificaciones | rechazar. 


\section{COBERTURA, DIFUSIÓN Y PRESENCIA EN BASES DE DATOS}

La revista está indizada en ESCI (WOS), DOAJ, REDIB, GenderWatch (ProQuest), InDICEs-CSIC, ERIH PLUS, MLA, CIRC, MlAR, Latindex, Dialnet, Ulrich's, Dulcinea, Google Scholar, SHERPA/RoMEO, RUA, DICE, REBIUN, RESH, OCLC WorldCat, Copac, SUDOC y ZDB/EZB.

\section{PRINCIPIOS ÉTICOS DE PUBLICACIÓN}

La publicación de artículos en una revista con revisión por pares es un reflejo directo de la calidad del trabajo de sus autoras/es, y del compromiso y cualificación de los investigadoras/es que actúan como revisoras/es. Por ello Feminismo/s es una publicación comprometida con los principios éticos de la actividad científica en los siguientes términos:

\section{Publicación y autoría}

Todos los artículos deben incluir un listado de referencias, así como indicar si han recibido apoyo económico. Los trabajos deben estar libres de plagio o fraude científico, cuyos supuestos* se enumeran de manera no exhaustiva a continuación:

- Plagio: copia literal sin entrecomillar y citar la fuente; copia sustancial (materiales de investigación, procesos, tablas...); parafrasear o reproducir ideas sin citar la fuente y/o cambiando el significado original; reutilizar y enviar textos propios ya publicados sin indicar la fuente y el parafraseo abusivo incluso citando la fuente.

- Fraude científico: no reconocimiento de todas/os las/los investigadoras/es participantes en la elaboración del trabajo, el envío simultáneo a varias publicaciones, la división de un trabajo en partes diferentes que comparten las mismas hipótesis, población y métodos, así como la utilización de datos falsos o no probados. Finalmente, las/los autoras/ 
es deben declarar a la revista los potenciales conflictos de interés cuando envían un trabajo.

* Fuente: http://www.ethics.elsevier.com/

\section{Responsabilidad de las/los autoras/es}

- El envío de trabajos a Feminismos/s supone la lectura y aceptación de las normas editoriales y de publicación de la revista, incluida la participación en un proceso anónimo de evaluación por pares.

- Todas/os las/los autoras/es que firman un trabajo deben haber contribuido de manera significativa a su elaboración y deben estar de acuerdo con el resultado final y con el envío del trabajo para su evaluación.

- Los trabajos deben reconocer a todas/os las/los autoras/ que han participado en su elaboración.

- Los datos utilizados en el artículo deben ser reales y auténticos.

- Las/los autoras/es asumen la obligación de corregir y/o retractarse ante posibles errores detectados posteriormente.

- Los artículos han de ser inéditos y no pueden ser enviados simultáneamente a ninguna otra publicación.

\section{Proceso de revisión}

Todos los artículos enviados a la revista se someten a un proceso de revisión por pares con las siguientes características:

- La selección de los revisores se realiza en función de normas y principios previos basados tanto en su cualificación como en la calidad de su producción científica.

- El proceso de revisión será totalmente anónimo tanto para las/ los autoras/es como para las/los revisoras/es. Los artículos y sus revisiones serán tratados confidencialmente.

- Las/los revisoras/es consideran, entre sus criterios de evaluación, el respeto a los principios éticos esenciales en la investigación científica.

- Los juicios expresados en las revisiones deben ser objetivos. 
- Tanto autoras/es como revisoras/es deben revelar las relaciones y fuentes de financiación que puedan generar potenciales conflictos de intereses.

\section{Responsabilidades de las editoras/editores}

- El equipo editorial tiene la responsabilidad y la autoridad para aceptar o rechazar un artículo basándose en las revisiones.

- El equipo editorial revelará en su caso las relaciones o fuentes de financiación que puedan ser potencialmente consideradas como conflictos de intereses respecto a los artículos que rechaza o acepta.

- Sólo se aceptarán los artículos en los que existe una evidencia cierta sobre el cumplimiento de las normas editoriales.

- El equipo editorial se compromete a preservar el anonimato de las/ los revisoras/revisores de manera que nunca puedan asociarse con los artículos revisados.

\section{Cuestiones éticas de publicación}

El equipo editorial se compromete a:

- Vigilar y preservar los principios éticos de publicación.

- Mantener la integridad del expediente académico.

- Evitar la publicación de material plagiado o elaborado de manera fraudulenta.

- Estar abierto a la publicación de correcciones, clarificaciones, retractaciones y disculpas siempre que sea necesario.

- Ofrecer apoyo en el proceso de retractación de artículos.

- Realizar todas las acciones necesarias para cumplir los estándares de compromiso intelectual y ético.

\section{Política anti-plagio}

El Consejo de Redacción de Feminismo/s es responsable de comprobar que los trabajos presentados sean originales y no incurran en plagio. La Universidad de Alicante cuenta con software específico a tal efecto, como Turnitin, una herramienta para prevenir y evitar el plagio académico y profesional que 
comprueba las similitudes de un documento con múltiples fuentes de información (Internet, artículos científicos y con su base de datos interna) e identifica el contenido no original traducido del inglés. Adicionalmente, el Consejo de Redacción tiene a su disposición, a través de la página web de la U.A. una serie de programas gratuitos de detección del plagio, tales como Copyscape, Plagium, PlagScan, Dupli Checker, Plagiarisma, Article Checker, Viper o Antiplagiarist (https://biblioteca.ua.es/es/investiga-y-publica/pi/ plagio.html)

El Consejo de Redacción se reserva el derecho de retirar cualquier trabajo recibido, aceptado o ya publicado en caso de constatarse plagio, falsificación o publicación duplicada, así como los diversos supuestos de fraude científico anteriormente enumerados. Del mismo modo, promueve la publicación de correcciones o retractaciones frente a errores detectados.

\section{AVISO LEGAL}

A efectos de lo estipulado en los artículos 138-143 de la Ley de Propiedad Intelectual, la publicación de un trabajo que atente contra dichos derechos será responsabilidad de la autora o del autor. El equipo editorial de Feminismo/s no se hace responsable, en ningún caso, de la credibilidad y autenticidad de los trabajos. Del mismo modo, las opiniones y hechos expresados en cada artículo son de exclusiva responsabilidad de sus autoras/es y Feminismo/s no se identifica necesariamente con ellas/os.

\section{AVISO DE DERECHOS DE AUTOR/A}

Las/los autoras/es que publican en Feminismo/s están de acuerdo en los siguientes términos:

1. Las/Los autoras/es conservan los derechos sobre sus trabajos, aunque ceden de forma no exclusiva los derechos de explotación (reproducción, edición, distribución, comunicación pública y exhibición) a la revista. Las/los autoras/es son, por tanto, libres de hacer acuerdos contractuales adicionales 
independientes para la distribución no exclusiva de la versión de la obra publicada en la revista (por ejemplo, alojarlo en un repositorio institucional o publicarlo en un libro), siempre que medie un reconocimiento de su publicación inicial en esta revista.

2. Las/los autoras/es aseguran que Feminismo/s es el primer medio que publica su obra y garantizan que mientras se encuentra en fase de valoración y posible publicación en nuestra revista no se ha enviado ni enviará a otros medios.

3. Los trabajos se publican bajo una licencia de Creative Commons Reconocimiento 4.0 (CC BY 4.0), salvo que se indique lo contrario, lo cual significa que se puede compartir y adaptar el material siempre que medie atribución del autor/a, del primer medio que publica y se proporcione un enlace a la licencia. Igualmente hay que indicar si se han realizado cambios.

4. Se permite y alienta a los/las autores/as a publicar su obra electrónicamente tras su publicación en Feminismo/s (como en repositorios institucionales, en su página web...) con el fin de lograr intercambios productivos y conseguir que la obra logre mayor citación (véase The Effect of Open Access, en inglés).

\section{CÓMO OBTENER LA REVISTA}

Los números 1-30 de la revista se venden a un precio de 12 euros a través del Servicio de Publicaciones de la Universidad de Alicante.

Ventas:

Teléfono: 965909445

E-Mail: Publicaciones.Ventas@ua.es

La revista mantiene intercambios con publicaciones pertenecientes a otras instituciones académicas y/o investigadoras, españolas y extranjeras. 


\section{POLÍTICA D'ACCÉS OBERT}

Feminismo/s s'ofereix a la comunitat investigadora en accés obert immediat al seu contingut, sense cap tipus de període d'embargament, basat en el principi que oferir al públic un accés lliure a les investigacions ajuda a un major intercanvi global de coneixement. En aquest sentit, Feminismo/s segueix la política d'accés obert definida per la Declaració de Budapest (BOAI, 2002): «disponibilitat gratuïta en la Internet pública, perquè qualsevol usuari la puga llegir, descarregar, copiar, distribuir, imprimir, amb la possibilitat de cercar o enllaçar tots els textos d'aquests articles, recórrer-los per a indexació exhaustiva, usar-los com a dades per a programari, o utilitzar-los per a qualsevol altre propòsit legal, sense barreres financeres, legals o tècniques, diferents de la fonamental de guanyar accés a la pròpia Internet»

Feminismo/s és una revista científica sense ànim de lucre i per tant no contempla l'abonament de cap taxa per presentació/enviament de manuscrits ni tampoc cap quota per la publicació d'articles.

\section{COM PRESENTAR UN ORIGINAL}

1. Els treballs seran el resultat d'una investigació original i hauran de contenir conclusions noves que tinguen el suport d'una metodologia degudament plantejada i justificada. Només s'admetran treballs inèdits que no estiguen en procés d'avaluació per altres revistes.

2. L'extensió dels treballs presentats no excedirà les 9.000 paraules, incloent-hi notes i bibliografia.

3. El nombre i l'extensió de les notes a peu es reduirà a allò que siga indispensable. 
4. Les autores o autors sotmetran els seus articles en Word a través del correu electrònic de la revista (revistafeminismos@ua.es) i hauran d'aportar imprescindiblement:

- En full a part: nom de l'autor o de l'autora, institució a la qual pertany, codi ORCID, adreça professional completa i adreça electrònica.

- Arxiu del text en format Word, ANONIMAT, amb:

- El títol en espanyol i en anglès.

- Un resum d'unes 150 paraules en espanyol, i la correcta versió anglesa. Aquest resum haurà d'atenir-se a l'esquema següent: objectius del treball, metodologia i conclusions o tesis.

- Cinc paraules-clau en espanyol, i la correcta versió anglesa.

- El text de l'original.

5. Els treballs seran sotmesos a un procés de selecció i avaluació anònim i d'experts, segons el procediment i els criteris fets públics per la revista.

\section{NORMES EDITORIALS I D'ESTILS}

\section{Directrius per a autores/autors}

La revista Feminismo/s publica dos tipus de treballs: articles d'investigació i ressenyes de llibres. El Consell de Redacció estableix les normes generals que es descriuen a continuació.

La revista no cobra taxes per enviament de treballs, ni tampoc quotes per la publicació dels articles.

S'accepten treballs en anglès o espanyol.

Per a poder enviar un article les autores o els autors han d'iniciar sessió o registrar-s'hi si no ho han fet amb anterioritat.

\section{ARTICLES D'INVESTIGACIÓ}

- Els articles d'investigació, que hauran de ser inèdits, tindran una extensió màxima de 9.000 paraules amb les notes i quadres inclusivament (excepte excepcions justificades, amb l'autorització del Consell de Redacció). 
- Hauran d'estar escrits amb lletra Times New Roman 12. El text es presentarà degudament justificat i amb un interlineat d'1'5. La primera línia de cada paràgraf estarà sagnada.

- Els diferents apartats del text s'ordenaran seguint la numeració aràbiga $(1,2,3, \ldots)$ i el títol de cadascun estarà en lletra majúscula i en negreta. Els subapartats s'enumeraran de la manera següent: 1.1, 1.2, 1.3 , etc. i els títols estaran en minúscula i en negreta.

- Les notes al peu, escrites amb lletra Times New Roman 10, es reduiran a allò indispensable, s'utilitzaran només per a informació suplementària i en cap cas seran bibliogràfiques. La crida en el text anirà abans del signe de puntuació.

- Després de les conclusions, l'article acabarà amb un apartat de Referències bibliogràfiques en el qual es col-loquen, seguint un criteri alfabètic i cronològic (en cas d'haver-hi diverses obres d'un/a mateix/a autor/a), tots els treballs que se citen al llarg de l'article. És important que cada referència bibliogràfica acabe amb un punt i que es deixe un salt de línia en blanc entre les referències. Vegeu Normes de citació i referències.

- Les fotografies i imatges es lliuraran en format digital, separades del text, en format Tif, amb una qualitat de 300 punts per polzada. Han d'estar identificades convenientment segons siguen citades en el text.

- En la primera versió els articles hauran de ser presentats de manera anònima (sense autoreferències que revelen l'autoria, sense esments a projectes d'investigació en els quals s'inscriga l'article i sense informació personal en les propietats del document), fet que garanteix el doble cec en el procés d'avaluació externa.

- Si l'article fóra acceptat per a la publicació, el text definitiu haurà d'estar signat en la primera pàgina, després del títol (alineat a la dreta) i les dades sobre l'autoria i l'afiliació institucional hauran d'aparèixer en aquest ordre: 
- El nom de l'autora/autor.

- La institució a la qual pertany (de forma desenvolupada i sense sigles) i la ciutat en la qual es troba la institució.

- El correu electrònic de l'autora/autor.

- El número d'identificació científica ORCID. Exemple: https:// orcid.org/0000-0002-1825-0097.

- A l'inici de cada article, i independentment de l'idioma en què estiga redactat, sempre s'afegirà el títol del treball (en espanyol i en anglès) i un resum amb una extensió màxima de 150 paraules (en espanyol i en anglès), en el qual es descriga la justificació de l'objecte d'estudi, els objectius, la metodologia, els principals resultats i les conclusions més rellevants. S'haurà d'incloure també entre 4 i 8 paraules clau (en espanyol i en anglès), separades per punt i coma.

- A més, en un arxiu a part, que s'adjuntarà en la plataforma OJS ( «Carregueu els arxius complementaris»), s'inclourà una breu nota curricular, d'una extensió aproximada d'unes 10 línies, sobre la formació acadèmica, la situació professional i la tasca investigadora de l'autora/autor.

- Lincompliment d'aquests criteris bàsics podrà ser motiu d'exclusió del procés d'avaluació per experts.

- La correcció de les primeres proves serà a càrrec de les/dels autores/ autors, per a la qual cosa disposaran d'un termini màxim de 10 dies.

\section{RESSENYES DE LLIBRES}

- Les ressenyes de llibres de recent publicació (dels dos últims anys) tindran una extensió màxima de 1.500 paraules, i s'hi especificarà l'autor/a o l'editor/a, el títol, el lloc de publicació, l'editorial, la data de publicació, l'ISBN i el nombre de pàgines.

- Lautora o l'autor de la ressenya, facilitarà el seu nom i cognoms, l'afiliació institucional, l'adreça de correu electrònic i l'identificador ORCID. 
- És aconsellable l'enviament, com un arxiu complementari, d'una imatge de la coberta principal de la publicació ressenyada.

- L'autora o l'autor seguirà les instruccions de l'apartat Normes de citació i referències.

\section{Llista de comprovació per a la preparació de trameses}

Com a part del procés de la tramesa, els/les autor/autores estan obligats/des a comprovar que la tramesa complisca tots els elements que es mostren a continuació. Se'ls retomaran aquells enviaments que no complisquen aquestes directrius.

1. Lenviament no ha sigut publicat prèviament ni s'ha sotmès a consideració per cap altra revista (o s'ha proporcionat una explicació sobre aquest tema en els Comentaris a l'editor/a).

2. Larxiu d'enviament està en format Microsoft Word (.DOCX) o Open Document Format (.ODT).

3. Sempre que siga possible, es proporcionen els identificadors DOI per a les referències.

4. El text té interlineat d'1,5; 12 punts de grandària de font Times New Roman; s'utilitza cursiva en comptes de subratllat (excepte en les direccions URL); i totes les il-lustracions, figures i taules es troben col-locades en els llocs del text apropiats, i no al final.

5. El text s'adhereix als requisits estilístics i bibliogràfics resumits en les Directrius de l'autor/a, que apareixen en l'apartat Sobre la revista.

6. Si s'envia a una secció avaluada per experts de la revista, cal seguir les instruccions de l'apartat Assegurar una avaluació anònima.

7. Compleix amb les normes arreplegades en Normes de citació i referències.

\section{NORMES DE CITACIÓ I REFERÈNCIES}

\section{Normes per a citar en el text}

1.1. Les referències bibliogràfiques de les cites en el text estaran entre parèntesi en el cos de l'article, mai en les notes al peu. 
1.2. Cites extenses (quatre o més línies): es destaquen del text mitjançant un paràgraf sagnat, amb lletra de 11 punts de grandària, sense cometes. En aquest cas, el punt estarà davant del parèntesi que conté la referència bibliogràfica i no després.

\subsection{Com citar un treball d'un/a autor/a}

- Referència a una idea d'un/a autor/a el nom del/de la qual no se cita expressament en el text: cognom de l'autor/a seguit del número de pàgina. No es posa coma [,] entre el cognom i el número de pàgina. Exemples:

«En la cultura renacentista y humanística italiana este debate sobre los sexos tuvo una muy especial viveza» (Blanco 265).

El debate sobre los sexos fue muy vivo en la cultura del Renacimiento y del Humanismo italianos (Blanco 265).

- Referència a una idea d'un/una autor/al nom del qual sí que se cita en el text: només s'indica la pàgina entre parèntesi. Exemple:

Segons Moi, «la obra de Kristeva no se puede considerar fundamentalmente feminista» (174).

\subsection{Com citar diversos treballs d'un/a mateix/a autor/a}

Si s'esmenta més d'una obra d'una mateixa autora o d'un mateix autor, s'hi ha d'incloure el nom de l'autora o l'autor i el títol abreujat de cada treball, en cursiva o entre cometes, d'acord amb el tipus de publicació de què es tracte. Ha d'inserir-s'hi una coma [,] SOLAMENT entre el nom de l'autora i l'autor i el títol de treball. Exemples:

(Frye, Anatomy 237)

(Haraway, «Manifiesto para Cyborgs» 620)

\subsection{Com citar diversos treballs d'un/a mateix/a autor/a}

- Si el treball té 2 o 3 autors/es, han de ser citats/des tots/es. Ex.: 
No podemos olvidar que «estableciendo relaciones igualitarias de poder se contribuye a una democratización de la sociedad y de la vida doméstica» (Orive Álvarez, Asián Chaves y González Limón 525).

- Si el treball té 4 o més autors/as, pot citar-se només el/la primer/a, afegir-hi després «et al.»

\subsection{Com citar un treball d'autoria corporativa}

Convé que el nom de l'entitat o organisme forme part del text. Si s'introdueix en el cos del text, han d'abreujar-se els termes coneguts. Ex.:

(ONU, Comissió Econòmica per a Àfrica 79-86).

1.7. Com citar un treball anònim: ha d'incloure's el títol en cursiva o entre cometes, depenent del tipus de referència bibliogràfica de què es tracte. Ex.:

(Lineamientos curriculares de la educación preescolar 21)

\subsection{Com citar un treball en diversos volums}

S'hi ha d'incloure, a més del cognom de l'autor/a, el número de volum separat per un espai, i les pàgines separades per dos punts. Si la cita es refereix a tot el volum, no és necessari indicar-hi la/les pàgina/es. Exemples:

(Wellek 2: 1-10)

(Wellek, vol. 2)

1.9. No s'empra «cf.», «véase», «vid.», «ver» o «comp.». En cap cas s'empren indicacions com «op. cit.», «art. cit.», «loc. cit.», «id.», «ibid.», «supra», «infra», «passim».

\section{Llista final d'obres citades}

2.1. Les entrades bibliogràfiques apareixeran únicament al final del document. S'inclouran únicament els recursos citats en la preparació del treball, de manera que cada cita tinga la seua corresponent referència en la llista de bibliografia final. 
2.2. Els noms de les autores o dels autors i de les editores o dels editors hi apareixeran complets (noms i cognoms), i mai en majúscules.

2.3. En incloure una obra de diverses/os autores/autors només en el primer es fa precedir el cognom.

2.4. Ordenació de referències en la llista de bibliografia final:

- Les referències s'ordenaran alfabèticament pel cognom de l'autor o de l'autora, o pel cognom del/de la primer/a autor/a en el cas que en siguen diversos/es.

- Quan s'hi inclou més d'una obra d'un/a mateix/a autor/a, s'ordenen cronològicament per l'any de publicació. A més, en la segona entrada i següents, si n'hi ha, s'ha de repetir el nom complet de l'autor/de l'autora. Exemples:

Canales Serrano, Antonio Francisco. «Las mujeres y la enseñanza científico-tecnológica en la España del siglo XX». Clepsydra: revista de estudios de género y teoría feminista 5 (2006): 111-128.

Canales Serrano, Antonio Francisco. «Mujer, franquismo y educación científica». Memorias del IX Congreso Iberoamericano de Ciencia, Tecnología y Género. Madrid: Organización de Estados Iberoamericanos, 2012.

Els treballs d'un/a mateix/a autor/a realitzats en col-laboració amb autors/es diferents, s'han d'ordenar pel cognom del/de la segon/a autor/a.

- Les publicacions individuals es col-loquen abans que les publicacions en col-laboració.

\subsection{Cada entrada s'organitzarà de la manera següent}

\subsubsection{Llibres i monografies}

- Amb un/a solo/a autor/a, compilador/a o editor/a: Cognom/s, Nom. Títol del llibre en cursiva. Nombre de volums [si n'hi ha més d'un ]. Edició utilitzada. Lloc de publicació: Nom de l'editorial, Data de publicació. Exemples: 
Bloom, Harold. Poetry and Repression: Revision from Blake to Stevens. New Haven: Yale University Press, 1976.

Moi, Toril, ed. The Kristeva Reader. Oxford: Blackwell Publishers, 1986.

Pardo Bazán, Emilia. Obres completes. Vol. 2. Ed. Federico Carlos Sainz de Robles. Madrid: Aguilar, 1957.

- Amb diversos/es autors/es, compiladors/es o editors/es: Cognom/s, Nom, i Nom Cognom/s. Títol en cursiva. Nombre de volums [si n'hi ha més d'un]. Ciutat: Editorial, any. Exemples:

Anderson, Bonnie, i Judith P. Zinsser. Historia de las mujeres: una historia propia. 2 vols. Barcelona: Crítica, 1991.

Martínez Costa, Carme, Amaia Lusa García, María Dolores Calvet Puig, Isabel Gallego Fernández, Olga Pons Peregort, i Marta Tura Solvas. Guía para el diseño y la implantación de un Plan de Igualdad en las universidades. Valencia: Institut Català de les Dones, 2006.

Perrot, Michelle, i Georges Duby, eds. Historia de las mujeres. Madrid: Taurus, 1991.

\subsubsection{Articles de revista}

En les revistes, el número de volum i fascicle es donarà sempre amb caràcters aràbics.

- Amb un sol/a autor/a: Cognom/s, Nom. «Títol». Revista en cursiva núm. de volum. Núm. de fascicle o exemplar (any): pàgina/es (sense p./pp.). Exemples.:

Valcárcel, Amelia. «El primer ensayo feminista de una teoría del poder». Panorama 9 (1990): 59-64.

Vogel, Lisa. «Erotica, the Academy and Art Publishing: A Review of Woman as Sex Object. Studies in Erotic Art, 1730-1970, Nova York, 1972». Art Journal 35.4 (1976): 378-385.

- Amb diversos/es autors/es: Cognom/s, Nom, i Nom Cognom/s. «Títol». Revista en cursiva núm. volum. Núm. de fascicle o exemplar (any): pàgines (sense p./pp.). Ex.: 
López-Zafra, Esther, i Rocío García Retamero. «Mujeres y liderazgo: ¿discapacitadas para ejercer el liderazgo en el ámbito público?». Feminismo/s 13 (2009): 85-104.

\subsubsection{Capítols de llibre i col-laboracions en llibres col-lectius}

Cognom/s de l'autor/a, Nom de l'autor/a. «Títol del treball». o Títol del llibre en cursiva. Ed./Eds. Nom i cognom/s de l'editor/a. Número de volum [si n'hi ha més d'un]. Lloc de publicació: Editorial, any de publicació. Pàgines. Ex:

Smith-Rosenberg, Carroll. «Writing History: Language, Class and Gender». Feminist Studies. Ed. Teresa de Lauretis. Bloomington: Indiana University Press, 1986. 31-54.

\subsubsection{Tesis Doctorals}

Cognom/s de l'autor o de l'autora, Nom. Títol de la tesi en cursiva. Diss. Universitat que atorga el títol, any. Exemples.:

Gómez Cama, M. ${ }^{a}$ del Carmen. Presencia, evolución y participación de las mujeres en la Universidad: la Universidad de Cadiz. Diss. U. de Cádiz, 2015.

Fullerton, Matilda. Women's Leadership in the Public Schools: Towards a Feminist Educational Leadership Model. Diss. Washington State University. Ann Arbor: UMI, 2001.

\subsubsection{Cites de premsa}

Cognom/s de l'autor/a, Nom. «Títol del treball». Nom del periòdic en cursiva Dia Mes Any: pàgina/es Ex.:

Lara, Fernando. «Victoria Kent, una mujer de suerte». Triunfo 22 octubre 1977: 62.

\subsubsection{Llocs web i llibres electrònics}

- Les referències dels documents electrònics segueixen el mateix esquema que les dels documents impresos, encara que hi afegeixen algunes dades.

- Com a mínim, han de constar de: Cognom/s, Nom. Títol. Nom del lloc web. Organització responsable. Data de consulta. 
- No és necessari incloure-hi la URL llevat que el text siga de difícil localització. En eixe cas, ha de col-locar-se després de la data de consulta. Exemples.:

Safa Barraza, Patricia, i Juan Manuel Ramírez Sáiz. «Deterioro urbano y calidad de vida en las grandes urbes: la participación de las mujeres en las organizaciones vecinales». La ventana 54 (2011): 110-145. 20 abril 2015.

Naciones Unidas. Informe de la Cuarta Conferencia Mundial sobre la Mujer, 1996. 4 junio 2014. http://www.un.org/womenwatch/daw/beijing/pdf/ Beijing\%20full\%20report\%20S.pdf

García Landa, José Ángel, comp. A Bibliography of Literary Theory, Criticism and Philology. U. de Saragossa, 2008. http://personal.unizar.es/ garciala/bibliography.html. 15 maig 2008.

\subsubsection{Referències bibliogràfiques amb DOI}

En aquells documents que disposen d'un DOI, aquest ha de figurar al final de la referència amb format d'enllaç URL. Ex:

Medina Arjona, Encarnación. «Ecofeminismo e interculturalidad». Feminismo/s 34 (2019): 199-214. DOI: https://doi.org/10.14198/ fem.2019.34.09

\section{COM PROPOSAR UN DOSSIER MONOGRÀFIC}

La proposta d'un dossier monogràfic per a la revista Feminismo/s es farà arribar a la directora de la revista (Helena.establier@ua.es) i contindrà la informació següent:

1. Títol provisional del dossier monogràfic.

2. Un CV complet de la coordinadora o del coordinador (o de les coordinadores o coordinadors) del monogràfic.

3. Una descripció dels objectius i una justificació de l'oportunitat del tema del dossier (tres-centes paraules). 
4. Una llista provisional de participants en el volum, acompanyada d'una breu ressenya biobibliogràfica de cadascun o cadascuna dels o les participants, dels títols dels treballs previstos i d'un breu resum de cadascun en el qual s'incloguen els objectius previstos (cent cinquanta paraules).

5. Les propostes seran considerades pel Consell de Redacció de Feminismo/s en el termini màxim d'un mes a partir de la data de recepció.

\section{PROCÉS D'AVALUACIÓ PER EXPERTES/EXPERTS}

1) Els originals rebuts són valorats, en primera instància, pel Consell de Redacció de la revista per a decidir sobre l'adequació a les àrees de coneixement $\mathrm{i}$ als requisits que la revista ha publicat per als autors o les autores.

2) El Consell de Redacció envia els originals, sense el nom de l'autor o de l'autora, a dos revisors/es externs/es al Consell Editorial. Sobre eixos dictàmens, el Consell de Redacció decideix rebutjar o acceptar l'article o sol-licitar modificacions a l'autor o a l'autora del treball. Els/les autors/as reben una notificació detallada i motivada en què s'exposa, retocat, el contingut dels informes originals, amb indicacions concretes per a la modificació, si escau. Feminismo/s pot enviar als/a les autors/es els informes originals rebuts, íntegres o en part, sempre de forma anònima.

3) Linforme emès pels/per les revisors/es inclou:

a) una valoració global de l'article i dels resums.

b) una valoració quantitativa de la qualitat (bona | acceptable | insuficient) segons aquests cinc criteris: originalitat i interès del tema; pertinència pel que fa a les investigacions actuals en l'àrea; rigor metodològic; bibliografia significativa i actualitzada; netedat formal i articulació expositiva.

c) una recomanació final: publicar | sol-licitar modificacions | rebutjar. 


\section{COBERTURA, DIFUSIÓ I PRESÈNCIA EN BASES DE DADES}

La revista està indexada en ESCI (WOS), DOAJ, REDIB, Gender Watch (Proquest), InDICEs-CSIC, ERIH PLUS, MLA, CIRC, MlAR, Latindex, Dialnet, Ulrich's, Dulcinea, Google Scholar, SHERPA/RoMEO, RUA, DICE, REBIUN, RESH, OCLC WorldCat, Copac, SUDOC i ZDB/EZB.

\section{PRINCIPIS ÈTICS DE PUBLICACIÓ}

La publicació d'articles en una revista amb avaluació d'experts és un reflex directe de la qualitat del treball dels/de les autors/es i del compromís i la qualificació dels/de les investigadors/es que actuen com a revisors/es. Per això Feminismo/s és una publicació compromesa amb els principis ètics de l'activitat científica en els termes següents:

\section{Publicació i autoria}

Tots els articles han d'incloure una llista de referències, com també indicar si han rebut suport econòmic. Els treballs han d'estar lliures de plagi o frau científic. Els supòsits* de plagi i frau científic són els esmentats a continuació:

- Plagi: còpia literal sense usar les cometes i citar la font; còpia substancial (materials d'investigació, processos, taules...); parafrasejar o reproduir idees sense citar la font o canviant el significat original; reutilitzar i enviar textos propis ja publicats sense indicar la font i parafrasejar de manera abusiva fins i tot citant la font.

- Frau científic: no reconeixement de tots/es els/les investigadors/es que participen en l'elaboració del treball; l'enviament simultani a diverses publicacions; la divisió d'un treball en parts diferents que comparteixen les mateixes hipòtesis, població i mètodes, com també la utilització de dades falses o no provades. Finalment, els/les autors/ es han de declarar a la revista els potencials conflictes d'interès quan envien un treball.

* Font: http://www.ethics.elsevier.com/

Feminismo/s 35, junio 2020 


\section{Responsabilitat dels/de les autors/es}

- L'enviament de treballs a Feminismo/s implica la lectura i l'acceptació de les normes editorials i de publicació de la revista, incloent-hi la participació en un procés anònim d'avaluació d'experts.

- Tots/es els/les autors/es que signen un treball han d'haver contribuït de manera significativa en l'elaboració i han d'estar d'acord amb el resultat final i amb l'enviament del treball perquè siga avaluat.

- Els treballs han de reconèixer a tots/es els/les autors/es que hi han participat.

- Les dades utilitzades en l'article han de ser reals i autèntiques.

- Els/les autors/es assumeixen l'obligació de corregir o retractar-se davant possibles errors detectats posteriorment.

- Els articles han de ser inèdits i no poden ser enviats simultàniament a cap altra publicació.

\section{Procés de revisió}

Tots els articles enviats a la revista se sotmeten a un procés d'avaluació d'experts amb les característiques següents:

- La selecció dels/de les revisors/es es fa d'acord amb les normes i els principis previs basats tant en la seua qualificació com en la qualitat de la seua producció científica.

- El procés de revisió serà totalment anònim tant pels/per els autors/es com pels/per les revisors/es. Els articles i les revisions seran tractats confidencialment.

- Els/les revisors/es consideren, entre els criteris d'avaluació, el respecte als principis ètics essencials en la investigació científica.

- Els judicis expressats en les revisions han de ser objectius.

- Tant autors/es com revisors/es han de revelar les relacions i les fonts de finançament que puguen generar potencials conflictes d'interessos.

\section{Responsabilitats dels/de les editors/es}

- L'equip editorial té la responsabilitat i autoritat per a acceptar o rebutjar un article basant-se en les revisions. 
- L'equip editorial revelarà, si escau, les relacions o les fonts de finançament que puguen ser potencialment considerades com a conflictes d'interessos pel que fa a l'acceptació o el rebuig dels treballs.

- Només s'acceptaran els articles en els quals hi ha una evidència certa sobre el compliment de les normes editorials.

- Lequip editorial es compromet a preservar l'anonimat dels/de les revisors/es de manera que mai puguen ser associats/des amb els articles revisats.

\section{Qüestions ètiques de publicació}

L'equip editorial es compromet a:

- Vigilar i preservar els principis ètics de publicació.

- Mantenir la integritat de l'expedient acadèmic.

- Evitar la publicació de material plagiat o elaborat de manera fraudulenta.

- Estar obert a la publicació de correccions, aclariments, retractacions i disculpes sempre que siga necessari.

- Oferir suport en el procés de retractació d'articles.

- Fer totes les accions necessàries per a complir els estàndards de compromís intel-lectual i ètic.

\section{Política antiplagi}

El Consell de Redacció de Feminismo/s és responsable de comprovar que els treballs presentats siguen originals i no incórreguen en plagi. La Universitat d'Alacant compta amb programari específic a l'efecte, com Turnitin, una eina per a prevenir i evitar el plagi acadèmic i professional que comprova les similituds d'un document amb múltiples fonts d'informació (Internet, articles científics i la seua base de dades interna) i n'identifica el contingut no original traduit de l'anglès. Addicionalment, el Consell de Redacció té a la seua disposició, a través de la pàgina web de la UA, una sèrie de programes gratuïts de detecció del plagi, tals com Copyscape, Plagium, PlagScan, Dupli Checker, Plagiarisma, Article Checker, Viper o Antiplagiarist (https://biblioteca.ua.es/ va/investiga-i-publica/pi/plagi.html). 
El Consell de Redacció es reserva el dret de retirar qualsevol treball rebut, acceptat o ja publicat en cas de constatar-s'hi plagi, falsificació o publicació duplicada, així com els diversos supòsits de frau científic enumerats anteriorment. De la mateixa manera, promou la publicació de correccions o retractacions dels errors detectats.

\section{AVÍS LEGAL}

A l'efecte de l'estipulat en els articles 138-143 de la Llei de Propietat Intel-lectual, la publicació d'un treball que atempte contra aquests drets serà responsabilitat de l'autora o de l'autor. L'equip editorial de Feminismo/s no es fa responsable, en cap cas, de la credibilitat i autenticitat dels treballs. De la mateixa manera, les opinions i fets expressats en cada article són d'exclusiva responsabilitat de les seues autores/autors i Feminismo/s no s'identifica necessàriament amb elles/ells.

\section{AVÍS DE DRETS D'AUTOR/A}

Les/els autores/autors que publiquen en Feminismo/s estan d'acord en els termes següents:

1. Les/Els autores/autors conserven els drets sobre els seus treballs, encara que cedeixen de forma no exclusiva els drets d'explotació (reproducció, edició, distribució, comunicació pública i exhibició) a la revista. Les/els autores/ autors són, per tant, lliures de fer acords contractuals addicionals independents per a la distribució no exclusiva de la versió de l'obra publicada en la revista (per exemple, allotjar-la en un repositori institucional o publicar-la en un llibre), sempre que intervinga un reconeixement de la seua publicació inicial en aquesta revista.

2. Les/els autores/autors asseguren que Feminismo/s és el primer mitjà que publica la seua obra i garanteixen que mentre es troba en fase de valoració 
i possible publicació en la nostra revista no s'ha enviat ni enviarà a altres mitjans.

3. Els treballs es publiquen sota una llicència de Creative Commons Reconeixement 4.0 (CC BY 4.0), llevat que s'indique el contrari, la qual cosa significa que es pot compartir i adaptar el material sempre que intervinga atribució de l'autor/a, del primer mitjà que publica i es proporcione un enllaç a la llicència. Igualment cal indicar si s'hi han fet canvis.

4. Es permet i encoratja als autors/autores a publicar la seua obra electrònicament després de la seua publicació en Feminismo/s (com en repositoris institucionals, en la seua pàgina web...) amb la finalitat d'aconseguir intercanvis productius i aconseguir que l'obra aconseguisca major citació (vegeu The Effect of Open Access, en anglès).

\title{
COM ES POT OBTENIR LA REVISTA
}

La revista (1-30) es ven a un preu de 12 euros a través del Servei de Publicacions de la Universitat d'Alacant

\author{
Vendes: \\ Telèfon: 965909445 \\ E-mail: Publicaciones.ventas@ua.es
}

La revista manté intercanvis amb publicacions pertanyents a altres institucions acadèmiques o investigadores, espanyoles i estrangeres. 


\section{Números anteriores publicados}

Feminismo/s 1. Feminismo y multidisciplinariedad. Helena Establier (coord.)

Feminismo/s 2. Imagin/ando a la mujer. Pilar Amador Carretero (coord.) y Mónica Moreno Seco (ed.)

Feminismo/s 3. Mujer y participación política. Mónica Moreno Seco y Clarisa Ramos Feijóo (coords.)

Feminismo/s 4. Writing, memoirs, autobiography and history. Silvia Caporale Bizzini (coord.)

Feminismo/s 5. Habitar / escribir / conquistar el espacio. Teresa Gómez Reus (ed.)

Feminismo/s 6. Violencia estructural y directa: mujeres y visibilidad. Carmen Mañas Viejo (coord.)

Feminismo/s 7. Hèléne Cixous: Huellas de intertextos. Maribel Peñalver Vicea y Rosa María Rodríguez Magda (eds.)

Feminismo/s 8. Mujeres y derecho. Nieves Montesinos Sánchez y M. ${ }^{a}$ del Mar Esquembre Valdés (coords.). Nieves Montesinos Sánchez (ed.)

Feminismo/s 9. Género, conflicto y construcción de la paz. Reflexiones y propuestas. Eva Espinar Ruiz y Eloisa Nos Aldás (coords.)

Feminismo/s 10. Medicines i Gènere. El torsimany necessari. Elizabeth Mora Torres, Albert Gras i Martí (coords.)

Feminismo/s 11. La representación/presencia de la mujer en los Medios de Comunicación. Sonia Núñez Puente (coord.) y Helena Establier Pérez (ed.)

Feminismo/s 12. Mujeres en democracia. Nieves Montesinos Sánchez y M. ${ }^{a}$ del Mar Esquembre Valdes (coords. y eds.)

Feminismo/s 13. Mujeres y diversidad funcional (discapacidad): construyendo un nuevo discurso. Carmen Mañas (coord.)

Feminismo/s 14. Género y nuevas tecnologías de la información y la comunicación. Eva Espinar Ruiz (Coord.) 
Feminismo/s 15. ¿Feminismo de la igualdad y feminismo de la diferencia? Elena Nájera (Coord.)

Feminismo/s 16. Género e imagen del poder en la historia contemporánea. Mónica Moreno Seco y Alicia Mira Abad (Coords.)

Feminismo/s 17. La arquitectura y el urbanismo con perspectiva de género. María-Elia Gutiérrez-Mozo (Coord.)

Feminismo/s 18. Salud pública desde la perspectiva de género: Hitos e innovación. María Teresa Ruiz Cantero (Coord.)

Feminismo/s 19. Mirada/s trans/identitarias. Ángel Amaro (Coord.)

Feminismo/s 20. La Diosa y el poder de las mujeres. Reflexiones sobre la espiritualidad femenina en el siglo XXI. Angie Simonis (Coord.)

Feminismo/s 21. Mujeres, actividad física, deporte y ocio. Juan Tortosa Martínez y Lilyan Vega Ramírez (Coords.)

Feminismo/s 22. Ecofeminismo/s: Mujeres y Naturaleza. Lorraine Kerslake y Terry Gifford (Coords.)

Feminismo/s 23. Todo sobre mi familia. Perspectivas de género. Adrián GrasVelázquez (Coord.)

Feminismo/s 24. Género y humor en discursos de mujeres y hombres. G. Angela Mura y Leonor Ruiz Gurillo (Coords.)

Feminismo/s 25. Violencia escolar y género. Almudena Iniesta Martínez (Coord.)

Feminismo/s 26. Feminismos en las sociedades árabes. Eva Lapiedra Gutiérrez (Coord.)

Feminismo/s 27. Comunicación y relaciones de género: prácticas, estructuras, discursos y consumo. Alejandra Hernández Ruiz y Marta Martín Llaguno (Coords.)

Feminismo/s 28. Laicidad y creencias. Nieves Montesinos Sánchez y Beatriz Souto Galván (Coords.) 
Feminismo/s 29. La (in)visibilidad de las mujeres en la Educación Superior: retos y desafíos en la Academia. Marcos Jesús Iglesias Martínez e Inés Lozano Cabezas (Coords.)

Feminismo/s 30. Dramaturgia femenina actual. De 1986 a 2016. Eva GarcíaFerrón y Cristina Ros-Berenguer (Coords.)

Feminismo/s 31. Dosier monográfico: Sexo y bienestar. Mujeres y diversidad. Carmen Mañas Viejo y Alicia Martínez Sanz (Coords.)

Feminismo/s 32. Dosier monográfico: MAS-MES: Mujeres, Arquitectura y Sostenibilidad - Medioambiental, Económica y Social. María-Elia GutiérrezMozo (Coord.)

Feminismo/s 33. Dosier monográfico: Estado actual de la investigación en Literatura francesa y Género: balance y nuevas perspectivas. Patricia Martínez-García y Jone Martínez-Palacios (Coords.)

Feminismo/s 34. Dosier monográfico: Diálogos entre la democracia participativa y la interseccionalidad. Construyendo marcos para la justicia social. Ángeles Sirvent Ramos (Coord.) 

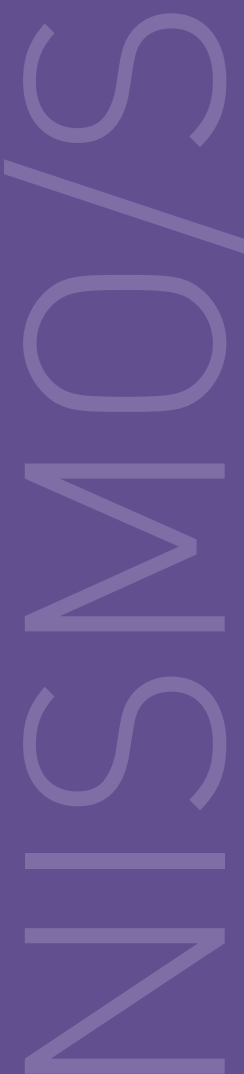

DE ESTUDIOS DE GÉNERO

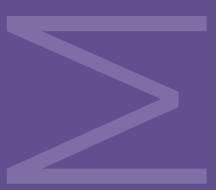

\section{Universitat d'Alacant \\ - Universidad de Alicante}

Vicerectorat d'Investigació i Transferència de Coneixement

Vicerrectorado de Investigación y Transferencia de Conocimiento 